Prepared for the U.S. Department of Energy

under Contract DE-AC05-76RL01830

\title{
Soil Vapor Extraction System Optimization, Transition, and Closure Guidance
}

\author{
MJ Truex \\ DJ Becker \\ MA Simon \\ M Oostrom \\ AK Rice \\ CD Johnson
}

February 2013

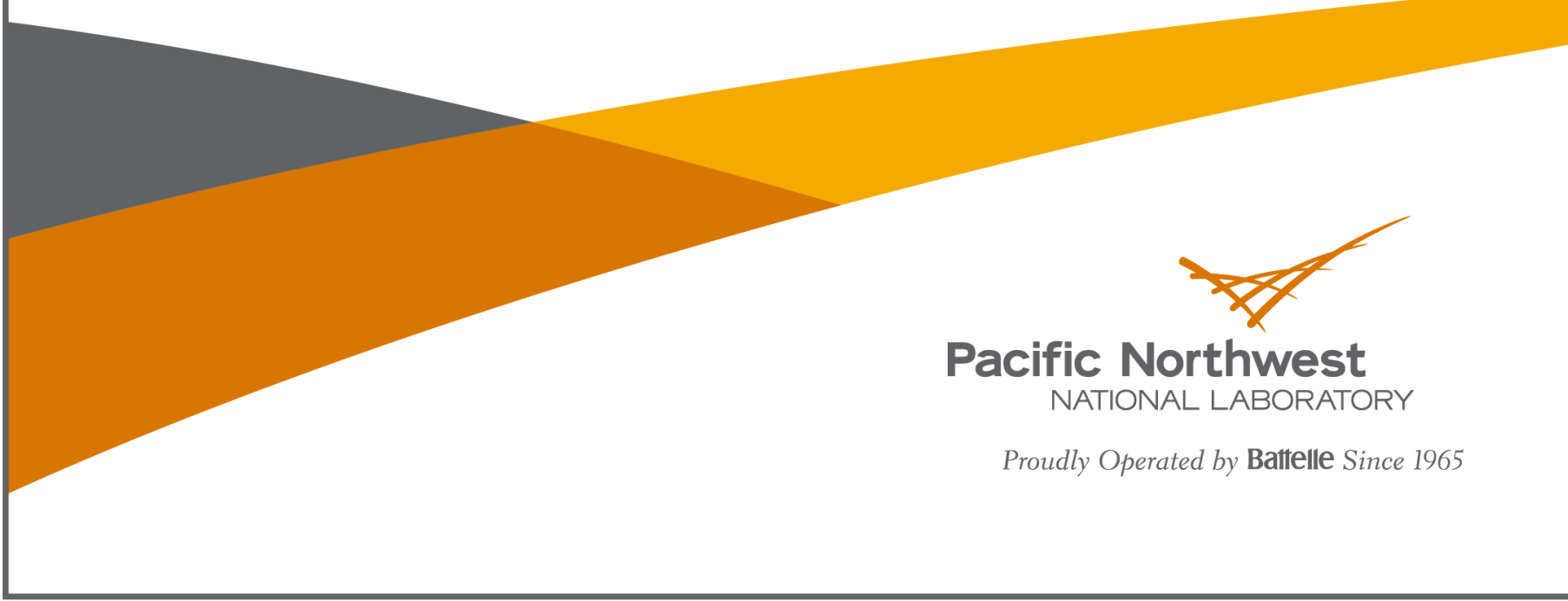




\title{
DISCLAIMER
}

This report was prepared as an account of work sponsored by an agency of the United States Government. Neither the United States Government nor any agency thereof, nor Battelle Memorial Institute, nor any of their employees, makes any warranty, express or implied, or assumes any legal liability or responsibility for the accuracy, completeness, or usefulness of any information, apparatus, product, or process disclosed, or represents that its use would not infringe privately owned rights. Reference herein to any specific commercial product, process, or service by trade name, trademark, manufacturer, or otherwise does not necessarily constitute or imply its endorsement, recommendation, or favoring by the United States Government or any agency thereof, or Battelle Memorial Institute. The views and opinions of authors expressed herein do not necessarily state or reflect those of the United States Government or any agency thereof.

\author{
PACIFIC NORTHWEST NATIONAL LABORATORY \\ operated by \\ BATTELLE \\ for the \\ UNITED STATES DEPARTMENT OF ENERGY \\ under Contract DE-AC05-76RL01830
}

Printed in the United States of America
Available to DOE and DOE contractors from the Office of Scientific and Technical Information, P.O. Box 62, Oak Ridge, TN 37831-0062; ph: (865) 576-8401 fax: $(865) 576-5728$
email: reports $a$ adonis.osti.gov
Available to the public from the National Technical Information Service 5301 Shawnee Rd., Alexandria, VA 22312 ph: (800) 553-NTIS (6847)

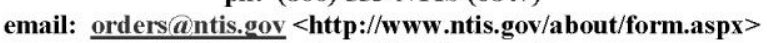 Online ordering: http://www.ntis.gov


PNNL-21843

RPT-DVZ-AFRI-006

\title{
Soil Vapor Extraction System Optimization, Transition, and Closure Guidance
}

\author{
MJ Truex ${ }^{1}$ \\ DJ Becker ${ }^{2}$ \\ MA Simon ${ }^{3}$ \\ M Oostrom $^{1}$ \\ AK Rice ${ }^{1}$ \\ CD Johnson ${ }^{1}$
}

February 2013

${ }^{1}$ Pacific Northwest National Laboratory

${ }^{2}$ U.S. Army Corps of Engineers

${ }^{3}$ Environmental Protection Agency, Office of Research and Development

Prepared for

the U.S. Department of Energy

under Contract DE-AC05-76RL01830

Pacific Northwest National Laboratory

Richland, Washington 99352 



\section{Summary}

Soil vapor extraction (SVE) is a prevalent remediation approach for volatile contaminants in the vadose zone. A diminishing rate of contaminant extraction over time is typically observed due to 1) diminishing contaminant mass, and/or 2) slow rates of removal for contamination in low-permeability zones. After a SVE system begins to show indications of diminishing contaminant removal rate, SVE performance needs to be evaluated to determine whether the system should be optimized, terminated, or transitioned to another technology to replace or augment SVE. This guidance specifically addresses the elements of this type of performance assessment. While not specifically presented, the approach and analyses in this guidance could also be applied at the onset of remediation selection for a site as a way to evaluate current or future impacts to groundwater from vadose zone contamination. The guidance presented here builds from existing guidance for SVE design, operation, optimization, and closure from the U.S. Environmental Protection Agency, U.S. Army Corps of Engineers, and the Air Force Center for Engineering and the Environment. The purpose of the material herein is to clarify and focus on the specific actions and decisions related to SVE optimization, transition, and/or closure.

The process of gathering information and performing evaluations to support SVE remedy decisions is presented in this guidance document in a stepwise approach. Steps start with revisiting the conceptual site model after SVE has operated for a period of time. The guidance also describes information that needs to be considered in terms of the environmental impact and compliance context for optimization, transition, and closure decisions. While these elements of the remediation goal may have been considered at the onset of remediation, they should also be revisited at the time of key remediation decisions. Quantitative approaches are provided to evaluate the impact or remaining vadose zone contaminant sources on groundwater in support of optimization, transition, and closure decisions. This material highlights relatively recent advances in use of mass flux/discharge approaches and includes a calculation tool to facilitate the evaluation process. The material in these initial steps is then synthesized using a decision logic approach to optimization, transition, and closure decisions. 



\section{Acknowledgments}

This document was prepared by the Deep Vadose Zone-Applied Field Research Initiative at Pacific Northwest National Laboratory. Funding for this work was provided by the U.S. Department of Energy Office of Environmental Management. The Pacific Northwest National Laboratory is operated by Battelle Memorial Institute for the U.S. Department of Energy under Contract DE-AC05-76RL01830. 



\section{Acronyms and Abbreviations}

AFCEE

CSM

DNAPL

EPA

ROD

SVE

USACE

VOC

Air Force Center for Engineering and the Environment

conceptual site model

dense non-aqueous phase liquid

U.S. Environmental Protection Agency

record of decision

soil vapor extraction

U.S. Army Corps of Engineers

volatile organic compounds 



\section{Contents}

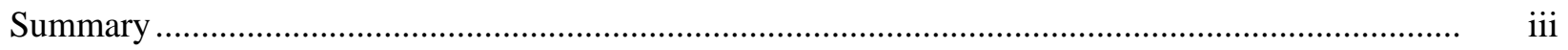

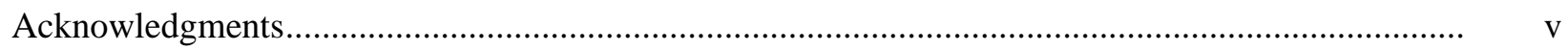

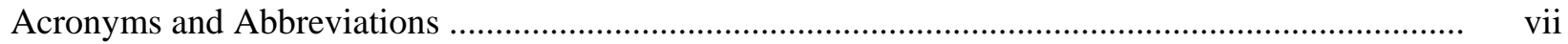

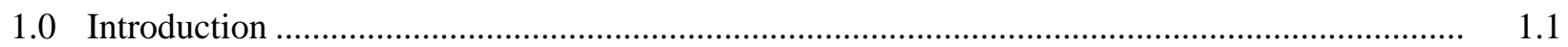

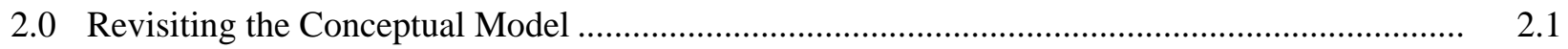

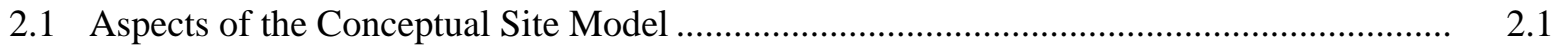

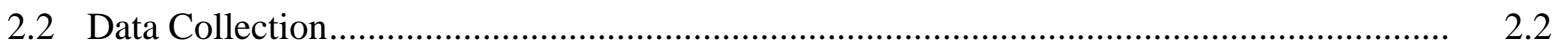

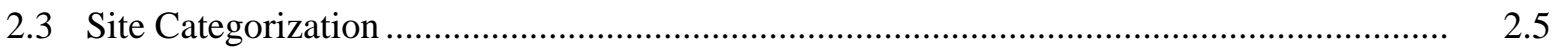

3.0 Identifying the Environmental Impact and Compliance Context .......................................... 3.1

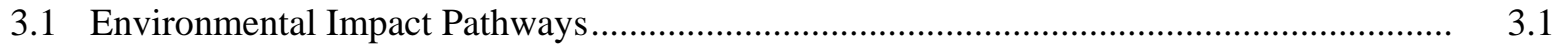

3.1.1 Ground Surface Exposure …...................................................................... 3.1

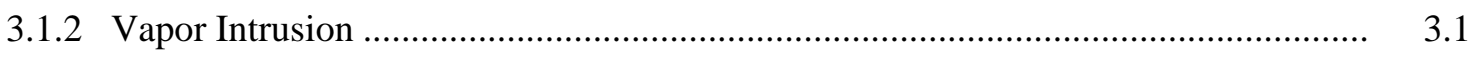

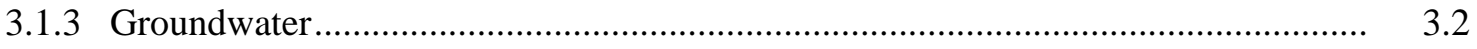

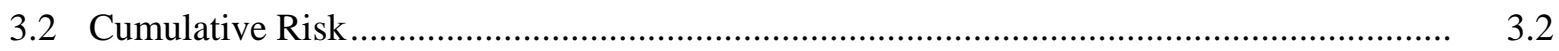

3.3 Identify Site Remediation Goal(s) ...................................................................... 3.2

4.0 Quantifying Remaining Sources and Impacts .....................................................................

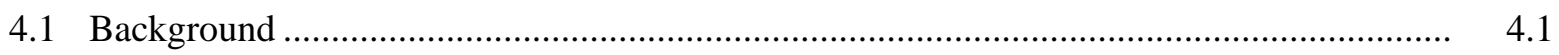

4.2 Recommended Analysis Approach ............................................................................ 4.1

4.2.1 Step 1: Quantify the Vadose Zone Contaminant Source ......................................... 4.3

4.2.2 Step 2: Estimate Impact to Groundwater (Type I and II Sites) .............................. 4.5

4.2.3 Step 3: Estimate Impact to Vapor Intrusion ....................................................... 4.6

4.2.4 Step 4: Estimate Impact of Source Decay, Sorption, and Attenuation Processes .... 4.6

5.0 Decision Approach for Soil Vapor Extraction Optimization, Transition, or Closure ................ 5.1

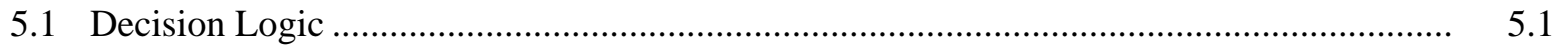

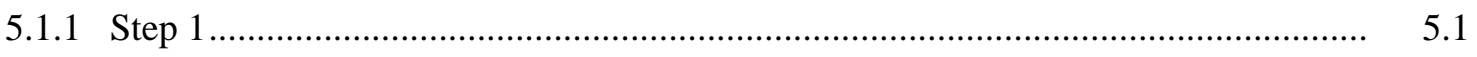

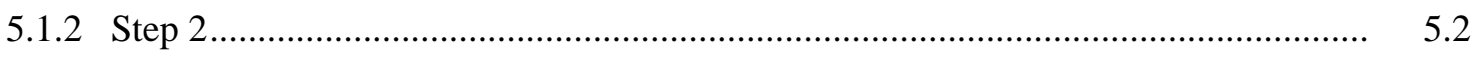

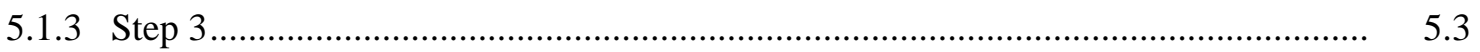

5.2 Enhancements to Soil Vapor Extraction and Alternative Technologies ........................... 5.4

5.2.1 SVE Enhancements ................................................................................. 5.4

5.2.2 Alternative/Transitional Technologies to SVE ....................................................... 5.5

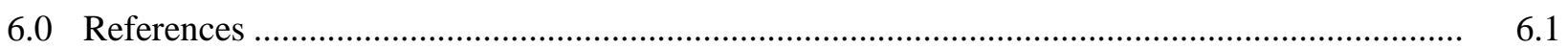

Appendix A Vadose Zone Source Characterization Approaches for Input to Appendix C Analyses .. A.1

Appendix B Methods for High Recharge Sites ......................................................................... B.1

Appendix C Estimating Groundwater Contaminant Concentrations as a Function of Vadose Zone

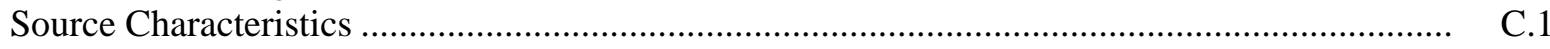

Appendix D Spreadsheet Tool ................................................................................... D. 1

Appendix E Technical Basis for Estimating Groundwater Contaminant Concentrations as a

Function of Vadose Zone Source Characteristics ................................................................... E.1 


\section{Figures}

4.1 Categories of conceptual site models for persistent vadose zone contamination ....................... 4.2

4.2 Conceptual model framework for impact to groundwater or for vapor intrusion ........................ 4.3 


\subsection{Introduction}

Soil vapor extraction (SVE) is a prevalent remediation approach for volatile contaminants in the vadose zone. SVE is generally effective for removal of contaminants from higher permeability portions of the vadose zone. Contamination in low-permeability zones, however, can persist as a result of mass transfer processes that limit removal effectiveness from these zones by SVE. A diminishing rate of contaminant extraction over time is typically observed due to 1) diminishing contaminant mass, and/or 2) slow rates of removal for contamination in low-permeability zones. After a SVE system begins to show indications of diminishing contaminant removal rate, SVE performance needs to be evaluated to determine whether the system should be optimized, terminated, or transitioned to another technology to replace or augment SVE. This guidance specifically addresses the elements of this type of performance assessment. While not specifically presented, the approach and analyses in this guidance could also be applied at the onset of remediation selection for a site as a way to evaluate current or future impacts to groundwater from vadose zone contamination.

The guidance presented here builds from existing guidance for SVE design, operation, optimization, and closure (EPA 2001b; USACE 2002; AFCEE 2001). The existing U.S. Environmental Protection Agency (EPA) and U.S. Army Corps of Engineers (USACE) documents established an overall framework for these actions and decisions, but do not present specific details for implementation. The Air Force Center for Engineering and the Environment (AFCEE) guidance presents actions and considerations for SVE system optimization, but has limited information related to approaches for SVE closure and meeting remediation goals. The purpose of the material herein is to clarify and focus on the specific actions and decisions related to SVE optimization, transition, and/or closure.

The process of gathering information and performing evaluations to support SVE remedy decisions is presented in this guidance document in a stepwise approach. Section 2.0 addresses actions needed to revisit the conceptual site model (CSM) for the site after SVE has operated for a period of time. Most sites will have a conceptual model that was used to support SVE system design. However, after SVE operation, this conceptual model should be revisited in the context of defining the current conditions, using the data compiled during SVE operations and any additional data as needed to support optimization, transition, and closure decisions. Section 3.0 provides information that needs to be considered in terms of the environmental impact and compliance context for optimization, transition, and closure decisions. Again, while these elements of the remediation goal may have been considered at the onset of remediation, they should also be revisited at the time of key remediation decisions. Section 4.0 outlines the approaches that can be used to quantify any remaining contaminant sources with a focus on identifying their impact on groundwater and in support of optimization, transition, and closure decisions. This section highlights relatively recent advances in use of mass flux/discharge approaches. The section also presents an approach to estimating the resultant groundwater concentration based on the characteristics of the vadose zone source that may be suitable for a number of site situations. The material in Sections 2.0, 3.0, and 4.0 is then synthesized in Section 5.0 as part of a decision logic approach to optimization, transition, and closure decisions. 



\subsection{Revisiting the Conceptual Model}

An assessment of SVE performance that is prompted by a diminishing contaminant removal rate would also require re-evaluation of the subsurface conditions to identify the distribution and strength of remaining sources. Updated information about the contamination source would be used to develop a conceptual site model that reflects current conditions and which would be suitable for supporting SVE endpoint decisions. Using the initial CSM (i.e., developed as part of the initial SVE design) and existing SVE operational data as a starting point, this section describes the process of developing a revised CSM. A key goal of this section is to develop a revised CSM that will provide qualitative and quantitative input to SVE optimization, closure, or transition decisions discussed in Section 5.0.

This section is organized to first describe the key aspects required for describing a CSM. Data collection processes for overall site characteristics and SVE system performance are then discussed, with an objective of identifying the location of remaining persistent contaminant sources that have not yet been treated by the SVE system. Several categories (i.e., Type I, II, or III) to describe the nature of a site based on the collected information are described.

\subsection{Aspects of the Conceptual Site Model}

The CSM for sites with vadose zone contamination has four primary aspects: remaining source(s), dominant transport process, contaminant transformations, and receptors. There are also other factors that complicate the analysis of the interaction between vadose zone contamination, groundwater, and the atmosphere at the ground surface. These aspects are each discussed below, while Section 2.2 discusses potential approaches to collect information on these aspects.

- Remaining source(s). After a time period of SVE operation, a key aspect of the conceptual model is the location of the bulk of remaining contaminant mass relative to groundwater and surface receptors. As discussed in Section 4.0, understanding this aspect is critical for making SVE endpoint decisions based on the risk posed by the remaining contamination. For SVE optimization or transition to other technologies, details of the vadose zone source distribution (i.e., occurrence of the contaminant mass within the soil or rock mass at a scale of a few meters) may be important.

- Dominant transport processes. It is presumed that after termination of SVE operations, remaining contamination can only migrate laterally and vertically under natural conditions by dissolution into infiltrating moisture, gaseous diffusion, or gaseous advection (which is possible to some extent if a persistent pressure gradient exists, such as near an actively decomposing landfill or near another source of subsurface gases). It is necessary for the CSM to assess the relative importance of each transport mechanism, and to the extent possible, bracket the magnitude of each.

- Biotic or abiotic transformations. The fate of the contaminant mass also depends on processes that degrade or transform the contaminant. For example, petroleum hydrocarbons can biodegrade and some chlorinated ethanes (such as 1,1,1-trichloroethane) can undergo significant abiotic hydrolysis. These processes need to be at least qualitatively understood for a useful CSM.

- Receptors. The site only poses a completed risk pathway if there are potential human or ecological receptors for the contamination. It is assumed that the remaining contamination is not a direct exposure risk (e.g., through direct contact with contaminated soil) if no exposure pathways are complete. The contaminants would likely reach potential receptors either through migration to the 
groundwater and incorporation into groundwater pumped for domestic or municipal use, or through vapor migration to the surface or into buildings (i.e., affecting indoor air via vapor intrusion).

Ecological receptors could also be exposed to contaminated groundwater at points of seepage such as wetlands, or through vapors reaching subsurface habitat. Risk issues are discussed further in Section 3.0. For simplicity, the subsequent analysis will focus only on the groundwater impact itself, not the end use or discharge point of the groundwater. At most sites undergoing SVE, the groundwater is already contaminated to some degree. The current degree of contamination must be known.

- Complicating factors. The conceptual model can become complex if there are other variables pertaining to contaminant migration. Large fluctuations of the water table elevation (e.g., seasonal variations) could potentially redistribute contaminant mass and moisture. The presence of a surface covering (e.g., sealed pavement, geomembrane) could inhibit the discharge of vapors to the atmosphere. Other complications include preferred vapor pathways or moisture sources, such as utility corridors and leaking water lines or sewers. These features need to be incorporated into the CSM.

\subsection{Data Collection}

To revisit the CSM and clarify the important aspects described above, information about the current site conditions is required. The required information is described in the following paragraphs. These data will support additional analyses and decisions that are discussed in subsequent sections of this guidance.

- Site characteristics. The following parameters are usually defined during initial site characterization and are typically used in the selection of the remedy and design of the SVE system. The installation and operations of the SVE system should also have provided valuable additional observations that can be compiled. Although specific values may have been assigned for some of these parameters in site reports or used in design, these values are uncertain and spatially variable. Some assessment of the uncertainties in these values is required to support the analyses recommended in later sections. Note that more detail on these parameters are provided in USACE (2002, Chapter 3) and AFCEE (2001, Section 2).

- Vadose zone stratigraphy and soil/rock properties. Stratigraphic information includes the location and continuity of geological units, with lower permeability layers being of particular interest. Key soil/rock/subsurface properties include the moisture content (water saturation), air conductivity, and subsurface temperature. Note that borehole logging conducted during SVE well installation drilling operations should have increased the understanding of the stratigraphy, particularly the continuity of layers. Pneumatic responses at the SVE wells during active operations should also have provided additional information on air permeability, at least qualitatively. Further measurement of pneumatic responses to extraction from representative SVE wells can be conducted to determine air permeability values for the current conditions.

- Contaminant properties. Considering that the composition of the contamination may have changed since the initial site characterization (i.e., as the more volatile constituents were removed), the current volatility, mobility, and toxicity properties of the contamination should be identified. Soil sampling may be required to determine these properties (as well as the abovementioned soil moisture content). It may be possible to make inferences about contaminant properties based on observed changes in the SVE system influent composition over time (Johnson et al. 1990). If influent sampling has not included compound-specific analysis, samples for 
analysis by gas chromatograph/mass spectrometer should be taken at least from the influent line, and ideally from representative SVE wells at the site.

- Water/groundwater conditions. Infiltration rates, the degree of groundwater contamination, potential submerged sources (e.g., dense non-aqueous phase liquid [DNAPL]), depth to the water table, and the degree of water table fluctuations are characteristics that should be determined. Note that depth to the water table and the extent of water table fluctuations may have changed since the initial characterization of the site because of drought, flooding, or changes in nearby pumping (for water supply or remediation). Any site changes that would affect infiltration rates, such as new pavement, irrigation, capping, etc., should be determined.

- Exposure changes. Changes in receptors (groundwater usage or gas exposure at ground surface) should be identified. Changes in nearby land use (farming, buildings, excavations, etc.) are also pertinent to assessing exposure changes. The significance of these changes is discussed in more detail in Section 3.0.

- Current SVE system performance. The measurement of operational parameters from the SVE system provides important information that was not necessarily available during initial site characterization on both the subsurface conditions and the strength and location of remaining contamination sources. Compilation and interpretation of these measurements contributes to a complete CSM and supports decisions on appropriate future actions. Additional detail on assessing SVE system performance is provided in the AFCEE (2001) guidance.

- Flow rates and concentrations from each extraction well, including concentration trends. The flows from each well, in conjunction with the corresponding applied vacuum, provide at least qualitative information on the spatial (horizontally and possibly vertically) distribution of relative air permeabilities. The contaminant concentrations in vapor extracted from each well should be assessed over time, or at least compared to baseline data collected at system start-up, even if the data are non-compound specific, such as photoionization detector data. The response (rebound or lack thereof) in concentrations after a cessation of extraction can be very instructive. Wells having elevated concentration relative to other wells, representing a significant percentage of mass removal at the site, and/or displaying rapid and/or significant rebound, are indicative of areas that have contaminant mass remaining. The relationship between mass removal at a well and the water table elevation may also indicate the significance of contaminant mass near the water table. The mass removal rates from extraction wells should be interpreted in light of the flow paths (discussed below) for air reaching each well. Short circuiting of clean air may reduce mass removal rates, even though significant mass remains in the vicinity of the extraction well. Brusseau et al. (2010) provide additional information on assessing the significance of extracted vapor concentration trends.

- Vacuum distribution, air flow paths. Provided adequate monitoring points are available, the measurement of observed vacuums at different locations and depths provides an indication of the air flow paths. Note that observed vacuums do not necessarily imply adequate air velocity or throughput to achieve good mass removal, so pressure gradients determined from the vacuum measurements must be coupled with estimates of horizontal and vertical air conductivity to assess travel times or velocity (USACE 2002; EPA 2001b). In particular, the vacuum data/airflow paths should be considered in the context of understanding the contaminant mass distribution at the site.

- Soil gas concentrations and concentration trends in monitoring points. While the concentration trends in extraction wells represent a composite of vapors collected over a wide range of depths 
and flow paths, the concentrations observed at monitoring points indicate more about the specific conditions in the immediate vicinity of the monitoring point itself. Consistent declines in soil gas concentrations at a monitoring point suggest that mass removal in the vicinity of the point has been occurring. Persistent soil gas concentrations suggest that the location is not being adequately addressed by the current extraction wells. The concentration response to cessation of SVE can also be informative; rapid and strong rebound in concentrations at the monitoring point would suggest nearby sources, whereas weak rebound would suggest little remaining mass.

- Treatment efficiency. The overall mass recovery (rate and cumulative totals) by the SVE system can be plotted to determine progress and predict future performance. Normally, the mass removal rates decrease along a first-order (exponential) decay curve with high initial rates. Mass removal rates often level out at some "asymptote" level that reflects inherent limitations in mass transfer from the subsurface. Assuming relatively consistent system operation, if mass removal rates remain relatively high (e.g., $>20 \%$ of the initial rate or more than several hundred grams/day), then mass transfer limitations may be significant. The costs for vapor treatment should be identified and cost per kilogram of contaminant mass removed over time should be plotted to assess the cost efficiency of the current treatment methods.

- Location and strength of remaining sources. A critical outcome from the CSM update is to better understand the location (both laterally and vertically) of the remaining mass in the vadose zone at the site. Similarly important is an understanding of the source strength (concentration or mass discharge). These characteristics drive the potential for contaminant migration to receptors upon termination of SVE operations. There are a number of lines of evidence that can be used in this evaluation. See also Appendix A.

- Source based on mass removal during SVE operation. Mass removal from individual extraction wells and as an overall system is described in the foregoing paragraphs, and is a primary - though somewhat qualitative - line of evidence regarding the location and strength of remaining contamination.

- Source based on flow/concentration profiling. If the extraction wells and/or monitoring points at a site have long screens relative to the thickness of the zone addressed by the SVE system, then profiling of in-well flow velocities and contaminant concentrations under active extraction (e.g., the Pneulog ${ }^{\circledR}$ system by Praxis Environmental Technologies, Inc., Burlingame, California [EPA 2000a, 2003a]) can provide information on the vertical distribution of remaining contamination sources. These data can be inverted to identify what zones yield most of the extracted air and what zones yield the contaminant mass to the well. If compared to a lithologic log of the well, these data can greatly enhance the CSM. The results can potentially indicate the mass-transfer-limited repositories of contaminant mass in the vadose zone (e.g., from a low-permeability layer) or "offgassing" from the water table (USACE 2002, Chapter 9).

- Source based on rebound testing. SVE uses induced gas advection to remove contaminant mass in the gas (vapor) phase. Gas advection preferentially affects zones or pathways with higher air permeability. As mass is removed from these permeable pathways, clean air, drawn from the surrounding soils and from the surface, may come to dominate the air removed and concentrations at individual wells and in the system influent may decrease over time. Gas-phase contaminant mass remaining in zones of low air-permeability (e.g., clay layers, the capillary fringe) migrates from these zones to the higher permeability pathways largely by diffusion. If vapor extraction ceases after being conducted for some period of time, the contaminant vapor concentrations will 
"rebound" (i.e., increase) due to the diffusion-driven mass transport from the zones having low airpermeability. The nature of this rebound behavior can be analyzed qualitatively and quantitatively, provided an adequate monitoring network is available. Methods can be used determine the overall mass flux and to clarify the nature and strength of the remaining mass in the low permeability zones. In particular, methods for assessing source strength based on rebound testing are outlined in Switzer et al. (2004), Brusseau et al. (2010), and USACE (2002, Appendix F). When coupled with flow and concentration profiling, as described above, these methods are powerful tools to improve the conceptual model.

- Groundwater as source or sink of vadose zone contaminants. At sites that have groundwater contamination (particularly the Type II and III sites discussed in Section 2.3), there is often a question as to what extent volatilization of contaminants from the water table is contributing to the mass removed by the SVE system, or to any observed rebound in vapor concentrations during SVE shutdown. The mass flux across (in either direction) the capillary fringe is an important piece of information. Groundwater concentrations near the water table can be used to help interpret this mass flux. If groundwater monitoring wells with screened intervals that include the water table are not available, either temporary or new permanent wells may be needed. A comparison is often done between the observed soil gas concentrations just above the water table and calculated vapor concentrations at equilibrium with the groundwater concentrations (based on Henry's Law). Where predicted equilibrium concentrations are near or above the observed vapor concentrations just above the water table, mass transfer may be occurring from the water table to the vadose zone. At sites with thick capillary fringes (i.e., in fine-grained materials), groundwater concentrations may be somewhat isolated from the vadose zone due to the relatively slow diffusion rate through this zone, particularly if there is significant downward moisture infiltration. In these cases, the comparison of observed to predicted equilibrium concentrations should be used with extreme caution. If it is suspected that contaminant vapors are emanating from the capillary fringe and water table, the use of flow and concentration profiling should be conducted to confirm this conclusion.

- Vapor path tomography. If the site has multiple vapor extraction wells, the approximate location of any remaining source materials in the vadose zone can be estimated. Based on the relative changes in concentrations observed in various monitoring points and/or extraction wells when the vapor extraction wells are operated individually or in combination, the flow paths that include the remaining sources may become apparent. Evaluation of spatial measurement data or tomographic survey data (i.e., extraction testing with monitoring across the site in multiple directions) can be used to evaluate the nature and extent of persistent, remaining contaminant source zones within the vadose zone. This approach is currently under development (Brusseau 2011; Truex et al., 2012; Carroll et al., 2013).

\subsection{Site Categorization}

Three basic categories of sites are defined to facilitate analysis of site-specific scenarios. In updating the CSM, the specific site scenario is mapped to one of the basic site categories. Section 5.0 presents decision logic for possible paths forward and is structured, in part, based on this site categorization.

- Type I Sites. Type I sites have contaminant source(s) remaining in the vadose zones with only low level dissolved phase contamination in the groundwater such that contaminant mass transfer in the area of the vadose zone source is from the vadose zone to the groundwater. Low-permeability layers 
or lenses may be present within the vadose zone and represent a potential repository of mass largely inaccessible to significant air flow during SVE. These diffusion-limited zones could represent a source of vapors or leachate that could impact groundwater or pose a risk of vapor intrusion.

- Type II Sites. Type II sites have contaminant mass residing in both the vadose and saturated zones. Low-permeability layers or lenses are likely present within the vadose zone and represent a potential repository of mass largely inaccessible to significant air flow during SVE. These diffusion-limited zones could represent a source of vapors or leachate that could impact groundwater or pose a risk of vapor intrusion. Contaminant mass transfer in the area of the vadose zone source may be either from the vadose zone to the groundwater or upward from the groundwater to the vadose zone and may vary locally depending on the distribution of the contaminants between the saturated and unsaturated zones. Type II sites represent a significant long-term challenge to attaining cleanup, and will require consideration of sources in both the saturated and unsaturated zones.

- Type III Sites. Type III sites may have some contaminant mass remaining in the vadose zone at the SVE site, but the primary remaining contaminant source is below the water table or trapped in a thick capillary fringe. At Type III sites, contaminant mass transfer in the area of the vadose zone source (site of the SVE system) is largely upward from the water table and/or capillary fringe. 


\subsection{Identifying the Environmental Impact and Compliance Context}

The environmental impact pathways and regulatory compliance relevant to a given site provide the context for evaluation of the (updated) conceptual site model developed using the process described in Section 2.0. While this environmental impact/regulatory compliance context may have been evaluated at the onset of remediation (e.g., as documented in a Record of Decision [ROD] or a Corrective Measure Decision), it may be important to re-examine these elements when evaluating SVE endpoint decisions after SVE has been applied for a period of time. This section provides information about the type of environmental impact pathways that need to be considered for a site, then discusses regulatory compliance issues pertinent to the decision process for SVE optimization, closure, or transition. Key types of information for supporting quantification of the environmental impacts and compliance with regulatory requirements are discussed. This information will be used in Section 4.0 to support the relevant analyses associated with quantifying impacts of contamination that still remains in the vadose zone. The last step in this section is to identify and define the remediation goal(s) that will be used as the targets for Section 4.0 analyses and to support the decision process in Section 5.0.

\subsection{Environmental Impact Pathways}

There are three main routes by which human or ecological receptors can be exposed to VOCs that originated in the vadose zone: surface exposure, vapor intrusion into buildings, and exposure to groundwater.

\subsubsection{Ground Surface Exposure}

In the context of this guidance document, the surface exposure pathway primarily consists of inhalation of volatiles. However, direct ingestion of soil/contamination, dermal absorption from handling soil/contamination, and ingestion of homegrown produce that has been contaminated via plant uptake may potentially be relevant for sites with very shallow source zones.

The EPA typically compares surface contaminant concentration levels to screening values. An excellent resource for assessing the risk due to surface exposure is the EPA Soil Screening Guidance (EPA 1996a, 1996b), which describes the process for collecting data, calculating soil screening levels, and assessing the results. In addition to the process described in the Soil Screening Guidance, the Visual Sampling Plan (http://vsp.pnnl.gov) is a software tool for developing a defensible, statistically rigorous surface soil sampling plan (Matzke et al. 2010). The EPA determines whether or not the soil at a site is statistically clean by the methodology discussed in Methods for Evaluating the Attainment of Cleanup Standards (EPA 1989).

\subsubsection{Vapor Intrusion}

Vapor intrusion into buildings, especially ground level and sub-ground floors, is of particular importance for VOCs. The current version of EPA's Subsurface Vapor Intrusion Guidance (EPA 2002a) provides current technical and policy recommendations on determining if the vapor intrusion pathway poses an unacceptable risk to human health at cleanup sites. This guidance presents the approach for assessing the potential for harmful concentrations of VOCs in buildings. The guidance leads the decision 
maker through an evaluation of decreasingly conservative assumptions for the potential of harmful vapor intrusion. If the soil gas concentrations are higher than $10^{-6}$ cancer risk action levels, then indoor air sampling is warranted. If the VOC concentration measured in the indoor air is above action levels, then vapor intrusion remediation is warranted.

\subsubsection{Groundwater}

If contaminants migrate into the groundwater, receptors using groundwater from downgradient locations are potentially at risk to exposure through ingestion, dermal absorption, inhalation, or ingestion of homegrown produce that has been contaminated via plant uptake.

The most common method for determining SVE site closure criteria is the assessment of potential aquifer degradation due to the transport of contaminants from the vadose zone to the groundwater. Section 4.0 of this document provides methods to evaluate this process. For some sites, the evaluation of aquifer degradation may also need to include consideration of attenuation processes that can reduce the concentration of VOCs in groundwater and the vadose zone over time and with distance from the source. EPA guidance on monitored natural attenuation (EPA 1998, 1999a), along with other technical publications on natural attenuation processes, provides relevant information. Additionally, there are many recent resources pertaining to MNA at the EPA's Hazardous Waste Clean-Up Information (CLU-IN) website (www.cluin.org).

\subsection{Cumulative Risk}

Cumulative risk also needs to be considered for SVE endpoint decisions. The EPA approach to risk assessment is evolving away from the potential of a single pollutant in one environmental medium for causing cancer toward integrated assessments involving suites of pollutants in several media that may cause adverse effects to humans, animals, plants, or ecological systems. The EPA has developed guidance for assessing cumulative risk (EPA 1997b, 2002b, 2003). Further EPA research will improve understanding on cumulative risks and develop methods to account for multiple elements. More recent information on the evolving topic of cumulative risk can be obtained online from the EPA's Risk Assessment Forum (http://www.epa.gov/raf/publications/framework-cra.htm).

Often, the EPA ROD for a site requires that the groundwater concentrations consider cumulative risks and drinking water standards at a compliance point. Quantification of the VOC flux into the groundwater and subsequent calculation of the VOC concentration in groundwater using a mixing approach is one method to address this requirement. Groundwater concentration goals will drive ultimate compliance at most sites and the analyses in Section 4.0 can be applied for the site-specific compliance location.

\subsection{Identify Site Remediation Goal(s)}

The EPA (2001b) and the USACE (2002) have outlined processes for assessing closure and transition of SVE systems using several types of analyses, including estimation of contaminant mass flux to groundwater and the resultant groundwater concentration. The EPA, in its report titled Development of Recommendations and Methods to Support Assessment of Soil Venting Performance and Closure, provides recommendations related to SVE system optimization, transition, or closure decisions (EPA 2001b): 
It is clear that an environmentally protective, flexible, technically achievable, and consistently applied approach for assessment of performance and closure of venting systems is needed. Any approach used to assess performance of a venting system should encourage good site characterization, design, and monitoring practices since mass removal can be limited by poor execution of any of these components. Also, any approach used to assess closure of a venting system must link ground-water remediation to vadose zone remediation since the two are interrelated. A strategy is proposed in section 2 for assessment of venting performance and closure based on regulatory evaluation of (1) site characterization, (2) design, (3) performance monitoring, and (4) mass flux to and from groundwater. These components form converging lines of evidence regarding performance and closure.

USACE (2002) states the following (wherein the concept of leaching is equivalent to a mass flux):

Shutdown strategies based on the need to protect ground water are becoming more common. In most cases, the removal of contaminant mass in the vadose zone must continue until the residual mass will not leach to the ground water in quantities that would cause exceedance of ground water quality standards. This typically is evaluated through the use of leaching models and the assumption that some mixing of the leachate and ground water occurs below the water table.

Given the four abovementioned assessment strategy components, the EPA (2001b) and USACE (2002) approaches for SVE closure/transition decisions related to protecting groundwater can be summarized as follows.

1. Define a conceptual model of the site that is appropriate for use as a context to support SVE data analysis relative to closure/transition decisions (e.g., how is the contaminant distributed in the vadose zone and how does this relate to SVE effectiveness and closure analyses?).

2. Provide design information that shows how SVE was configured and operated to appropriately address the contamination.

3. Provide SVE performance monitoring to demonstrate mass extraction and decreases in the subsurface contamination.

4. Quantify the mass flux to/from groundwater to define the impact of remaining vadose zone contamination on groundwater remediation goals, which will provide a quantitative basis for determining a remediation endpoint for the vadose zone contamination.

Using the above elements in the approach to SVE system decisions, the remediation goal can be related to the remediation goal in the underlying groundwater. Vapor intrusion goals may also be considered in establishing remediation goals, as outlined in the relevant EPA guidance (EPA 2002a).

The EPA, as documented in RODs, has applied several approaches for identifying site remediation goals for the closure of sites where SVE was the selected remedy. Examples of these approaches include the following:

- One approach is to calculate the maximum VOC mass flux from soil into the groundwater whereby concentrations in the groundwater would be below regulatory maximum contaminant levels. This approach was applied at the Tucson International Airport Site (EPA 2004b). 
- Sampling can be conducted to determine if the soil gas at a site is below a specified cleanup value. EPA calculated the equilibrium vapor concentration with the maximum contaminant levels for comparison of sampling results at the Del Amo Site in California, an EPA Region 9 Superfund Site (EPA 1999b).

- Soil can be sampled to compare to a cleanup value, per EPA soil cleanup standards (EPA 1989), vapor intrusion levels (EPA 2002a), or other site-specific modeling risk levels. EPA has a standard approach for determining soil remediation criteria based on protection of groundwater, which is described in a document providing the technical background for guidance on soil screening (EPA, $1996 \mathrm{~b}$ and c). This standard approach includes default cleanup criteria for soil.

- Assessment of concentrations at vapor monitoring points is another viable approach. The EPA determined that a $90 \%$ drop from initial vapor concentration was adequate groundwater protection at the Keystone landfill site in Pennsylvania (EPA 2000b). EPA does not usually recommend a specific percentage drop in VOC concentrations but calculates the cumulative risk for various reductions in site-specific VOCs and reports them as a percentage drop. Many of the soil gas cleanup values at the Keystone site were non-detects.

- Assessment of the rate of VOC mass removal by the SVE system may be an approach for identifying remediation goals. Many SVE operators recommend that SVE be discontinued when the VOC removal rate reaches an asymptote (essentially constant rate). However, significant mass removal can often be achieved, even though the VOC mass removal rate is constant. Operational strategies can be implemented to improve the mass removal rate (see Section 5.0). EPA will not close a site based solely on the observation that the rate of mass removal has reached an asymptote because substantial mass removal can continue to occur, even under asymptotic conditions. 


\subsection{Quantifying Remaining Sources and Impacts}

Quantitative analysis of vadose zone contamination and its environmental impact is needed to support decisions to optimize or terminate SVE operations or to transition to another remediation technology.

\subsection{Background}

Material presented in this section builds off of previous efforts to develop an approach for quantifying contamination sources that still remain in the vadose zone and the impact of those sources on contaminant fate. Several types of quantitative analyses have been developed previously to assess vadose zone contamination and its fate, providing a basis to support an updated site conceptual model. Temporal extraction-concentration profiles (i.e., elution tails) have been analyzed to evaluate rate-limited mass transfer (e.g., Digiulio et al. 1998; USACE 2002). Data from a single rebound period (e.g., Brusseau et al. 1989, 2007; Harvey et al. 1994; USACE 2002) or multiple rebound periods (Brusseau et al. 2010) can serve as a source of information to help characterize mass-transfer constraints. SVE rebound data have also been analyzed to provide information on contaminant source location (e.g., Switzer and Kosson 2007; USACE 2002; Brusseau et al. 2010). Modeling approaches to examine interaction of vadose zone contaminants with the groundwater in the context of SVE performance evaluation have also been applied recently (Truex et al. 2009; Oostrom et al. 2010; Carroll et al. 2012) and in the past (Varadhan and Johnson 1997; DiGiulio et al. 1999; DiGiulio and Varadhan 2001; EPA 2001b).

\subsection{Recommended Analysis Approach}

The analyses in this section build from the conceptual model developed in Section 2.0 and use the environmental impact and regulatory context information from Section 3.0. The results of these analyses will be used in Section 5.0 as input to the decision logic. These analyses address the following aspects of quantifying vadose zone contamination and its impact to receptors.

- What is the mass discharge from the remaining sources under SVE operational conditions?

- What would the mass discharge be from the remaining sources if the SVE system were shut down?

- What is the projected trend in mass recovery and mass discharge from the remaining sources over time for continued SVE operations?

- What is the dominant transport mechanism to the groundwater if the SVE system were shut down?

- What is the projected impact to groundwater if the SVE system were shut down and what factors influence this impact?

- What is the projected impact of remaining sources on vapor intrusion if the SVE system were shut down?

- How much would the source need to be diminished such that it would not impact receptors if the SVE system were shut down?

- Is the site on target to reach this reduced source strength through application of SVE?

- Based on the source and mass discharge characteristics, where and how should the source be diminished to most readily meet goals? 
A stepwise evaluation process to quantify the vadose zone contamination and its impact to receptors is provided below. The evaluation process focuses on Type I and Type II sites (Section 2.3) where there are contaminant sources in the vadose zone. Type III sites are fundamentally different because the contaminant source is the groundwater and analyses for these sites are highlighted as a special case. While each site is unique, there are three general categories of sites with vadose zone contaminant sources, as depicted in Figure 4.1. These categories reflect common types of subsurface heterogeneities and are based on the premise that, at the time of evaluating SVE optimization, closure, or transition to other remedies, the remaining vadose zone contaminant sources are persistent because they reside within lower permeability zones or areas that are poorly swept by the SVE system (e.g., high moisture zones). For many sites, the vadose zone contaminant sources that remain would be expected to exist within a localized portion of the vadose zone as a remnant of contaminant transport pathways that occurred during the waste disposal period. For sites with widely dispersed remaining sources and unique subsurface features, a site-specific analysis may be most appropriate. However, for sites where the remaining sources are more localized, a generalized approach to the evaluation process can be followed as described below.

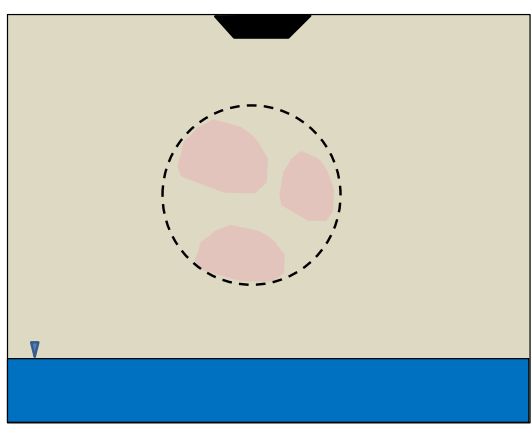

A

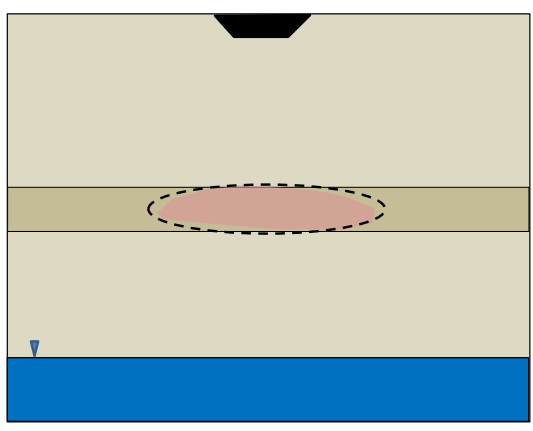

B

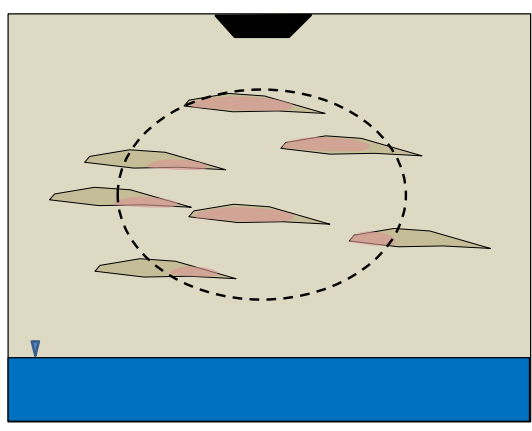

$\mathrm{C}$

Figure 4.1. Categories of conceptual site models for persistent vadose zone contamination. A) homogenous subsurface; B) simple layered subsurface; and C) multiple layers or lenses in the subsurface. Red = contamination source; blue = groundwater; $\tan =$ high permeability; brown $=$ low permeability; black $=$ waste disposal site). The dashed lines show zones where, over time, vapor concentrations will nominally equilibrate to an effective source concentration as a result of diffusion from the source zones.

While the nature of the subsurface is significantly different for the three conceptual model categories shown in Figure 4.1, the vadose zone source may, in each case, be approximated as a single zone of specified dimension and concentration (Figure 4.2). This generalized source is most apparent for Figure 4.1 (B), where remaining contaminants reside primarily in a distinct low-permeability layer. However, in both Figure 4.1 (A) and 4.1 (C), the contamination resides within a defined volume of the vadose zone and a composite concentration can be assigned. For instance, in both Figure 4.1 (A) and 4.1 (C), vapors may emanate from smaller distinct portions of the composite source zone. In the long term, however, vapor concentrations will equilibrate within the dashed outline on the figure between these distinct sources, resulting in a vapor concentration within an effective composite source zone that acts as the source concentration driving diffusion to the surface or to the groundwater. Aqueous recharge moving through this zone will become contaminated. However, the concentration of the pore water at the water table will be in equilibrium with the vapor concentration at that location. Thus, for sites with relatively low recharge rates, the composite vapor concentration will also be a primary factor in the long-term aqueous phase contaminant discharge to the groundwater. The generalized conceptual model in Figure 
4.2 is appropriate for sites where vapor-phase transport dominates contaminant movement. Diffusion is the primary vapor transport process even at relatively high vapor concentrations (Oostrom et al. 2010). The generalized conceptual model assumes uniform diffusion conditions in the vadose zone. Thus since most sites have diffusion outside the source zone that varies significantly, a site specific analysis should be considered. At sites with higher recharge rates where vapor-phase transport does not dominate contaminant movement, a special case analysis can be applied as described in the evaluation steps below.

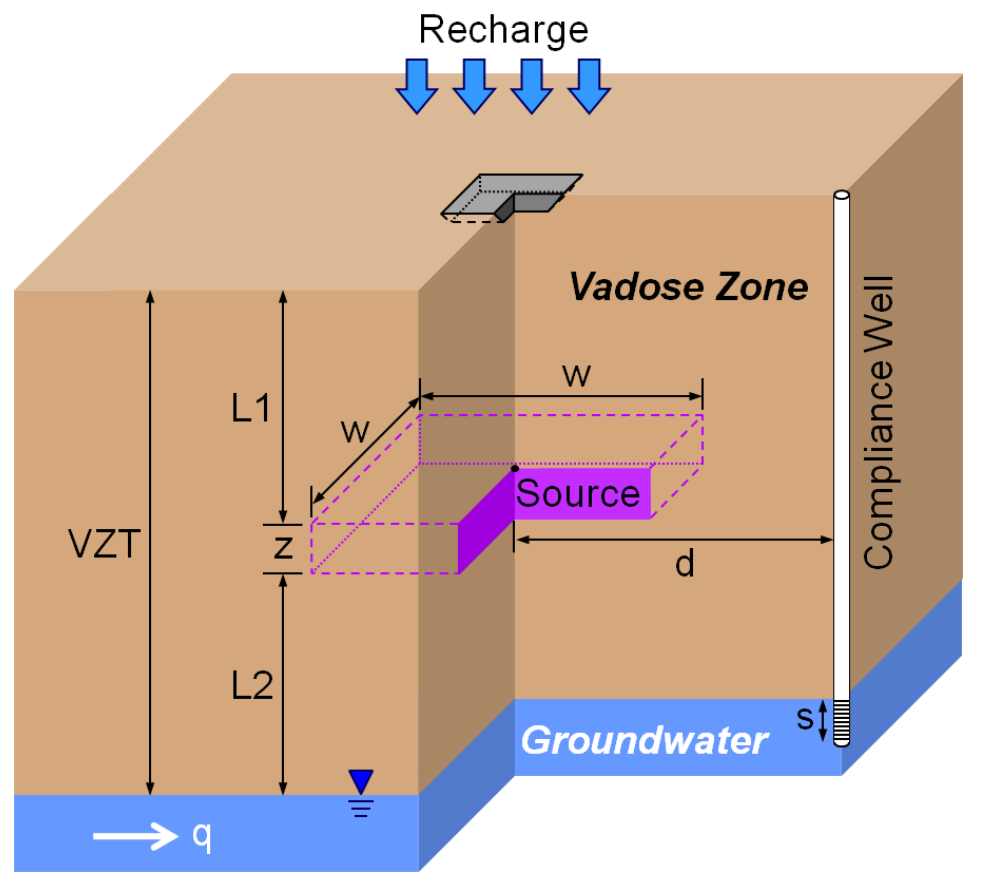

Figure 4.2. Conceptual model framework for impact to groundwater or for vapor intrusion

\subsubsection{Step 1: Quantify the Vadose Zone Contaminant Source}

The contaminant mass removal rate during SVE operations provides a measure of the current contamination in relation to historical SVE operations. As described in Section 2.0, contaminant removal rates typically decline over time due to SVE operation, but the rate of decline may diminish such that the removal rate approaches an asymptotic value. Asymptotic contaminant removal rate behavior is often attributed to the impact of rate-limited mass transfer. Rate-limited mass-transfer processes may include evaporation and dissolution of trapped organic liquid, diffusion within and mass transfer between gas and water, diffusive mass transfer between lower-permeability and higher-permeability domains, desorption, or some combination thereof. If the asymptotic value is high relative to initial removal rates, then a masstransfer limitation may exist with respect to SVE removal effectiveness. Under these conditions, it will be useful to assess mass transfer constraints. Temporal concentration profiles during extraction (i.e., elution tails) can be analyzed to evaluate rate-limited mass transfer (e.g., Digiulio et al. 1998; USACE 2002). Refer to Appendix A for more information on the USACE (2002) method.

Data from a single SVE rebound period can serve as an alternate or additional source of information to help characterize mass-transfer constraints (e.g., Brusseau et al. 1989, 2007; Harvey et al. 1994;

USACE 2002). Data from cyclic operation of the SVE system (i.e., multiple rebound periods) can also be analyzed and evaluated in terms of vadose zone contaminant mass discharge behavior and how it changes 
over time (Brusseau et al. 2010). Using one or more of these techniques, data should be collected to describe the current SVE performance in terms of contaminant removal rate (mass per time for a specified time period) and how this rate has changed over time. Compilation of this type of data, consistent with refinement of the site conceptual model as described in Section 2.0, is useful to provide a context for assessing SVE system performance. Those systems where contaminant removal rates are still significantly declining over time are still operating effectively and are candidates for continued operation without change. If an asymptotic removal rate is being approached, additional analyses are warranted to evaluate the system in terms of optimization, closure, or transition to another technology.

The above analyses can be used to quantify the mass discharge from the contaminant source under SVE conditions (induced soil gas flow) using the mass removed (product of SVE concentration and SVE extraction rate) per time period. Information from mass transfer rate limitation can be evaluated with respect to the presence and significance of contaminant sources that are resistant to SVE treatment. The contaminant mass discharge of persistent sources should be quantified at sites where persistent sources are present and expected to be significant with respect to SVE operational and closure decisions.

To assess the impact of the vadose zone source on groundwater contaminant concentrations, the vadose zone source must be characterized with respect to source strength (contaminant mass discharge or contaminant concentration) and its location and extent within the vadose zone. The contaminant mass within the source is conceptually important in terms of source longevity, but is, in practice, very difficult to measure. Therefore, the recommended approach for assessing impact to groundwater does not explicitly consider the contaminant mass in the vadose zone source. Appendix A provides information about vadose zone source characterization. Additional considerations based on the site category are listed below.

- Type I Site

For these site types, the contamination sources are in the vadose zone. Analyses can assume that measured vadose zone concentrations and/or mass discharge are from these vadose zone sources (see Appendix A). If high groundwater contaminant concentrations exist and this assumption is not reasonable, then analysis as described for Type II sites should be performed.

- Type II Site

The analysis for Type II sites is the same as for Type I except that the contribution of contaminant discharge from the groundwater to the vadose zone must be considered. Thus, the same type of source evaluation as described for a Type I site is applicable, but must be combined with an analysis of groundwater to vadose zone discharge using either vertical profiling or calculations (see Type III discussion).

\section{- Type III Site}

For the Type III site, contamination is entering the vadose zone from the groundwater. This condition is fundamentally different from Type I and II sites. Analyses of groundwater contamination and vertical profiling of vapor concentrations above the water table can provide means to quantify the impact of groundwater contamination on the vadose zone contaminant conditions. Methods for quantifying SVE contaminant removal rates, such as those described for Type I and II sites, are applicable to Type III sites but need to be interpreted in the context of a groundwater source. For Type III sites, mitigating vapor intrusion is the primary driver for SVE application, so assessment of these sites should be conducted as defined originally for the specific site or as outlined in Step 3. 


\subsubsection{Outcomes}

1. Quantify SVE performance in terms of the trend in mass removal rate (see Section 2.0 herein and Section 9 of USACE 2002).

2. Verify rate-limited mass transfer conditions and the need to evaluate SVE optimization, transition, or termination.

3. Quantify the characteristics of contaminant sources that would remain if SVE were terminated. See Appendix A for details.

\subsubsection{Special Case - High Recharge Sites}

The above analyses assume that vapor and pore water are in equilibrium and that vapor transport away from the source zone is faster than aqueous phase transport. If this is not the case, alternative analyses based on quantifying pore water or sediment concentrations may be needed. Sites with recharge greater than $2.5 \mathrm{~cm} / \mathrm{yr}$ should evaluate the relative role of vapor-phase and aqueous-phase contaminant transport (see Step 2). Appendix B provides guidance for high recharge sites.

\subsubsection{Step 2: Estimate Impact to Groundwater (Type I and II Sites)}

\subsubsection{Framework and Assumptions}

A basic framework for determining the impact to groundwater as depicted in Figure 4.2 is recommended. This framework uses the following assumptions. Note that the assumptions and associated inputs for analysis of the impact to groundwater should be agreed on by the decision makers for the SVE endpoint decisions.

- The actual vadose zone contaminant source can be represented by a generalized single source with defined dimensions, location with respect to the surface and water table, and concentration.

- The source is assumed to remain constant for the purpose of estimating impact to groundwater. Note: The effect of a diminishing source can be evaluated as a subsequent effort.

- Basic site subsurface properties and their distribution can be estimated for use in the impact assessment and can be generalized to be consistent with the generalized source configuration.

- Compliance is assumed to be defined as a specific groundwater contaminant concentration in a well of defined location and screen length (groundwater mixing zone).

- The recharge rate through the source can be defined and used as input to calculate the aqueous-phase contaminant discharge into the groundwater.

- Groundwater flow (defined by the Darcy flux) is constant directly toward the compliance well.

- Variations in the dimensions, location, and concentration of the generalized source, recharge rate, and subsurface properties can be evaluated as sensitivities within the framework approach to examine the impact of uncertainties in these values on the estimated impact to the groundwater.

- The ground surface is open for vapor transport and the vapor concentration is zero at ground surface (boundary condition for vapor intrusion flux calculation). 
- Vapor phase mass transfer across the water table in this analysis has been maximized for this analysis with the assumption of a thin capillary zone (conservative approach). Mass transfer limitations for thicker capillary fringes may need to be considered in a site-specific analysis.

For some sites, notably sites with contaminant sources that are widely dispersed, the basic framework shown in Figure 4.2 may not be appropriate and a site-specific approach will be necessary. However, the site-specific approach can use an overall approach similar to that described for the basic framework.

\subsubsection{Analysis Process}

1. Consider the following actions depending on the recharge rate at the site.

Note: The recharge rate is not equal to the precipitation and must be estimated based on the net infiltration of water from the surface to the groundwater.

- If the recharge rate is $<2.5 \mathrm{~cm} / \mathrm{yr}$, the analyses in this guidance are directly applicable to the site.

- If the recharge rate is between 2.5 and $7.5 \mathrm{~cm} / \mathrm{yr}$, the analyses in this guidance are likely applicable (Oostrom et al. 2010), but the site should consider whether or not the contaminant mass transfer is predominantly in the vapor or in the aqueous phase. A scoping assessment such as presented in Truex et al. (2009) can be used for this assessment. If the estimated mass flux from the scoping analysis is dominantly in the aqueous phase (e.g., more than double the vapor-phase mass flux), then the site should consider the guidance listed in Appendix B to compute the impact of the vadose zone source to groundwater.

- If the recharge rate is $>7.5 \mathrm{~cm} / \mathrm{yr}$, then the site should likely consider the guidance listed in Appendix B to compute the impact of the vadose zone source to groundwater.

2. Estimate the source dimensions and strength. Appendix A provides information on techniques to estimate these source characteristics.

3. Compile analysis input parameters and use the procedure provided in Appendix $\mathrm{C}$ to estimate the groundwater contaminant concentration at the specified compliance well. A sensitivity analysis to consider reasonable ranges for the input parameters is recommended to evaluate the potential variability in the estimated impact. The approach in Appendix $\mathrm{C}$ has been implemented in a spreadsheet tool for user convenience (Appendix D).

\subsubsection{Step 3: Estimate Impact to Vapor Intrusion}

Vapor intrusion issues are strongly influenced by the specific structures and conditions at the ground surface. Existing vapor intrusion analyses, therefore, typically rely on surface-based measurements and analyses and are covered under other guidance (e.g., EPA 2002a; ITRC 2007). Vapor path tomographic methods are also under development for application to vapor intrusion analysis (Brusseau 2011) and may provide an alternative means to estimate the impact of vapor intrusion.

\subsubsection{Step 4: Estimate Impact of Source Decay, Sorption, and Attenuation Processes}

In many cases, it may be appropriate to consider the effect of a diminishing vadose zone source over time. Variants from the base case analysis (Step 2) can be used to evaluate how the resultant groundwater concentration changes as the vadose zone source size and/or concentration is diminished (Appendix C). 
Sorption can delay the impact to groundwater, but has minimal impact on the overall long-term impact if the source strength remains constant (Carroll et al. 2012). However, at sites where the source is expected to decay, sorption processes may need to be considered as an additional factor attenuating the impact of the vadose zone source on the groundwater. This type of sorption analysis is not included in this guidance.

The analysis process in Step 2 does not include consideration of attenuation processes in the groundwater. As appropriate, the Step 2 analyses could be applied and then augmented with a groundwater analysis considering the distance and travel time to the compliance well to estimate the amount of attenuation (mass or concentration per time) that would be needed to meet the compliance goal. This computed value can be compared to information on the type, rate, and extent of attenuation processes in the aquifer to determine if attenuation in the groundwater may help meet the concentration goal at the compliance well. Alternatively, a groundwater model (a numerical model or a tool such as BIOCHLOR $^{1}$ ) could be applied and use the near-source contaminant concentration provided in the Step 2 analysis as the groundwater source to compute the downgradient contaminant concentration profile. The groundwater model can generate the expected concentration profile over time at the compliance well based on the input attenuation parameters.

1 BIOCHLOR is a screening model that simulates natural attenuation of dissolved solvents at chlorinated solvent release sites (additional information is available at http://www.epa.gov/ada/csmos/models/biochlor.html). 



\subsection{Decision Approach for Soil Vapor Extraction Optimization, Transition, or Closure}

This section presents a decision logic process for decision makers to determine if 1) the site is ready for SVE termination and closure, 2) the existing SVE system should be optimized to improve performance, or 3) other alternative technologies should be considered to meet remediation goals. Quantitative information from Section 4.0 provides input to this decision logic. The primary focus of this section is to identify if and when SVE can be terminated based on the analyses in Section 4.0. If termination is not possible, potential SVE optimization processes are presented. If the remediation goal is unlikely to be attained through optimization, then potential alternative approaches can be considered. These alternatives are introduced in the context of augmenting or replacing SVE applications for a site. For specific information about how to apply these technologies, the user will need to consult other information sources.

The concepts developed here are also valuable for development of a closure strategy for a site in advance of significant operation of a SVE system. The concept of optimizing the SVE and/or transitioning to other technologies would be a common component of closure strategies. The metrics for assessing progress can be based on the data compilation discussions in Section 2.0.

This section also builds on the analysis and decisions developed in Sections 2.0 and 3.0. Section 2.0 guides data collection, updating of the conceptual site model, and categorizing the site. Site categorization is important in developing recommendations, as discussed in this section. Section 3.0 helps clarify the requirements and goals for the site based on the regulatory framework and risk posed by the site. These requirements and goals must be compared to the achievable end point for SVE. The output of these analyses is integral to the decisions to be considered in this section.

\subsection{Decision Logic}

Based on the analysis of the conceptual site model and site categorization, the determination of the appropriate site goals, and likely impacts from remaining sources, the following decision logic may be used to determine appropriate future actions at the site. For situations where the future action points to use of an SVE enhancement or alternative technology, Section 5.2 provides a brief overview of options.

\subsubsection{Step 1}

If SVE is terminated, will remediation goals be met? Lines of evidence supporting termination are typically considered by the site and regulatory agency decision makers. Supporting evidence includes SVE operational and performance history, CSM elements that demonstrate knowledge of the remaining source characteristics, context of the site in terms of environmental impact and compliance, and the estimated impact to ground surface or groundwater using the results of Section 4.0 analyses. The operational and performance history, as described more fully in Section 2.0, would need to demonstrate that the well locations and flow rates were adequate to address the full target treatment volume (i.e., the final design was valid), and that the system was operated for a sufficient duration to remove most of the available mass. The CSM elements would have been updated as suggested by the information analysis outlined in Section 2.0, including the mass removal, concentration profiling, rebound testing, and/or vapor-phase tomography methods. The data analysis would have to consider the regulatory context/metrics as outlined in Section 3.0 and the risk to groundwater as determined using the methods outlined in Section 4.0. 
Ideally, analyses in Section 4.0 will have been conducted with consideration of the above SVE operational history, CSM, and environmental/compliance setting and provide a direct quantitative estimate that can be compared to the remediation goal. In that case, with appropriate documentation, the following question may form the primary basis for the decision.

- Will the remaining contamination cause groundwater goals to be exceeded?

If the answer to this question is "yes," proceed to Step 2 - consideration of SVE optimization. If the answer this questions is "no," then stop and seek site closure pending vapor intrusion evaluation, if appropriate.

If there are mitigating factors related to the SVE operational history, CSM, and environmental/compliance setting that render Section 4.0 analyses uncertain, then the site will need to consider the lines of evidence associated with the SVE decision and/or the need to collect additional data/information to reduce the level of uncertainty. Pending these actions, the site may either proceed toward closure or proceed to Step 2.

\subsubsection{Step 2}

Can the existing SVE system be optimized? An optimized SVE system may have the potential to remove contaminant mass more efficiently and reach conditions suitable for closure.

- Is there accessible mass in permeable zones (refer to methods outlined in Section 2.0)? If the answer is "no," proceed to Step 3.

- Is there evidence that SVE is diminishing the contaminant source strength? Is there evidence that SVE treatment will diminish contamination sufficiently to meet remediation goals within a reasonable amount of time (following the outcome of the Section 4.0 analysis)? If yes, consider continued operation of SVE and re-evaluation for closure at a later time.

- If the rate of contaminant diminishment will require a long period of time to reach goals, consider the following optimization approaches outlined by the USACE (2002, Chapter 8) and/or AFCEE (2001, Section 5) to decrease this timeframe by optimizing the SVE system. If these approaches are not applicable or deemed uncertain for the site, proceed to Step 3. Optimization alternatives include:

- Focusing active extraction in areas with significant mass removal

- Achieving adequate air throughput by adding extraction wells if necessary or replacing extraction wells having inappropriate screened intervals with wells that are appropriately screened

- Adding passive/active air injection wells in areas where better air throughput is needed

- Pulsing of the extraction system may achieve the same mass removal with lower operational costs

- Passive extraction may be appropriate if the site stratigraphy and air permeability is appropriate to create air flow needed to remove/capture site mass flux

- Supplementing SVE with air sparging or multiphase extraction if the target mass is near the water table/capillary fringe.

- After a period of revised operation, apply the Section 4.0 performance assessment and revisit the CSM and re-evaluation for closure. 


\subsubsection{Step 3}

If optimization is not viable for a site, then enhancements or alternatives to SVE can be considered. Potential technology approaches are presented in Section 5.2. The site should also consider the SVE operational history, CSM, environmental/compliance setting, and site category (e.g., Type I, II, or III) in selecting alternatives.

Type I and II Sites: For Type I sites with homogeneous subsurface conditions, it is anticipated that an optimized SVE design should be sufficient for Type I sites. If SVE performance is poor at this type of site, then additional characterization would be needed to identify the reason for the unexpected performance. For Type I and II sites where the SVE operation has not been able to sufficiently diminish the vadose zone source and the CSM indicates the remaining source is within low permeability zones that will not be impacted through optimization, alternatives to consider should include three categories of action depending on the environmental/compliance setting for the site.

- In some cases, control of contaminant flux from the remaining sources to the groundwater may be sufficient to meet remediation goals. Flux-control approaches may be cost effective for these sites if mass removal options appear difficult and costly. Thus, approaches such as infiltration barriers, passive SVE, oil injection at the water table, or use of active SVE periodically to control vapor migration (rather than for source treatment) could be considered (see Section 5.2 for technology information).

- If control of contaminant flux to the surface for vapor intrusion issues is the primary remediation need, flux control or surface treatments can be considered. Flux control could apply passive SVE, use of active SVE periodically to control vapor migration (rather than for source treatment), use of hydraulic or pneumatic fracturing with active or passive SVE to enhance capture, or active air injection to prevent vapor migration to sensitive surface areas. In some cases, surface remedies, as are commonly applied for vapor intrusion, may be the most cost-effective approach (EPA 2008) (see Section 5.2 for technology information).

- If site closeout is necessary and includes the need to significantly reduce the vadose zone contamination source, then more aggressive remedies may be needed. These approaches include pneumatic/hydraulic fracturing of low-permeability zones with continued SVE, multi-phase extraction or air sparging (if the mass is primarily concentrated in high-moisture soils near the water table), and/or in-situ thermal remediation of the remaining low-permeability source zones (see Section 5.2 for technology information).

Type III Site: These sites have contamination sources in the groundwater in addition to the vadose zone. For these sites, the contaminant mass in the vadose zone may not be a significant additional threat to groundwater compared to the sources within the groundwater. Two likely remediation scenarios are 1) control of upward migrating vapors, or 2) site closeout with treatment of the vadose zone sources.

- If control of contaminant flux to the surface for vapor intrusion issues is the primary remediation need, flux control or surface treatments can be considered. Flux control could apply passive SVE, use of active SVE periodically to control vapor migration (rather than for source treatment), use of hydraulic or pneumatic fracturing with active or passive SVE to control vapor migration, oil injection at the water table, or active air injection to prevent vapor migration to sensitive surface areas. In some cases, surface remedies as are commonly applied for vapor intrusion may be the most cost-effective approach (EPA 2008) (see Section 5.2 for technology information). 
- If site closeout is necessary and includes the need to significantly reduce the vadose zone contamination source, then more aggressive remedies may be needed. These approaches include pneumatic/hydraulic fracturing of low-permeability zones with continued SVE, multi-phase extraction or air sparging (if the mass is primarily concentrated in high-moisture soils near the water table), and/or in-situ thermal remediation of the remaining low-permeability source zones (see Section 5.2 for technology information).

\subsection{Enhancements to Soil Vapor Extraction and Alternative Technologies}

There are a number of enhancements to SVE that can help optimize the cleanup as well as alternative technologies that could follow active SVE at the site. These enhancements and alternative technologies are briefly described in the following paragraphs:

\subsubsection{SVE Enhancements}

- Focused Extraction and Additional Wells. The existing SVE system can be tailored to enhance removal of remaining mass by focusing extraction on existing wells that are still moving air through or past the source(s) and terminating superfluous wells. In some cases, air throughput is inadequate at specific locations and depths and new wells with carefully selected screened intervals are appropriate. Modeling of air flow can assist in this at more complex sites (USACE 2002).

- Pulsing. As the remaining mass becomes more diffusion-limited, SVE operation can be transitioned to a periodic or "pulsed" operation such that active extraction occurs in intervals separated by periods of no extraction during which diffusion allows mass to re-enter permeable pathways. Pulsing can be done on a rotating basis at a large site such that active extraction is occurring at a subset of wells while other wells at the site are inactive. The period of inactivity depends on the rate of diffusion and can be determined based on monitoring of the rebound of concentrations following cessation of extraction. The length of the inactive period may represent the time to a rebound to some percentage (e.g., 60\%) of a baseline concentration (USACE 2002).

- Active or Passive Air Injection. Coupling air injection with active extraction can better focus air flow through zones with remaining mass and can overcome "stagnation zones" between active extraction wells. The use of air injection can reduce required applied vacuum and water table upwelling at sites where contaminants are concentrated near the water table. Air injection can be done passively by allowing some wells to be open to the atmosphere, or actively through the use of separate piping and blowers. Passive air injection is usually limited by the low vacuum experienced by venting wells; active air injection, which is effective at delivering more air, should be limited to a rate that can certainly be captured by the vapor extraction wells. Active injection is usually limited to some fraction of the total extraction rates (USACE 2002).

- Hydraulic or Pneumatic Fracturing. If the remaining mass resides in relatively thick low permeability material, careful hydraulic or pneumatic fracturing of the soil may shorten the diffusion distance to paths where advective removal of contaminant can occur (EPA 1997a).

- Passive SVE. At sites where there is a significant lag in subsurface pressure response to atmospheric pressure changes so there are large differential pressures between subsurface and the atmosphere, passive extraction may be an option. Provided air permeability is adequate in the soils 
separating the remaining source and the exposure pathway, vapors can passively be extracted at a rate adequate to control the remaining mass flux. Passive extraction is often done simply by placing a check valve that allows air to exit the well, but does not allow air into the well. Extraction is typically observed during the warmer times of the day when atmospheric pressure drops, and during the passage of low pressure systems. Treatment of the extracted vapor is possible, typically with vapor-phase carbon, provided that adequate flow can be maintained accounting for the pressure drop across the carbon vessel (Kamath et al. 2009).

\subsubsection{Alternative/Transitional Technologies to SVE}

There are a number of other cleanup technologies that can be used as follow-on or replacements for active SVE. In several cases, vapor extraction is part of the technology, but other mechanisms of mass removal are also added. These technologies may be applied to control small mass fluxes after SVE has largely removed the source, or where SVE alone is unlikely to attain significant source reduction, the SVE system would be replaced by these technologies. In several cases, existing infrastructure (wells, piping, blowers, etc.) may still be used so the capital investment for SVE may not be totally unproductive.

- Bioventing. At sites where the contaminants are primarily aerobically biodegradable (or cometabolically degradable), replacing active extraction with air injection would provide oxygen to the native bacteria and stimulate additional contaminant removal without the cost of off-gas treatment. Air injection can be pulsed, with the pulse frequency and duration based on observed oxygen uptake rates. Air can be supplemented by a co-metabolite, such as methane, propane, or toluene vapors to promote the expression of enzymes in aerobic bacteria that fortuitously degrade certain compounds such as trichloroethene. Existing wells, piping, and blowers can often be used. The addition of gaseous nutrients (e.g., nitrous oxide, triethyl phosphate) may be needed to maximize the degradation rates, though many sites have been addressed without nutrient addition (EPA 1995b, 2000c).

- Multi-Phase Extraction. Multiphase extraction involves the simultaneous extraction of vapors and liquids from the same well, using either a single vacuum pump or separate pumps for the separate phases. The liquid extraction may enhance the removal of mass from the location of the smear zone/capillary fringe by lowering both the water table and levels of soil saturation. The application of vacuum can also enhance the removal of liquids from soils with modest permeabilities (e.g., 1E-3 to $1 \mathrm{E}-5 \mathrm{~cm} / \mathrm{sec}$ ) for simultaneous recovery of dissolved mass or NAPL from the source areas (USACE 1999).

- In-Situ Thermal Treatment. The application of heat to contaminated soil results in higher vapor pressures for most organic contaminants and is accompanied by changes in the solubility, viscosity, surface tension, and density of non-aqueous phase liquids. Rates of bioremediation (and hydrolysis for chlorinated ethanes) may be significantly enhanced at elevated temperatures due to faster kinetics for reactions at higher temperatures and/or the enhancement of activity by robust thermophilic bacteria. Soil heating is more tolerant of soil heterogeneity than most other in-situ technologies. Heat may be introduced through electrical resistivity heating (passing currents between electrodes placed into the soils to be treated), thermal conduction heating (heat propagates through conduction from heaters placed in wells), or steam injection. The vapors generated by the process are typically collected via vapor extraction wells (USACE 2009; Kingston et al. 2010). 
- Oil Injection. The placement of a neat, non-toxic oil (e.g., vegetable oil) within a zone, particularly near the water table, may act to blanket remaining sources of VOC vapors so as to reduce vapor intrusion potential and would adsorb contaminant mass flux impacting groundwater from the vadose zone through contamination partitioning into the oil. The oil would slowly dissolve and may act as an electron donor to promote reductive dechlorination in the groundwater and would need to be replenished (Riha et al. 2012).

- In-Situ Air Sparging. Air sparging involves the injection of air into wells with screened intervals below the water table. The injected air moves through channels outwards and upwards from the well based on buoyancy and air-entry pressures of the soil strata (closely related to typical pore size and connectedness). If the remaining sources are concentrated in the vicinity of the water table and capillary fringe, the mass may not be easily accessible to SVE. In-situ air sparging may allow air passage through these zones for either subsequent capture of the contaminant vapors with the existing SVE system or discharge to the vadose zone and ultimately to the atmosphere. The air may also provide a source of dissolved oxygen to promote aerobically degradable compounds in both the groundwater and vadose zone (USACE 2008). 


\subsection{References}

AFCEE. 2001. United States Air Force Environmental Restoration Program: Guidance on Soil Vapor Extraction Optimization. Air Force Center for Environmental Excellence, Brooks Air Force Base, Texas. Last accessed July 17, 2012, at http://www.dtic.mil/docs/citations/ADA392205

AFCEE. 2012. "Air Force Center for Engineering and the Environment - Soil Vapor Extraction" (website). Air Force Center for Engineering and the Environment, Lackland AFB, Texas. Last accessed July 17, 2012, at http://www.afcee.af.mil/resources/technologytransfer/programsandinitiatives/ sourcezonetreatment/background/soilvaporextract/index.asp

Brusseau ML, PSC Rao, RE Jessup and JM Davidson. 1989. "Flow Interruption: A Method for Investigating Sorption Nonequilibrium.” J. Contam. Hydrol., 4(3):223-240.

Brusseau ML, NT Nelson, Z Zhang, JE Blue, J Rohrer, and T Allen. 2007. "Source-zone Characterization of a Chlorinated-Solvent Contaminated Superfund Site in Tucson, AZ." J. Contam. Hydrol., 90(1-2):21-40.

Brusseau ML, VJ Rohay, and MJ Truex. 2010. "Analysis of Soil Vapor Extraction Data to Evaluate Mass-Transfer Constraints and Estimate Source-Zone Mass Flux." Ground Water Monit. Remed., 30(3):57-64. doi: 10.1111/j1745-6592.2010.001286.x

Brusseau ML. 2011. "Use of Mass-Flux Measurement and Vapor-Phase Tomography to Quantify Vadose-Zone Source Strength and Distribution.” SERDP Project 201125 Fact Sheet, Strategic Environmental Research and Development Program (SERDP) and Environmental Security Technology Certification Program (ESTCP), Alexandria, Virginia. Last accessed July 17, 2012, at http://www.serdp.org/Program-Areas/Environmental-Restoration/Contaminated-Groundwater/EmergingIssues/ER-201125

Carroll KC, M Oostrom, MJ Truex, VJ Rohay, and ML Brusseau. 2012. "Assessing Performance and Closure for Soil Vapor Extraction: Integrating Vapor Discharge and Impact to Groundwater Quality." J. Contam. Hydrol., 128(1-4):71-82. doi: 10.1016/j.jconhyd.2011.10.003.

Carroll, K.C., M.J. Truex, M.L. Brusseau, K.R. Parker, R.D. Mackley, and V.J. Rohay. 2013. "Characterization of Persistent Volatile Contaminant Sources in the Vadose Zone." Ground Water Monitoring and Remediation, in press.

DiGiulio DC, V Ravi, and ML Brusseau. 1999. "Evaluation of Mass Flux to and from Ground Water Using a Vertical Flux Model (VFLUX): Application to the Soil Vacuum Extraction Closure Problem." Ground Water Monit. Remed., 19(2):96-104.

DiGiulio DC and R Varadhan. 2001. "Analysis of Water Saturation, NAPL Content, Degradation HalfLife, and Lower Boundary Conditions on VOC Transport Modeling: Implications for Closure of Soil Venting Systems." Ground Water Monit. Remed., 21(4):83-95.

DiGiulio DC, ML Brusseau, and V. Ravi. 1998. "Use of Diffusion Modeling to Aid Assessment of RateLimited Vapor Transport for SVE Closure.” In: Physical, Chemical, and Thermal Technologies: 
Remediation of Chlorinated and Recalcitrant Compounds, GB Wickramanayake and RE Hinchee, Eds. Battelle Press, Columbus, Ohio.

EPA. 1989. Methods for Evaluating the Attainment of Cleanup Standards, Volume 1: Soils and Solid Media. EPA/230/02-89/042, U.S. Environmental Protection Agency, Washington, D.C. Last accessed July 17, 2012, at http://www.epa.gov/tio/download/stats/vol1soils.pdf

EPA. 1995a. Soil Vapor Extraction (SVE) Enhancement Technology Resource Guide.

EPA/542/B-95/003, U.S. Environmental Protection Agency, Washington, D.C. Last accessed July 17, 2012, at http://www.epa.gov/tio/download/remed/sveresgd.pdf

EPA. 1995b. Manual: Bioventing Principles and Practice. EPA/540/R-95/534a, U.S. Environmental Protection Agency, Washington, D.C.

EPA. 1996a. Soil Screening Guidance: Fact Sheet. EPA/540/F-95/041, U.S. Environmental Protection Agency, Washington, D.C. Last accessed July 17, 2012, at http://www.epa.gov/superfund/health/conmedia/soil/index.htm\#fact

EPA. 1996b. Soil Screening Guidance: User's Guide, Second Ed. EPA/540/R-96/018, U.S. Environmental Protection Agency, Washington, D.C. Last accessed July 17, 2012, at http://www.epa.gov/superfund/health/conmedia/soil/index.htm\#user

EPA. 1996c. Soil Screening Guidance: Technical Background Document. EPA/540/R-95/128, U.S. Environmental Protection Agency, Washington, D.C. Last accessed July 17, 2012, at http://www.epa.gov/superfund/health/conmedia/soil/toc.htm

EPA. 1997a. Analysis of Selected Enhancements for Soil Vapor Extraction. EPA/542/R-97/007, U.S. Environmental Protection Agency, Washington, D.C. Last accessed July 17, 2012, at http://www.epa.gov/tio/download/remed/sveenhmt.pdf

EPA. 1997b. "Guidance on Cumulative Risk Assessment. Part 1: Planning and Scoping." Attachment to memo dated July 3, 1997 from the Administrator, Carol Browner, and Deputy Administrator, Fred Hansen, titled "Cumulative Risk Assessment Guidance-Phase I Planning and Scoping." Science Policy Council, U.S. Environmental Protection Agency, Washington, D.C. Last accessed July 17, 2012, at http://www.epa.gov/osa/spc/pdfs/cumrisk2.pdf

EPA. 1998. Technical Protocol for Evaluation Natural Attenuation of Chlorinated Solvents in Groundwater. EPA/600/R-98/128, U.S. Environmental Protection Agency, Washington, D.C.

EPA. 1999a. Use of Monitored Natural Attenuation at Superfund, RCRA Corrective Action, and Underground Storage Tank Sites. OSWER Directive 9200.4-17P, Office of Solid Waste and Emergency Response, U.S. Environmental Protection Agency, Washington, D.C.

EPA. 1999b. EPA Superfund Record of Decision: Montrose Chemical Corp. and Del Amo. EPA/ROD/R09-99/035, Region 9, U.S. Environmental Protection Agency, San Francisco, California. Last accessed July 17, 2012, at http://www.epa.gov/superfund/sites/rods/fulltext/r0999035.pdf 
EPA. 2000a. “Tech Trends, Issue 37.” EPA/542/N-00/003, U.S. Environmental Protection Agency, National Service Center for Environmental Publications, Cincinnati, Ohio.

EPA. 2000b. EPA Superfund Record of Decision Amendment: Keystone Sanitation Landfill. EPA/AMD/R03-00/065, Region 3, U.S. Environmental Protection Agency, Philadelphia, Pennsylvania. Last accessed July 17, 2012, at http://www.epa.gov/superfund/sites/rods/fulltext/a0300065.pdf

EPA. 2000c. Cost and Performance Report: Cometabolic Bioventing at Building 719, Dover Air Force Base, Dover, Delaware. U.S. Environmental Protection Agency, Washington, D.C. Last accessed July 17, 2012, at http://costperformance.org/pdf/Dover719Bio.PDF

EPA. 2001a. A Citizen's Guide to Soil Vapor Extraction and Air Sparging. EPA/542/F-01/006, U.S. Environmental Protection Agency, Washington, D.C. Last accessed July 17, 2012, at http://www.epa.gov/tio/download/citizens/citsve.pdf

EPA. 2001b. Development of Recommendations and Methods to Support Assessment of Soil Venting Performance and Closure. EPA/600/R-01/070, U.S. Environmental Protection Agency, Washington, D.C.

EPA. 2002a. OSWER Draft Guidance for Evaluating the Vapor Intrusion to Indoor Air Pathway from Groundwater and Soils (Subsurface Vapor Intrusion Guidance). EPA/530/D-02/004, U.S. Environmental Protection Agency, Washington, D.C. Last accessed July 17, 2012, at http://www.epa.gov/osw/hazard/correctiveaction/eis/vapor.htm

EPA. 2002b. Guidance on Cumulative Risk Assessment of Pesticide Chemicals that Have a Common Mechanism of Toxicity. OPP-00658B, Office of Pesticide Programs, U.S. Environmental Protection Agency, Washington, D.C. Last accessed July 17, 2012, at http://www.epa.gov/scipoly/sap/meetings/2003/december11/cumulativeguidance2002.pdf

EPA. 2003a. "Site Characterization and Monitoring Case Study Vertical Profiling at Nellis Air Force Base, Site 46, Las Vegas, NV.” U.S. Environmental Protection Agency, Washington, D.C. Last accessed August 2, 2012, at http://www.frtr.gov/pdf/20030709_9.pdf

EPA. 2003b. Framework for Cumulative Risk Assessment. EPA/630/P-02/001F, U.S. Environmental Protection Agency, Washington, D.C. Last accessed July 17, 2012, at http://www.epa.gov/raf/publications/framework-cra.htm

EPA. 2004a. How to Evaluate Alternative Cleanup Technologies for Underground Storage Tank Sites. EPA/510/R-04/002, U.S. Environmental Protection Agency, Washington, D.C. Last accessed July 17, 2012, at http://www.epa.gov/swerust1/pubs/tums.htm

EPA. 2004b. EPA Superfund Record of Decision Amendment: Tucson International Airport Area. EPA/AMD/R09-04/604, Region 9, U.S. Environmental Protection Agency, San Francisco, California. Last accessed July 17, 2012, at http://www.epa.gov/superfund/sites/rods/fulltext/a0904604.pdf

EPA. 2006. EPA Superfund Record of Decision Amendment: Solvent Savers. EPA/AMD/A2006020001429, Region 2, U.S. Environmental Protection Agency, New York, New York. Last accessed July 17, 2012, at http://www.epa.gov/superfund/sites/rods/fulltext/a2006020001429.pdf 
EPA. 2008. Engineering Issue Paper, Indoor Air Vapor Intrusion Mitigation Approaches. EPA/600/R-08/115, U.S. Environmental Protection Agency, Washington, D.C.

Harvey CF, R Haggerty, and SM Gorelick. 1994. "Aquifer Remediation: A Method for Estimating Mass Transfer Rate Coefficients and an Evaluation of Pulsed Pumping." Water Resour. Res., 30(7):1979-1991.

ITRC. 2007. Vapor Intrusion Pathway: A Practical Guideline. Interstate Technology \& Regulatory Council, Washington, D.C.

Johnson PC, CC Stanley, MW Kemblowski, DL Byers, and JD Colthart. 1990. "A Practical Approach to the Design, Operation, and Monitoring of In Situ Soil-Venting Systems." Ground Water Monit. Remed., 10(2):159-178.

Kamath R, DT Adamson, and CJ Newell. 2009. Enhanced Attenuation Technologies: Passive Soil Vapor Extraction. SRNL-STI-2009-00571, Savannah River National Laboratory, Aiken, South Carolina.

Kingston JT, PR Dahlen, PC Johnson, E Foote, and S Williams. 2010. Critical Evaluation of State-ofthe-Art In Situ Thermal Treatment Technologies for DNAPL Source Zone Treatment, Final Report. ESTCP Project ER-0314, Environmental Security Technology Certification Program, Alexandria, Virginia. Last accessed July 17, 2012, at http://www.serdp.org/content/download/4576/67301/file/ER0314-FR.pdf

Matzke BD, JE Wilson, LL Nuffer, ST Dowson, JE Hathaway, NL Hassig, LH Sego, CJ Murray, BA Pulsipher, B Roberts, and S McKenna. 2010. Visual Sample Plan Version 6.0 User's Guide. PNNL19915, Pacific Northwest National Laboratory, Richland, Washington. Last accessed August 2, 2012, at http://vsp.pnnl.gov/documentation.stm

Noyes R. 1994. Unit Operations in Environmental Engineering. Noyes Publications, Park Ridge, New Jersey.

Oostrom M, ML Rockhold, PD Thorne, GV Last, MJ Truex, and VJ Rohay. 2007. "Carbon Tetrachloride Flow and Transport in the Subsurface of the 216-Z-9 Trench at the Hanford Site." Vadose Zone J., 6(4):971-984.

Oostrom M, MJ Truex, GD Tartakovsky, and TW Wietsma. 2010. "Three-Dimensional Simulation of Volatile Organic Compound Mass Flux from the Vadose Zone to Groundwater." Ground Water Monit. Remed., 30(3):45-56. doi: 10.1111/j1745-6592.2010.001285.x

Riha B, B Looney, J Noonkester, K Hyde, and R Walker. 2012. Treatability Study for Edible Oil Deployment for Enhanced cVOC Attenuation for T-Area, Savannah River Site. SRNL-STI-2012-00290, Savannah River National Laboratory, Aiken, South Carolina. Last accessed August 2, 2012, at http://sti.srs.gov/fulltext/SRNL-STI-2012-00290.pdf

Stamnes R and J Blanchard. 1997. "Engineering Forum Issue Paper: Soil Vapor Extraction Implementation Experiences." EPA 540/F-95/030, U.S. Environmental Protection Agency, Washington, D.C. Last accessed July 17, 2012, at http://www.epa.gov/tio/tsp/download/sveissue.pdf 
Switzer C, T Slagle, D Hunter, and DS Kosson. 2004. "Use of Rebound Testing for Evaluation of Soil Vapor Extraction Performance at the Savannah River Site." Ground Water Monit. Remed., 24(4):106117.

Switzer C and DS Kosson. 2007. "Soil Vapor Extraction Performance in Layered Vadose Zone Materials." Vadose Zone J., 6(2):397-405.

Truex MJ, M Oostrom, and ML Brusseau. 2009. "Estimating Persistent Mass Flux of Volatile Contaminants from the Vadose Zone to Ground Water." Ground Water Monit. Remed., 29(2):63-72.

Truex MJ, KC Carroll, VJ Rohay, RM Mackley, and KR Parker. 2012. Treatability Test Report: Characterization of Vadose Zone Carbon Tetrachloride Source Strength Using Tomographic Methods at the 216-Z-9 Site. PNNL-21326, Pacific Northwest National Laboratory, Richland, Washington.

USACE. 1999. Engineering and Design: Multi-Phase Extraction. EM 1110-1-4010, U.S. Army Corps of Engineers, Washington, D.C. Last accessed July 17, 2012, at http://publications.usace.army.mil/publications/eng-manuals/EM_1110-1-4010_sec/toc.htm

USACE. 2002. Engineering and Design: Soil Vapor Extraction and Bioventing. EM 1110-1-4001, U.S. Army Corps of Engineers, Washington, D.C. Last accessed July 17, 2012, at http://publications.usace.army.mil/publications/eng-manuals/EM_1110-1-4001_sec/toc.htm

USACE. 2008. Engineering and Design: In-Situ Air Sparging. EM 1110-1-4005, U.S. Army Corps of Engineers, Washington, D.C. Last accessed July 17, 2012, at http://publications.usace.army.mil/publications/eng-manuals/EM_1110-1-4005_sec/toc.htm

USACE. 2009. Engineering and Design: Design: In Situ Thermal Remediation. EM 1110-1-4015, U.S. Army Corps of Engineers, Washington, D.C. Last accessed July 17, 2012, at http://publications.usace.army.mil/publications/eng-manuals/EM_1110-1-4015_pflsec/toc.html

van Deuren J, T Lloyd, S Chhetry, R Liou, and J Peck. 2002. “4.8 Soil Vapor Extraction” (website). In: Remediation Technologies Screening Matrix and Reference Guide, $4^{\text {th }}$ Edition. U.S. Army Environmental Center, Aberdeen Proving Ground, Maryland. Last accessed July 17, 2012, at http://www.frtr.gov/matrix 2/section4/4-7.html

Varadhan R and JA Johnson. 1997. VLEACH: A One-Dimensional Finite Difference Vadose Zone Leaching Model, Version 2.2. Center for Subsurface Modeling Support, U.S. Environmental Protection Agency, Ada, Oklahoma. Last accessed July 17, 2012, at http://www.epa.gov/ada/csmos/models/vleach.html 



\section{Appendix A}

Vadose Zone Source Characterization Approaches for Input to Appendix C Analyses 



\section{Appendix A}

\section{Vadose Zone Characterization Approaches for Input to Appendix C Analyses}

This appendix provides source characterization methods that support the low-recharge system analyses as described in the guidance document and in Appendix C.

To support assessment of how a vadose zone contaminant source impacts groundwater (Appendix C), the vadose zone source must be characterized with respect to source strength (contaminant mass discharge or contaminant concentration) and its location and extent within the vadose zone. The contaminant mass within the source is conceptually important in terms of source longevity, but is in practice, very difficult to measure. Therefore, the recommended approach for assessing impact to groundwater does not explicitly consider the contaminant mass in the vadose zone source. As described below, other techniques can be used to evaluate source longevity.

\section{A.1 Source Strength}

Three aspects of characterizing source strength can be applied along with the groundwater impact assessment methods presented in the guidance document and Appendix C. The sections below discuss approaches to quantify the source in terms of source vapor concentration, vapor-phase contaminant mass discharge, and source longevity. Either the source vapor concentration or the vapor-phase contaminant mass discharge can be used with the pre-modeled scenario approach in Appendix $\mathrm{C}$ to define the sitespecific source strength. The baseline method in Appendix $\mathrm{C}$ uses an assumption of a constant source strength over time. The source longevity method discussed below provides an approach to enable consideration of a changing (e.g., decaying) source over time within the Appendix C analysis.

\section{A.1.1 Source Vapor Concentration}

Vapor diffusion is the primary contaminant transport mechanism under low-recharge conditions (Oostrom et al. 2010), which are assumed for the Appendix $\mathrm{C}$ analyses. The rate of diffusion is a function of the concentration gradient, going from high vapor concentrations in the source to lower concentrations away from the source. Contaminant vapor concentration should be determined under quiescent conditions (i.e., when SVE is not operating) at the interface between the source and higher-permeability zones that were remediated by SVE. For these measurements, it is necessary to consider 1) where to measure and how many measurements are appropriate to represent the whole source with reasonable certainty and accuracy and 2) the possibility that vapor concentrations at measurement points will change over time following SVE operations as the vadose zone system reverts to a diffusion controlled condition.

\section{A.1.2 Source Vapor-Phase Contaminant Mass Discharge}

Vapor-phase contaminant mass discharge from the vadose zone source provides an integrated measure of the whole source and can be directly used in the pre-modeled scenario approach described in Appendix C (in lieu of the contaminant vapor concentration for the source). The vapor-phase 
contaminant mass discharge is related to the diffusion driving force for the vadose zone source and will change over time as diffusion gradients evolve under quiescent conditions (i.e., without SVE operating). In addition, the location of the source with respect to the ground surface significantly influences the magnitude of the vapor-phase contaminant mass discharge, yet the associated variation in mass discharge is not directly proportional to how the source impacts contaminant concentrations in groundwater.

Vapor-phase contaminant mass discharge can be quantified using data from the SVE system while using standard SVE operational approaches with the minor modifications described below. The approach to quantifying the vapor-phase contaminant mass discharge that is described here is adapted from Brusseau et al. (2010). A more detailed step-by-step summary of the Brusseau et al. (2010) approach is provided in the Addendum to this appendix. The data required for this approach include the following:

1. Frequent measurements of the composite extracted gas flow rate and the associated contaminant gas concentration need to be collected for the SVE system during an operational cycle conducted after a period where the system has been shut down (i.e., rebound period). The duration of the rebound period is related to the specific characteristics of the site. Typical data are shown in Figure A.1. The SVE system should be configured to extract from all wells surrounding the suspected remaining source.

2. Duration of the rebound period.

3. Pore volume of the SVE system swept volume (see below).

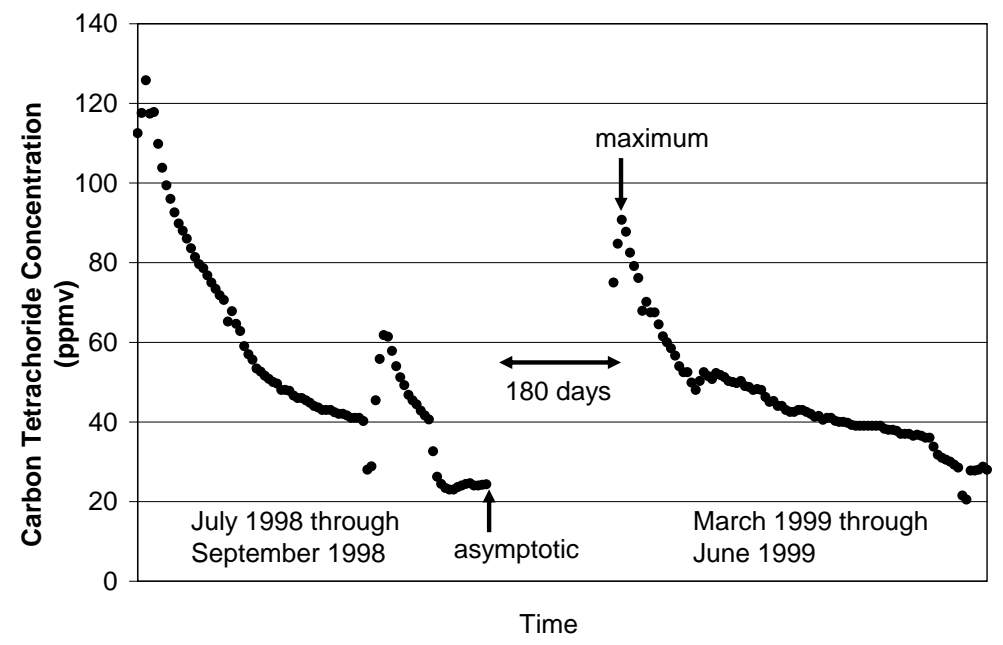

Figure A.1. Example of SVE data for two operational cycles surrounding a quiescent (180 day) rebound period.

The mass discharged from any persistent source zones within the vadose zone during the rebound time is computed from SVE extraction concentration and flow rate data collected during restart after a rebound period as shown in Equation A.1:

$$
M_{P V}=\sum_{i=1}^{n}\left(C_{i}-C_{a}\right) \cdot Q_{i} \cdot \Delta T_{i}
$$


where the $n^{\text {th }}$ sample corresponds to the point where the cumulative gas volume extracted equals one pore volume, $C_{i}$ is the contaminant concentration in the extracted soil gas $\left[\mathrm{M} / \mathrm{L}^{3}\right]$ for the $i^{\text {th }}$ sample, $\mathrm{C}_{\mathrm{a}}$ is the contaminant concentration at the end of the one pore volume of extraction, $Q_{i}$ is the extraction flow rate $\left[\mathrm{L}^{3} / \mathrm{T}\right]$, and $\Delta T_{\mathrm{i}}$ is the interval between sample times [T]. This calculation uses the equation from Brusseau et al. (2010) with modification to explicitly account for non-negligible background contaminant concentrations, either from outside the persistent source zone or from incomplete extraction of the vaporphase contaminants from previous SVE operations (see also Truex et al. 2012). The pore volume for this calculation is estimated as the pore volume within the subsurface volume where SVE operation causes soil gas flow above a threshold velocity relevant for treatment at the site (i.e., a swept volume; see USACE 2002).

The average vapor-phase contaminant mass discharge $\left(M F_{r}\right)$ during rebound is calculated as the mass discharged from the source zone during rebound $\left(M_{P V}\right)$ divided by the rebound time. The $M F_{r}$ quantity represents the short-term, vapor-phase contaminant mass discharge from the source. The mass discharge from the source will decline over time because of the initial high concentration gradient induced by the previous SVE operation creating low vapor-phase concentrations in permeable areas surrounding the source concentrations will become lower as vapors diffuse from the source. As shown by Carroll et al. (2012), long-term mass discharge is typically 10 times lower than the value measured using the method of Brusseau et al. (2010). The short-term, vapor-phase contaminant mass discharge value, $M F_{r}$ (in grams per day), is used as input to Appendix $\mathrm{C}$ calculations because it is can be readily measured in the field and the Appendix C analysis (similar to Carroll et al. 2012) has taken into account changes over time in the mass discharge.

\section{A.1.3 Source Longevity}

In Appendix $\mathrm{C}$ of this guidance document, the method to estimate the groundwater contaminant concentration resulting from a vadose zone source uses an assumption that the source strength stays constant over time. Sources remaining after SVE has been applied would be expected to persist over a relatively long duration because the contaminants are present in zones where mass-transfer limitations limit the rate of mass removal, either under SVE conditions or post-SVE, quiescent conditions. However, strength of these persistent sources will likely not remain perfectly constant over time.

Over time, mass transfer out of the persistent zones will diminish the contaminant mass and eventually change the mass discharge rate from these sources, although contaminant mass and mass discharge are not necessarily directly proportional.

The steady-state approach for the Appendix C method enables sorption in the vadose zone to be ignored. However, sorption (or other attenuation mechanisms if present in the vadose zone) may be important in terms of the timeframe for the steady-state conditions to be established and therefore may be relevant to source longevity evaluation. Several methods for evaluating source longevity are presented below.

Brusseau et al. (2010) presented a method to quantify how the vapor-phase contaminant mass discharge $\left(M F_{r}\right)$ changes over time with multiple SVE operational cycles (operation + quiescent rebound). For sites where cyclic SVE operations have been applied (i.e., multiple rebound cycles), data related to the rate of change in the source strength could be extrapolated into the future as a guide in evaluating how the source may decay in the absence of SVE. 
If there are not historical data to estimate the rate of change in the source mass discharge, an estimate for how the source may diminish over time could be conducted by computing the amount of decrease in mass in the source zone over time as an integration of the source mass discharge. For thin vadose zones or when the source is relatively close to the surface, the source mass discharge, even in the absence of SVE, may be significant with respect to source longevity. This decrease in mass must be put in context by estimating the contaminant mass within the remaining source at the end of SVE operations. There is significant uncertainty in this type of mass estimate. However, it may be possible to evaluate with reasonable certainty the amount of post-SVE time that would be required to reduce the mass by a significant fraction and to then use this information to determine whether or how a decrease in the source strength should be considered in the groundwater impact assessment (Appendix C). An approach to estimating the contaminant mass remaining in low-permeability zones following long-term SVE as originally presented in USACE (2002) is summarized in the Addendum to this appendix.

If continued vapor monitoring is planned for the site, trends in concentration over time can also be used to project changes into the future. Care is needed in tracking vapor phase concentrations because concentrations will likely increase over time due to diffusion from the source zone. The time required for concentrations to represent steady-state conditions with respect to the source area is related to the dimensions of the vadose zone and source, the location of the source within the vadose zone, and by the influence of sorption or other attenuation processes.

\section{A.2 Location and Extent}

In Appendix $\mathrm{C}$ of this guidance document, the method to estimate the groundwater contaminant concentration resulting from a vadose zone source requires inputs that describe the location and extent of the source within the vadose zone. The conceptual site model updated to represent post-SVE conditions is a starting point for this information (see Section 2.0 and Figure 4.2 of the guidance document). Key outcomes for this evaluation include the following:

- Estimated dimensions of the effective vadose zone source that remains (either a single source or a composite zone representative of multiple smaller sources) are required. The source area representation will be simplified to that of a square prism having a specified width (w) and thickness (z). The length (l) equals the width in this simplified representation.

- The estimated position of the effective vadose zone source that remains is described by specifying the distance from the ground surface to the top of the source zone (L1), and the distance from the bottom of the source zone to the water table (L2).

Additionally, the location of individual source areas may be required if SVE optimization and/or use of other remedial technologies are being considered.

Several methods to obtain the above information are listed in Section 2.0 of the guidance document.

\section{A.3 References}

Brusseau ML. 2011. "Use of Mass-Flux Measurement and Vapor-Phase Tomography to Quantify Vadose-Zone Source Strength and Distribution.” SERDP Project 201125 Fact Sheet, Strategic Environmental Research and Development Program (SERDP) and Environmental Security Technology 
Certification Program (ESTCP), Alexandria, Virginia. Last accessed July 17, 2012, at http://www.serdp.org/Program-Areas/Environmental-Restoration/Contaminated-Groundwater/EmergingIssues/ER-201125

Brusseau ML, VJ Rohay, and MJ Truex. 2010. “Analysis of Soil Vapor Extraction Data to Evaluate Mass-Transfer Constraints and Estimate Source-Zone Mass Flux." Ground Water Monit. Remed., 30(3):57-64. doi: 10.1111/j1745-6592.2010.001286.x

Carroll KC, M Oostrom, MJ Truex, VJ Rohay, and ML Brusseau. 2012. "Assessing Performance and Closure for Soil Vapor Extraction: Integrating Vapor Discharge and Impact to Groundwater Quality." J. Contam. Hydrol., 128(1-4):71-82. doi: 10.1016/j.jconhyd.2011.10.003.

EPA. 2000. “Tech Trends, Issue 37.” EPA/542/N-00/003, U.S. Environmental Protection Agency, National Service Center for Environmental Publications, Cincinnati, Ohio.

EPA. 2003. "Site Characterization and Monitoring Case Study Vertical Profiling at Nellis Air Force Base, Site 46, Las Vegas, NV.” U.S. Environmental Protection Agency, Washington, D.C. Last accessed August 2, 2012, at http://www.frtr.gov/pdf/20030709_9.pdf

Oostrom M, MJ Truex, GD Tartakovsky, and TW Wietsma. 2010. “Three-Dimensional Simulation of Volatile Organic Compound Mass Flux from the Vadose Zone to Groundwater." Ground Water Monit. Remed., 30(3):45-56. doi: 10.1111/j1745-6592.2010.001285.x

Truex MJ, KC Carroll, VJ Rohay, RM Mackley, and KR Parker. 2012. Treatability Test Report: Characterization of Vadose Zone Carbon Tetrachloride Source Strength Using Tomographic Methods at the 216-Z-9 Site. PNNL-21326, Pacific Northwest National Laboratory, Richland, Washington.

Truex MJ, M Oostrom, and ML Brusseau. 2009. "Estimating Persistent Mass Flux of Volatile Contaminants from the Vadose Zone to Ground Water." Ground Water Monit. Remed., 29(2):63-72.

USACE. 2002. Engineering and Design: Soil Vapor Extraction and Bioventing. EM 1110-1-4001, U.S. Army Corps of Engineers, Washington, D.C. Last accessed July 17, 2012, at http://publications.usace.army.mil/publications/eng-manuals/EM_1110-1-4001_sec/toc.htm 


\section{Addendum to Appendix A \\ Published Approaches to Assessing the Strength of Vadose Zone Sources}

Introduction. This addendum summarizes key aspects for two publications that provide approaches to evaluate the strength of contamination sources that remain after having applied SVE for a significant duration. The two publications are:

- USACE. 2002. Engineering and Design: Soil Vapor Extraction and Bioventing, Appendix F. Engineer Manual EM 1110-1-4001, U.S. Army Corps of Engineers, Military Bookshop, Washington, D.C. Last accessed July 17, 2012, at http://publications.usace.army.mil/publications/eng-manuals/EM_1110-1-4001/toc.htm

- Brusseau ML, VJ Rohay, and MJ Truex. 2010. "Analysis of Soil Vapor Extraction Data to Evaluate Mass-Transfer Constraints and Estimate Source-Zone Mass Flux." Ground Water Monit. Remed., 30(3):57-64. doi: 10.1111/j1745-6592.2010.001286.x

The summary for each approach includes the following elements:

- Purpose of the approach

- Underlying assumptions and conceptual models

- Data needed to conduct analysis

- A summary of the process, including data analysis

- Output from the approach.

The approach summaries are not intended as a substitute for the publications and the reader is referred to the original text for the detail needed to conduct the analysis.

Method of USACE (2002). The approach presented in Appendix F of USACE (2002) is summarized below.

Purpose. The approach in USACE (2002), Appendix F, is intended to identify the mass remaining in the vadose zone following SVE application for significant duration. In particular, it attempts to quantify the mass remaining in a low permeability "immobile" zone that does not significantly participate in air flow under SVE conditions. Such air flow is concentrated in more permeable "mobile" zones. The approach relies on the behavior observed during rebound testing and provides guidance for conducting rebound testing.

Underlying Assumptions and Conceptual Site Model. This approach assumes the following:

- The subsurface is heterogeneous with high permeability zones and low permeability zones; most of the contaminant mass resides in the low permeability zones.

- There is no NAPL remaining; only vapor-phase, sorbed, and dissolved volatile organics.

- The SVE system has been operated long enough to achieve a long-term asymptotic decline in mass removal rates. 
- The SVE system has been adequately designed and addresses the full volume of contaminated soil.

- Equilibrium linear partitioning relationships apply for partitioning between gas and liquid (Henry's Law) and between soil solids and dissolved contaminants in soil moisture.

The conceptual site model on which the approach is based is that SVE initially sweeps mass and vapors from the mobile zones and that mass continues to be released from the immobile zone during further extraction. During the rebound period, when no extraction occurs, mass will diffuse from the immobile zones until an equilibrium vapor concentration is reached in the mobile zones. When SVE is resumed, these vapors are removed and the slow asymptotic decline resumes.

Data Needed to Conduct Analysis. The approach primarily requires extracted vapor concentration data collected over time during both active extraction and rebound (rest) periods. The concentration data are usually routinely collected during active extraction, but data usually are not collected from the extraction well(s) during the rebound period. Therefore, collection of these data would be an additional step beyond normal monitoring. The initial concentrations are also required (concentrations at the time of the original start of SVE). The approach would also require the following:

- Operational air flow rates $(Q)$

- Estimate of fraction of the "mobile" and "immobile" zones in the subsurface, $f_{m}$ and $f_{i}$ (this can be estimated on various bases, including the results of Pneulog or similar testing)

- Soil porosity $(\theta)$ and typical moisture saturation in mobile and immobile zones $\left(S_{m}, S_{i}\right)$

- Henry's Law constant $(H)$, diffusion coefficient in air $(D)$, and organic carbon distribution coefficient $K_{o c}$ for site contaminants

- Fraction of organic carbon in soil $\left(f_{o c}\right)$ and soil solid density $\left(\rho_{\text {soil }}\right)$

- Estimated biodegradation rates for contaminants $(\lambda)$ in immobile and mobile zones

- Estimated volume of contaminated soil (V).

Summary of Approach. Equations (A.2) are given to estimate the immobile, $V_{i}$, and mobile, $V_{m}$, zone air-filled volumes.

$$
\begin{aligned}
& V_{i}=\frac{\theta_{i} \cdot\left(1-S_{i}\right) \cdot\left(1-f_{m}\right)}{\theta_{m} \cdot\left(1-S_{m}\right) \cdot f_{m}} \\
& V_{m}=\theta_{m} \cdot\left(1-S_{m}\right) \cdot f_{m} \cdot V
\end{aligned}
$$

Note that $V_{m}$ is adjusted to match the decay in concentration during the initial active extraction cycle using the Equation (A.3).

$$
C_{v, m}=C_{m, 0} \exp \left[\frac{-Q_{t}}{V_{m} \cdot R_{m}}\right]
$$

where $C_{m, 0}$ is the average vapor concentration at $t=0$. 
The mass transfer coefficient $(\alpha)$ from the immobile to the mobile zone can be initially estimated from Equation A.4:

$$
\alpha=D \cdot \theta_{i}^{4 / 3} \cdot\left(1-S_{i}\right)^{10 / 3} \cdot \frac{\pi^{2}}{R_{i} \cdot a}
$$

where $a$ is the half diffusion path length (half thickness of immobile lens or layer) and

$$
R_{j}=1+\frac{S_{i} \cdot \theta_{i}+\rho_{\text {soil }} \cdot K_{d, i} \cdot\left(1-\theta_{i}\right)}{H \cdot\left(1-S_{i}\right) \cdot \theta_{i}}
$$

where $R_{j}$ in Equation A.5 is the vapor phase retardation factor in the $\mathrm{j}^{\text {th }}$ zone (either the immobile or mobile zone).

The concentration vs. time data from the extraction well(s) are used, essentially, as calibration targets for an analytical model based on the theoretical development of mass exchange between immobile and mobile zones. The model represents a solution for the ordinary differential equations in Equations A.6 and A.7:

$$
\begin{gathered}
R_{m} \cdot \frac{d C_{v, i}}{d t}=\frac{Q \cdot C_{v, m}}{\theta_{m} \cdot\left(1-S_{m}\right) \cdot f_{m} \cdot V}-\frac{\lambda_{m} \cdot S_{m} \cdot C_{v, m}}{\left(1-S_{m}\right) \cdot H}+\frac{\theta_{i} \cdot\left(1-S_{i}\right) \cdot f_{i} \cdot \alpha \cdot\left(C_{v, i}-C_{v, m}\right)}{\theta_{m} \cdot\left(1-S_{m}\right) \cdot f_{m}} \\
R_{i} \cdot \frac{d C_{v, i}}{d t}=\frac{\lambda_{i} \cdot S_{i} \cdot C_{v, i}}{\left(1-S_{i}\right) \cdot H}-\alpha \cdot\left(C_{v, i}-C_{v, m}\right)
\end{gathered}
$$

The ultimate solution, considering an assumed initial concentration $C_{v, m}=0$ at $t=0$ (at the end of active extraction and just before the start of the rebound period) is shown in Equation A.8.

$$
C_{v, m}=\frac{C_{i, 0} \frac{\alpha \cdot V_{i}}{R_{m} \cdot V_{m}}}{\frac{Q}{R_{m} \cdot V_{m}}-\frac{\alpha}{R_{i}}} \cdot\left[\exp \left(\frac{-\alpha \cdot t}{R_{i}}\right)-\exp \left(\frac{-Q \cdot t}{R_{m} \cdot V_{m}}\right)\right]
$$

where $C_{i, 0}$ is the average initial vapor concentration in the immobile volume.

The model requires the known or measured quantities described in "Data Needed to Conduct Analysis," and there are several parameters that are adjusted to achieve the match to the observed concentrations. These variables are as follows:

- $C_{i, 0}=$ Concentration in the immobile fraction at time $=0$ (this is generally not well known)

- $\quad V=$ Volume of contaminated soil

- $f_{m}=$ fraction of soil that is the mobile zone, and

- $\alpha=$ mass transfer coefficient.

The solution is not complicated if flow rates and rebound periods are relatively constant. The solutions must be done piecewise for segments of the record of concentrations over time if the flow rates and rebound periods are not uniform. When the match is complete and these variables have been more definitively estimated, the total mass in the soil is estimated from Equation (A.9). 


$$
M_{\text {total }}=m_{m}+m_{i}=C_{v, m} \cdot R_{m} \cdot \theta_{m} \cdot\left(1-S_{m}\right) \cdot f_{m} \cdot V+C_{v, i} \cdot R_{i} \cdot \theta_{i} \cdot\left(1-S_{i}\right) \cdot\left(1-f_{m}\right) \cdot V
$$

Output from the Approach. The primary output is the estimate of mass present in the subsurface. This mass estimate and the mass transfer coefficient may assist in modeling the impacts of the remaining mass on groundwater quality or vapor migration. The analysis also yields an estimate of the time to equilibrium during rebound periods that may assist in planning pulsed operations of the SVE system.

Method of Brusseau et al. (2010). This approach — termed mass flux analysis — was published in Ground Water Monitoring and Remediation. The approach is summarized below.

Purpose. The approach is intended to provide an estimate of the magnitudes and time frames for mass flux from remaining vadose zone sources in low permeability zones following an extended history of SVE operational data. The magnitudes of mass flux from low air permeability zones under natural pressure and concentration gradients and under extraction-induced gradients are interpreted to assess SVE performance.

Underlying Assumptions and Conceptual Site Model. This approach, like the USACE (2002) method, uses concentration data collected from the extraction system during cyclic operation of the SVE. It is based on a conceptual model where the remaining mass lies within low permeability zones. It assumes the following:

- The SVE extraction system encompasses the entire contaminated zone

- Vapors extracted during the removal of the first pore volume of gas primarily represent the mass present in the permeable zones

- There is minimal contaminant mass present in the permeable zones just before the start of the rebound period

- During removal of the first pore volume, vapor removal is ideal (vapors are uniformly swept from the entire permeable domain).

Data Needed to Conduct Analysis. The approach primarily requires extracted vapor concentration and extraction flow rate data collected during active extraction. The duration of the active extraction and rebound periods must also be documented. The concentration and flow data are usually routinely collected during active extraction at most SVE sites. Multiple extraction/rebound cycles are needed for some of the data analysis described in this guidance report. Other potentially useful data include concentration trends in monitoring points near the remaining low-permeability source areas.

Summary of Approach. The mass flux from the low permeability zones during the rebound period is estimated by calculating (Equation A.10) the mass removed during the first pore volume extracted following SVE restart:

$$
M_{P V}=\sum_{i=1}^{n}\left(C_{i}-C_{a}\right) \cdot Q_{i} \cdot \Delta T_{i}
$$


where the $n^{\text {th }}$ sample corresponds to the point where the cumulative gas volume extracted equals one pore volume, $C_{i}$ is the contaminant concentration in the extracted soil gas $\left[\mathrm{M} / \mathrm{L}^{3}\right]$ for the $i^{\text {th }}$ sample, $C_{a}$ is the contaminant concentration at the end of the one pore volume of extraction, $Q_{i}$ is the extraction flow rate $\left[\mathrm{L}^{3} / \mathrm{T}\right]$, and $\Delta T_{\mathrm{i}}$ is the interval between sample times [T]. This calculation uses the equation from Brusseau et al. (2010) with modification to explicitly account for non-negligible background contaminant concentrations, either from outside the persistent source zone or from incomplete extraction of the vapor-phase contaminants from previous SVE operations (see also Truex et al. 2012). The pore volume for this calculation is estimated as the pore volume within the subsurface volume where SVE operation causes soil gas flow above a threshold velocity relevant for treatment at the site (i.e., a swept volume; see USACE 2002). Note also that $C_{a}$ can be assumed to be negligible, as was done for the example in Brusseau et al. (2010), and omitted from the equation if appropriate. However, in some cases, $C_{a}$ must be included in the calculation (e.g., Truex et al. 2012).

The mass removed in the first pore volume, $M_{P V}$, is normalized by the length of the rebound time period to calculate the rebound mass flux, $M F_{r}$. It is expected that the mass removed following rebound would increase with the length of the rebound period. If rebound concentration data are available, the time to reach pseudo-equilibrium concentrations following shut down may need to be considered as the rebound time instead of directly using the duration of the shutdown period. $M F_{r}$ is generally representative of the mass flux from the low permeability zones under natural concentration and pressure gradients.

Output from the Approach. The primary output from the approach is a set of metrics (mass fluxes) that can be interpreted as a basis for operational and shut-down decisions. 


\section{Appendix B}

\section{Methods for High Recharge Sites}





\section{Appendix B}

\section{Methods for High Recharge Sites}

At sites with a recharge rate that is high enough to dominate contaminant transport from the vadose zone to the groundwater (nominally over $7.5 \mathrm{~cm} / \mathrm{yr}$, although potentially applicable to sites with greater than $2.5 \mathrm{~cm} / \mathrm{yr}$ ), the following methods for estimating the groundwater concentration resulting from a vadose zone contaminant source can be applied.

If the mass flux from the vadose source zone can be measured or estimated, a direct mixing method (DMM) can be used to calculate a resultant groundwater concentration. This method requires selection of a cross-sectional area in the groundwater that is representative of the assumed mixing depth and the crosssectional distance (perpendicular to the direction of groundwater flow) that is affected by the vadose zone source. The DMM assumes that all of the contamination from the vadose zone source enters the groundwater and would likely be a reasonable estimating method for conditions where the cross-sectional area can be effectively selected, such as when aqueous transport in the vadose zone dominates the mass flux to groundwater. The direct mixing method may provide a simple, yet reasonable, method for computing the resultant groundwater concentration.

Contaminant mass flux from the vadose zone to the groundwater and the resultant groundwater concentrations may also be estimated using one-dimensional (1D) modeling-based approaches (DiGiulio et al. 1999; DiGiulio and Varadhan 2001; Varadhan and Johnson 1997). One-dimensional solutions use concentration boundary or initial conditions for the source. Contaminant mass flux to the groundwater is controlled by these inputs and the lower boundary condition or function used to represent water table mass transfer. Similar to the DMM, these 1D methods will likely be reasonable estimating methods for conditions where aqueous transport in the vadose zone dominates the mass flux to groundwater. Truex et al. (2009) demonstrated that these approaches using a specified water table boundary condition without consideration of groundwater processes are problematic for the vapor-phase transport component of the estimate. Thus, the flux-continuity method (Truex et al. 2009) may be more appropriate in some cases with moderate recharge rates where vapor transport may still be a significant fraction of the overall contaminant flux to groundwater

\section{B.1 Direct Mixing Method}

\section{B.1.1 Basis and Assumptions}

The DMM assumes that the mass flux in the vadose zone is directly transferred to the groundwater. It is also used to calculate a resultant groundwater concentration based on a selected or estimated value for the contact area between the vadose zone plume and the groundwater and the contaminant mixing depth within the aquifer. 


\section{B.1.2 Required Data}

The required data include the following:

- Estimate of the vadose zone vapor, soil, or pore water contaminant concentration in the source zone and the water recharge rate

- Estimate of the contact area between the vadose zone plume and the groundwater

- Estimate of the groundwater Darcy flux

- Selection of a mixing depth within the aquifer.

\section{B.1.3 Approach}

The vadose zone concentration in the pore water is estimated from the available contaminant concentration data and multiplied by the recharge rate (e.g., $\mathrm{m} / \mathrm{yr}$ ) and the contact area (e.g., $\mathrm{m}^{2}$ ) to calculate the mass flux to the groundwater. A cross-sectional area in the groundwater is calculated that is representative of the assumed mixing depth and the cross-sectional distance perpendicular to groundwater flow that is affected by the vadose zone source. The DMM computes the resultant groundwater concentration as the calculated mass flux from the vadose zone source divided by the groundwater flow through the defined cross-sectional area.

\section{B.2 One-Dimensional Modeling}

\section{B.2.1 Basis and Assumptions}

Contaminant mass flux from the vadose zone to the groundwater and the resultant groundwater concentrations may be estimated using 1D modeling-based approaches (DiGiulio et al. 1999; DiGiulio and Varadhan 2001; Varadhan and Johnson 1997). One-dimensional solutions specify the source with either boundary or initial concentration conditions. Contaminant mass flux to the groundwater is controlled by these inputs as well as the lower boundary condition or function used to represent water table mass transfer. Similar to the DMM, these 1D methods will likely be reasonable estimating methods for conditions where aqueous transport in the vadose zone dominates the mass flux to groundwater. An advantage of these techniques is that they can provide a transient solution to evaluate how mass flux may be expected to change over time with changing conditions in the vadose zone. Truex et al. (2009) demonstrated that the vapor-phase mass flux from the vadose zone across the water table is controlled by the ability of the groundwater to transport contaminant. As a result, computed mass fluxes using a coupled vadose zone-groundwater system will be lower than for the methods where only gas transport is considered from a source to a zero-concentration boundary. The flux-continuity method by Truex et al. (2009) can be used as a steady-state solution to estimate the vapor-phase flux component of the mass transfer.

If vapor-phase flux from the source is a dominant transport mechanism and the recharge rate is low, the mass flux from the zone of persistent contamination will move in multiple directions and a 1D analysis will not accurately represent the mass flux to the groundwater. 


\section{B.2.2 Required Data}

The data for each 1D analysis is prescribed in the references for each method.

\section{B.2.3 Approach}

The VLEACH model (Varadhan and Johnson 1997) is a 1D, finite difference numerical simulation technique for estimating contaminant profiles in the vadose zone over time and the mass flux of contaminant to the groundwater. The initial conditions include the contaminant concentration as a function of location (e.g., z coordinate), a specified-concentration boundary condition for the upper vadose zone, and a specified-concentration boundary condition for the water table. The model can provide both transient and steady-state solutions for mass flux to the groundwater based on the specified initial and boundary conditions. The model does not explicitly couple the vadose zone and groundwater, thus care should be taken when applying the model to sites where vapor transport dominates.

The flux-continuity-based assessment is an analytical approach that uses 1D (downward) vapor transport in the vadose zone coupled to lateral groundwater movement (Truex et al. 2009). The assessment considers vertical, but not lateral, concentration gradients in the groundwater. The approach uses a control volume assessment at the water table to link the vapor-phase contaminant flux from the vadose zone to the flux in the groundwater. The method is for steady-state conditions and a vadose zone contaminant configuration with a source zone located a known distance from the water table.

\section{B.3 References}

DiGiulio DC, V Ravi, and ML Brusseau. 1999. "Evaluation of Mass Flux to and from Ground Water Using a Vertical Flux Model (VFLUX): Application to the Soil Vacuum Extraction Closure Problem." Ground Water Monit. Remed., 19(2):96-104.

DiGiulio DC and R Varadhan. 2001. "Analysis of Water Saturation, NAPL Content, Degradation HalfLife, and Lower Boundary Conditions on VOC Transport Modeling: Implications for Closure of Soil Venting Systems." Ground Water Monit. Remed., 21(4):83-95.

Truex MJ, M Oostrom, and ML Brusseau. 2009. "Estimating Persistent Mass Flux of Volatile Contaminants from the Vadose Zone to Ground Water." Ground Water Monit. Remed., 29(2):63-72.

Varadhan R and JA Johnson. 1997. VLEACH: A One-Dimensional Finite Difference Vadose Zone Leaching Model, Version 2.2. Center for Subsurface Modeling Support, U.S. Environmental Protection Agency, Ada, Oklahoma. Last accessed July 17, 2012, at http://www.epa.gov/ada/csmos/models/vleach.html 



\section{Appendix C}

\section{Estimating Groundwater Contaminant Concentrations as a}

Function of Vadose Zone Source Characteristics 



\section{Appendix C}

\section{Estimating Groundwater Contaminant Concentrations as a Function of Vadose Zone Source Characteristics}

When vapor-phase transport is an important component of the overall contaminant fate and transport from a vadose zone source, the contaminant concentration expected in groundwater is controlled by a limited set of parameters, including specific site dimensions, vadose zone properties, and source characteristics. Under these circumstances, it is possible to pre-model contaminant transport for a matrix of parameter value combinations that cover a range of conditions and to estimate the results at a specific site by comparing the site-specific characteristics to the characteristics of the pre-modeled scenarios. This approach consists of three steps: 1) defining site-specific inputs, 2) interpolating between pre-modeled scenario results for parameters that have nonlinear impacts on the groundwater contaminant concentration, and 3) scaling the interpolated results for parameters that have linear impacts on the groundwater contaminant concentration. This appendix provides a detailed description of the steps for this approach (summarized in Figure C.1) and the required inputs. An example is provided to illustrate the calculation process. The approach described herein has been implemented in a spreadsheet tool for user convenience (Appendix D).

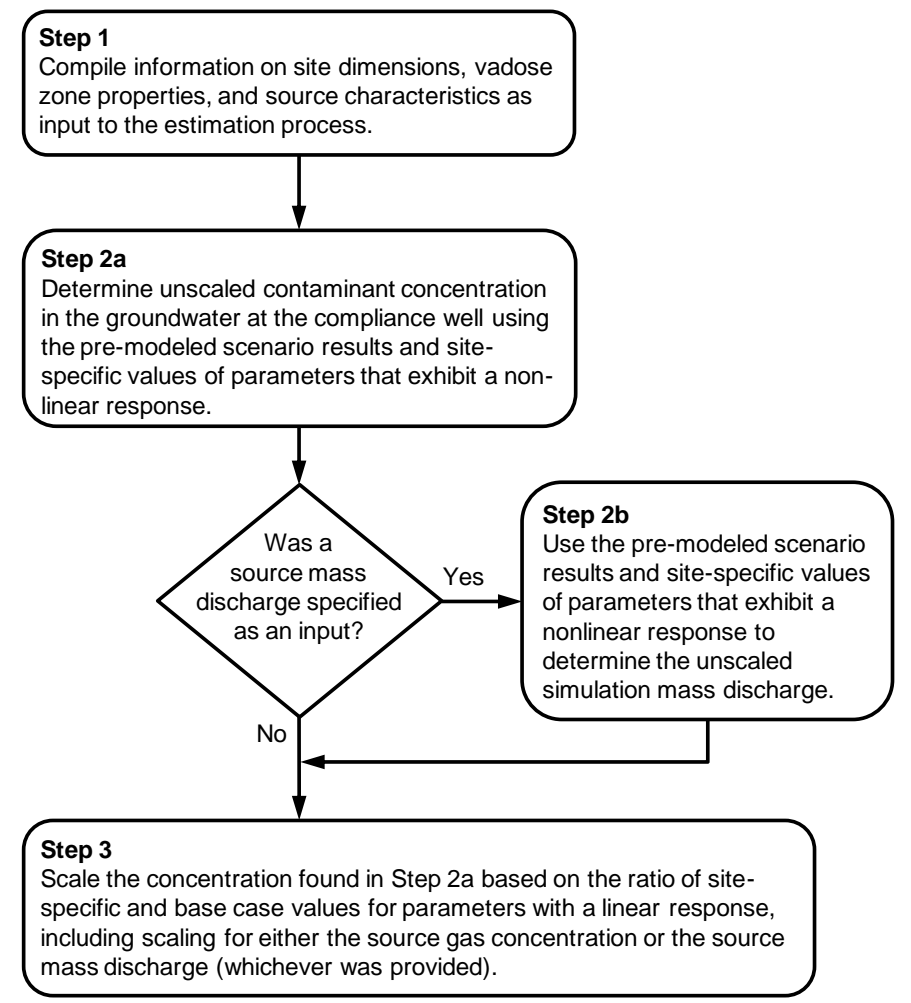

Figure C.1. Flow chart of the three steps involved in the process for estimating contaminant groundwater concentrations at the compliance well

Additional factors may affect the estimated contaminant groundwater concentrations. One category of such factors is the uncertainty of input parameter values. A sensitivity analysis can readily be 
conducted to assess the potential impact of reasonable variation in specific input parameters on the estimated groundwater concentrations. Other factors are outside the scope of the approach described here, but should be considered for potential impacts. Such factors include the degree of source depletion over time, adsorption, biological transformation, and other physical attenuation mechanisms (as discussed in Section 4.0). Sites will also need to consider the appropriateness of the simplifying assumptions used in the approach with respect to the site-specific conditions (Section 4.0). For instance, the generalized conceptual model used in the approach is appropriate for sites where vapor-phase transport dominates contaminant movement.

The procedure described here is intended to estimate the contaminant concentration in groundwater at a compliance well resulting from a contaminant source located in the vadose zone. This estimation process could contribute to the design of a soil vapor extraction (SVE) system by providing information about the vadose zone remediation performance required to meet groundwater contaminant concentration goals. For existing SVE systems, this estimation process could provide input for decisions pertaining to system optimization, site closure, or transition to another remedy.

\section{C.1 Step 1: Compilation of Inputs}

The estimation method is based on the site conceptualization depicted in Figure C.2, centered on a source area present at a specified vertical location within the vadose zone and with a compliance well located in the downgradient direction (with respect to groundwater flow) from the source.

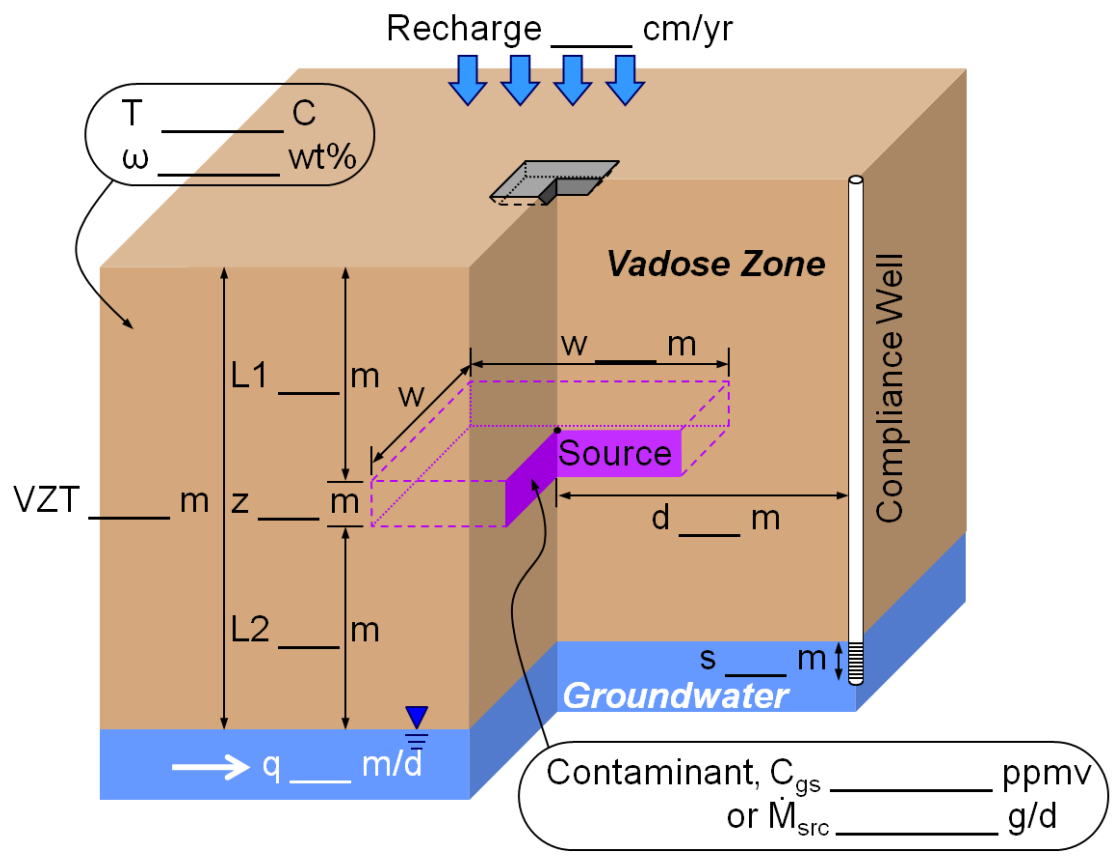

Figure C.2. Conceptual framework for estimating the impact of a vadose zone contaminant source on groundwater concentration at a compliance well

The calculational procedure for estimating the contaminant concentration in groundwater at a compliance well requires a set of inputs, relative to the conceptual framework in Figure C.2, that describe the scenario of interest. The user is asked to provide the input parameters listed in Table C.1, from which 
several input parameters are calculated (i.e., the parameters in the shaded rows of Table C.1). Appendix A discusses approaches for determining or estimating certain information about the source area, including the lateral extent, location within the vadose zone, and "source strength." The source strength calculational input may be represented as either the vapor-phase contaminant concentration $\left(C_{g s}\right)$ or the mass discharge of contaminant $\left(\dot{M}_{s r c}\right)$, but not both. Because there may be uncertainty associated with input parameters, users are encouraged to conduct the estimation process using a sensitivity analysis approach where multiple estimates are made using appropriate ranges for input parameter values and the effect of these variations on the estimated contaminant concentration in groundwater can be assessed. The spreadsheet tool (Appendix D) allows for multiple input scenarios to be evaluated as a group.

The site characteristics listed in Table C.1 are separated into categories of parameters based on how the parameters are used in subsequent steps of this estimation procedure. Parameters that exhibit a nonlinear response in the contaminant concentration at the compliance well are examined in the context of the pre-modeled scenario simulation results. To avoid extrapolation outside of the pre-modeled scenarios, the input parameters are restricted to be within the permissible ranges noted in Table C.1. An alternative approach (e.g., site-specific simulations) would be required for sites with site characteristics that are outside of the ranges specified here for parameters with a nonlinear groundwater concentration relationship. Ranges have also been defined for parameters that exhibit a linear or inverse linear relationship to contaminant concentrations in the groundwater (including the "source strength" parameters). The range for the average recharge to the site is constrained as described in Section 4.2 and Appendix B. The compliance well screen length has a minimum based on the value used in the premodeled scenarios and a maximum based on reasonable extrapolation from this value. The ranges for the source strength variables $\left(C_{g s}\right.$ and $\left.\dot{M}_{s r c}\right)$ are based on reasonable extrapolation from the "base case" source strength that was used in the pre-modeled scenarios. The range for Henry's Law constant is determined by the permitted range for the subsurface temperature and the choice of the contaminant. 
Table C.1. Site characteristics for estimating contaminant concentration in groundwater at a compliance well (shaded cells are calculated parameters; non-shaded cells are user inputs)

\begin{tabular}{|c|c|c|c|c|}
\hline Site Characteristic & Units & $\begin{array}{c}\text { Parameter } \\
\text { Name }\end{array}$ & Permissible Range & Key Values ${ }^{a}$ \\
\hline \multicolumn{5}{|c|}{ Input parameters used to calculate other parameters } \\
\hline Contaminant Name & - & - & $\begin{array}{l}\text { CT, PCE, TCE, } 1,1,1-\mathrm{TCA} \\
\text { or } 1,1-\mathrm{DCA}\end{array}$ & CT \\
\hline Average subsurface temperature & ${ }^{\circ} \mathrm{C}$ & $T$ & $10-30$ & 20 \\
\hline Depth to the top of the source zone & $\mathrm{m}$ & $L 1$ & $0.5-49$ & - \\
\hline Vertical thickness of the source zone & $\mathrm{m}$ & $z$ & $1-30$ & - \\
\hline $\begin{array}{l}\text { Width for plan view extent of source } \\
\text { (source is assumed square, thus width = length) }\end{array}$ & $\mathrm{m}$ & $w$ & $10-50$ & - \\
\hline \multicolumn{5}{|c|}{ Parameters having a nonlinear relationship with groundwater concentration at the compliance well } \\
\hline $\begin{array}{l}\text { Average gravimetric moisture content in } \\
\text { vadose zone } \\
\text { (mass of water per mass of dry porous medium) }\end{array}$ & wt $\%$ & $\omega$ & $1-9$ & $1,5,9$ \\
\hline Vadose zone thickness & $\mathrm{m}$ & $V Z T$ & $10-60$ & $10,30,60$ \\
\hline $\begin{array}{l}\text { Source thickness ratio (fraction of vadose } \\
\text { zone thickness that is source material) } \\
(\text { STR }=z / V Z T)\end{array}$ & - & STR & $0.1-0.5$ & $0.1,0.25,0.5$ \\
\hline $\begin{array}{l}\text { Relative vert. source position in the vadose } \\
\text { zone (i.e., near surface, aquifer or middle) } \\
(R S P=L 1 / L 2=L 1 /[V Z T-L 1-z])\end{array}$ & - & $R S P$ & $0.1-10$ & $0.1,1,10$ \\
\hline $\begin{array}{l}\text { Source area as a plan-view areal extent } \\
\left(S A=w^{2}\right)\end{array}$ & $m^{2}$ & $S A$ & $100-2500$ & $100,400,900,2500$ \\
\hline $\begin{array}{l}\text { Groundwater Darcy velocity } \\
\text { ( } \mathrm{q} \text { is input directly, but can be calc. from } \mathrm{q}=\mathrm{K}_{\mathrm{h}} \cdot \mathrm{i}, \mathrm{K}_{\mathrm{h}} \\
\text { = horiz. hydraul. conductivity, } \mathrm{i}=\text { hydraul. grad.) }\end{array}$ & $\mathrm{m} / \mathrm{d}$ & $q$ & $0.005-0.3$ & $0.005,0.03,0.3$ \\
\hline $\begin{array}{l}\text { Distance from center of source area to } \\
\text { downgradient compliance well }^{c}\end{array}$ & $\mathrm{~m}$ & $d$ & $\begin{array}{l}10-100 \text { for } S A \leq 400 \mathrm{~m}^{2} \\
25-100 \text { for } \mathrm{SA}>400 \mathrm{~m}^{2}\end{array}$ & $10,25,50,75,100$ \\
\hline
\end{tabular}

Parameters having a linear (or inverse linear) relationship with groundwater concentration at the compliance well

\begin{tabular}{|l|c|c|c|c|}
\hline Henry's Law constant $^{d}$ & - & $H$ & contaminant-specific value & 0.89 \\
\hline Average recharge rate to the site & $\mathrm{cm} / \mathrm{yr}$ & $R$ & $0.4-2.5\left(7.5^{\mathrm{e}}\right)$ & 0.4 \\
\hline $\begin{array}{l}\text { Compliance well screen length } \\
\text { (top of well screen assumed to be at top of aquifer) }\end{array}$ & $\mathrm{m}$ & $s$ & $5-30$ & 5 \\
\hline
\end{tabular}

Source strength characteristics (linear relationship with groundwater concentration at the compliance well)

\begin{tabular}{|l|c|c|c|c|}
\hline $\begin{array}{c}\text { Gas-phase contaminant concentration in } \\
\text { the source }\end{array}$ & ppmv & $C_{g s}$ & $1-2000$ & 159 \\
\hline $\begin{array}{c}\text { Mass discharge of vapor-phase } \\
\text { contamination from the source }\end{array}$ & $\mathrm{g} / \mathrm{d}$ & $\dot{M}_{s r c}$ & $0.1-5000$ & from STOMP simulations \\
\hline
\end{tabular}

a The key values indicate either the values used in the STOMP simulations of pre-modeled scenarios (for parameters having nonlinear relationship) or the "base case" scenario values (for parameters having a linear/inverse linear or source strength relationship).

b STOMP simulations actually use the residual water saturation $\left(S_{r}\right)$, which is calculated from moisture content as: $S_{r}=\left(\omega \cdot \rho_{\text {bulk }}\right) /$ $\left(100 \cdot \theta_{\text {total }} \cdot \rho_{\text {water }}\right)$, where $\rho_{\text {bulk }}$ is the dry bulk density of the porous media $(1.855 \mathrm{~g} / \mathrm{mL}), \theta_{\text {total }}$ is the total porosity of the porous media $(0.3)$, and $\rho_{\text {water }}$ is the density of water. The range for $S_{r}$ was 0.05 to 0.55 in STOMP simulations, so $\omega$ is constrained accordingly.

c The distance from the center of the source area to the compliance well is restricted to specific distances of $10,25,50,75$, and $100 \mathrm{~m}$.

d The dimensionless Henry's Law Constant is calculated based on the site-specific subsurface temperature and contaminant-specific, temperature-dependant property correlations (i.e., for vapor pressure [Yaws 2009] and solubility [Yaws 2009; Mackay et al. 2006]).

e Up to $7.5 \mathrm{~cm} / \mathrm{yr}$ may be suitable (see Section 0 and Appendix B).

f The user may provide either $C_{g s}$ or $M D_{s}$, but not both. 


\section{C.2 Step 2: Interpolation from Pre-Modeled Scenario Results for Nonlinear Variables}

A total of 972 pre-modeled scenarios were simulated with the Subsurface Flow Over Multiple Phases (STOMP) code (White and Oostrom 2006) to assess the impact of variation in parameters that have a nonlinear relationship with the contaminant concentration in groundwater at the compliance well. These pre-modeled scenarios all used "base case" values for the linear parameters. These base case values represent a site with $0.4 \mathrm{~cm} / \mathrm{yr}$ of recharge, a $159 \mathrm{ppmv}$ source (equivalent to $1 \mathrm{mg} / \mathrm{L}_{\mathrm{gas}}$ for carbon tetrachloride), a Henry's Law constant of 0.89 , a porosity of 0.3 , and a dry bulk density of $1855 \mathrm{~kg} / \mathrm{m}^{3}$. Simulations were run to obtain steady-state concentration distributions in the gas and aqueous phases throughout the computational domain. Groundwater concentrations were tabulated for each pre-modeled scenario for a compliance well with a 5-m-long screen (with the top at the water table) at specific distances from the center of the source area. Table C.1 lists the key values used for each of the parameters with a nonlinear relationship to groundwater contaminant concentration; it is the combinations of these values that compose the suite of pre-modeled scenarios. Scoping simulations were used to select the key values for the parameters that exhibit a nonlinear response in groundwater concentrations, with the intent that linear interpolation between bounding cases gives a reasonable estimate. Note that the compliance well is not permitted to be located within the source area, which eliminated some combinations (e.g., where $d=10 \mathrm{~m}$ and $S A=400 \mathrm{~m}^{2}$, hence $w=20 \mathrm{~m}$ ). Further details of the simulations for the pre-modeled scenarios are shown in Appendix E.

This step in the estimation of the contaminant concentration in groundwater at the compliance well is based on a sequence of table lookups and/or linear interpolations to find the unscaled groundwater concentration $\left(C_{w u}\right)$ at the compliance well for the site-specific parameters. Interpolation is needed when site-specific values are not the same as one of the pre-modeled scenarios. Interpolated values are calculated using Equation C.1, where $P$ denotes the parameter value, $C$ is the simulation concentration, and the subscripts upper and lower represent the known values above and below the interpolation point of interest (interp). If the input for a nonlinear relationship parameter consists of a value that is equal to one of the key values in Table C.1, then no interpolation is needed with respect to that parameter. Otherwise, linear interpolation will be performed using results from the bounding simulations. As noted above, key values were selected in an effort to obtain reasonable estimates using linear interpolation between bounds. The lookups/interpolations are performed in the sequence of RSP, q, SA, VZT, STR, and $\omega$ (converted to the corresponding water saturation value). No interpolation is done for the distance to the compliance well, $d$, which must be equal to one of the key values.

$$
C_{\text {interp }}=\left[\frac{P_{\text {interp }}-P_{\text {lower }}}{P_{\text {upper }}-P_{\text {lower }}}\right] \cdot\left(C_{\text {upper }}-C_{\text {lower }}\right)+C_{\text {lower }}
$$

If each of the six parameters $(R S P, q, S A, V Z T, S T R$, and $\omega)$ that give a nonlinear groundwater concentration response require interpolation, then there are $2^{6}=64 C_{\text {sim }}$ values from the pre-modeled scenarios (for a given value of $d$ ) that represent the lower and upper boundaries of the range into which each of the six parameters falls. For every site-specific input value of $R S P, q, S A, V Z T, S T R$, and $\omega$, a value of $C_{\text {sim }}$ can be found in the data tables for each boundary above and below the input value. Interpolation proceeds by interpolating between boundary values based on $R S P$ (e.g., between the $C_{s i m}$ values for $R S P$ values of 0.1 and 1.0), then interpolating between these results based on $q$ (e.g., between $q$ values of 0.03 and 0.3), then between those results based on $S A$ (e.g., between $S A$ values of 100 and 400), and so on for VZT, STR, and $\omega$. 
If the source strength input parameter provided was the $\dot{M}_{s r c}$ value (i.e., not the $C_{g s}$ value), then a second sequence of lookups/interpolations (in the same order of RSP, q, SA, VZT, STR, and $\omega$ ) is performed to determine the simulated contaminant mass discharge corresponding to the input site parameters $\left(\dot{M}_{\text {sim }}\right)$. This $\dot{M}_{\text {sim }}$ value is needed in Step 3 of the procedure as a linear scaling factor. The process for obtaining the interpolated $\dot{M}_{s i m}$ mass discharge value is the same as for $C_{w u}$, except that the distance $(d)$ parameter does not apply.

In the interest of concise reporting in this document, the $C_{\text {sim }}$ and $\dot{M}_{\text {sim }}$ results are organized into tables (see Addendum to Appendix C) to represent the combinations of parameter values (for the key values of $d, R S P, q, S A, V Z T, S T R$, and $\omega)$. The VZT and STR parameter values are paired and assigned a Source Assessment Category designation, as shown in Table C.2. For each value of $\omega$, the $C_{\text {sim }}$ results for combinations of $d, R S P, q$, and $S A$ parameter values are shown in nine tables (one for each Source Assessment Category). Table C.3 is an example of a table for a particular $\omega$ and Source Assessment Category. Depending on whether a lookup or an interpolation is required, a total of one to eight of these tables will be used to determine the $C_{w u}$ value for a particular set of inputs.

Table C.2. Categorization of pairs of VZT and STR values to assist in data organization

\begin{tabular}{|c|c|c|c|}
\cline { 2 - 4 } \multicolumn{1}{c|}{} & \multicolumn{3}{c|}{ VZT (m) } \\
\hline STR (-) & 10 & 30 & 60 \\
\hline 0.1 & Category 1 & Category 2 & Category 3 \\
\hline 0.25 & Category 4 & Category 5 & Category 6 \\
\hline 0.5 & Category 7 & Category 8 & Category 9 \\
\hline
\end{tabular}

Table C.3. Example of unscaled contaminant concentration results $(\mu \mathrm{g} / \mathrm{L})$ in the groundwater at a compliance well for pre-modeled scenarios where $\omega=1 \%$ and the VZT and STR inputs equate to "Category 1" for the Source Assessment Category. Bold values are used in the example at the end of the appendix.

\begin{tabular}{|c|c|c|c|c|c|c|c|c|c|c|c|c|c|c|c|c|}
\hline \multicolumn{2}{|c|}{ Category 1} & \multicolumn{5}{|c|}{ RSP0.1 } & \multicolumn{5}{|c|}{ RSP1 } & \multicolumn{5}{|c|}{ RSP10 } \\
\hline$q$ & SA & $d=10$ & $d=25$ & $d=50$ & $d=75$ & $d=100$ & $d=10$ & $d=25$ & $d=50$ & $d=75$ & $d=100$ & $d=10$ & $d=25$ & $d=50$ & $d=75$ & $d=100$ \\
\hline 0.005 & 100 & 55.24 & 29.13 & 18.52 & 14.73 & 12.47 & 98.69 & 51.96 & 32.97 & 26.22 & 22.21 & 107.40 & 56.27 & 35.93 & 28.61 & 24.26 \\
\hline 0.03 & 100 & 24.19 & 14.88 & 9.01 & 6.92 & 5.73 & 43.12 & 26.57 & 16.08 & 12.34 & 10.22 & 47.56 & 28.95 & 17.56 & 13.49 & 11.18 \\
\hline 0.3 & 100 & 5.26 & 4.33 & 3.36 & 2.85 & 2.49 & 9.40 & 7.75 & 6.03 & 5.11 & 4.46 & 10.46 & 8.53 & 6.63 & 5.62 & 4.90 \\
\hline 0.005 & 400 & 134.99 & 76.28 & 46.89 & 37.32 & 31.64 & 166.31 & 96.33 & 58.63 & 46.61 & 39.50 & 176.84 & 97.84 & 59.88 & 47.63 & 40.39 \\
\hline 0.03 & 400 & 56.85 & 38.32 & 22.76 & 17.48 & 14.49 & 69.50 & 48.26 & 28.56 & 21.91 & 18.14 & 73.13 & 49.35 & 29.26 & 22.46 & 18.60 \\
\hline 0.3 & 400 & 12.25 & 10.97 & 8.48 & 7.19 & 6.28 & 15.06 & 13.83 & 10.69 & 9.06 & 7.91 & 15.81 & 14.28 & 11.04 & 9.36 & 8.17 \\
\hline 0.005 & 900 & $\# \mathrm{~N} / \mathrm{A}$ & 176.54 & 121.57 & 71.69 & 56.76 & $\# \mathrm{~N} / \mathrm{A}$ & 142.23 & 82.45 & 65.11 & 55.04 & $\# \mathrm{~N} / \mathrm{A}$ & 143.50 & 83.58 & 66.05 & 55.86 \\
\hline 0.03 & 900 & $\# \mathrm{~N} / \mathrm{A}$ & 73.60 & 59.40 & 34.85 & 26.62 & $\# \mathrm{~N} / \mathrm{A}$ & 68.98 & 40.23 & 30.65 & 25.29 & $\# \mathrm{~N} / \mathrm{A}$ & 70.10 & 40.89 & 31.17 & 25.73 \\
\hline 0.3 & 900 & $\# \mathrm{~N} / \mathrm{A}$ & 16.63 & 12.87 & 10.90 & 9.51 & $\# \mathrm{~N} / \mathrm{A}$ & 19.27 & 14.91 & 12.62 & 11.00 & $\# \mathrm{~N} / \mathrm{A}$ & 19.77 & 15.28 & 12.93 & 11.28 \\
\hline 0.005 & 2500 & \#N/A & 221.59 & 124.05 & 95.18 & 79.62 & \#N/A & 244.29 & 136.49 & 103.92 & 86.69 & $\#$ N/A & 253.82 & 137.51 & 104.86 & 87.54 \\
\hline 0.03 & 2500 & $\# \mathrm{~N} / \mathrm{A}$ & 99.76 & 60.40 & 44.88 & 36.56 & $\# \mathrm{~N} / \mathrm{A}$ & 108.29 & 66.59 & 49.19 & 39.96 & $\# N / A$ & 111.38 & 67.29 & 49.75 & 40.42 \\
\hline 0.3 & 2500 & $\# \mathrm{~N} / \mathrm{A}$ & 26.39 & 21.42 & 18.01 & 15.65 & $\# \mathrm{~N} / \mathrm{A}$ & 28.59 & 23.58 & 19.80 & 17.20 & $\# \mathrm{~N} / \mathrm{A}$ & 29.36 & 24.02 & 20.17 & 17.52 \\
\hline
\end{tabular}

\section{C.3 Step 3: Scaling for Linear Variables}

The last step in the procedure to estimate the site-specific contaminant concentration in groundwater at a compliance well is to scale the $C_{w u}$ value obtained in Step 2 to account for the parameters where the contaminant concentration in groundwater varies linearly or inverse linearly with the parameter value. The base case (key) values discussed above and listed in Table C. 3 form the basis for the scaling. 
The Henry's Law constant for the site conditions (contaminant and temperature) is required as part of the scaling process. In Table C.1 it was noted that the Henry's Law constant can be calculated based on the site-specific subsurface temperature and contaminant-specific, temperature-dependent property correlations. The Henry's Law constant and its temperature dependence have been examined in a wide range of literature for contaminants of environmental interest (e.g., Staudinger and Roberts 2001; Warneck 2007; Chen et al. 2012). Brennan et al. (1998) suggest calculating the Henry's Law constant as the ratio of the vapor pressure to the water solubility as the preferred approach for dilute contaminant concentrations ( $<0.02 \mathrm{~mol}$ fraction). Thus, a temperature-dependent Henry's Law constant can be found using temperature-dependent vapor pressure and water solubility values. However, the accuracy of this approach depends on the accuracy of the vapor pressure and water solubility information.

The vapor pressure temperature-dependent correlation selected for use in this work is the Antoine correlation given in Equation C. 2 where $T$ is temperature in ${ }^{\circ} \mathrm{C}, P_{\text {vap }}$ is the vapor pressure in $\mathrm{mm} \mathrm{Hg}$, and $A, B$, and $C$ are contaminant-specific correlation coefficients (Yaws et al. 2009).

$$
\log _{10}\left(P_{\text {vap }}\right)=A-\frac{B}{T+C} \quad \mathrm{~T} \text { is in }{ }^{\circ} \mathrm{C}
$$

For most of the contaminants of interest, a polynomial correlation (Mackay et al. 2006) is used to obtain the temperature-dependent solubility, as shown in Equation C.3. Here, $x_{p}$ is the mass fraction in weight percent, $T$ is temperature in $\mathrm{K}$ (unless the contaminant is $\mathrm{CT}, \mathrm{CF}, \mathrm{DCM}, \mathrm{CM}$, or CE, in which case the temperature is in ${ }^{\circ} \mathrm{C}$ ), and $A, B, C, D, E$, and $F$ are tabulated contaminant-specific correlation coefficients (Mackay et al. 2006). Where fewer than six coefficients are given by Mackay et al. (2006), the missing coefficients are taken to be 0.0. Equation C.4 is used to calculate the solubility for VC, where $x_{f}$ is the mass fraction, $T$ is the temperature in $\mathrm{K}$, and $A, B, C$, and $D$ are tabulated contaminant-specific correlation coefficients (Yaws 2003). Mass fraction values are converted to mole fraction, $x$, in Equation C. 5 by multiplying by the ratio of the molecular weight of water $\left(M W_{w}, 18.01528 \mathrm{~g} / \mathrm{mol}\right)$ to the molecular weight of the contaminant $\left(M W_{i}, \mathrm{~g} / \mathrm{mol}\right)$.

$$
\begin{aligned}
& \mathrm{x}_{\mathrm{p}}=\mathrm{A}+\mathrm{B} \cdot \mathrm{T}+\mathrm{C} \cdot \mathrm{T}^{2}+\mathrm{D} \cdot \mathrm{T}^{3}+\mathrm{E} \cdot \mathrm{T}^{4}+\mathrm{F} \cdot \mathrm{T}^{5} \\
& \log _{10}\left(\mathrm{x}_{\mathrm{f}}\right)=\mathrm{A}+\mathrm{B} / \mathrm{T}+\mathrm{C} \cdot \log _{10}(\mathrm{~T})+\mathrm{D} \cdot \mathrm{Tk}
\end{aligned} \quad \begin{aligned}
& \mathrm{T} \text { is in } \mathrm{K}, \text { except use }{ }^{\circ} \mathrm{C} \text { for } \mathrm{CT}, \mathrm{CF}, \mathrm{DCM}, \mathrm{CM}, \text { or CE } \\
& x=\frac{x_{p}}{100} \cdot \frac{M W_{w}}{M W_{i}}=x_{f} \cdot \frac{M W_{w}}{M W_{i}}
\end{aligned}
$$

The contaminants available in the software and their tabulated correlation coefficients are shown in Table C.4. 
Table C.4. Tabulated correlation coefficients for contaminants of interest from Yaws et al. (2009), Mackay et al. (2006), and Yaws (2003)

\begin{tabular}{|c|c|c|c|c|c|c|c|c|c|c|c|}
\hline \multirow[b]{2}{*}{$\begin{array}{c}\text { Contaminant } \\
\text { Abbrev. }\end{array}$} & \multirow[b]{2}{*}{ Contaminant } & \multirow{2}{*}{$\begin{array}{c}\text { Molecular } \\
\text { Weight } \\
(\mathrm{g} / \mathrm{mol})\end{array}$} & \multicolumn{3}{|c|}{ Vapor Pressure $(\mathrm{mm} \mathrm{Hg})$} & \multicolumn{6}{|c|}{ Solubility (mass fraction) } \\
\hline & & & $\mathbf{A}$ & B & C & A & B & C & D & $\mathbf{E}$ & $\mathbf{F}$ \\
\hline CT & Carbon Tetrachloride & 153.823 & 7.01144 & 1278.54 & 232.888 & $9.7842 \mathrm{E}-2$ & $-1.4942 \mathrm{E}-3$ & $3.5854 \mathrm{E}-5$ & $2.2775 \mathrm{E}-7$ & 0 & 0 \\
\hline CF & Chloroform & 119.376 & 7.11148 & 1232.79 & 230.213 & $9.9500 \mathrm{E}-1$ & $-1.0531 \mathrm{E}-2$ & $7.9819 \mathrm{E}-5$ & $6.6431 \mathrm{E}-7$ & 0 & 0 \\
\hline $\mathrm{DCM}$ & Dichloromethane & 84.932 & 7.11464 & 1152.41 & 232.442 & 1.9610 & $-4.4883 E-2$ & $8.6617 \mathrm{E}-4$ & 4.9463 E-6 & 0 & 0 \\
\hline $\mathrm{CM}$ & Chloromethane & 50.487 & 6.99771 & 870.17 & 235.586 & 1.4019 & $-6.3562 \mathrm{E}-2$ & $1.7198 \mathrm{E}-3$ & -2.8262 E-5 & $2.5268 \mathrm{E}-7$ & $-9.3470 \mathrm{E}-10$ \\
\hline PCE & Tetrachloroethene & 165.832 & 7.06892 & 1458.45 & 226.986 & $2.6479 \mathrm{E}-1$ & $-1.5487 \mathrm{E}-3$ & $2.4477 \mathrm{E}-6$ & 0 & 0 & 0 \\
\hline TCE & Trichloroethene & 131.387 & 6.87981 & 1157.83 & 202.58 & 1.4049 & $-8.2223 \mathrm{E}-3$ & $1.3218 \mathrm{E}-5$ & 0 & 0 & 0 \\
\hline 1,1-DCE & 1,1-Dichloroethene & 96.943 & 7.21678 & 1181.12 & 240.84 & 6.2741 & $-3.8257 \mathrm{E}-2$ & $6.0461 \mathrm{E}-5$ & 0 & 0 & 0 \\
\hline cDCE & cis-1,2-Dichloroethene & 96.943 & 7.21953 & 1290.28 & 236.887 & $2.7735 E+1$ & $-1.7832 \mathrm{E}-1$ & $2.9328 \mathrm{E}-4$ & 0 & 0 & 0 \\
\hline tDCE & trans-1,2-Dichloroethene & 96.943 & 7.21356 & 1244.35 & 239.497 & 7.8039 & $-4.5457 \mathrm{E}-2$ & $6.9676 \mathrm{E}-4$ & 0 & 0 & 0 \\
\hline VC & Vinyl Chloride & 62.498 & 6.91423 & 911.15 & 239.8 & $-4.6670 E+2$ & $1.3479 E+4$ & $1.8523 E+2$ & $-1.3236 \mathrm{E}-1$ & 0 & 0 \\
\hline 1,1,1,2-TeCA & 1,1,1,2-Tetrachloroethane & 167.848 & 7.03897 & 1467.16 & 222.34 & 2.1790 & -1.3966 E-3 & $2.9328 \mathrm{E}-5$ & 0 & 0 & 0 \\
\hline $1,1,2,2-\mathrm{TeCA}$ & 1,1,2,2-Tetrachloroethane & 167.848 & 6.91043 & 1378.88 & 197.086 & 4.8798 & $-3.0937 \mathrm{E}-3$ & $5.2051 E-5$ & 0 & 0 & 0 \\
\hline 1,1,1-TCA & 1,1,1-Trichloroethane & 133.403 & 7.00718 & 1253.2 & 229.624 & 1.0909 & $-6.5278 \mathrm{E}-3$ & $1.1075 \mathrm{E}-5$ & 0 & 0 & 0 \\
\hline 1,1,2-TCA & 1,1,2-Trichloroethane & 133.403 & 7.14357 & 1457.65 & 228.099 & 2.8980 & -1.8585 E-2 & $3.4896 \mathrm{E}-5$ & 0 & 0 & 0 \\
\hline 1,1-DCA & 1,1-Dichloroethane & 98.959 & 7.18316 & 1269.43 & 237.755 & 9.4136 & $-5.7249 \mathrm{E}-2$ & $9.1784 \mathrm{E}-5$ & 0 & 0 & 0 \\
\hline 1,2-DCA & 1,2-Dichloroethane & 98.959 & 7.29525 & 1407.85 & 235.48 & $1.7915 \mathrm{E}+1$ & $-1.1684 \mathrm{E}-1$ & $2.0003 \mathrm{E}-4$ & 0 & 0 & 0 \\
\hline CE & Chloroethane & 64.514 & 7.13047 & 1097.6 & 246.009 & $5.8420 \mathrm{E}-1$ & -1.6863 E-3 & $9.3949 \mathrm{E}-5$ & -2.5316 E-6 & 0 & 0 \\
\hline
\end{tabular}

As discussed above, the dimensionless Henry's Law constant itself is calculated from the ratio of the vapor pressure $\left(P_{\text {vap }}\right)$ to the mole fraction $(x)$, with appropriate conversions from units of atm/mol fraction to units of concentration per concentration (i.e., dimensionless). See Sander (1999) for a thorough job of distinguishing between multiple representations of the units for the Henry's Law constant. Equation C.6 shows the calculation for the unitless Henry's Law constant $(H)$, where $\rho_{w}$ is the density of water $(\mathrm{g} / \mathrm{mL})$, $R_{\text {gas }}$ is the gas constant $\left(0.08205746 \mathrm{~L} \cdot \mathrm{atm} \cdot \mathrm{K}^{-1} \cdot \mathrm{mol}^{-1}\right), T$ is the average subsurface temperature $(\mathrm{K})$, and other quantities were defined above.

$$
H=\frac{P_{v a p}}{x} \cdot \frac{M W_{w}}{\rho_{w} \cdot R_{\text {gas }} \cdot T} \cdot \frac{1 \mathrm{~L}}{1000 \mathrm{~mL}} \cdot \frac{1 \mathrm{~atm}}{760 \mathrm{mmHg}} \quad \text { T is in } \mathrm{K}
$$

The impact of recharge on the contaminant concentration in groundwater at the compliance well is a function of both the recharge rate $(R)$ and the groundwater flux $(q)$. This interrelationship stems from the process of the recharge water mixing with the groundwater at the water table. For a given groundwater flux, STOMP simulations show that variation in recharge has a linear (albeit not one-to-one) impact on the contaminant groundwater concentration at a compliance well. Figure C.3 shows an example of the variation in groundwater concentrations with respect to the recharge and the groundwater flux. The magnitude of the variation with recharge (i.e., the linear proportionality factor) differs to a small degree based on the distance of the compliance well from the source area. More distant locations generally show more change as recharge increases than do compliance well locations close to the source area. The proportionality factor magnitude changes more significantly as the groundwater flux changes. Figure C.4 shows the average slope and average intercept of multiple concentration versus recharge plots (taking both parameters relative to the base case of $0.4 \mathrm{~cm} / \mathrm{yr}$ recharge), from which it is clear that the recharge proportionality factor varies more when the groundwater flux is low. For use in the scaling process, the relationship of $q$ and $R$ is approximated using in two regimes, a low groundwater flux regime and a high groundwater flux regime, where the variation is linear within each regime. Other positional/geometric parameters (VZT, STR, RSP, SA) were found to have negligible influence on the impact of recharge on groundwater contaminant concentrations. 


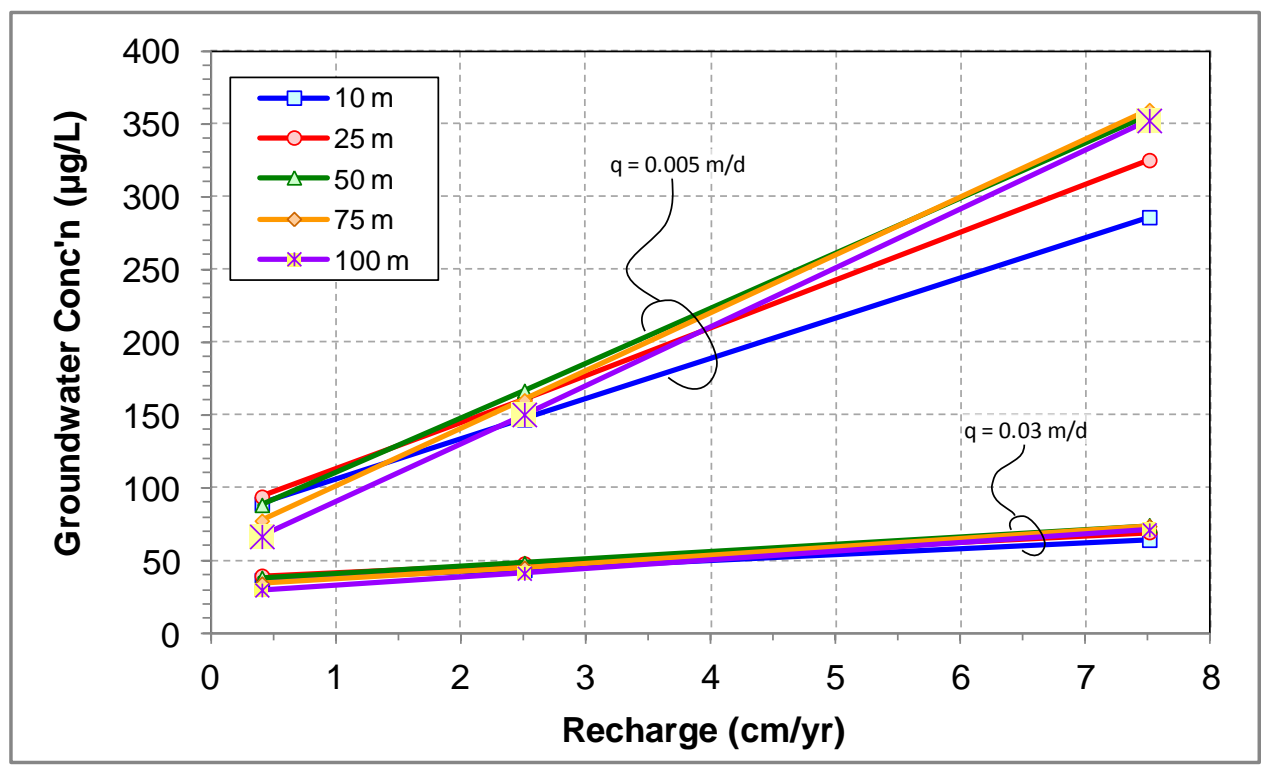

Figure C.3. Example of the variation in groundwater concentration results at multiple compliance well distances $(10,25,50,75$, and $100 \mathrm{~m})$ from the source area for two groundwater flux scenarios $(0.005$ and $0.03 \mathrm{~m} / \mathrm{d})$. There are small differences in the slope of the linear relationships amongst the compliance well distances for a given groundwater flux, but larger differences in the nominal slope between groundwater flux scenarios.

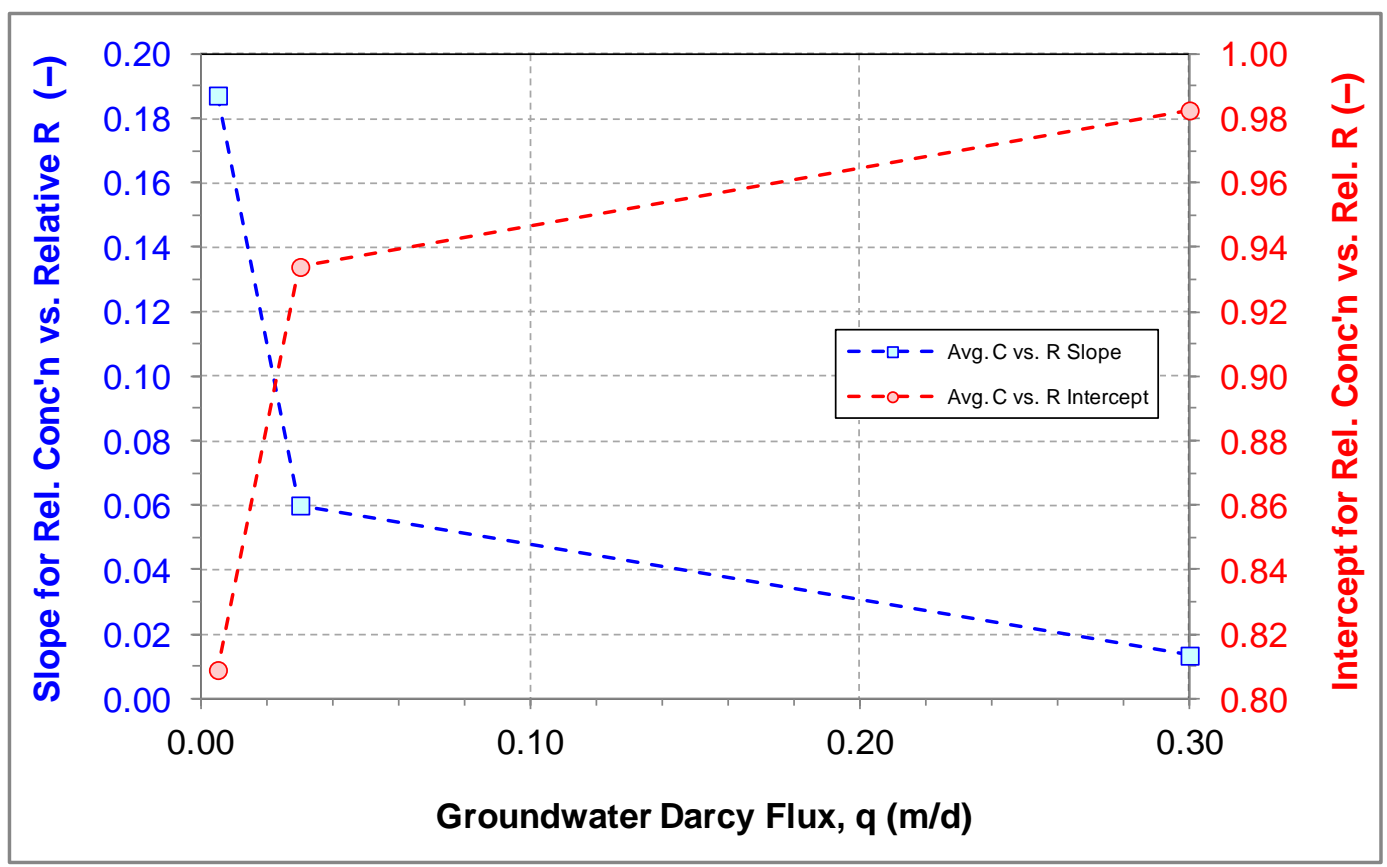

Figure C.4. Variation of the average slope and intercept for concentration versus recharge plots (where the parameters are normalized relative to the $0.4 \mathrm{~cm} / \mathrm{yr}$ base case).

Equations C.7 and C.8 were determined from the average linear characteristics for variation of groundwater concentration as a function of recharge for a specified groundwater flux scenario. The 
equations are divided into a low groundwater flux regime $\left(\mathrm{q}<0.03\right.$, i.e., where $\left.{ }^{q} / 0.03<1.0\right)$ and a high flux regime. Equations C.7 and C.8 are used to determine the slope, $m_{r q}$, and intercept, $b_{r q}$, (describing the variation of groundwater concentration with recharge) for a given groundwater flux.

$$
\begin{array}{ll}
m_{r q}=\left[-2.545 \cdot\left(\frac{q}{0.03}\right)+3.545\right] \cdot 0.05999 & \text { for } \frac{q}{0.03}<1.0 \\
m_{r q}=\left[-0.0863 \cdot\left(\frac{q}{0.03}\right)+1.0863\right] \cdot 0.05999 & \text { for } \frac{q}{0.03} \geq 1.0 \\
b_{r q}=\left[0.161 \cdot\left(\frac{q}{0.03}\right)+0.839\right] \cdot 0.934 & \text { for } \frac{q}{0.03}<1.0 \\
b_{r q}=\left[0.00578 \cdot\left(\frac{q}{0.03}\right)+0.994\right] \cdot 0.934 & \text { for } \frac{q}{0.03} \geq 1.0
\end{array}
$$

After calculating the Henry's Law constant and the recharge variation slope/intercept, the unscaled concentration found in Step 2, $C_{w u}$, can be scaled to the final groundwater concentration based on the sitespecific values of the Henry's Law constant $(H)$, the recharge rate $(R)$, the compliance well screen length $(s)$, and the source strength. If the input included a value for $C_{g s}$, then Equation C.9 is used to calculate the final estimated groundwater contaminant concentration, $C_{w}$, at the compliance well. If the input included $\dot{M}_{s r c}$, then Equation C.10 is used to calculate $C_{w}$.

$$
\begin{aligned}
& C_{w}=C_{w u} \cdot \frac{0.89}{H} \cdot\left[\left(\frac{R}{0.4}\right) \cdot m_{r q}+b_{r q}\right] \cdot \frac{5.0}{s} \cdot \frac{C_{g s}}{159.0} \\
& C_{w}=C_{w u} \cdot \frac{0.89}{H} \cdot\left[\left(\frac{R}{0.4}\right) \cdot m_{r q}+b_{r q}\right] \cdot \frac{5.0}{s} \cdot \frac{\dot{M}_{s r c}}{\dot{M}_{s i m}}
\end{aligned}
$$

\section{C.4 Example Calculation}

To illustrate the procedure for estimating the contaminant concentration in groundwater at a compliance well, consider the scenarios shown in Table C.5. These scenarios represent the compiled set of input data (Step 1) for two variants (Case A and Case B), which differ only in the way that the source strength is specified. 
Table C.5. User input for the scenario variants applied in the example calculations for the groundwater concentration estimation procedure

\begin{tabular}{|c|r|c|c|c|}
\hline & Scenario Name: & - & Case A & Case B \\
\hline Contaminant: & - & TCE & TCE \\
\hline T & Temperature: & {$\left[{ }^{\circ} \mathrm{C}\right]$} & 20 & 20 \\
\hline$w$ & Avg. Moisture Content: & {$[\mathrm{wt} \%]$} & 2.825 & 2.825 \\
\hline $\mathrm{R}$ & Avg. Recharge: & {$[\mathrm{cm} / \mathrm{yr}]$} & 0.5 & 0.5 \\
\hline VZT & Vadose Zone Thickness: & {$[\mathrm{m}]$} & 20 & 20 \\
\hline L1 & Depth to Top of Source: & {$[\mathrm{m}]$} & 5.85 & 5.85 \\
\hline $\mathrm{Z}$ & Source Thickness: & {$[\mathrm{m}]$} & 3.5 & 3.5 \\
\hline $\mathrm{w}(=\mathrm{I})$ & Source Width (= Length): & {$[\mathrm{m}]$} & 15.8 & 15.8 \\
\hline $\mathrm{q}$ & GW Darcy Velocity: & {$[\mathrm{m} / \mathrm{day}]$} & 0.165 & 0.165 \\
\hline $\mathrm{d}$ & Distance to Compliance Well: & {$[\mathrm{m}]$} & 10 & 10 \\
\hline $\mathrm{S}$ & Compl. Well Screen Length: & {$[\mathrm{m}]$} & 10 & 10 \\
\hline & Source Strength Input Type: & - & Gas Concentration & Mass Discharge \\
\hline $\mathrm{C}_{\mathrm{gs}}$ & Source Gas Concentration: & {$[\mathrm{ppmv}]$} & 20 & \\
\hline$\dot{\mathrm{M}}_{\mathrm{src}}$ & Source Mass Discharge: & {$[\mathrm{g} / \mathrm{day}]$} & & 100 \\
\hline
\end{tabular}

The calculated values of $R S P, S A, S T R$, and $S_{r}$ (i.e., the converted value of $\omega$, as indicated in Table C.1), along with the user-specified values of VZT, $q$, and $d$, compose the seven quantities used in the lookup/interpolation calculations of the second step in the procedure (Table C.6). Aside from the distance to the compliance well, none of these parameter values for the example cases equal a corresponding key value (Table C.1); thus, interpolation is required at each step.

Table C.6. Parameter values for the example that are used in Step 2 for the lookup/interpolation

\begin{tabular}{|c|r|c|c|c|}
\hline & Scenario Name: & - & Case A & Case B \\
\hline Sr & Residual Saturation*: & {$[--]$} & 0.175 & 0.175 \\
\hline STR & Source Thickness Ratio: & {$[--]$} & 0.175 & 0.175 \\
\hline VZT & Vadose Zone Thickness: & {$[\mathrm{m}]$} & 20 & 20 \\
\hline SA & Areal Footprint of Source: & {$\left[\mathrm{m}^{2}\right]$} & 250 & 250 \\
\hline q & GW Darcy Velocity: & {$[\mathrm{m} /$ day] } & 0.165 & 0.165 \\
\hline RSP & Relative Source Position: & {$[--]$} & 0.55 & 0.55 \\
\hline d & Distance to Compliance Well: & {$[\mathrm{m}]$} & 10 & 10 \\
\hline
\end{tabular}

${ }^{*}$ Residual saturation $=\omega \cdot 0.06194$ for these scenario variants.

Start the Step 2 by finding $C_{\text {sim }}$ values in the data tables for specific combinations of parameter key values above and below the scenario values. For example, we can use Table C.3 to obtain the first few values. Looking at RSP boundary points of 0.1 and 1.0 for a distance of $10, q$ of 0.03 , and $S A$ of 100 , we find $C_{s i m}$ values of 24.19 and 43.12. Applying Equation C.1, we get:

$$
\left[\frac{0.55-0.1}{1.0-0.1}\right] \cdot(43.12-24.19)+24.19=33.65
$$

We can perform the same value lookup and interpolation for additional Category 1 combinations of $d$, $R S P, q$, and $S A$ (which are indicated by bold values in Table C.3). Interpolating the second set of RSP values gives a result of:

$$
\left[\frac{0.55-0.1}{1.0-0.1}\right] \cdot(9.40-5.26)+5.26=7.33
$$


Once interpolation is performed between pairs of $R S P$ concentration values, we can then perform interpolation between pairs of $q$ values. Interpolating between the first set of $q$ values gives:

$$
\left[\frac{0.165-0.03}{0.3-0.03}\right] \cdot(33.65-7.33)+7.33=20.49
$$

This process continues for all the combinations of pairs of $R S P, q, S A, V Z T, S T R$, and $S_{r}(i . e ., \omega)$ parameter boundary values. Table C.7 shows the completed set of Step 2 sequential interpolations to find the final $C_{w u}$ for the example $(28.67 \mu \mathrm{g} / \mathrm{L})$.

For Case B of the example, the same interpolation process (but without consideration of distance to the compliance well) is also applied to determine the corresponding $\dot{M}_{\text {sim }}$ mass discharge, which has a value of $58.36 \mathrm{~g} / \mathrm{day}$. 
Table C.7. Sequential interpolation to determine $C_{w u}$ for the example; each column beyond the first shows the results of the indicated interpolations

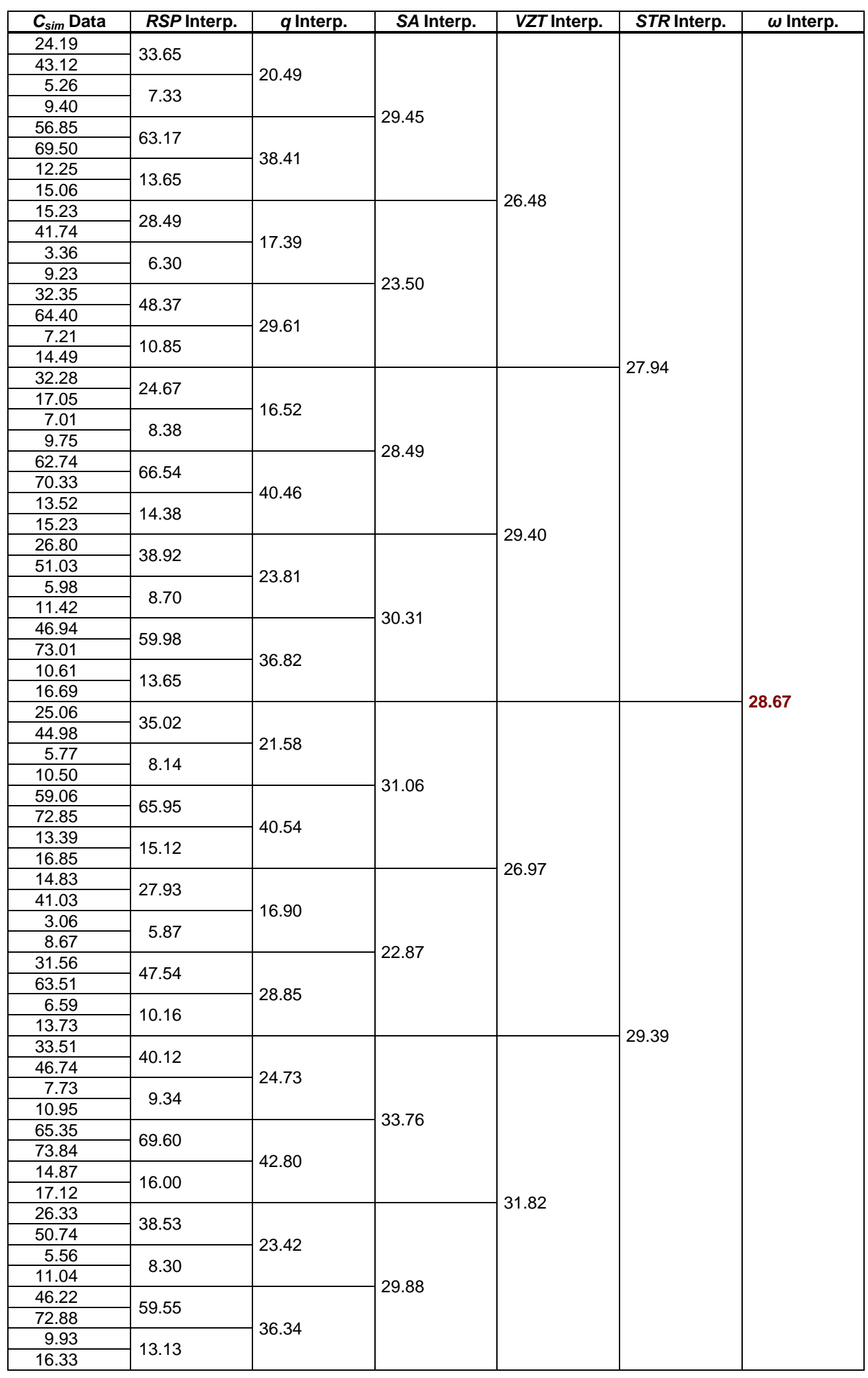


Once $C_{w u}$ and $\dot{M}_{\text {sim }}$ are found, Step 3 can be applied to find the scaled concentration, which is the desired end result. The vapor pressure and solubility for trichloroethene at $20{ }^{\circ} \mathrm{C}$ are calculated using contaminant-specific correlations:

$$
\begin{aligned}
& P_{\text {vap }}=10^{[6.87981-1157.83 /(20.0+202.58)]}=47.6376 \mathrm{~mm} \mathrm{Hg} \\
& x_{p}=\left[1.4049-0.0082223 \cdot(20.0+273.15)+0.000013218 \cdot(20.0+273.15)^{2}\right] / 100=0.13045 \\
& x=(0.13045 / 100) \cdot(18.01528 / 131.387)=1.7886 \times 10^{-4}
\end{aligned}
$$

These results are then plugged into Equation C.6 to obtain the value for the Henry's Law constant:

$$
\frac{47.6376}{0.00017886} \cdot \frac{18.01528}{0.9982 \cdot 0.08205746293 .15} \cdot \frac{1}{1000} \cdot \frac{1}{760}=0.263
$$

The slope and intercepts for the linear variation with recharge can be calculated using the high groundwater flux portion of Equations C.7 and C.8 (because $q>0.03$ ), with $q / 0.03=5.5$ ). These calculations result in:

$$
\begin{aligned}
& m_{r q}=(-0.0863 \cdot 5.5+1.0863) \cdot 0.05999=0.0367 \\
& b_{r q}=(0.00578 \cdot 5.5+0.994) \cdot 0.934=0.958
\end{aligned}
$$

For Case A of the example, Equation C.9 is applied to obtain final estimated groundwater contaminant concentration, $C_{w}$, at the compliance well. For Case B, Equation C.10 is applied to obtain $C_{w}$. These final calculations give the following results:

$$
\begin{array}{lr}
\text { Case A : } & 28.67 \cdot \frac{0.89}{0.263} \cdot\left[\left(\frac{0.5}{0.4}\right) \cdot 0.0367+0.958\right] \cdot \frac{5.0}{10.0} \cdot \frac{20.0}{159.0}=6 \mu \mathrm{g} / \mathrm{L} \\
\text { Case B : } & 28.67 \cdot \frac{0.89}{0.263} \cdot\left[\left(\frac{0.5}{0.4}\right) \cdot 0.0367+0.958\right] \cdot \frac{5.0}{10.0} \cdot \frac{100}{58.36}=83 \mu \mathrm{g} / \mathrm{L}
\end{array}
$$

\section{C.5 References}

Brennan RA, N Nirmalakhandan, and RE Speece. 1998. "Comparison of Predictive Methods for Henrys Law Coefficients of Organic Chemicals.” Water Res., 32(6):1901-1911.

Chen F, DL Freedman, RW Falta, and LC Murdoch. 2012. "Henry's Law Constants of Chlorinated Solvents at Elevated Temperatures." Chemosphere, 86(2):156-165.

Mackay D, WY Shiu, K Ma, and SC Lee. 2006. Handbook of Physical-Chemical Properties and Environmental Fate for Organic Chemicals, Second Ed, Volume II, Halogenated Hydrocarbons. CRC Press, Boca Raton, Florida.

Sander R. 1999. "Modeling Atmospheric Chemistry: Interactions Between Gas-Phase Species and Liquid Cloud/Aerosol Particles.” Surv. Geophys., 20(1):1-31. 
Staudinger J and PV Roberts. 2001. “A Critical Compilation of Henry's Law Constant Temperature Dependence Relations for Organic Compounds in Dilute Aqueous Solutions." Chemosphere, 44(4):561576.

Warneck P. 2007. “A Review of Henry's Law Coefficients for Chlorine-Containing $\mathrm{C}_{1}$ and $\mathrm{C}_{2}$ Hydrocarbons." Chemosphere, 69(3):347-361.

White MD and M Oostrom. 2006. STOMP Subsurface Transport Over Multiple Phases, Version 4.0, User's Guide. PNNL-15782, Pacific Northwest National Laboratory, Richland, Washington.

Yaws CL. 2003. Yaws' Handbook of Thermodynamic and Physical Properties of Chemical Compounds. Knovel, New York. Electronic ISBN 978-1-59124-444-8.

Yaws CL, PK Narasimhan, and C Gabbula. 2009. Yaws' Handbook of Antoine Coefficients for Vapor Pressure (2nd Electronic Edition). Knovel, New York. Electronic ISBN 978-1-59124-879-8. 


\section{Addendum to Appendix C Pre-Modeled Scenario Results for Concentration and Source Mass Discharge}

The following tables show unscaled contaminant concentration $\left(\mathrm{C}_{\mathrm{wu}}\right.$ in $\left.\mu \mathrm{g} / \mathrm{L}\right)$ results of the pre-modeled scenarios and are the root data used for interpolation as discussed in Appendix $\mathrm{C}$ and as incorporated into the spreadsheet tool, SVEET (Appendix D). Parameters are defined in Appendix C. 
Compliance Well Contaminant Concentration $(\mu \mathrm{g} / \mathrm{L})$ for Categories Listed in Table C.2.

\section{Set 1: Water Saturation of $\mathbf{0 . 0 5}$}

\begin{tabular}{|c|c|c|c|c|c|c|c|c|c|c|c|c|c|c|c|c|}
\hline \multicolumn{2}{|c|}{ Category 1} & \multicolumn{5}{|c|}{ RSP0.1 } & \multicolumn{5}{|c|}{ RSP1 } & \multicolumn{5}{|c|}{ RSP10 } \\
\hline$q$ & SA & $d=10$ & $d=25$ & $d=50$ & $d=75$ & $d=100$ & $d=10$ & $d=25$ & $d=50$ & $d=75$ & $d=100$ & $d=10$ & $d=25$ & $d=50$ & $d=75$ & $d=100$ \\
\hline 0.005 & 100 & 55.24 & 29.13 & 18.52 & 14.73 & 12.47 & 98.69 & 51.96 & 32.97 & 26.22 & 22.21 & 107.40 & 56.27 & 35.93 & 28.61 & 24.26 \\
\hline 0.03 & 100 & 24.19 & 14.88 & 9.01 & 6.92 & 5.73 & 43.12 & 26.57 & 16.08 & 12.34 & 10.22 & 47.56 & 28.95 & 17.56 & 13.49 & 11.18 \\
\hline 0.3 & 100 & 5.26 & 4.33 & 3.36 & 2.85 & 2.49 & 9.40 & 7.75 & 6.03 & 5.11 & 4.46 & 10.46 & 8.53 & 6.63 & 5.62 & 4.90 \\
\hline 0.005 & 400 & 134.99 & 76.28 & 46.89 & 37.32 & 31.64 & 166.31 & 96.33 & 58.63 & 46.61 & 39.50 & 176.84 & 97.84 & 59.88 & 47.63 & 40.39 \\
\hline 0.03 & 400 & 56.85 & 38.32 & 22.76 & 17.48 & 14.49 & 69.50 & 48.26 & 28.56 & 21.91 & 18.14 & 73.13 & 49.35 & 29.26 & 22.46 & 18.60 \\
\hline 0.3 & 400 & 12.25 & 10.97 & 8.48 & 7.19 & 6.28 & 15.06 & 13.83 & 10.69 & 9.06 & 7.91 & 15.81 & 14.28 & 11.04 & 9.36 & 8.17 \\
\hline 0.005 & 900 & $\# N / A$ & 176.54 & 121.57 & 71.69 & 56.76 & $\# N / A$ & 142.23 & 82.45 & 65.11 & 55.04 & $\# N / A$ & 143.50 & 83.58 & 66.05 & 55.86 \\
\hline 0.03 & 900 & $\# N / A$ & 73.60 & 59.40 & 34.85 & 26.62 & $\# \mathrm{~N} / \mathrm{A}$ & 68.98 & 40.23 & 30.65 & 25.29 & \#N/A & 70.10 & 40.89 & 31.17 & 25.73 \\
\hline 0.3 & 900 & $\# \mathrm{~N} / \mathrm{A}$ & 16.63 & 12.87 & 10.90 & 9.51 & $\# N / A$ & 19.27 & 14.91 & 12.62 & 11.00 & $\# \mathrm{~N} / \mathrm{A}$ & 19.77 & 15.28 & 12.93 & 11.28 \\
\hline 0.005 & 2500 & $\# N / A$ & 221.59 & 124.05 & 95.18 & 79.62 & $\# N / A$ & 244.29 & 136.49 & 103.92 & 86.69 & $\# N / A$ & 253.82 & 137.51 & 104.86 & 87.54 \\
\hline 0.03 & 2500 & $\# N / A$ & 99.76 & 60.40 & 44.88 & 36.56 & $\# N / A$ & 108.29 & 66.59 & 49.19 & 39.96 & \#N/A & 111.38 & 67.29 & 49.75 & 40.42 \\
\hline 0.3 & 2500 & \#N/A & 26.39 & 21.42 & 18.01 & 15.65 & $\# \mathrm{~N} / \mathrm{A}$ & 28.59 & 23.58 & 19.80 & 17.20 & $\# \mathrm{~N} / \mathrm{A}$ & 29.36 & 24.02 & 20.17 & 17.52 \\
\hline
\end{tabular}

\begin{tabular}{|c|c|c|c|c|c|c|c|c|c|c|c|c|c|c|c|c|}
\hline \multicolumn{2}{|c|}{ Category 2} & \multicolumn{5}{|c|}{ RSP0.1 } & \multicolumn{5}{|c|}{ RSP1 } & \multicolumn{5}{|c|}{ RSP10 } \\
\hline$q$ & SA & $d=10$ & $d=25$ & $d=50$ & $d=75$ & $d=100$ & $d=10$ & $d=25$ & $d=50$ & $d=75$ & $d=100$ & $\mathrm{~d}=10$ & $d=25$ & $d=50$ & $d=75$ & $d=100$ \\
\hline 0.005 & 100 & 36.53 & 32.73 & 22.87 & 17.43 & 14.29 & 99.74 & 85.70 & 59.05 & 45.16 & 37.11 & 147.36 & 106.77 & 71.28 & 55.19 & 45.80 \\
\hline 0.03 & 100 & 15.23 & 14.71 & 10.71 & 8.16 & 6.59 & 41.74 & 38.97 & 27.86 & 21.23 & 17.19 & 62.90 & 50.78 & 34.39 & 26.29 & 21.45 \\
\hline 0.3 & 100 & 3.36 & 3.77 & 3.41 & 2.97 & 2.62 & 9.23 & 10.13 & 9.03 & 7.84 & 6.92 & 14.03 & 13.91 & 11.84 & 10.24 & 9.02 \\
\hline 0.005 & 400 & 77.42 & 71.49 & 49.92 & 38.22 & 31.32 & 153.44 & 139.14 & 95.94 & 73.60 & 60.44 & 194.52 & 158.24 & 104.75 & 81.07 & 67.12 \\
\hline 0.03 & 400 & 32.35 & 32.00 & 23.41 & 17.88 & 14.46 & 64.40 & 62.85 & 45.33 & 34.63 & 28.04 & 82.06 & 73.93 & 50.53 & 38.69 & 31.53 \\
\hline 0.3 & 400 & 7.21 & 8.20 & 7.47 & 6.51 & 5.74 & 14.49 & 16.37 & 14.76 & 12.85 & 11.34 & 18.72 & 20.17 & 17.44 & 15.12 & 13.34 \\
\hline 0.005 & 900 & $\# N / A$ & 116.10 & 83.37 & 63.64 & 51.99 & $\# N / A$ & 185.25 & 132.30 & 101.04 & 82.57 & $\# \mathrm{~N} / \mathrm{A}$ & 202.58 & 136.48 & 104.90 & 86.36 \\
\hline 0.03 & 900 & $\# N / A$ & 51.61 & 38.93 & 29.75 & 24.00 & $\# \mathrm{~N} / \mathrm{A}$ & 82.71 & 62.17 & 47.53 & 38.37 & $\# N / A$ & 92.53 & 65.45 & 50.05 & 40.62 \\
\hline 0.3 & 900 & $\# N / A$ & 13.22 & 12.33 & 10.77 & 9.50 & $\# N / A$ & 21.55 & 20.04 & 17.51 & 15.46 & \#N/A & 25.08 & 22.31 & 19.41 & 17.14 \\
\hline 0.005 & 2500 & $\# N / A$ & 193.03 & 154.34 & 116.83 & 94.12 & $\# N / A$ & 245.54 & 198.85 & 150.21 & 120.80 & $\# N / A$ & 267.26 & 200.43 & 150.93 & 122.19 \\
\hline 0.03 & 2500 & $\# N / A$ & 84.80 & 70.78 & 54.35 & 43.49 & $\# N / A$ & 107.91 & 91.56 & 70.30 & 56.20 & $\# N / A$ & 117.59 & 94.17 & 71.66 & 57.49 \\
\hline 0.3 & 2500 & $\# N / A$ & 21.79 & 21.68 & 19.16 & 16.92 & $\# N / A$ & 28.36 & 28.56 & 25.25 & 22.32 & $\# \mathrm{~N} / \mathrm{A}$ & 31.80 & 30.92 & 27.10 & 23.92 \\
\hline
\end{tabular}

\begin{tabular}{|c|c|c|c|c|c|c|c|c|c|c|c|c|c|c|c|c|}
\hline \multicolumn{2}{|c|}{ Category 3} & \multicolumn{5}{|c|}{ RSP0.1 } & \multicolumn{5}{|c|}{ RSP1 } & \multicolumn{5}{|c|}{ RSP10 } \\
\hline$q$ & SA & $d=10$ & $d=25$ & $d=50$ & $d=75$ & $d=100$ & $d=10$ & $d=25$ & $d=50$ & $d=75$ & $d=100$ & $d=10$ & $d=25$ & $d=50$ & $d=75$ & $d=100$ \\
\hline 0.005 & 100 & 34.10 & 36.13 & 35.13 & 31.58 & 27.47 & 88.93 & 93.29 & 87.68 & 77.10 & 66.36 & 179.50 & 165.78 & 136.15 & 114.22 & 97.07 \\
\hline 0.03 & 100 & 13.96 & 15.13 & 15.09 & 13.79 & 12.13 & 36.45 & 39.33 & 38.04 & 33.98 & 29.56 & 75.32 & 73.74 & 62.05 & 52.44 & 44.72 \\
\hline 0.3 & 100 & 3.14 & 3.62 & 3.99 & 3.98 & 3.80 & 8.15 & 9.44 & 10.22 & 10.02 & 9.49 & 17.20 & 19.04 & 18.66 & 17.43 & 16.12 \\
\hline 0.005 & 400 & 55.80 & 59.16 & 57.28 & 51.80 & 45.08 & 123.42 & 129.80 & 121.71 & 107.66 & 92.70 & 220.02 & 213.87 & 175.88 & 148.28 & 125.99 \\
\hline 0.03 & 400 & 22.87 & 24.80 & 24.69 & 22.63 & 19.92 & 50.75 & 54.85 & 53.04 & 47.55 & 41.37 & 92.86 & 94.94 & 80.60 & 68.39 & 58.33 \\
\hline 0.3 & 400 & 5.17 & 5.96 & 6.57 & 6.55 & 6.26 & 11.47 & 13.29 & 14.42 & 14.15 & 13.38 & 21.92 & 24.99 & 24.75 & 23.18 & 21.45 \\
\hline 0.005 & 900 & $\# \mathrm{~N} / \mathrm{A}$ & 85.86 & 83.72 & 76.08 & 66.49 & $\# N / A$ & 166.43 & 158.06 & 140.64 & 121.60 & $\# \mathrm{~N} / \mathrm{A}$ & 249.74 & 212.12 & 179.78 & 153.05 \\
\hline 0.03 & 900 & $\# N / A$ & 36.01 & 36.05 & 33.20 & 29.35 & $\# N / A$ & 70.39 & 68.86 & 62.10 & 54.26 & $\# N / A$ & 109.97 & 96.84 & 82.85 & 70.90 \\
\hline 0.3 & 900 & $\#$ N/A & 8.67 & 9.60 & 9.61 & 9.20 & $\# N / A$ & 17.20 & 18.79 & 18.52 & 17.58 & $\#$ N/A & 29.30 & 29.81 & 28.14 & 26.15 \\
\hline 0.005 & 2500 & $\# \mathrm{~N} / \mathrm{A}$ & 143.92 & 143.87 & 131.80 & 115.51 & $\# N / A$ & 227.78 & 225.62 & 203.72 & 176.94 & $\# N / A$ & 293.13 & 273.87 & 234.96 & 200.26 \\
\hline 0.03 & 2500 & $\# \mathrm{~N} / \mathrm{A}$ & 60.43 & 61.69 & 57.41 & 50.96 & $\# \mathrm{~N} / \mathrm{A}$ & 96.44 & 97.69 & 89.71 & 78.92 & $\# N / A$ & 127.83 & 123.15 & 107.52 & 92.56 \\
\hline 0.3 & 2500 & $\# N / A$ & 14.69 & 16.41 & 16.57 & 15.95 & $\# N / A$ & 23.95 & 26.65 & 26.68 & 25.50 & $\# \mathrm{~N} / \mathrm{A}$ & 34.93 & 37.64 & 36.23 & 33.96 \\
\hline
\end{tabular}


Set 1: Water Saturation of 0.05 (continued)

\begin{tabular}{|c|c|c|c|c|c|c|c|c|c|c|c|c|c|c|c|c|}
\hline \multicolumn{2}{|c|}{ Category 4} & \multicolumn{5}{|c|}{ RSP0.1 } & \multicolumn{5}{|c|}{ RSP1 } & \multicolumn{5}{|c|}{ RSP10 } \\
\hline$q$ & SA & $d=10$ & $d=25$ & $d=50$ & $d=75$ & $d=100$ & $d=10$ & $d=25$ & $d=50$ & $d=75$ & $d=100$ & $d=10$ & $d=25$ & $d=50$ & $d=75$ & $d=100$ \\
\hline 0.005 & 100 & 73.84 & 38.54 & 24.53 & 19.52 & 16.54 & 102.32 & 53.38 & 33.94 & 27.01 & 22.88 & 113.10 & 59.09 & 37.61 & 29.94 & 25.38 \\
\hline 0.03 & 100 & 32.28 & 19.72 & 11.94 & 9.17 & 7.60 & 17.05 & 8.90 & 5.66 & 4.50 & 3.81 & 49.69 & 30.36 & 18.38 & 14.11 & 11.69 \\
\hline 0.3 & 100 & 7.01 & 5.74 & 4.46 & 3.78 & 3.30 & 9.75 & 8.00 & 6.21 & 5.27 & 4.59 & 10.90 & 8.92 & 6.94 & 5.88 & 5.13 \\
\hline 0.005 & 400 & 149.52 & 84.66 & 51.93 & 41.34 & 35.06 & 168.52 & 96.83 & 59.00 & 46.92 & 39.79 & 178.19 & 101.04 & 61.53 & 48.92 & 41.46 \\
\hline 0.03 & 400 & 62.74 & 42.55 & 25.23 & 19.38 & 16.06 & 70.33 & 48.60 & 28.75 & 22.05 & 18.27 & 73.79 & 50.82 & 30.07 & 23.06 & 19.09 \\
\hline 0.3 & 400 & 13.52 & 12.19 & 9.42 & 7.99 & 6.97 & 15.23 & 13.95 & 10.78 & 9.14 & 7.97 & 16.00 & 14.66 & 11.34 & 9.61 & 8.39 \\
\hline 0.005 & 900 & $\# N / A$ & 129.70 & 75.94 & 60.12 & 50.88 & $\# N / A$ & 142.88 & 82.72 & 65.36 & 55.27 & $\# N / A$ & 147.51 & 85.31 & 67.35 & 56.94 \\
\hline 0.03 & 900 & $\# N / A$ & 63.27 & 36.96 & 28.22 & 23.31 & $\# N / A$ & 69.38 & 40.37 & 30.76 & 25.39 & $\# N / A$ & 71.73 & 41.74 & 31.79 & 26.23 \\
\hline 0.3 & 900 & $\# N / A$ & 17.70 & 13.67 & 11.58 & 10.10 & $\# N / A$ & 19.41 & 14.99 & 12.68 & 11.06 & \#N/A & 20.16 & 15.57 & 13.18 & 11.49 \\
\hline 0.005 & 2500 & $\# N / A$ & 231.39 & 128.74 & 98.59 & 82.43 & $\# N / A$ & 246.15 & 136.71 & 104.16 & 86.94 & $\# N / A$ & 254.71 & 139.72 & 106.29 & 88.66 \\
\hline 0.03 & 2500 & $\# N / A$ & 103.49 & 62.77 & 46.56 & 37.90 & $\# N / A$ & 108.93 & 66.73 & 49.31 & 40.05 & $\# N / A$ & 111.77 & 68.33 & 50.43 & 40.94 \\
\hline 0.3 & 2500 & $\# N / A$ & 27.31 & 22.25 & 18.70 & 16.25 & $\# N / A$ & 28.75 & 23.68 & 19.87 & 17.26 & $\# N / A$ & 29.51 & 24.33 & 20.42 & 17.73 \\
\hline
\end{tabular}

\begin{tabular}{|c|c|c|c|c|c|c|c|c|c|c|c|c|c|c|c|c|}
\hline \multicolumn{2}{|c|}{ Category 5} & \multicolumn{5}{|c|}{ RSP0.1 } & \multicolumn{5}{|c|}{ RSP1 } & \multicolumn{5}{|c|}{ RSP10 } \\
\hline$q$ & SA & $d=10$ & $d=25$ & $\mathrm{~d}=50$ & $d=75$ & $d=100$ & $d=10$ & $d=25$ & $d=50$ & $d=75$ & $d=100$ & $d=10$ & $d=25$ & $d=50$ & $d=75$ & $d=100$ \\
\hline 0.005 & 100 & 64.00 & 57.51 & 40.63 & 31.07 & 25.44 & 121.33 & 103.85 & 72.09 & 55.28 & 45.41 & 163.15 & 125.01 & 84.64 & 65.32 & 54.01 \\
\hline 0.03 & 100 & 26.80 & 25.90 & 19.02 & 14.53 & 11.74 & 51.03 & 47.41 & 34.05 & 26.01 & 21.07 & 69.53 & 58.82 & 40.64 & 31.06 & 25.28 \\
\hline 0.3 & 100 & 5.98 & 6.70 & 6.08 & 5.30 & 4.67 & 11.42 & 12.47 & 11.13 & 9.68 & 8.54 & 15.71 & 16.08 & 13.90 & 12.04 & 10.60 \\
\hline 0.005 & 400 & 111.80 & 104.23 & 73.77 & 56.65 & 46.37 & 173.04 & 157.89 & 109.87 & 84.48 & 69.32 & 202.79 & 175.17 & 118.31 & 91.30 & 75.27 \\
\hline 0.03 & 400 & 46.94 & 46.71 & 34.57 & 26.51 & 21.43 & 73.01 & 71.50 & 51.95 & 39.80 & 32.23 & 85.88 & 80.95 & 56.76 & 43.47 & 35.31 \\
\hline 0.3 & 400 & 10.61 & 12.10 & 11.10 & 9.70 & 8.55 & 16.69 & 18.86 & 17.07 & 14.89 & 13.13 & 19.93 & 22.05 & 19.42 & 16.87 & 14.88 \\
\hline 0.005 & 900 & $\# N / A$ & 150.78 & 110.30 & 84.48 & 68.90 & $\# N / A$ & 201.77 & 145.86 & 111.69 & 91.17 & $\# N / A$ & 217.38 & 151.00 & 115.79 & 94.90 \\
\hline 0.03 & 900 & $\# N / A$ & 67.06 & 51.46 & 39.50 & 31.86 & $\# \mathrm{~N} / \mathrm{A}$ & 90.23 & 68.57 & 52.59 & 42.45 & $\# N / A$ & 98.40 & 71.95 & 55.07 & 44.57 \\
\hline 0.3 & 900 & $\# N / A$ & 17.39 & 16.38 & 14.36 & 12.67 & $\# N / A$ & 23.83 & 22.30 & 19.53 & 17.24 & $\# N / A$ & 26.70 & 24.30 & 21.20 & 18.71 \\
\hline 0.005 & 2500 & $\# N / A$ & 220.31 & 180.78 & 137.64 & 110.71 & $\# N / A$ & 256.99 & 211.85 & 160.73 & 129.15 & $\# N / A$ & 273.12 & 215.91 & 162.88 & 131.24 \\
\hline 0.03 & 2500 & $\# N / A$ & 96.87 & 82.81 & 64.04 & 51.24 & $\# N / A$ & 113.09 & 97.53 & 75.27 & 60.19 & $\# N / A$ & 120.11 & 100.65 & 77.02 & 61.63 \\
\hline 0.3 & 2500 & $\# \mathrm{~N} / \mathrm{A}$ & 25.31 & 25.56 & 22.70 & 20.07 & $\# \mathrm{~N} / \mathrm{A}$ & 30.21 & 30.70 & 27.24 & 24.09 & \#N/A & 32.79 & 32.77 & 28.86 & 25.49 \\
\hline
\end{tabular}

\begin{tabular}{|c|c|c|c|c|c|c|c|c|c|c|c|c|c|c|c|c|}
\hline \multicolumn{2}{|c|}{ Category 6} & \multicolumn{5}{|c|}{ RSP0.1 } & \multicolumn{5}{|c|}{ RSP1 } & \multicolumn{5}{|c|}{ RSP10 } \\
\hline$q$ & SA & $d=10$ & $d=25$ & $d=50$ & $d=75$ & $d=100$ & $d=10$ & $d=25$ & $d=50$ & $d=75$ & $d=100$ & $d=10$ & $d=25$ & $d=50$ & $d=75$ & $d=100$ \\
\hline 0.005 & 100 & 68.36 & 72.35 & 70.57 & 63.95 & 56.08 & 115.61 & 121.13 & 114.36 & 101.40 & 87.94 & 209.59 & 202.00 & 175.02 & 150.77 & 129.87 \\
\hline 0.03 & 100 & 28.05 & 30.35 & 30.33 & 27.90 & 24.73 & 47.50 & 51.17 & 49.63 & 44.66 & 39.13 & 88.16 & 88.99 & 78.89 & 68.58 & 59.43 \\
\hline 0.3 & 100 & 6.37 & 7.32 & 8.06 & 8.06 & 7.74 & 10.72 & 12.38 & 13.41 & 13.19 & 12.53 & 20.63 & 23.11 & 23.39 & 22.30 & 20.89 \\
\hline 0.005 & 400 & 96.57 & 102.32 & 99.49 & 90.70 & 79.62 & 150.64 & 158.38 & 149.33 & 133.25 & 115.65 & 240.49 & 242.00 & 210.90 & 182.90 & 157.66 \\
\hline 0.03 & 400 & 39.71 & 43.00 & 42.91 & 39.61 & 35.14 & 62.16 & 67.09 & 65.12 & 58.83 & 51.58 & 101.79 & 106.47 & 95.47 & 83.46 & 72.40 \\
\hline 0.3 & 400 & 9.08 & 10.43 & 11.50 & 11.51 & 11.05 & 14.21 & 16.42 & 17.83 & 17.56 & 16.69 & 24.61 & 28.21 & 28.87 & 27.61 & 25.89 \\
\hline 0.005 & 900 & $\# N / A$ & 134.89 & 132.23 & 121.24 & 106.90 & $\# \mathrm{~N} / \mathrm{A}$ & 195.11 & 186.65 & 167.68 & 146.19 & $\# N / A$ & 272.19 & 245.09 & 214.30 & 185.41 \\
\hline 0.03 & 900 & $\# \mathrm{~N} / \mathrm{A}$ & 56.72 & 57.01 & 52.91 & 47.15 & $\# \mathrm{~N} / \mathrm{A}$ & 82.75 & 81.38 & 74.04 & 65.20 & $\# \mathrm{~N} / \mathrm{A}$ & 119.07 & 110.55 & 97.64 & 85.11 \\
\hline 0.3 & 900 & $\#$ N/A & 13.83 & 15.32 & 15.40 & 14.82 & $\# N / A$ & 20.48 & 22.41 & 22.19 & 21.15 & $\# N / A$ & 32.02 & 33.57 & 32.39 & 30.52 \\
\hline 0.005 & 2500 & $\# N / A$ & 195.79 & 197.27 & 182.86 & 162.01 & $\# \mathrm{~N} / \mathrm{A}$ & 252.24 & 252.08 & 230.29 & 202.01 & $\# N / A$ & 308.37 & 301.90 & 268.90 & 233.92 \\
\hline 0.03 & 2500 & $\# \mathrm{~N} / \mathrm{A}$ & 82.47 & 84.72 & 79.68 & 71.45 & $\# \mathrm{~N} / \mathrm{A}$ & 107.15 & 109.30 & 101.43 & 90.09 & $\# N / A$ & 134.14 & 134.41 & 121.66 & 107.04 \\
\hline 0.3 & 2500 & \#N/A & 20.39 & 22.81 & 23.18 & 22.44 & $\# N / A$ & 27.07 & 30.19 & 30.40 & 29.22 & $\# N / A$ & 37.13 & 40.79 & 40.17 & 38.24 \\
\hline
\end{tabular}


Set 1: Water Saturation of 0.05 (continued)

\begin{tabular}{|c|c|c|c|c|c|c|c|c|c|c|c|c|c|c|c|c|}
\hline \multicolumn{2}{|c|}{ Category 7} & \multicolumn{5}{|c|}{ RSP0.1 } & \multicolumn{5}{|c|}{ RSP1 } & \multicolumn{5}{|c|}{ RSP10 } \\
\hline$q$ & SA & $d=10$ & $d=25$ & $d=50$ & $d=75$ & $d=100$ & $d=10$ & $d=25$ & $d=50$ & $d=75$ & $d=100$ & $d=10$ & $d=25$ & $d=50$ & $d=75$ & $d=100$ \\
\hline 0.005 & 100 & 96.74 & 50.45 & 32.05 & 25.50 & 21.61 & 112.67 & 59.19 & 37.49 & 29.82 & 25.26 & 117.75 & 61.63 & 39.08 & 31.10 & 26.36 \\
\hline 0.03 & 100 & 42.14 & 25.82 & 15.62 & 11.99 & 9.93 & 49.04 & 30.27 & 18.30 & 14.04 & 11.63 & 51.40 & 31.59 & 19.10 & 14.66 & 12.14 \\
\hline 0.3 & 100 & 9.16 & 7.53 & 5.85 & 4.96 & 4.32 & 10.69 & 8.84 & 6.87 & 5.82 & 5.08 & 11.24 & 9.26 & 7.20 & 6.10 & 5.32 \\
\hline 0.005 & 400 & 164.36 & 94.96 & 57.84 & 46.00 & 39.00 & 174.18 & 102.52 & 62.06 & 49.30 & 41.78 & 179.13 & 104.19 & 63.12 & 50.14 & 42.49 \\
\hline 0.03 & 400 & 68.70 & 47.61 & 28.16 & 21.60 & 17.89 & 72.57 & 51.28 & 30.28 & 23.21 & 19.21 & 74.30 & 52.22 & 30.84 & 23.64 & 19.57 \\
\hline 0.3 & 400 & 14.86 & 13.63 & 10.53 & 8.93 & 7.79 & 15.77 & 14.69 & 11.36 & 9.62 & 8.40 & 16.16 & 15.02 & 11.61 & 9.84 & 8.59 \\
\hline 0.005 & 900 & $\# N / A$ & 140.97 & 81.61 & 64.49 & 54.54 & $\# N / A$ & 149.55 & 85.97 & 67.80 & 57.30 & $\# N / A$ & 151.41 & 87.02 & 68.63 & 58.00 \\
\hline 0.03 & 900 & $\# N / A$ & 68.39 & 39.79 & 30.33 & 25.03 & $\# N / A$ & 72.23 & 42.00 & 31.96 & 26.35 & $\# N / A$ & 73.26 & 42.57 & 32.39 & 26.71 \\
\hline 0.3 & 900 & $\# N / A$ & 19.08 & 14.74 & 12.47 & 10.88 & $\# N / A$ & 20.14 & 15.58 & 13.18 & 11.50 & \#N/A & 20.50 & 15.85 & 13.41 & 11.69 \\
\hline 0.005 & 2500 & $\# N / A$ & 242.70 & 135.45 & 103.25 & 86.20 & $\# N / A$ & 250.83 & 140.78 & 106.83 & 89.05 & $\# N / A$ & 255.25 & 141.94 & 107.69 & 89.76 \\
\hline 0.03 & 2500 & $\# N / A$ & 107.67 & 66.08 & 48.84 & 39.68 & $\# N / A$ & 110.61 & 68.70 & 50.63 & 41.07 & $\# N / A$ & 112.04 & 69.35 & 51.10 & 41.45 \\
\hline 0.3 & 2500 & $\# N / A$ & 28.40 & 23.40 & 19.64 & 17.06 & $\# N / A$ & 29.22 & 24.32 & 20.40 & 17.72 & \#N/A & 29.61 & 24.63 & 20.66 & 17.94 \\
\hline
\end{tabular}

\begin{tabular}{|c|c|c|c|c|c|c|c|c|c|c|c|c|c|c|c|c|}
\hline \multicolumn{2}{|c|}{ Category 8} & \multicolumn{5}{|c|}{ RSP0.1 } & \multicolumn{5}{|c|}{ RSP1 } & \multicolumn{5}{|c|}{ RSP10 } \\
\hline$q$ & SA & $d=10$ & $d=25$ & $d=50$ & $d=75$ & $d=100$ & $d=10$ & $d=25$ & $d=50$ & $d=75$ & $d=100$ & $d=10$ & $d=25$ & $d=50$ & $d=75$ & $d=100$ \\
\hline 0.005 & 100 & 96.64 & 84.79 & 58.38 & 44.47 & 36.51 & 134.93 & 114.95 & 79.10 & 60.53 & 49.76 & 174.40 & 141.41 & 98.74 & 76.33 & 62.86 \\
\hline 0.03 & 100 & 40.36 & 38.36 & 27.51 & 20.90 & 16.90 & 56.66 & 52.51 & 37.45 & 28.53 & 23.12 & 74.37 & 65.79 & 47.04 & 36.17 & 29.40 \\
\hline 0.3 & 100 & 8.91 & 9.90 & 8.85 & 7.69 & 6.78 & 12.62 & 13.77 & 12.24 & 10.64 & 9.38 & 17.05 & 17.94 & 15.87 & 13.83 & 12.21 \\
\hline 0.005 & 400 & 147.85 & 136.70 & 94.58 & 72.26 & 59.26 & 182.75 & 167.71 & 115.99 & 88.93 & 72.97 & 209.51 & 189.48 & 132.69 & 102.72 & 84.36 \\
\hline 0.03 & 400 & 61.97 & 61.40 & 44.59 & 33.97 & 27.47 & 76.98 & 75.84 & 54.93 & 41.97 & 33.97 & 89.08 & 86.77 & 63.16 & 48.71 & 39.53 \\
\hline 0.3 & 400 & 13.92 & 15.86 & 14.40 & 12.53 & 11.05 & 17.54 & 19.92 & 18.02 & 15.69 & 13.85 & 21.01 & 23.64 & 21.34 & 18.67 & 16.49 \\
\hline 0.005 & 900 & \#N/A & 182.53 & 131.39 & 99.92 & 81.51 & \#N/A & 209.80 & 151.28 & 115.40 & 94.14 & \#N/A & 229.01 & 166.22 & 128.21 & 104.73 \\
\hline 0.03 & 900 & $\# N / A$ & 81.13 & 61.58 & 46.94 & 37.83 & $\# \mathrm{~N} / \mathrm{A}$ & 93.57 & 71.16 & 54.42 & 43.88 & $\# \mathrm{~N} / \mathrm{A}$ & 103.01 & 78.57 & 60.71 & 49.11 \\
\hline 0.3 & 900 & $\# N / A$ & 20.98 & 19.66 & 17.17 & 15.15 & $\# N / A$ & 24.59 & 23.06 & 20.17 & 17.81 & \#N/A & 28.04 & 26.22 & 23.06 & 20.40 \\
\hline 0.005 & 2500 & \#N/A & 242.61 & 199.00 & 149.80 & 120.19 & $\# N / A$ & 261.78 & 216.96 & 163.75 & 131.34 & $\# N / A$ & 278.19 & 231.12 & 176.69 & 142.17 \\
\hline 0.03 & 2500 & $\# N / A$ & 106.40 & 91.32 & 70.00 & 55.85 & $\# N / A$ & 114.89 & 99.80 & 76.75 & 61.26 & $\# N / A$ & 122.35 & 106.88 & 83.09 & 66.63 \\
\hline 0.3 & 2500 & \#N/A & 27.79 & 28.20 & 24.94 & 22.03 & $\# N / A$ & 30.58 & 31.26 & 27.71 & 24.49 & $\# N / A$ & 33.70 & 34.50 & 30.74 & 27.25 \\
\hline
\end{tabular}

\begin{tabular}{|c|c|c|c|c|c|c|c|c|c|c|c|c|c|c|c|c|}
\hline \multicolumn{2}{|c|}{ Category 9} & \multicolumn{5}{|c|}{ RSP0.1 } & \multicolumn{5}{|c|}{ RSP1 } & \multicolumn{5}{|c|}{ RSP10 } \\
\hline$q$ & SA & $d=10$ & $d=25$ & $d=50$ & $d=75$ & $d=100$ & $d=10$ & $d=25$ & $d=50$ & $d=75$ & $d=100$ & $d=10$ & $d=25$ & $d=50$ & $d=75$ & $d=100$ \\
\hline 0.005 & 100 & 100.44 & 105.67 & 99.87 & 87.84 & 75.43 & 144.26 & 149.80 & 138.19 & 120.36 & 103.10 & 220.53 & 213.13 & 186.59 & 161.49 & 139.30 \\
\hline 0.03 & 100 & 41.09 & 44.45 & 43.25 & 38.70 & 33.64 & 59.28 & 63.57 & 60.41 & 53.47 & 46.29 & 93.68 & 94.43 & 84.31 & 73.54 & 63.73 \\
\hline 0.3 & 100 & 9.15 & 10.61 & 11.54 & 11.34 & 10.74 & 13.30 & 15.41 & 16.49 & 16.05 & 15.13 & 22.60 & 25.17 & 25.55 & 24.39 & 22.83 \\
\hline 0.005 & 400 & 134.07 & 141.44 & 133.46 & 118.16 & 101.49 & 180.06 & 188.24 & 173.70 & 152.35 & 130.60 & 247.53 & 250.08 & 220.30 & 192.02 & 165.77 \\
\hline 0.03 & 400 & 55.04 & 59.63 & 58.05 & 52.17 & 45.38 & 74.38 & 80.11 & 76.32 & 67.85 & 58.79 & 105.63 & 110.53 & 99.87 & 87.62 & 76.03 \\
\hline 0.3 & 400 & 12.39 & 14.37 & 15.66 & 15.41 & 14.59 & 16.97 & 19.68 & 21.13 & 20.61 & 19.43 & 26.28 & 29.98 & 30.77 & 29.48 & 27.63 \\
\hline 0.005 & 900 & $\# \mathrm{~N} / \mathrm{A}$ & 177.82 & 170.06 & 151.62 & 130.79 & $\# \mathrm{~N} / \mathrm{A}$ & 224.07 & 210.95 & 186.54 & 160.65 & $\# N / A$ & 278.69 & 253.44 & 222.81 & 193.13 \\
\hline 0.03 & 900 & \#N/A & 75.04 & 73.95 & 66.94 & 58.49 & $\# \mathrm{~N} / \mathrm{A}$ & 95.41 & 92.61 & 83.05 & 72.32 & $\# \mathrm{~N} / \mathrm{A}$ & 122.47 & 114.46 & 101.49 & 88.51 \\
\hline 0.3 & 900 & $\# N / A$ & 18.24 & 20.03 & 19.81 & 18.83 & $\# N / A$ & 23.72 & 25.78 & 25.30 & 23.95 & $\# N / A$ & 33.70 & 35.38 & 34.19 & 32.20 \\
\hline 0.005 & 2500 & $\# \mathrm{~N} / \mathrm{A}$ & 237.03 & 236.38 & 214.31 & 185.84 & $\# \mathrm{~N} / \mathrm{A}$ & 273.87 & 272.79 & 246.33 & 213.60 & $\# N / A$ & 313.19 & 308.75 & 276.76 & 241.35 \\
\hline 0.03 & 2500 & $\# \mathrm{~N} / \mathrm{A}$ & 100.17 & 102.17 & 94.36 & 83.15 & $\# \mathrm{~N} / \mathrm{A}$ & 116.70 & 118.81 & 109.19 & 96.03 & $\# N / A$ & 136.87 & 137.73 & 125.20 & 110.26 \\
\hline 0.3 & 2500 & $\# N / A$ & 24.77 & 27.69 & 27.84 & 26.67 & $\# N / A$ & 29.68 & 33.12 & 33.15 & 31.69 & $\# N / A$ & 38.75 & 42.53 & 41.95 & 39.92 \\
\hline
\end{tabular}


Set 2: Water Saturation of 0.3

\begin{tabular}{|c|c|c|c|c|c|c|c|c|c|c|c|c|c|c|c|c|}
\hline \multicolumn{2}{|c|}{ Category 1} & \multicolumn{5}{|c|}{ RSP0.1 } & \multicolumn{5}{|c|}{ RSP1 } & \multicolumn{5}{|c|}{ RSP10 } \\
\hline$q$ & SA & $d=10$ & $d=25$ & $d=50$ & $d=75$ & $d=100$ & $d=10$ & $d=25$ & $d=50$ & $d=75$ & $d=100$ & $d=10$ & $d=25$ & $d=50$ & $d=75$ & $d=100$ \\
\hline 0.005 & 100 & 55.49 & 29.00 & 18.47 & 14.70 & 12.46 & 99.27 & 51.79 & 32.92 & 26.21 & 22.22 & 108.05 & 56.24 & 35.99 & 28.69 & 24.35 \\
\hline 0.03 & 100 & 25.06 & 14.94 & 8.94 & 6.86 & 5.70 & 44.98 & 26.86 & 16.06 & 12.33 & 10.23 & 50.03 & 29.55 & 17.72 & 13.61 & 11.30 \\
\hline 0.3 & 100 & 5.77 & 4.61 & 3.51 & 2.94 & 2.55 & 10.50 & 8.41 & 6.41 & 5.37 & 4.65 & 12.01 & 9.50 & 7.24 & 6.07 & 5.26 \\
\hline 0.005 & 400 & 136.34 & 75.99 & 46.75 & 37.25 & 31.62 & 168.56 & 96.10 & 58.57 & 46.61 & 39.54 & 180.13 & 97.78 & 59.97 & 47.76 & 40.53 \\
\hline 0.03 & 400 & 59.06 & 38.56 & 22.60 & 17.36 & 14.41 & 72.85 & 48.94 & 28.59 & 21.93 & 18.19 & 77.52 & 50.42 & 29.54 & 22.68 & 18.82 \\
\hline 0.3 & 400 & 13.39 & 11.66 & 8.84 & 7.43 & 6.44 & 16.85 & 15.04 & 11.40 & 9.58 & 8.30 & 18.19 & 15.92 & 12.08 & 10.15 & 8.80 \\
\hline 0.005 & 900 & $\# N / A$ & 121.26 & 71.46 & 56.64 & 47.98 & $\# N / A$ & 142.07 & 82.32 & 65.07 & 55.07 & $\# N / A$ & 143.45 & 83.62 & 66.16 & 56.00 \\
\hline 0.03 & 900 & $\# N / A$ & 59.96 & 34.63 & 26.44 & 21.88 & $\# N / A$ & 70.13 & 40.25 & 30.66 & 25.33 & $\# N / A$ & 71.67 & 41.21 & 31.42 & 25.97 \\
\hline 0.3 & 900 & $\# N / A$ & 17.68 & 13.41 & 11.25 & 9.75 & $\# N / A$ & 20.98 & 15.89 & 13.33 & 11.54 & \#N/A & 22.01 & 16.67 & 13.98 & 12.12 \\
\hline 0.005 & 2500 & $\# N / A$ & 222.44 & 123.57 & 94.89 & 79.46 & $\# N / A$ & 246.01 & 136.14 & 103.77 & 86.67 & $\# N / A$ & 256.49 & 137.35 & 104.88 & 87.64 \\
\hline 0.03 & 2500 & $\# N / A$ & 101.71 & 60.17 & 44.59 & 36.34 & $\# N / A$ & 111.21 & 66.71 & 49.15 & 39.94 & $\# N / A$ & 115.20 & 67.75 & 49.98 & 40.65 \\
\hline 0.3 & 2500 & $\# N / A$ & 28.18 & 22.34 & 18.59 & 16.04 & $\# N / A$ & 31.22 & 25.13 & 20.88 & 18.01 & \#N/A & 32.76 & 26.11 & 21.71 & 18.72 \\
\hline
\end{tabular}

\begin{tabular}{|c|c|c|c|c|c|c|c|c|c|c|c|c|c|c|c|c|}
\hline \multicolumn{2}{|c|}{ Category 2} & \multicolumn{5}{|c|}{ RSP0.1 } & \multicolumn{5}{|c|}{ RSP1 } & \multicolumn{5}{|c|}{ RSP10 } \\
\hline$q$ & SA & $d=10$ & $d=25$ & $d=50$ & $d=75$ & $d=100$ & $d=10$ & $d=25$ & $d=50$ & $d=75$ & $d=100$ & $d=10$ & $d=25$ & $d=50$ & $d=75$ & $d=100$ \\
\hline 0.005 & 100 & 36.38 & 32.68 & 23.01 & 17.62 & 14.46 & 99.36 & 85.56 & 59.41 & 45.64 & 37.56 & 148.22 & 107.38 & 72.28 & 56.17 & 46.67 \\
\hline 0.03 & 100 & 14.83 & 14.39 & 10.63 & 8.20 & 6.68 & 41.03 & 38.39 & 27.85 & 21.50 & 17.54 & 64.64 & 51.73 & 35.50 & 27.46 & 22.54 \\
\hline 0.3 & 100 & 3.06 & 3.44 & 3.14 & 2.77 & 2.48 & 8.67 & 9.50 & 8.52 & 7.52 & 6.72 & 14.91 & 14.50 & 12.38 & 10.83 & 9.64 \\
\hline 0.005 & 400 & 77.21 & 71.53 & 50.32 & 38.71 & 31.77 & 153.02 & 139.15 & 96.70 & 74.53 & 61.29 & 196.22 & 159.24 & 106.35 & 82.69 & 68.57 \\
\hline 0.03 & 400 & 31.56 & 31.39 & 23.29 & 18.03 & 14.69 & 63.51 & 62.22 & 45.53 & 35.26 & 28.77 & 84.61 & 75.59 & 52.43 & 40.69 & 33.39 \\
\hline 0.3 & 400 & 6.59 & 7.53 & 6.92 & 6.12 & 5.47 & 13.73 & 15.55 & 14.13 & 12.48 & 11.16 & 20.13 & 21.39 & 18.57 & 16.34 & 14.59 \\
\hline 0.005 & 900 & \#N/A & 116.17 & 84.04 & 64.47 & 52.76 & \#N/A & 185.21 & 133.30 & 102.35 & 83.80 & \#N/A & 203.66 & 138.43 & 107.01 & 88.29 \\
\hline 0.03 & 900 & $\# N / A$ & 50.62 & 38.74 & 30.01 & 24.41 & $\# \mathrm{~N} / \mathrm{A}$ & 81.95 & 62.48 & 48.46 & 39.46 & $\# \mathrm{~N} / \mathrm{A}$ & 94.46 & 67.75 & 52.61 & 43.08 \\
\hline 0.3 & 900 & \#N/A & 12.13 & 11.40 & 10.11 & 9.05 & $\# N / A$ & 20.53 & 19.25 & 17.09 & 15.31 & \#N/A & 26.72 & 23.84 & 21.08 & 18.88 \\
\hline 0.005 & 2500 & \#N/A & 192.43 & 155.10 & 118.15 & 95.46 & $\# N / A$ & 245.06 & 199.79 & 151.99 & 122.65 & $\# N / A$ & 268.73 & 202.35 & 153.58 & 124.81 \\
\hline 0.03 & 2500 & $\# N / A$ & 82.73 & 70.08 & 54.64 & 44.18 & $\# N / A$ & 106.78 & 91.65 & 71.50 & 57.82 & $\# N / A$ & 119.98 & 96.52 & 74.76 & 60.72 \\
\hline 0.3 & 2500 & $\# N / A$ & 19.73 & 19.87 & 17.83 & 16.01 & $\# N / A$ & 27.06 & 27.47 & 24.67 & 22.16 & $\# N / A$ & 34.05 & 32.97 & 29.34 & 26.34 \\
\hline
\end{tabular}

\begin{tabular}{|c|c|c|c|c|c|c|c|c|c|c|c|c|c|c|c|c|}
\hline \multicolumn{2}{|c|}{ Category 3} & \multicolumn{5}{|c|}{ RSP0.1 } & \multicolumn{5}{|c|}{ RSP1 } & \multicolumn{5}{|c|}{ RSP10 } \\
\hline$q$ & SA & $d=10$ & $d=25$ & $d=50$ & $d=75$ & $d=100$ & $d=10$ & $d=25$ & $d=50$ & $d=75$ & $d=100$ & $d=10$ & $d=25$ & $d=50$ & $d=75$ & $d=100$ \\
\hline 0.005 & 100 & 32.67 & 34.89 & 34.24 & 31.02 & 27.16 & 85.55 & 90.47 & 85.93 & 76.28 & 66.23 & 176.73 & 163.73 & 135.76 & 114.98 & 98.51 \\
\hline 0.03 & 100 & 12.22 & 13.48 & 13.75 & 12.82 & 11.52 & 32.17 & 35.33 & 34.95 & 31.91 & 28.39 & 72.52 & 71.22 & 60.90 & 52.57 & 45.78 \\
\hline 0.3 & 100 & 2.21 & 2.60 & 2.92 & 2.96 & 2.89 & 5.88 & 6.95 & 7.65 & 7.62 & 7.35 & 15.45 & 17.04 & 16.64 & 15.71 & 14.78 \\
\hline 0.005 & 400 & 53.99 & 57.70 & 56.46 & 51.49 & 45.17 & 119.64 & 126.87 & 120.36 & 107.58 & 93.59 & 217.58 & 212.23 & 176.30 & 150.08 & 128.60 \\
\hline 0.03 & 400 & 20.24 & 22.33 & 22.75 & 21.29 & 19.16 & 45.25 & 49.77 & 49.26 & 45.12 & 40.16 & 90.59 & 93.08 & 80.34 & 69.63 & 60.66 \\
\hline 0.3 & 400 & 3.68 & 4.32 & 4.87 & 4.94 & 4.80 & 8.41 & 9.94 & 10.98 & 10.94 & 10.55 & 20.40 & 23.35 & 23.09 & 21.88 & 20.60 \\
\hline 0.005 & 900 & $\# N / A$ & 83.65 & 82.37 & 75.41 & 66.33 & $\# \mathrm{~N} / \mathrm{A}$ & 162.50 & 156.06 & 140.18 & 122.27 & $\# N / A$ & 247.98 & 212.71 & 182.15 & 156.46 \\
\hline 0.03 & 900 & $\# \mathrm{~N} / \mathrm{A}$ & 32.42 & 33.20 & 31.18 & 28.12 & $\# \mathrm{~N} / \mathrm{A}$ & 64.07 & 64.14 & 59.07 & 52.74 & $\# \mathrm{~N} / \mathrm{A}$ & 108.25 & 96.87 & 84.70 & 74.08 \\
\hline 0.3 & 900 & $\#$ N/A & 6.33 & 7.15 & 7.27 & 7.09 & $\# N / A$ & 12.96 & 14.43 & 14.45 & 13.97 & $\# N / A$ & 27.86 & 28.34 & 27.08 & 25.63 \\
\hline 0.005 & 2500 & $\# N / A$ & 140.57 & 141.93 & 131.17 & 115.89 & $\# \mathrm{~N} / \mathrm{A}$ & 222.19 & 222.49 & 203.06 & 178.20 & $\# N / A$ & 291.08 & 273.87 & 237.70 & 204.86 \\
\hline 0.03 & 2500 & $\# \mathrm{~N} / \mathrm{A}$ & 54.53 & 56.92 & 54.07 & 49.02 & $\# \mathrm{~N} / \mathrm{A}$ & 87.86 & 91.05 & 85.45 & 76.94 & $\# N / A$ & 126.09 & 122.81 & 109.62 & 96.72 \\
\hline 0.3 & 2500 & \#N/A & 10.73 & 12.25 & 12.59 & 12.34 & $\# N / A$ & 18.07 & 20.55 & 20.92 & 20.39 & $\# N / A$ & 33.71 & 36.38 & 35.40 & 33.84 \\
\hline
\end{tabular}


Set 2: Water Saturation of 0.3 (continued)

\begin{tabular}{|c|c|c|c|c|c|c|c|c|c|c|c|c|c|c|c|c|}
\hline \multicolumn{2}{|c|}{ Category 4} & \multicolumn{5}{|c|}{ RSP0.1 } & \multicolumn{5}{|c|}{ RSP1 } & \multicolumn{5}{|c|}{ RSP10 } \\
\hline$q$ & SA & $d=10$ & $d=25$ & $d=50$ & $d=75$ & $d=100$ & $d=10$ & $d=25$ & $d=50$ & $d=75$ & $d=100$ & $d=10$ & $d=25$ & $d=50$ & $d=75$ & $d=100$ \\
\hline 0.005 & 100 & 74.21 & 38.37 & 24.47 & 19.49 & 16.53 & 102.96 & 53.20 & 33.90 & 27.00 & 22.90 & 118.22 & 60.73 & 38.57 & 30.70 & 26.04 \\
\hline 0.03 & 100 & 33.51 & 19.83 & 11.87 & 9.11 & 7.56 & 46.74 & 27.67 & 16.54 & 12.70 & 10.54 & 53.85 & 31.84 & 19.00 & 14.57 & 12.08 \\
\hline 0.3 & 100 & 7.73 & 6.14 & 4.68 & 3.92 & 3.40 & 10.95 & 8.71 & 6.62 & 5.55 & 4.81 & 12.80 & 10.18 & 7.74 & 6.49 & 5.62 \\
\hline 0.005 & 400 & 151.19 & 84.35 & 51.80 & 41.28 & 35.03 & 170.93 & 96.59 & 58.94 & 46.92 & 39.82 & 181.51 & 100.98 & 61.61 & 49.03 & 41.60 \\
\hline 0.03 & 400 & 65.35 & 42.90 & 25.10 & 19.28 & 16.00 & 73.84 & 49.31 & 28.77 & 22.08 & 18.31 & 78.20 & 51.91 & 30.33 & 23.27 & 19.30 \\
\hline 0.3 & 400 & 14.87 & 13.04 & 9.88 & 8.29 & 7.19 & 17.12 & 15.23 & 11.53 & 9.68 & 8.38 & 18.41 & 16.35 & 12.39 & 10.40 & 9.02 \\
\hline 0.005 & 900 & $\# N / A$ & 129.41 & 75.73 & 60.01 & 50.82 & $\# N / A$ & 142.70 & 82.58 & 65.32 & 55.29 & $\# N / A$ & 147.51 & 85.34 & 67.46 & 57.08 \\
\hline 0.03 & 900 & $\# N / A$ & 64.00 & 36.79 & 28.07 & 23.22 & $\# N / A$ & 70.58 & 40.39 & 30.77 & 25.43 & $\# N / A$ & 73.36 & 42.04 & 32.01 & 26.46 \\
\hline 0.3 & 900 & $\# N / A$ & 18.95 & 14.33 & 12.02 & 10.41 & $\# N / A$ & 21.20 & 16.02 & 13.42 & 11.62 & \#N/A & 22.45 & 16.98 & 14.24 & 12.33 \\
\hline 0.005 & 2500 & $\# N / A$ & 232.61 & 128.32 & 98.36 & 82.32 & $\# N / A$ & 248.07 & 136.37 & 104.03 & 86.91 & $\# N / A$ & 257.41 & 139.54 & 106.29 & 88.75 \\
\hline 0.03 & 2500 & $\# N / A$ & 105.77 & 62.61 & 46.31 & 37.71 & $\# N / A$ & 112.00 & 66.85 & 49.25 & 40.04 & $\# N / A$ & 115.60 & 68.78 & 50.64 & 41.15 \\
\hline 0.3 & 2500 & $\# N / A$ & 29.37 & 23.36 & 19.42 & 16.75 & $\# N / A$ & 31.51 & 25.29 & 21.00 & 18.09 & \#N/A & 32.93 & 26.45 & 21.97 & 18.94 \\
\hline
\end{tabular}

\begin{tabular}{|c|c|c|c|c|c|c|c|c|c|c|c|c|c|c|c|c|}
\hline \multicolumn{2}{|c|}{ Category 5} & \multicolumn{5}{|c|}{ RSP0.1 } & \multicolumn{5}{|c|}{ RSP1 } & \multicolumn{5}{|c|}{ RSP10 } \\
\hline$q$ & SA & $d=10$ & $d=25$ & $\mathrm{~d}=50$ & $d=75$ & $d=100$ & $d=10$ & $d=25$ & $d=50$ & $d=75$ & $d=100$ & $d=10$ & $d=25$ & $d=50$ & $d=75$ & $d=100$ \\
\hline 0.005 & 100 & 63.89 & 57.48 & 40.86 & 31.39 & 25.75 & 121.24 & 103.86 & 72.59 & 55.91 & 46.01 & 164.30 & 125.72 & 85.75 & 66.45 & 55.02 \\
\hline 0.03 & 100 & 26.33 & 25.47 & 18.91 & 14.63 & 11.92 & 50.74 & 47.08 & 34.20 & 26.45 & 21.59 & 71.60 & 59.96 & 41.87 & 32.38 & 26.52 \\
\hline 0.3 & 100 & 5.56 & 6.23 & 5.68 & 5.01 & 4.48 & 11.04 & 11.99 & 10.74 & 9.46 & 8.45 & 16.80 & 16.85 & 14.56 & 12.75 & 11.36 \\
\hline 0.005 & 400 & 111.71 & 104.38 & 74.34 & 57.36 & 47.04 & 173.11 & 158.17 & 110.82 & 85.62 & 70.38 & 204.67 & 176.28 & 119.97 & 93.02 & 76.83 \\
\hline 0.03 & 400 & 46.22 & 46.13 & 34.51 & 26.79 & 21.83 & 72.88 & 71.42 & 52.48 & 40.73 & 33.24 & 88.63 & 82.78 & 58.69 & 45.54 & 37.28 \\
\hline 0.3 & 400 & 9.93 & 11.35 & 10.46 & 9.25 & 8.27 & 16.33 & 18.45 & 16.76 & 14.81 & 13.23 & 21.53 & 23.48 & 20.69 & 18.22 & 16.26 \\
\hline 0.005 & 900 & $\# N / A$ & 150.97 & 111.14 & 85.56 & 69.93 & $\# N / A$ & 202.11 & 147.08 & 113.25 & 92.66 & $\# N / A$ & 218.61 & 152.94 & 117.96 & 96.91 \\
\hline 0.03 & 900 & $\# N / A$ & 66.24 & 51.40 & 39.97 & 32.51 & $\# \mathrm{~N} / \mathrm{A}$ & 90.23 & 69.32 & 53.92 & 43.91 & $\# N / A$ & 100.52 & 74.22 & 57.66 & 47.08 \\
\hline 0.3 & 900 & $\# N / A$ & 16.33 & 15.47 & 13.73 & 12.29 & $\# N / A$ & 23.44 & 22.02 & 19.56 & 17.51 & $\# N / A$ & 28.57 & 25.98 & 22.99 & 20.57 \\
\hline 0.005 & 2500 & $\# N / A$ & 219.94 & 181.69 & 139.20 & 112.32 & $\# N / A$ & 257.10 & 213.06 & 162.79 & 131.30 & $\# N / A$ & 274.79 & 217.85 & 165.57 & 133.94 \\
\hline 0.03 & 2500 & $\# N / A$ & 95.38 & 82.45 & 64.67 & 52.30 & $\# N / A$ & 113.03 & 98.23 & 76.95 & 62.26 & $\# N / A$ & 122.69 & 103.00 & 80.08 & 64.87 \\
\hline 0.3 & 2500 & $\# \mathrm{~N} / \mathrm{A}$ & 23.62 & 24.06 & 21.66 & 19.45 & $\# \mathrm{~N} / \mathrm{A}$ & 29.84 & 30.43 & 27.37 & 24.59 & \#N/A & 35.28 & 35.00 & 31.25 & 28.03 \\
\hline
\end{tabular}

\begin{tabular}{|c|c|c|c|c|c|c|c|c|c|c|c|c|c|c|c|c|}
\hline \multicolumn{2}{|c|}{ Category 6} & \multicolumn{5}{|c|}{ RSP0.1 } & \multicolumn{5}{|c|}{ RSP1 } & \multicolumn{5}{|c|}{ RSP10 } \\
\hline$q$ & SA & $d=10$ & $d=25$ & $d=50$ & $d=75$ & $d=100$ & $d=10$ & $d=25$ & $d=50$ & $d=75$ & $d=100$ & $d=10$ & $d=25$ & $d=50$ & $d=75$ & $d=100$ \\
\hline 0.005 & 100 & 65.29 & 69.61 & 68.46 & 62.43 & 55.02 & 111.24 & 117.46 & 111.95 & 100.10 & 87.49 & 206.30 & 199.27 & 173.94 & 151.05 & 131.09 \\
\hline 0.03 & 100 & 24.59 & 27.06 & 27.61 & 25.87 & 23.39 & 42.14 & 46.16 & 45.72 & 41.98 & 37.58 & 85.29 & 86.21 & 77.30 & 68.42 & 60.48 \\
\hline 0.3 & 100 & 4.50 & 5.28 & 5.93 & 6.02 & 5.88 & 7.80 & 9.19 & 10.11 & 10.08 & 9.75 & 18.84 & 21.01 & 21.10 & 20.24 & 19.23 \\
\hline 0.005 & 400 & 93.08 & 99.36 & 97.51 & 89.52 & 79.07 & 146.18 & 154.92 & 147.70 & 133.11 & 116.68 & 237.69 & 239.81 & 210.67 & 184.25 & 160.07 \\
\hline 0.03 & 400 & 35.20 & 38.74 & 39.51 & 37.15 & 33.63 & 55.74 & 61.18 & 60.68 & 55.93 & 50.09 & 99.61 & 104.53 & 94.81 & 84.37 & 74.65 \\
\hline 0.3 & 400 & 6.51 & 7.63 & 8.59 & 8.72 & 8.52 & 10.55 & 12.44 & 13.72 & 13.70 & 13.24 & 23.25 & 26.74 & 27.18 & 26.16 & 24.88 \\
\hline 0.005 & 900 & $\# N / A$ & 131.04 & 129.62 & 119.63 & 106.06 & $\# \mathrm{~N} / \mathrm{A}$ & 190.49 & 184.12 & 166.87 & 146.65 & $\# N / A$ & 269.84 & 244.86 & 215.97 & 188.39 \\
\hline 0.03 & 900 & $\# \mathrm{~N} / \mathrm{A}$ & 51.20 & 52.57 & 49.67 & 45.09 & $\# \mathrm{~N} / \mathrm{A}$ & 75.77 & 76.14 & 70.62 & 63.48 & $\# \mathrm{~N} / \mathrm{A}$ & 117.35 & 110.14 & 99.04 & 88.06 \\
\hline 0.3 & 900 & $\#$ N/A & 10.19 & 11.51 & 11.74 & 11.49 & $\# N / A$ & 15.67 & 17.45 & 17.52 & 16.99 & $\# N / A$ & 30.90 & 32.22 & 31.29 & 29.91 \\
\hline 0.005 & 2500 & $\# N / A$ & 190.52 & 193.77 & 181.06 & 161.59 & $\# \mathrm{~N} / \mathrm{A}$ & 246.14 & 248.51 & 229.33 & 203.18 & $\# N / A$ & 305.81 & 301.00 & 270.68 & 237.85 \\
\hline 0.03 & 2500 & $\# \mathrm{~N} / \mathrm{A}$ & 74.66 & 78.33 & 75.08 & 68.69 & $\# \mathrm{~N} / \mathrm{A}$ & 98.35 & 102.47 & 97.02 & 88.09 & $\# N / A$ & 132.53 & 133.73 & 123.15 & 110.75 \\
\hline 0.3 & 2500 & \#N/A & 15.06 & 17.21 & 17.78 & 17.52 & $\# N / A$ & 20.82 & 23.71 & 24.23 & 23.71 & $\# N / A$ & 36.39 & 39.87 & 39.47 & 38.13 \\
\hline
\end{tabular}


Set 2: Water Saturation of 0.3 (continued)

\begin{tabular}{|c|c|c|c|c|c|c|c|c|c|c|c|c|c|c|c|c|}
\hline \multicolumn{2}{|c|}{ Category 7} & \multicolumn{5}{|c|}{ RSP0.1 } & \multicolumn{5}{|c|}{ RSP1 } & \multicolumn{5}{|c|}{ RSP10 } \\
\hline$q$ & SA & $d=10$ & $d=25$ & $d=50$ & $d=75$ & $d=100$ & $d=10$ & $d=25$ & $d=50$ & $d=75$ & $d=100$ & $d=10$ & $d=25$ & $d=50$ & $d=75$ & $d=100$ \\
\hline 0.005 & 100 & 97.36 & 50.28 & 32.00 & 25.49 & 21.61 & 113.53 & 59.07 & 37.49 & 29.85 & 25.31 & 118.75 & 61.59 & 39.14 & 31.18 & 26.45 \\
\hline 0.03 & 100 & 43.92 & 26.07 & 15.58 & 11.96 & 9.92 & 51.38 & 30.73 & 18.36 & 14.09 & 11.69 & 54.13 & 32.23 & 19.26 & 14.78 & 12.26 \\
\hline 0.3 & 100 & 10.19 & 8.13 & 6.19 & 5.19 & 4.50 & 12.07 & 9.69 & 7.38 & 6.19 & 5.36 & 12.88 & 10.29 & 7.84 & 6.58 & 5.69 \\
\hline 0.005 & 400 & 166.52 & 94.72 & 57.76 & 45.99 & 39.02 & 176.88 & 102.39 & 62.07 & 49.36 & 41.86 & 182.39 & 104.15 & 63.20 & 50.26 & 42.63 \\
\hline 0.03 & 400 & 71.88 & 48.22 & 28.14 & 21.59 & 17.91 & 76.38 & 52.19 & 30.42 & 23.32 & 19.33 & 78.65 & 53.35 & 31.10 & 23.84 & 19.77 \\
\hline 0.3 & 400 & 16.54 & 14.76 & 11.18 & 9.39 & 8.13 & 17.84 & 16.14 & 12.23 & 10.27 & 8.90 & 18.55 & 16.71 & 12.66 & 10.63 & 9.21 \\
\hline 0.005 & 900 & $\# N / A$ & 140.82 & 81.46 & 64.44 & 54.54 & $\# N / A$ & 149.54 & 85.92 & 67.84 & 57.37 & $\# N / A$ & 151.49 & 87.04 & 68.73 & 58.13 \\
\hline 0.03 & 900 & $\# N / A$ & 69.46 & 39.76 & 30.29 & 25.03 & $\# N / A$ & 73.67 & 42.16 & 32.07 & 26.48 & $\# N / A$ & 74.96 & 42.87 & 32.61 & 26.93 \\
\hline 0.3 & 900 & $\# N / A$ & 20.68 & 15.64 & 13.11 & 11.35 & $\# N / A$ & 22.14 & 16.77 & 14.06 & 12.18 & $\# N / A$ & 22.81 & 17.26 & 14.47 & 12.53 \\
\hline 0.005 & 2500 & $\# N / A$ & 244.43 & 135.13 & 103.11 & 86.16 & $\# N / A$ & 253.03 & 140.55 & 106.78 & 89.09 & $\# N / A$ & 257.91 & 141.77 & 107.69 & 89.85 \\
\hline 0.03 & 2500 & $\# N / A$ & 110.45 & 66.13 & 48.74 & 39.62 & $\# \mathrm{~N} / \mathrm{A}$ & 113.92 & 69.00 & 50.72 & 41.17 & $\# \mathrm{~N} / \mathrm{A}$ & 115.82 & 69.82 & 51.31 & 41.65 \\
\hline 0.3 & 2500 & $\# N / A$ & 30.88 & 24.83 & 20.62 & 17.78 & $\# N / A$ & 32.20 & 26.13 & 21.70 & 18.71 & \#N/A & 33.01 & 26.74 & 22.20 & 19.14 \\
\hline
\end{tabular}

\begin{tabular}{|c|c|c|c|c|c|c|c|c|c|c|c|c|c|c|c|c|}
\hline \multicolumn{2}{|c|}{ Category 8} & \multicolumn{5}{|c|}{ RSP0.1 } & \multicolumn{5}{|c|}{ RSP1 } & \multicolumn{5}{|c|}{ RSP10 } \\
\hline$q$ & SA & $d=10$ & $d=25$ & $d=50$ & $d=75$ & $d=100$ & $d=10$ & $d=25$ & $d=50$ & $d=75$ & $d=100$ & $d=10$ & $d=25$ & $d=50$ & $d=75$ & $d=100$ \\
\hline 0.005 & 100 & 96.32 & 84.77 & 58.84 & 45.03 & 37.03 & 134.76 & 115.06 & 79.80 & 61.34 & 50.50 & 175.61 & 142.13 & 99.89 & 77.59 & 64.03 \\
\hline 0.03 & 100 & 39.54 & 37.72 & 27.48 & 21.16 & 17.25 & 56.19 & 52.13 & 37.72 & 29.13 & 23.77 & 76.49 & 66.96 & 48.29 & 37.58 & 30.79 \\
\hline 0.3 & 100 & 8.27 & 9.19 & 8.29 & 7.31 & 6.53 & 12.13 & 13.19 & 11.80 & 10.40 & 9.30 & 18.19 & 18.77 & 16.55 & 14.58 & 13.02 \\
\hline 0.005 & 400 & 147.44 & 136.83 & 95.47 & 73.29 & 60.19 & 182.64 & 168.04 & 117.17 & 90.27 & 74.19 & 211.40 & 190.60 & 134.34 & 104.57 & 86.09 \\
\hline 0.03 & 400 & 60.84 & 60.63 & 44.71 & 34.55 & 28.15 & 76.59 & 75.66 & 55.59 & 43.07 & 35.13 & 91.82 & 88.61 & 65.05 & 50.85 & 41.63 \\
\hline 0.3 & 400 & 13.00 & 14.88 & 13.63 & 12.04 & 10.77 & 17.03 & 19.36 & 17.63 & 15.59 & 13.95 & 22.66 & 25.13 & 22.63 & 20.04 & 17.93 \\
\hline 0.005 & 900 & $\# N / A$ & 182.57 & 132.54 & 101.35 & 82.84 & $\# N / A$ & 210.09 & 152.71 & 117.16 & 95.78 & \#N/A & 230.28 & 168.13 & 130.49 & 106.92 \\
\hline 0.03 & 900 & $\# N / A$ & 80.11 & 61.75 & 47.79 & 38.85 & $\# N / A$ & 93.39 & 72.01 & 55.90 & 45.49 & \#N/A & 105.16 & 80.76 & 63.33 & 51.76 \\
\hline 0.3 & 900 & $\# N / A$ & 19.71 & 18.65 & 16.55 & 14.82 & $\# N / A$ & 24.02 & 22.67 & 20.15 & 18.06 & $\# N / A$ & 29.99 & 27.92 & 24.88 & 22.33 \\
\hline 0.005 & 2500 & $\# N / A$ & 242.03 & 200.10 & 151.75 & 122.15 & $\# N / A$ & 261.74 & 218.29 & 166.01 & 133.64 & $\# N / A$ & 279.91 & 233.03 & 179.48 & 145.09 \\
\hline 0.03 & 2500 & \#N/A & 104.82 & 91.17 & 71.05 & 57.35 & $\# N / A$ & 114.58 & 100.46 & 78.53 & 63.45 & $\# N / A$ & 124.94 & 109.17 & 86.16 & 70.01 \\
\hline 0.3 & 2500 & $\# N / A$ & 26.08 & 26.74 & 24.03 & 21.58 & $\# N / A$ & 29.99 & 30.82 & 27.73 & 24.91 & $\# N / A$ & 36.26 & 36.78 & 33.16 & 29.86 \\
\hline
\end{tabular}

\begin{tabular}{|c|c|c|c|c|c|c|c|c|c|c|c|c|c|c|c|c|}
\hline \multicolumn{2}{|c|}{ Category 9} & \multicolumn{5}{|c|}{ RSP0.1 } & \multicolumn{5}{|c|}{ RSP1 } & \multicolumn{5}{|c|}{ RSP10 } \\
\hline$q$ & SA & $d=10$ & $d=25$ & $d=50$ & $d=75$ & $d=100$ & $d=10$ & $d=25$ & $d=50$ & $d=75$ & $d=100$ & $d=10$ & $d=25$ & $d=50$ & $d=75$ & $d=100$ \\
\hline 0.005 & 100 & 96.87 & 102.82 & 98.33 & 87.43 & 75.85 & 139.50 & 146.09 & 136.37 & 120.11 & 103.95 & 217.95 & 210.95 & 185.81 & 161.89 & 140.52 \\
\hline 0.03 & 100 & 36.20 & 39.89 & 39.78 & 36.44 & 32.44 & 52.96 & 57.79 & 56.22 & 50.94 & 45.18 & 91.72 & 92.35 & 83.24 & 73.74 & 65.03 \\
\hline 0.3 & 100 & 6.56 & 7.76 & 8.60 & 8.59 & 8.30 & 9.87 & 11.65 & 12.65 & 12.51 & 12.04 & 21.26 & 23.48 & 23.64 & 22.70 & 21.53 \\
\hline 0.005 & 400 & 130.16 & 138.55 & 132.46 & 118.69 & 103.18 & 174.87 & 184.40 & 172.31 & 152.84 & 132.43 & 245.51 & 248.41 & 220.30 & 193.36 & 168.02 \\
\hline 0.03 & 400 & 48.97 & 54.03 & 53.95 & 49.62 & 44.22 & 67.14 & 73.59 & 71.80 & 65.31 & 57.95 & 104.38 & 109.27 & 99.67 & 88.81 & 78.42 \\
\hline 0.3 & 400 & 9.02 & 10.67 & 11.86 & 11.87 & 11.46 & 12.86 & 15.21 & 16.59 & 16.43 & 15.80 & 25.47 & 29.05 & 29.57 & 28.50 & 27.07 \\
\hline 0.005 & 900 & $\# N / A$ & 174.05 & 168.61 & 152.10 & 132.71 & $\# N / A$ & 219.54 & 209.29 & 187.18 & 162.93 & $\# N / A$ & 276.89 & 253.47 & 224.50 & 195.93 \\
\hline 0.03 & 900 & $\# N / A$ & 68.17 & 68.87 & 63.77 & 57.04 & $\# \mathrm{~N} / \mathrm{A}$ & 88.00 & 87.46 & 80.21 & 71.49 & $\# \mathrm{~N} / \mathrm{A}$ & 121.45 & 114.49 & 103.11 & 91.52 \\
\hline 0.3 & 900 & $\# N / A$ & 13.65 & 15.29 & 15.38 & 14.90 & $\# N / A$ & 18.52 & 20.47 & 20.41 & 19.70 & $\# N / A$ & 33.22 & 34.60 & 33.64 & 32.11 \\
\hline 0.005 & 2500 & $\# N / A$ & 231.59 & 233.85 & 214.88 & 188.97 & $\# \mathrm{~N} / \mathrm{A}$ & 267.90 & 269.85 & 246.70 & 216.62 & $\# \mathrm{~N} / \mathrm{A}$ & 311.31 & 308.19 & 278.53 & 245.00 \\
\hline 0.03 & 2500 & $\# N / A$ & 91.04 & 95.11 & 89.92 & 81.24 & $\# N / A$ & 107.86 & 112.22 & 105.48 & 95.10 & $\# N / A$ & 136.09 & 137.53 & 126.89 & 113.92 \\
\hline 0.3 & 2500 & $\# N / A$ & 18.55 & 21.20 & 21.70 & 21.22 & $\# N / A$ & 23.30 & 26.52 & 26.97 & 26.30 & $\# N / A$ & 38.81 & 42.32 & 41.90 & 40.41 \\
\hline
\end{tabular}




\section{Set 3: Water Saturation of $\mathbf{0 . 5 5}$}

\begin{tabular}{|c|c|c|c|c|c|c|c|c|c|c|c|c|c|c|c|c|}
\hline \multicolumn{2}{|c|}{ Category 1} & \multicolumn{5}{|c|}{ RSP0.1 } & \multicolumn{5}{|c|}{ RSP1 } & \multicolumn{5}{|c|}{ RSP10 } \\
\hline$q$ & SA & $d=10$ & $d=25$ & $d=50$ & $d=75$ & $d=100$ & $d=10$ & $d=25$ & $d=50$ & $d=75$ & $d=100$ & $d=10$ & $d=25$ & $d=50$ & $d=75$ & $d=100$ \\
\hline 0.005 & 100 & 55.31 & 29.68 & 18.91 & 15.02 & 12.71 & 99.46 & 53.36 & 33.96 & 26.99 & 22.84 & 109.75 & 58.86 & 37.75 & 30.05 & 25.46 \\
\hline 0.03 & 100 & 23.74 & 14.94 & 9.24 & 7.11 & 5.89 & 43.97 & 27.73 & 17.15 & 13.20 & 10.93 & 51.53 & 32.18 & 19.97 & 15.39 & 12.76 \\
\hline 0.3 & 100 & 4.91 & 4.07 & 3.25 & 2.79 & 2.46 & 9.65 & 8.03 & 6.41 & 5.50 & 4.85 & 12.62 & 10.37 & 8.28 & 7.11 & 6.26 \\
\hline 0.005 & 400 & 134.73 & 77.55 & 47.84 & 38.03 & 32.22 & 167.61 & 98.71 & 60.50 & 48.06 & 40.71 & 181.19 & 101.62 & 62.80 & 49.94 & 42.32 \\
\hline 0.03 & 400 & 55.40 & 38.30 & 23.38 & 18.02 & 14.92 & 71.01 & 50.28 & 30.73 & 23.68 & 19.61 & 79.20 & 54.10 & 33.24 & 25.66 & 21.27 \\
\hline 0.3 & 400 & 11.18 & 10.15 & 8.12 & 7.00 & 6.18 & 15.59 & 14.41 & 11.54 & 9.96 & 8.81 & 19.27 & 17.32 & 13.90 & 12.00 & 10.62 \\
\hline 0.005 & 900 & $\# N / A$ & 122.89 & 73.01 & 57.73 & 48.81 & $\# N / A$ & 144.68 & 84.95 & 67.06 & 56.67 & $\# N / A$ & 147.18 & 87.12 & 68.86 & 58.22 \\
\hline 0.03 & 900 & $\# N / A$ & 58.89 & 35.70 & 27.40 & 22.63 & $\# N / A$ & 70.94 & 42.95 & 32.94 & 27.21 & $\# N / A$ & 75.04 & 45.65 & 35.09 & 29.02 \\
\hline 0.3 & 900 & \#N/A & 15.23 & 12.21 & 10.54 & 9.32 & $\# N / A$ & 19.98 & 16.02 & 13.83 & 12.24 & $\# N / A$ & 23.56 & 18.91 & 16.34 & 14.46 \\
\hline 0.005 & 2500 & $\# N / A$ & 221.47 & 125.86 & 96.50 & 80.64 & $\# N / A$ & 245.50 & 139.49 & 106.33 & 88.69 & $\# N / A$ & 257.44 & 141.78 & 108.39 & 90.49 \\
\hline 0.03 & 2500 & $\# N / A$ & 97.93 & 61.25 & 45.92 & 37.46 & $\# \mathrm{~N} / \mathrm{A}$ & 109.80 & 69.63 & 52.10 & 42.45 & $\# \mathrm{~N} / \mathrm{A}$ & 116.75 & 72.66 & 54.54 & 44.53 \\
\hline 0.3 & 2500 & $\# N / A$ & 24.13 & 20.16 & 17.30 & 15.26 & $\# N / A$ & 29.53 & 24.94 & 21.41 & 18.89 & \#N/A & 34.41 & 28.70 & 24.67 & 21.78 \\
\hline
\end{tabular}

\begin{tabular}{|c|c|c|c|c|c|c|c|c|c|c|c|c|c|c|c|c|}
\hline \multicolumn{2}{|c|}{ Category 2} & \multicolumn{5}{|c|}{ RSP0.1 } & \multicolumn{5}{|c|}{ RSP1 } & \multicolumn{5}{|c|}{ RSP10 } \\
\hline$q$ & SA & $d=10$ & $d=25$ & $d=50$ & $d=75$ & $d=100$ & $d=10$ & $d=25$ & $d=50$ & $d=75$ & $d=100$ & $d=10$ & $d=25$ & $d=50$ & $d=75$ & $d=100$ \\
\hline 0.005 & 100 & 33.27 & 31.43 & 23.51 & 18.59 & 15.46 & 91.09 & 82.56 & 60.92 & 48.25 & 40.21 & 144.75 & 109.99 & 78.04 & 62.10 & 52.05 \\
\hline 0.03 & 100 & 10.89 & 11.39 & 9.43 & 7.86 & 6.74 & 31.08 & 31.35 & 25.49 & 21.22 & 18.19 & 59.73 & 50.82 & 38.78 & 31.98 & 27.33 \\
\hline 0.3 & 100 & 1.62 & 1.89 & 1.84 & 1.73 & 1.63 & 4.85 & 5.51 & 5.28 & 4.94 & 4.66 & 12.31 & 12.07 & 10.94 & 10.10 & 9.43 \\
\hline 0.005 & 400 & 71.22 & 69.33 & 52.05 & 41.33 & 34.38 & 141.12 & 134.88 & 100.11 & 79.60 & 66.33 & 191.55 & 162.44 & 115.58 & 92.34 & 77.40 \\
\hline 0.03 & 400 & 23.44 & 25.15 & 20.96 & 17.52 & 15.02 & 48.97 & 51.72 & 42.58 & 35.58 & 30.52 & 79.63 & 75.22 & 58.73 & 48.90 & 41.95 \\
\hline 0.3 & 400 & 3.51 & 4.19 & 4.12 & 3.87 & 3.65 & 7.84 & 9.28 & 9.01 & 8.47 & 7.99 & 17.44 & 18.77 & 17.41 & 16.27 & 15.31 \\
\hline 0.005 & 900 & $\# \mathrm{~N} / \mathrm{A}$ & 112.08 & 86.66 & 68.79 & 57.12 & $\# \mathrm{~N} / \mathrm{A}$ & 178.26 & 137.35 & 109.27 & 90.88 & \#N/A & 204.74 & 149.13 & 119.19 & 99.77 \\
\hline 0.03 & 900 & $\# N / A$ & 40.39 & 34.69 & 29.09 & 24.96 & $\# N / A$ & 68.05 & 58.26 & 48.99 & 42.11 & $\# N / A$ & 92.87 & 74.87 & 62.89 & 54.19 \\
\hline 0.3 & 900 & $\# N / A$ & 6.70 & 6.73 & 6.36 & 6.01 & $\# \mathrm{~N} / \mathrm{A}$ & 12.28 & 12.29 & 11.62 & 11.00 & $\# N / A$ & 23.90 & 22.62 & 21.30 & 20.16 \\
\hline 0.005 & 2500 & $\# N / A$ & 181.57 & 155.75 & 124.14 & 102.50 & $\# \mathrm{~N} / \mathrm{A}$ & 232.88 & 201.24 & 160.56 & 132.75 & $\# \mathrm{~N} / \mathrm{A}$ & 265.37 & 211.66 & 168.31 & 140.03 \\
\hline 0.03 & 2500 & $\# N / A$ & 64.25 & 60.36 & 51.38 & 44.26 & $\# \mathrm{~N} / \mathrm{A}$ & 88.36 & 83.35 & 71.04 & 61.30 & $\# \mathrm{~N} / \mathrm{A}$ & 116.37 & 101.75 & 86.13 & 74.51 \\
\hline 0.3 & 2500 & \#N/A & 10.52 & 11.28 & 10.78 & 10.24 & $\# N / A$ & 16.30 & 17.53 & 16.74 & 15.92 & $\# N / A$ & 31.23 & 31.33 & 29.66 & 28.18 \\
\hline
\end{tabular}

\begin{tabular}{|c|c|c|c|c|c|c|c|c|c|c|c|c|c|c|c|c|}
\hline \multicolumn{2}{|c|}{ Category 3} & \multicolumn{5}{|c|}{ RSP0.1 } & \multicolumn{5}{|c|}{ RSP1 } & \multicolumn{5}{|c|}{ RSP10 } \\
\hline$q$ & SA & $d=10$ & $d=25$ & $d=50$ & $d=75$ & $d=100$ & $d=10$ & $d=25$ & $d=50$ & $d=75$ & $d=100$ & $d=10$ & $d=25$ & $d=50$ & $d=75$ & $d=100$ \\
\hline 0.005 & 100 & 19.69 & 21.73 & 21.46 & 18.99 & 16.15 & 59.27 & 65.01 & 62.68 & 55.16 & 47.24 & 152.81 & 145.16 & 122.82 & 105.02 & 90.40 \\
\hline 0.03 & 100 & 5.66 & 6.60 & 7.08 & 6.76 & 6.21 & 17.00 & 19.82 & 20.81 & 19.77 & 18.26 & 53.31 & 54.50 & 49.19 & 44.44 & 40.38 \\
\hline 0.3 & 100 & 0.75 & 0.92 & 1.07 & 1.10 & 1.09 & 2.19 & 2.69 & 3.06 & 3.11 & 3.07 & 8.73 & 9.68 & 9.58 & 9.27 & 8.96 \\
\hline 0.005 & 400 & 33.68 & 37.18 & 36.65 & 32.58 & 27.70 & 87.70 & 96.57 & 93.80 & 83.59 & 72.07 & 193.88 & 194.95 & 166.98 & 144.22 & 124.67 \\
\hline 0.03 & 400 & 10.33 & 12.06 & 13.04 & 12.60 & 11.68 & 25.07 & 29.28 & 30.89 & 29.46 & 27.25 & 70.81 & 76.33 & 70.10 & 63.83 & 58.23 \\
\hline 0.3 & 400 & 1.33 & 1.63 & 1.90 & 1.96 & 1.94 & 3.27 & 4.02 & 4.59 & 4.67 & 4.62 & 12.43 & 14.55 & 14.65 & 14.27 & 13.86 \\
\hline 0.005 & 900 & $\# N / A$ & 56.64 & 56.52 & 50.82 & 43.64 & $\# N / A$ & 127.08 & 125.58 & 113.04 & 98.14 & $\# N / A$ & 229.51 & 204.00 & 178.13 & 154.91 \\
\hline 0.03 & 900 & $\# \mathrm{~N} / \mathrm{A}$ & 17.27 & 18.67 & 18.00 & 16.62 & $\# N / A$ & 38.58 & 41.24 & 39.63 & 36.81 & \#N/A & 90.87 & 86.50 & 79.75 & 73.26 \\
\hline 0.3 & 900 & $\# N / A$ & 2.41 & 2.81 & 2.91 & 2.89 & $\# N / A$ & 5.33 & 6.14 & 6.29 & 6.24 & $\# N / A$ & 18.12 & 18.72 & 18.40 & 17.98 \\
\hline 0.005 & 2500 & $\# N / A$ & 95.84 & 98.26 & 89.73 & 77.53 & $\# N / A$ & 176.69 & 182.98 & 169.36 & 149.20 & $\# N / A$ & 270.34 & 262.15 & 234.12 & 206.06 \\
\hline 0.03 & 2500 & \#N/A & 29.70 & 32.74 & 32.11 & 29.94 & $\# N / A$ & 53.40 & 59.12 & 58.26 & 54.89 & $\# N / A$ & 108.18 & 110.34 & 103.99 & 96.92 \\
\hline 0.3 & 2500 & \#N/A & 4.13 & 4.88 & 5.12 & 5.12 & $\# N / A$ & 7.37 & 8.70 & 9.09 & 9.09 & $\# N / A$ & 23.05 & 25.23 & 25.10 & 24.72 \\
\hline
\end{tabular}


Set 3: Water Saturation of 0.55 (continued)

\begin{tabular}{|c|c|c|c|c|c|c|c|c|c|c|c|c|c|c|c|c|}
\hline \multicolumn{2}{|c|}{ Category 4} & \multicolumn{5}{|c|}{ RSP0.1 } & \multicolumn{5}{|c|}{ RSP1 } & \multicolumn{5}{|c|}{ RSP10 } \\
\hline$q$ & SA & $d=10$ & $d=25$ & $d=50$ & $d=75$ & $d=100$ & $d=10$ & $d=25$ & $d=50$ & $d=75$ & $d=100$ & $d=10$ & $d=25$ & $d=50$ & $d=75$ & $d=100$ \\
\hline 0.005 & 100 & 74.09 & 39.34 & 25.09 & 19.94 & 16.88 & 103.37 & 54.87 & 34.98 & 27.81 & 23.55 & 119.81 & 63.47 & 40.41 & 32.12 & 27.20 \\
\hline 0.03 & 100 & 31.97 & 19.99 & 12.35 & 9.50 & 7.87 & 46.03 & 28.72 & 17.72 & 13.63 & 11.29 & 55.35 & 34.55 & 21.34 & 16.42 & 13.60 \\
\hline 0.3 & 100 & 6.68 & 5.53 & 4.41 & 3.78 & 3.33 & 10.25 & 8.47 & 6.73 & 5.77 & 5.08 & 13.45 & 11.10 & 8.84 & 7.58 & 6.68 \\
\hline 0.005 & 400 & 149.57 & 86.27 & 53.11 & 42.23 & 35.78 & 170.28 & 99.28 & 60.88 & 48.39 & 41.00 & 182.61 & 104.81 & 64.43 & 51.22 & 43.39 \\
\hline 0.03 & 400 & 61.88 & 43.02 & 26.21 & 20.19 & 16.72 & 72.51 & 50.91 & 30.99 & 23.87 & 19.77 & 79.93 & 55.55 & 34.01 & 26.23 & 21.74 \\
\hline 0.3 & 400 & 12.74 & 11.64 & 9.29 & 8.01 & 7.07 & 16.16 & 14.85 & 11.85 & 10.20 & 9.01 & 19.54 & 17.76 & 14.22 & 12.27 & 10.84 \\
\hline 0.005 & 900 & $\# N / A$ & 131.48 & 77.63 & 61.38 & 51.91 & $\# N / A$ & 145.27 & 85.08 & 67.19 & 56.78 & $\# N / A$ & 151.17 & 88.81 & 70.14 & 59.28 \\
\hline 0.03 & 900 & $\# N / A$ & 63.43 & 38.26 & 29.35 & 24.24 & $\# N / A$ & 71.70 & 43.14 & 33.07 & 27.31 & $\# N / A$ & 76.65 & 46.42 & 35.64 & 29.46 \\
\hline 0.3 & 900 & $\# N / A$ & 16.80 & 13.43 & 11.58 & 10.23 & $\# N / A$ & 20.54 & 16.38 & 14.11 & 12.46 & \#N/A & 24.01 & 19.23 & 16.59 & 14.67 \\
\hline 0.005 & 2500 & $\# N / A$ & 231.63 & 130.87 & 100.20 & 83.70 & $\# N / A$ & 247.74 & 139.67 & 106.53 & 88.89 & $\# N / A$ & 258.40 & 143.94 & 109.76 & 91.57 \\
\hline 0.03 & 2500 & $\# N / A$ & 102.59 & 64.18 & 48.04 & 39.16 & $\# N / A$ & 111.04 & 69.88 & 52.21 & 42.54 & $\# N / A$ & 117.19 & 73.61 & 55.13 & 44.97 \\
\hline 0.3 & 2500 & $\# N / A$ & 25.89 & 21.66 & 18.57 & 16.37 & $\# N / A$ & 30.27 & 25.44 & 21.78 & 19.17 & \#N/A & 34.65 & 29.05 & 24.93 & 21.99 \\
\hline
\end{tabular}

\begin{tabular}{|c|c|c|c|c|c|c|c|c|c|c|c|c|c|c|c|c|}
\hline \multicolumn{2}{|c|}{ Category 5} & \multicolumn{5}{|c|}{ RSP0.1 } & \multicolumn{5}{|c|}{ RSP1 } & \multicolumn{5}{|c|}{ RSP10 } \\
\hline$q$ & SA & $d=10$ & $d=25$ & $\mathrm{~d}=50$ & $d=75$ & $d=100$ & $d=10$ & $d=25$ & $d=50$ & $d=75$ & $d=100$ & $d=10$ & $d=25$ & $d=50$ & $d=75$ & $d=100$ \\
\hline 0.005 & 100 & 59.18 & 55.66 & 41.81 & 33.12 & 27.53 & 113.09 & 101.37 & 74.91 & 59.43 & 49.53 & 160.93 & 128.32 & 92.15 & 73.23 & 61.26 \\
\hline 0.03 & 100 & 20.00 & 20.73 & 17.07 & 14.22 & 12.17 & 40.32 & 40.01 & 32.28 & 26.84 & 22.98 & 67.23 & 59.22 & 45.69 & 37.70 & 32.19 \\
\hline 0.3 & 100 & 3.07 & 3.57 & 3.45 & 3.23 & 3.05 & 6.65 & 7.46 & 7.08 & 6.61 & 6.22 & 14.46 & 14.50 & 13.22 & 12.22 & 11.40 \\
\hline 0.005 & 400 & 104.42 & 102.03 & 77.36 & 61.78 & 51.54 & 162.49 & 155.07 & 115.49 & 92.03 & 76.70 & 200.53 & 179.04 & 129.44 & 103.28 & 86.36 \\
\hline 0.03 & 400 & 35.58 & 38.06 & 31.70 & 26.49 & 22.69 & 59.28 & 62.08 & 50.86 & 42.48 & 36.41 & 84.65 & 82.51 & 65.23 & 54.32 & 46.54 \\
\hline 0.3 & 400 & 5.55 & 6.63 & 6.50 & 6.10 & 5.74 & 10.17 & 11.96 & 11.54 & 10.82 & 10.20 & 19.45 & 21.28 & 19.87 & 18.56 & 17.45 \\
\hline 0.005 & 900 & $\# N / A$ & 146.22 & 114.50 & 91.19 & 75.69 & $\# N / A$ & 196.83 & 152.57 & 121.72 & 101.25 & $\# N / A$ & 219.26 & 163.53 & 130.57 & 108.99 \\
\hline 0.03 & 900 & $\# N / A$ & 54.48 & 47.02 & 39.47 & 33.84 & $\# \mathrm{~N} / \mathrm{A}$ & 78.59 & 67.12 & 56.46 & 48.52 & $\# N / A$ & 99.17 & 81.29 & 68.27 & 58.72 \\
\hline 0.3 & 900 & $\# N / A$ & 9.50 & 9.57 & 9.02 & 8.53 & $\# N / A$ & 15.39 & 15.32 & 14.46 & 13.68 & $\# N / A$ & 26.41 & 25.23 & 23.74 & 22.45 \\
\hline 0.005 & 2500 & $\# N / A$ & 209.31 & 182.87 & 146.54 & 121.02 & $\# N / A$ & 250.24 & 218.00 & 174.64 & 144.55 & $\# N / A$ & 271.95 & 226.53 & 180.40 & 149.62 \\
\hline 0.03 & 2500 & $\# N / A$ & 77.20 & 73.23 & 62.47 & 53.80 & $\# N / A$ & 98.46 & 92.90 & 79.24 & 68.39 & $\# N / A$ & 120.04 & 107.94 & 91.47 & 78.98 \\
\hline 0.3 & 2500 & $\# \mathrm{~N} / \mathrm{A}$ & 13.49 & 14.57 & 13.92 & 13.22 & $\# \mathrm{~N} / \mathrm{A}$ & 19.95 & 21.38 & 20.39 & 19.38 & \#N/A & 33.55 & 34.08 & 32.28 & 30.65 \\
\hline
\end{tabular}

\begin{tabular}{|c|c|c|c|c|c|c|c|c|c|c|c|c|c|c|c|c|}
\hline \multicolumn{2}{|c|}{ Category 6} & \multicolumn{5}{|c|}{ RSP0.1 } & \multicolumn{5}{|c|}{ RSP1 } & \multicolumn{5}{|c|}{ RSP10 } \\
\hline$q$ & SA & $d=10$ & $d=25$ & $d=50$ & $d=75$ & $d=100$ & $d=10$ & $d=25$ & $d=50$ & $d=75$ & $d=100$ & $d=10$ & $d=25$ & $d=50$ & $d=75$ & $d=100$ \\
\hline 0.005 & 100 & 39.92 & 43.93 & 43.24 & 38.26 & 32.54 & 78.83 & 86.19 & 83.07 & 73.37 & 63.02 & 179.20 & 176.00 & 154.83 & 134.25 & 115.94 \\
\hline 0.03 & 100 & 11.74 & 13.66 & 14.59 & 13.93 & 12.80 & 22.71 & 26.39 & 27.54 & 26.09 & 24.05 & 65.32 & 67.80 & 62.93 & 57.57 & 52.60 \\
\hline 0.3 & 100 & 1.57 & 1.92 & 2.22 & 2.28 & 2.26 & 2.98 & 3.66 & 4.13 & 4.19 & 4.14 & 11.51 & 12.79 & 12.83 & 12.49 & 12.12 \\
\hline 0.005 & 400 & 60.44 & 66.61 & 65.75 & 58.75 & 50.19 & 109.11 & 119.92 & 116.66 & 104.44 & 90.37 & 212.27 & 219.05 & 195.94 & 172.06 & 149.44 \\
\hline 0.03 & 400 & 18.03 & 20.97 & 22.52 & 21.66 & 20.00 & 31.82 & 37.06 & 39.05 & 37.34 & 34.64 & 80.85 & 87.84 & 83.06 & 76.66 & 70.36 \\
\hline 0.3 & 400 & 2.40 & 2.92 & 3.39 & 3.50 & 3.48 & 4.21 & 5.17 & 5.88 & 5.99 & 5.93 & 15.39 & 18.00 & 18.35 & 17.98 & 17.52 \\
\hline 0.005 & 900 & $\# N / A$ & 91.43 & 91.42 & 82.59 & 71.17 & $\# \mathrm{~N} / \mathrm{A}$ & 151.13 & 149.81 & 135.54 & 118.05 & $\# N / A$ & 248.76 & 231.08 & 205.76 & 180.16 \\
\hline 0.03 & 900 & $\# \mathrm{~N} / \mathrm{A}$ & 28.53 & 30.88 & 29.88 & 27.69 & $\# \mathrm{~N} / \mathrm{A}$ & 46.82 & 50.05 & 48.21 & 44.86 & $\# \mathrm{~N} / \mathrm{A}$ & 100.96 & 98.77 & 92.40 & 85.49 \\
\hline 0.3 & 900 & $\#$ N/A & 4.00 & 4.67 & 4.84 & 4.82 & $\# N / A$ & 6.60 & 7.60 & 7.79 & 7.73 & $\# N / A$ & 21.80 & 22.77 & 22.52 & 22.07 \\
\hline 0.005 & 2500 & $\# N / A$ & 137.50 & 142.35 & 131.81 & 115.18 & $\# \mathrm{~N} / \mathrm{A}$ & 198.79 & 207.02 & 193.08 & 171.02 & $\# N / A$ & 283.74 & 285.05 & 261.05 & 232.13 \\
\hline 0.03 & 2500 & $\# \mathrm{~N} / \mathrm{A}$ & 42.74 & 47.35 & 46.84 & 43.98 & $\# \mathrm{~N} / \mathrm{A}$ & 61.58 & 68.30 & 67.58 & 63.88 & $\# N / A$ & 116.59 & 121.11 & 116.05 & 109.07 \\
\hline 0.3 & 2500 & \#N/A & 5.98 & 7.08 & 7.46 & 7.49 & $\# N / A$ & 8.73 & 10.32 & 10.79 & 10.82 & $\# N / A$ & 27.08 & 29.74 & 29.79 & 29.44 \\
\hline
\end{tabular}


Set 3: Water Saturation of 0.55 (continued)

\begin{tabular}{|c|c|c|c|c|c|c|c|c|c|c|c|c|c|c|c|c|}
\hline \multicolumn{2}{|c|}{ Category 7} & \multicolumn{5}{|c|}{ RSP0.1 } & \multicolumn{5}{|c|}{ RSP1 } & \multicolumn{5}{|c|}{ RSP10 } \\
\hline$q$ & SA & $d=10$ & $d=25$ & $d=50$ & $d=75$ & $d=100$ & $d=10$ & $d=25$ & $d=50$ & $d=75$ & $d=100$ & $d=10$ & $d=25$ & $d=50$ & $d=75$ & $d=100$ \\
\hline 0.005 & 100 & 97.51 & 51.81 & 32.98 & 26.21 & 22.19 & 114.30 & 61.27 & 38.95 & 30.95 & 26.21 & 120.39 & 64.38 & 41.01 & 32.61 & 27.62 \\
\hline 0.03 & 100 & 42.60 & 26.74 & 16.52 & 12.71 & 10.52 & 51.18 & 32.36 & 20.03 & 15.41 & 12.76 & 55.44 & 34.89 & 21.60 & 16.63 & 13.77 \\
\hline 0.3 & 100 & 9.17 & 7.62 & 6.07 & 5.22 & 4.59 & 11.63 & 9.70 & 7.74 & 6.65 & 5.86 & 13.38 & 11.10 & 8.86 & 7.61 & 6.70 \\
\hline 0.005 & 400 & 165.33 & 97.29 & 59.58 & 47.34 & 40.10 & 176.65 & 105.67 & 64.51 & 51.21 & 43.37 & 183.33 & 108.05 & 66.08 & 52.48 & 44.45 \\
\hline 0.03 & 400 & 69.46 & 49.23 & 30.00 & 23.10 & 19.13 & 75.86 & 54.48 & 33.29 & 25.65 & 21.24 & 80.14 & 56.89 & 34.78 & 26.81 & 22.20 \\
\hline 0.3 & 400 & 14.94 & 13.84 & 11.06 & 9.54 & 8.43 & 17.40 & 16.21 & 12.99 & 11.22 & 9.92 & 19.52 & 17.98 & 14.40 & 12.42 & 10.98 \\
\hline 0.005 & 900 & $\# N / A$ & 143.29 & 83.83 & 66.18 & 55.92 & $\# N / A$ & 152.59 & 88.98 & 70.16 & 59.25 & $\# N / A$ & 155.20 & 90.58 & 71.45 & 60.35 \\
\hline 0.03 & 900 & $\# N / A$ & 69.89 & 42.11 & 32.28 & 26.65 & $\# N / A$ & 75.47 & 45.65 & 35.00 & 28.90 & $\# N / A$ & 78.12 & 47.24 & 36.24 & 29.93 \\
\hline 0.3 & 900 & $\# N / A$ & 19.29 & 15.42 & 13.30 & 11.76 & $\# N / A$ & 22.05 & 17.69 & 15.27 & 13.51 & \#N/A & 24.20 & 19.39 & 16.73 & 14.79 \\
\hline 0.005 & 2500 & $\# N / A$ & 243.68 & 138.30 & 105.46 & 87.98 & $\# N / A$ & 252.97 & 144.48 & 109.82 & 91.52 & $\# N / A$ & 258.78 & 146.25 & 111.22 & 92.70 \\
\hline 0.03 & 2500 & $\# N / A$ & 108.49 & 68.68 & 51.33 & 41.81 & $\# N / A$ & 113.69 & 72.79 & 54.40 & 44.31 & $\# N / A$ & 117.24 & 74.62 & 55.79 & 45.47 \\
\hline 0.3 & 2500 & $\# N / A$ & 28.61 & 24.15 & 20.71 & 18.25 & $\# N / A$ & 31.79 & 27.01 & 23.18 & 20.45 & \#N/A & 34.53 & 29.19 & 25.05 & 22.09 \\
\hline
\end{tabular}

\begin{tabular}{|c|c|c|c|c|c|c|c|c|c|c|c|c|c|c|c|c|}
\hline \multicolumn{2}{|c|}{ Category 8} & \multicolumn{5}{|c|}{ RSP0.1 } & \multicolumn{5}{|c|}{ RSP1 } & \multicolumn{5}{|c|}{ RSP10 } \\
\hline$q$ & SA & $d=10$ & $d=25$ & $\mathrm{~d}=50$ & $d=75$ & $d=100$ & $d=10$ & $d=25$ & $d=50$ & $d=75$ & $d=100$ & $d=10$ & $d=25$ & $d=50$ & $d=75$ & $d=100$ \\
\hline 0.005 & 100 & 88.46 & 82.10 & 60.79 & 48.04 & 40.00 & 125.30 & 112.60 & 83.01 & 65.78 & 54.83 & 171.84 & 143.90 & 106.19 & 84.85 & 70.95 \\
\hline 0.03 & 100 & 29.64 & 30.54 & 25.02 & 20.84 & 17.87 & 44.20 & 44.11 & 35.75 & 29.76 & 25.51 & 72.04 & 65.65 & 51.78 & 43.06 & 36.91 \\
\hline 0.3 & 100 & 4.53 & 5.24 & 5.05 & 4.73 & 4.47 & 7.22 & 8.11 & 7.74 & 7.24 & 6.82 & 15.87 & 16.24 & 14.96 & 13.87 & 12.97 \\
\hline 0.005 & 400 & 135.90 & 132.82 & 99.43 & 78.91 & 65.70 & 170.46 & 164.54 & 122.71 & 97.62 & 81.33 & 207.27 & 192.39 & 143.41 & 115.17 & 96.29 \\
\hline 0.03 & 400 & 46.21 & 49.71 & 41.39 & 34.61 & 29.69 & 61.44 & 65.14 & 53.83 & 45.04 & 38.65 & 88.08 & 87.84 & 71.02 & 59.59 & 51.24 \\
\hline 0.3 & 400 & 7.22 & 8.65 & 8.47 & 7.97 & 7.53 & 10.39 & 12.30 & 11.96 & 11.25 & 10.62 & 20.79 & 22.99 & 21.69 & 20.31 & 19.13 \\
\hline 0.005 & 900 & $\# N / A$ & 175.57 & 137.03 & 108.79 & 90.34 & $\# N / A$ & 203.88 & 158.86 & 126.54 & 105.22 & $\# N / A$ & 230.15 & 178.00 & 143.29 & 119.68 \\
\hline 0.03 & 900 & $\# N / A$ & 65.41 & 56.77 & 47.77 & 41.06 & $\# \mathrm{~N} / \mathrm{A}$ & 80.38 & 69.38 & 58.48 & 50.33 & $\# \mathrm{~N} / \mathrm{A}$ & 103.54 & 87.09 & 73.74 & 63.68 \\
\hline 0.3 & 900 & $\# N / A$ & 11.42 & 11.55 & 10.92 & 10.35 & $\# N / A$ & 15.44 & 15.49 & 14.66 & 13.89 & $\# N / A$ & 28.06 & 27.15 & 25.64 & 24.28 \\
\hline 0.005 & 2500 & $\# N / A$ & 229.15 & 201.62 & 160.80 & 132.68 & $\# N / A$ & 251.07 & 221.42 & 177.05 & 146.30 & $\# N / A$ & 277.06 & 240.56 & 194.17 & 161.45 \\
\hline 0.03 & 2500 & $\# N / A$ & 84.95 & 81.47 & 69.54 & 59.98 & $\# N / A$ & 98.71 & 94.27 & 80.55 & 69.56 & $\# N / A$ & 122.55 & 113.29 & 97.09 & 84.27 \\
\hline 0.3 & 2500 & $\# \mathrm{~N} / \mathrm{A}$ & 15.10 & 16.43 & 15.71 & 14.95 & $\# \mathrm{~N} / \mathrm{A}$ & 19.66 & 21.25 & 20.30 & 19.32 & \#N/A & 35.01 & 36.01 & 34.28 & 32.63 \\
\hline
\end{tabular}

\begin{tabular}{|c|c|c|c|c|c|c|c|c|c|c|c|c|c|c|c|c|}
\hline \multicolumn{2}{|c|}{ Category 9} & \multicolumn{5}{|c|}{ RSP0.1 } & \multicolumn{5}{|c|}{ RSP1 } & \multicolumn{5}{|c|}{ RSP10 } \\
\hline$q$ & SA & $d=10$ & $d=25$ & $d=50$ & $d=75$ & $d=100$ & $d=10$ & $d=25$ & $d=50$ & $d=75$ & $d=100$ & $d=10$ & $d=25$ & $d=50$ & $d=75$ & $d=100$ \\
\hline 0.005 & 100 & 68.71 & 75.78 & 74.12 & 65.85 & 56.71 & 105.66 & 115.15 & 110.57 & 98.23 & 85.19 & 193.44 & 189.32 & 167.24 & 144.69 & 124.31 \\
\hline 0.03 & 100 & 19.27 & 22.54 & 23.91 & 22.85 & 21.17 & 30.04 & 34.82 & 36.09 & 34.30 & 31.83 & 74.82 & 76.41 & 70.79 & 64.46 & 58.47 \\
\hline 0.3 & 100 & 2.48 & 3.05 & 3.48 & 3.56 & 3.52 & 3.93 & 4.81 & 5.36 & 5.43 & 5.36 & 14.70 & 15.92 & 15.91 & 15.46 & 14.95 \\
\hline 0.005 & 400 & 97.16 & 107.56 & 106.07 & 95.47 & 82.80 & 139.22 & 153.36 & 149.88 & 136.00 & 119.70 & 222.98 & 229.52 & 206.35 & 180.96 & 156.43 \\
\hline 0.03 & 400 & 28.09 & 32.93 & 35.44 & 34.45 & 32.37 & 39.82 & 46.42 & 48.62 & 46.58 & 43.48 & 89.60 & 95.88 & 90.55 & 83.27 & 75.93 \\
\hline 0.3 & 400 & 3.54 & 4.35 & 5.00 & 5.12 & 5.08 & 5.30 & 6.52 & 7.33 & 7.44 & 7.35 & 19.21 & 21.90 & 22.23 & 21.77 & 21.16 \\
\hline 0.005 & 900 & $\# N / A$ & 138.22 & 138.74 & 126.40 & 110.52 & $\# \mathrm{~N} / \mathrm{A}$ & 183.18 & 182.25 & 166.36 & 146.62 & $\# N / A$ & 258.01 & 240.72 & 214.32 & 186.94 \\
\hline 0.03 & 900 & $\# \mathrm{~N} / \mathrm{A}$ & 41.29 & 44.69 & 43.39 & 40.58 & $\# \mathrm{~N} / \mathrm{A}$ & 56.29 & 60.06 & 58.01 & 54.31 & $\# \mathrm{~N} / \mathrm{A}$ & 108.69 & 105.99 & 98.86 & 90.91 \\
\hline 0.3 & 900 & $\#$ N/A & 5.64 & 6.55 & 6.75 & 6.72 & $\# N / A$ & 8.00 & 9.15 & 9.36 & 9.29 & $\# N / A$ & 26.33 & 27.25 & 26.93 & 26.35 \\
\hline 0.005 & 2500 & $\# N / A$ & 187.46 & 197.05 & 185.62 & 165.67 & $\# \mathrm{~N} / \mathrm{A}$ & 224.26 & 235.48 & 221.77 & 198.79 & $\# N / A$ & 293.01 & 294.31 & 269.77 & 239.06 \\
\hline 0.03 & 2500 & $\# \mathrm{~N} / \mathrm{A}$ & 55.53 & 62.07 & 61.89 & 58.78 & $\# \mathrm{~N} / \mathrm{A}$ & 69.64 & 77.47 & 76.94 & 73.19 & $\# N / A$ & 124.25 & 128.07 & 122.42 & 114.39 \\
\hline 0.3 & 2500 & \#N/A & 7.60 & 9.02 & 9.48 & 9.53 & $\# N / A$ & 10.04 & 11.85 & 12.38 & 12.41 & $\# N / A$ & 32.56 & 35.15 & 35.15 & 34.67 \\
\hline
\end{tabular}


Source Mass Discharge (g/d) for Categories Listed in Table C.2.

Set 1: Water Saturation of 0.05

\begin{tabular}{|r|r|r|r|r|}
\hline \multicolumn{2}{|l|}{ Category 1 } & & & \\
\hline \multicolumn{1}{|l|}{ q } & SA & RSP0.1 & RSP1 & RSP10 \\
\hline 0.005 & 100 & 89.68 & 13.92 & 8.48 \\
\hline 0.03 & 100 & 89.68 & 13.93 & 8.49 \\
\hline 0.3 & 100 & 89.69 & 13.98 & 8.57 \\
\hline & & & & \\
\hline 0.005 & 400 & 323.65 & 37.57 & 22.23 \\
\hline 0.03 & 400 & 323.66 & 37.59 & 22.26 \\
\hline 0.3 & 400 & 323.70 & 37.76 & 22.49 \\
\hline & & & & \\
\hline 0.005 & 900 & 702.21 & 72.65 & 42.48 \\
\hline 0.03 & 900 & 702.21 & 72.67 & 42.52 \\
\hline 0.3 & 900 & 702.30 & 72.99 & 42.95 \\
\hline & & & & \\
\hline 0.005 & 2500 & 1892.88 & 176.23 & 101.84 \\
\hline 0.03 & 2500 & 1892.88 & 176.27 & 101.90 \\
\hline 0.3 & 2500 & 1893.06 & 176.91 & 102.77 \\
\hline
\end{tabular}

\begin{tabular}{|r|r|r|r|r|}
\hline \multicolumn{2}{|l|}{ Category 4 } & & \\
\hline$q$ & SA & RSP0.1 & RSP1 & RSP10 \\
\hline 0.005 & 100 & 113.75 & 17.14 & 10.45 \\
\hline 0.03 & 100 & 113.75 & 17.15 & 10.47 \\
\hline 0.3 & 100 & 113.77 & 17.21 & 10.56 \\
\hline & & & & \\
\hline 0.005 & 400 & 406.87 & 47.29 & 27.00 \\
\hline 0.03 & 400 & 406.87 & 47.30 & 27.03 \\
\hline 0.3 & 400 & 406.96 & 47.49 & 27.27 \\
\hline & & & & \\
\hline 0.005 & 900 & 881.00 & 92.50 & 51.33 \\
\hline 0.03 & 900 & 881.01 & 92.52 & 51.37 \\
\hline 0.3 & 900 & 881.18 & 92.87 & 51.81 \\
\hline & & & & \\
\hline 0.005 & 2500 & 2371.64 & 227.13 & 122.47 \\
\hline 0.03 & 2500 & 2371.65 & 227.16 & 122.53 \\
\hline 0.3 & 2500 & 2371.98 & 227.86 & 123.41 \\
\hline
\end{tabular}

\begin{tabular}{|r|r|r|r|r|}
\hline \multicolumn{2}{|l|}{ Category 2 } & & \\
\hline \multicolumn{1}{|l|}{$\mathbf{q}$} & SA & RSP0.1 & RSP1 & RSP10 \\
\hline 0.005 & 100 & 23.18 & 11.36 & 6.24 \\
\hline 0.03 & 100 & 23.18 & 11.36 & 6.25 \\
\hline 0.3 & 100 & 23.18 & 11.36 & 6.32 \\
\hline & & & & \\
\hline 0.005 & 400 & 69.14 & 25.55 & 13.40 \\
\hline 0.03 & 400 & 69.14 & 25.55 & 13.42 \\
\hline 0.3 & 400 & 69.14 & 25.55 & 13.62 \\
\hline & & & & \\
\hline 0.005 & 900 & 139.73 & 44.92 & 23.09 \\
\hline 0.03 & 900 & 139.73 & 44.92 & 23.12 \\
\hline 0.3 & 900 & 139.73 & 44.92 & 23.48 \\
\hline & & & & \\
\hline 0.005 & 2500 & 353.96 & 97.53 & 48.81 \\
\hline 0.03 & 2500 & 353.96 & 97.53 & 48.85 \\
\hline 0.3 & 2500 & 353.96 & 97.53 & 49.57 \\
\hline
\end{tabular}

\begin{tabular}{|r|r|r|r|r|}
\hline \multicolumn{3}{|l|}{ Category 5 } & & \\
\hline$q$ & SA & RSP0.1 & RSP1 & RSP10 \\
\hline 0.005 & 100 & 33.54 & 13.44 & 9.83 \\
\hline 0.03 & 100 & 33.54 & 13.44 & 9.84 \\
\hline 0.3 & 100 & 33.56 & 13.44 & 9.93 \\
\hline & & & & \\
\hline 0.005 & 400 & 99.13 & 29.02 & 19.87 \\
\hline 0.03 & 400 & 99.13 & 29.03 & 19.89 \\
\hline 0.3 & 400 & 99.16 & 29.03 & 20.12 \\
\hline & & & & \\
\hline 0.005 & 900 & 200.09 & 50.14 & 33.18 \\
\hline 0.03 & 900 & 200.09 & 50.14 & 33.21 \\
\hline 0.3 & 900 & 200.09 & 50.14 & 33.61 \\
\hline & & & & \\
\hline 0.005 & 2500 & 506.39 & 106.34 & 66.96 \\
\hline 0.03 & 2500 & 506.39 & 106.34 & 67.01 \\
\hline 0.3 & 2500 & 506.39 & 106.35 & 67.80 \\
\hline
\end{tabular}

\begin{tabular}{|r|r|r|r|r|}
\cline { 2 - 5 } \multicolumn{2}{|l|}{ Category 3 } & & \\
\hline \multicolumn{1}{|l|}{$\mathrm{q}$} & SA & RSP0.1 & RSP1 & RSP10 \\
\hline 0.005 & 100 & 13.57 & 12.00 & 8.48 \\
\hline 0.03 & 100 & 13.57 & 12.00 & 8.48 \\
\hline 0.3 & 100 & 13.57 & 12.00 & 8.49 \\
\hline & & & & \\
\hline 0.005 & 400 & 32.60 & 25.39 & 16.96 \\
\hline 0.03 & 400 & 32.60 & 25.39 & 16.97 \\
\hline 0.3 & 400 & 32.60 & 25.39 & 17.02 \\
\hline & & & & \\
\hline 0.005 & 900 & 59.89 & 43.30 & 27.91 \\
\hline 0.03 & 900 & 59.89 & 43.30 & 27.92 \\
\hline 0.3 & 900 & 59.89 & 43.30 & 28.01 \\
\hline & & & & \\
\hline 0.005 & 2500 & 137.28 & 90.17 & 55.12 \\
\hline 0.03 & 2500 & 137.28 & 90.17 & 55.13 \\
\hline 0.3 & 2500 & 137.28 & 90.17 & 55.30 \\
\hline
\end{tabular}

\begin{tabular}{|c|c|c|c|c|}
\hline \multicolumn{2}{|c|}{ Category 6} & \multirow[b]{2}{*}{ RSP0.1 } & \multirow[b]{2}{*}{ RSP1 } & \multirow[b]{2}{*}{ RSP10 } \\
\hline q & SA & & & \\
\hline 0.005 & 100 & 21.72 & 15.78 & 14.50 \\
\hline 0.03 & 100 & 21.72 & 15.78 & 14.50 \\
\hline 0.3 & 100 & 21.72 & 15.78 & 14.54 \\
\hline 0.005 & 400 & 49.95 & 30.76 & 25.95 \\
\hline 0.03 & 400 & 49.95 & 30.76 & 25.96 \\
\hline 0.3 & 400 & 49.95 & 30.76 & 26.06 \\
\hline 0.005 & 900 & 90.18 & 50.40 & 40.17 \\
\hline 0.03 & 900 & 90.18 & 50.40 & 40.18 \\
\hline 0.3 & 900 & 90.18 & 50.40 & 40.37 \\
\hline 0.005 & 2500 & 202.31 & 98.70 & 71.34 \\
\hline 0.03 & 2500 & 202.31 & 98.70 & 71.36 \\
\hline 0.3 & 2500 & 202.31 & 98.70 & 71.73 \\
\hline
\end{tabular}


Set 1: Water Saturation of 0.05 (continued)

\begin{tabular}{|r|r|r|r|r|}
\hline \multicolumn{2}{|l|}{ Category 7 } & & & \\
\hline \multicolumn{1}{|l|}{} & SA & RSP0.1 & RSP1 & RSP10 \\
\hline 0.005 & 100 & 80.94 & 19.56 & 14.43 \\
\hline 0.03 & 100 & 80.94 & 19.57 & 14.44 \\
\hline 0.3 & 100 & 80.99 & 19.65 & 14.53 \\
\hline & & & & \\
\hline 0.005 & 400 & 279.79 & 54.12 & 37.73 \\
\hline 0.03 & 400 & 279.80 & 54.11 & 37.75 \\
\hline 0.3 & 400 & 279.95 & 54.33 & 38.00 \\
\hline & & & & \\
\hline 0.005 & 900 & 599.34 & 106.15 & 72.21 \\
\hline 0.03 & 900 & 599.36 & 106.18 & 72.25 \\
\hline 0.3 & 900 & 599.65 & 106.57 & 72.69 \\
\hline & & & & \\
\hline 0.005 & 2500 & 1599.38 & 261.59 & 173.56 \\
\hline 0.03 & 2500 & 1599.41 & 261.64 & 173.62 \\
\hline 0.3 & 2500 & 1599.98 & 262.42 & 174.50 \\
\hline
\end{tabular}

\begin{tabular}{|r|r|r|r|r|}
\hline \multicolumn{2}{|l|}{ Category 8 } & & \\
\hline $\mathrm{q}$ & SA & RSP0.1 & RSP1 & RSP10 \\
\hline 0.005 & 100 & 50.57 & 17.10 & 12.43 \\
\hline 0.03 & 100 & 50.57 & 17.10 & 12.44 \\
\hline 0.3 & 100 & 50.57 & 17.10 & 12.53 \\
\hline & & & & \\
\hline 0.005 & 400 & 152.29 & 35.13 & 22.80 \\
\hline 0.03 & 400 & 152.29 & 35.13 & 22.82 \\
\hline 0.3 & 400 & 152.29 & 35.14 & 23.06 \\
\hline & & & & \\
\hline 0.005 & 900 & 310.64 & 59.52 & 36.17 \\
\hline 0.03 & 900 & 310.64 & 59.52 & 36.20 \\
\hline 0.3 & 900 & 310.64 & 59.54 & 36.62 \\
\hline & & & & \\
\hline 0.005 & 2500 & 793.49 & 122.70 & 67.02 \\
\hline 0.03 & 2500 & 793.49 & 122.70 & 67.07 \\
\hline 0.3 & 2500 & 793.49 & 122.74 & 67.89 \\
\hline
\end{tabular}

\begin{tabular}{|r|r|r|r|r|}
\hline \multicolumn{2}{|l|}{ Category 9 } & & \\
\hline \multicolumn{1}{|l|}{$\mathbf{q}$} & SA & RSP0.1 & RSP1 & RSP10 \\
\hline 0.005 & 100 & 34.30 & 24.00 & 20.99 \\
\hline 0.03 & 100 & 34.30 & 24.00 & 21.00 \\
\hline 0.3 & 100 & 34.30 & 24.00 & 21.08 \\
\hline & & & & \\
\hline 0.005 & 400 & 77.57 & 43.33 & 35.81 \\
\hline 0.03 & 400 & 77.57 & 43.33 & 35.83 \\
\hline 0.3 & 400 & 77.57 & 43.33 & 36.02 \\
\hline & & & & \\
\hline 0.005 & 900 & 139.59 & 67.86 & 54.04 \\
\hline 0.03 & 900 & 139.59 & 67.86 & 54.06 \\
\hline 0.3 & 900 & 139.59 & 67.86 & 54.41 \\
\hline & & & & \\
\hline 0.005 & 2500 & 311.19 & 122.86 & 91.07 \\
\hline 0.03 & 2500 & 311.19 & 122.86 & 91.10 \\
\hline 0.3 & 2500 & 311.19 & 122.86 & 91.80 \\
\hline
\end{tabular}


Set 2: Water Saturation of 0.3

\begin{tabular}{|r|r|r|r|r|}
\hline \multicolumn{2}{|l|}{ Category 1 } & & \\
\hline \multicolumn{1}{|l|}{$\mathbf{q}$} & SA & RSP0.1 & RSP1 & RSP10 \\
\hline 0.005 & 100 & 32.74 & 5.52 & 3.37 \\
\hline 0.03 & 100 & 32.74 & 5.52 & 3.39 \\
\hline 0.3 & 100 & 32.74 & 5.56 & 3.49 \\
\hline & & & & \\
\hline 0.005 & 400 & 118.90 & 14.87 & 8.78 \\
\hline 0.03 & 400 & 118.90 & 14.87 & 8.81 \\
\hline 0.3 & 400 & 118.90 & 14.99 & 9.10 \\
\hline & & & & \\
\hline 0.005 & 900 & 258.65 & 28.68 & 16.69 \\
\hline 0.03 & 900 & 258.65 & 28.69 & 16.74 \\
\hline 0.3 & 900 & 258.66 & 28.90 & 17.26 \\
\hline & & & & \\
\hline 0.005 & 2500 & 698.90 & 69.46 & 39.82 \\
\hline 0.03 & 2500 & 698.90 & 69.48 & 39.90 \\
\hline 0.3 & 2500 & 698.92 & 69.87 & 40.95 \\
\hline
\end{tabular}

\begin{tabular}{|r|r|r|r|r|}
\hline \multicolumn{2}{|l|}{ Category 4 } & & \\
\hline \multicolumn{1}{|l|}{$\mathbf{q}$} & SA & RSP0.1 & \multicolumn{1}{|l|}{ RSP1 } & RSP10 \\
\hline 0.005 & 100 & 41.57 & 6.61 & 4.14 \\
\hline 0.03 & 100 & 41.57 & 6.62 & 4.16 \\
\hline 0.3 & 100 & 41.58 & 6.66 & 4.27 \\
\hline & & & & \\
\hline 0.005 & 400 & 149.06 & 18.09 & 10.35 \\
\hline 0.03 & 400 & 149.06 & 18.10 & 10.38 \\
\hline 0.3 & 400 & 149.08 & 18.25 & 10.68 \\
\hline & & & & \\
\hline 0.005 & 900 & 323.07 & 35.21 & 19.51 \\
\hline 0.03 & 900 & 323.07 & 35.22 & 19.55 \\
\hline 0.3 & 900 & 323.11 & 35.49 & 20.08 \\
\hline & & & & \\
\hline 0.005 & 2500 & 870.44 & 86.07 & 46.19 \\
\hline 0.03 & 2500 & 870.44 & 86.09 & 46.27 \\
\hline 0.3 & 2500 & 870.50 & 86.61 & 47.33 \\
\hline
\end{tabular}

\begin{tabular}{|r|r|r|r|r|}
\hline \multicolumn{2}{|l|}{ Category 2 } & & & \\
\hline $\mathrm{q}$ & SA & RSP0.1 & RSP1 & RSP10 \\
\hline 0.005 & 100 & 8.71 & 5.42 & 3.10 \\
\hline 0.03 & 100 & 8.71 & 5.42 & 3.10 \\
\hline 0.3 & 100 & 8.71 & 5.42 & 3.16 \\
\hline & & & & \\
\hline 0.005 & 400 & 26.13 & 13.22 & 7.01 \\
\hline 0.03 & 400 & 26.13 & 13.22 & 7.03 \\
\hline 0.3 & 400 & 26.13 & 13.22 & 7.20 \\
\hline & & & & \\
\hline 0.005 & 900 & 52.96 & 24.28 & 12.35 \\
\hline 0.03 & 900 & 52.96 & 24.28 & 12.37 \\
\hline 0.3 & 900 & 52.96 & 24.28 & 12.68 \\
\hline & & & & \\
\hline 0.005 & 2500 & 134.53 & 55.84 & 27.08 \\
\hline 0.03 & 2500 & 134.53 & 55.84 & 27.11 \\
\hline 0.3 & 2500 & 134.53 & 55.84 & 27.72 \\
\hline
\end{tabular}

\begin{tabular}{|r|r|r|r|r|}
\cline { 3 - 5 } \multicolumn{2}{|l|}{ Category 5 } & & \\
\hline $\mathrm{q}$ & SA & RSP0.1 & RSP1 & RSP10 \\
\hline 0.005 & 100 & 12.77 & 6.44 & 4.94 \\
\hline 0.03 & 100 & 12.77 & 6.44 & 4.95 \\
\hline 0.3 & 100 & 12.77 & 6.44 & 5.03 \\
\hline & & & & \\
\hline 0.005 & 400 & 37.59 & 14.94 & 10.61 \\
\hline 0.03 & 400 & 37.59 & 14.94 & 10.63 \\
\hline 0.3 & 400 & 37.59 & 14.94 & 10.87 \\
\hline & & & & \\
\hline 0.005 & 900 & 75.67 & 26.69 & 18.06 \\
\hline 0.03 & 900 & 75.67 & 26.69 & 18.09 \\
\hline 0.3 & 900 & 75.67 & 26.69 & 18.53 \\
\hline & & & & \\
\hline 0.005 & 2500 & 191.19 & 59.53 & 38.05 \\
\hline 0.03 & 2500 & 191.19 & 59.53 & 38.10 \\
\hline 0.3 & 2500 & 191.19 & 59.53 & 38.95 \\
\hline
\end{tabular}

\begin{tabular}{|r|r|r|r|r|}
\hline \multicolumn{2}{|l|}{ Category 3 } & & & \\
\hline $\mathrm{q}$ & SA & RSP0.1 & RSP1 & RSP10 \\
\hline 0.005 & 100 & 5.79 & 5.89 & 4.40 \\
\hline 0.03 & 100 & 5.79 & 5.89 & 4.40 \\
\hline 0.3 & 100 & 5.79 & 5.89 & 4.40 \\
\hline & & & & \\
\hline 0.005 & 400 & 13.97 & 13.56 & 9.96 \\
\hline 0.03 & 400 & 13.97 & 13.56 & 9.96 \\
\hline 0.3 & 400 & 13.97 & 13.56 & 9.97 \\
\hline & & & & \\
\hline 0.005 & 900 & 25.53 & 24.09 & 17.54 \\
\hline 0.03 & 900 & 25.53 & 24.09 & 17.54 \\
\hline 0.3 & 900 & 25.53 & 24.10 & 17.55 \\
\hline & & & & \\
\hline 0.005 & 2500 & 58.48 & 53.39 & 38.43 \\
\hline 0.03 & 2500 & 58.48 & 53.39 & 38.43 \\
\hline 0.3 & 2500 & 58.48 & 53.39 & 38.45 \\
\hline
\end{tabular}

\begin{tabular}{|r|r|r|r|r|}
\cline { 2 - 5 } \multicolumn{2}{|l|}{ Category 6 } & & \\
\hline \multicolumn{1}{|l|}{$\mathbf{q}$} & SA & RSP0.1 & RSP1 & RSP10 \\
\hline 0.005 & 100 & 9.52 & 7.96 & 7.87 \\
\hline 0.03 & 100 & 9.52 & 7.96 & 7.87 \\
\hline 0.3 & 100 & 9.52 & 7.96 & 7.88 \\
\hline & & & & \\
\hline 0.005 & 400 & 21.90 & 16.53 & 15.79 \\
\hline 0.03 & 400 & 21.90 & 16.53 & 15.79 \\
\hline 0.3 & 400 & 21.90 & 16.53 & 15.83 \\
\hline & & & & \\
\hline 0.005 & 900 & 38.93 & 27.46 & 25.57 \\
\hline 0.03 & 900 & 38.93 & 27.46 & 25.57 \\
\hline 0.3 & 900 & 38.93 & 27.46 & 25.63 \\
\hline & & & & \\
\hline 0.005 & 2500 & 86.52 & 55.99 & 50.27 \\
\hline 0.03 & 2500 & 86.52 & 55.99 & 50.27 \\
\hline 0.3 & 2500 & 86.52 & 55.99 & 50.38 \\
\hline
\end{tabular}


Set 2: Water Saturation of $\mathbf{0 . 3}$ (continued)

\begin{tabular}{|r|r|r|r|r|}
\hline \multicolumn{2}{|l|}{ Category 7 } & & & \\
\hline \multicolumn{1}{|l|}{} & SA & RSP0.1 & RSP1 & RSP10 \\
\hline 0.005 & 100 & 29.78 & 7.46 & 5.53 \\
\hline 0.03 & 100 & 29.78 & 7.47 & 5.55 \\
\hline 0.3 & 100 & 29.81 & 7.55 & 5.66 \\
\hline & & & & \\
\hline 0.005 & 400 & 102.65 & 20.37 & 14.30 \\
\hline 0.03 & 400 & 102.66 & 20.38 & 14.33 \\
\hline 0.3 & 400 & 102.74 & 20.60 & 14.63 \\
\hline & & & & \\
\hline 0.005 & 900 & 219.65 & 39.65 & 27.14 \\
\hline 0.03 & 900 & 219.66 & 39.68 & 27.18 \\
\hline 0.3 & 900 & 219.81 & 40.07 & 27.71 \\
\hline & & & & \\
\hline 0.005 & 2500 & 585.62 & 97.08 & 64.76 \\
\hline 0.03 & 2500 & 585.63 & 97.13 & 64.84 \\
\hline 0.3 & 2500 & 585.92 & 97.90 & 65.90 \\
\hline
\end{tabular}

\begin{tabular}{|r|r|r|r|r|}
\hline \multicolumn{2}{|l|}{ Category 8 } & & \\
\hline $\mathrm{q}$ & SA & RSP0.1 & \multicolumn{1}{c|}{ RSP1 } & RSP10 \\
\hline 0.005 & 100 & 18.28 & 8.14 & 6.11 \\
\hline 0.03 & 100 & 18.26 & 8.14 & 6.19 \\
\hline 0.3 & 100 & 18.29 & 8.14 & 6.14 \\
\hline & & & & \\
\hline 0.005 & 400 & 54.20 & 17.24 & 11.78 \\
\hline 0.03 & 400 & 54.21 & 17.24 & 11.78 \\
\hline 0.3 & 400 & 54.20 & 17.24 & 12.02 \\
\hline & & & & \\
\hline 0.005 & 900 & 109.70 & 29.05 & 18.84 \\
\hline 0.03 & 900 & 109.70 & 29.05 & 18.84 \\
\hline 0.3 & 900 & 109.70 & 29.05 & 18.87 \\
\hline & & & & \\
\hline 0.005 & 2500 & 278.80 & 60.37 & 35.45 \\
\hline 0.03 & 2500 & 278.80 & 60.37 & 35.45 \\
\hline 0.3 & 2500 & 278.80 & 60.38 & 35.47 \\
\hline
\end{tabular}

\begin{tabular}{|r|r|r|r|r|}
\hline \multicolumn{2}{|l|}{ Category 9 } & & & \\
\hline \multicolumn{1}{|l|}{$\mathbf{q}$} & SA & RSP0.1 & RSP1 & RSP10 \\
\hline 0.005 & 100 & 15.49 & 12.60 & 11.41 \\
\hline 0.03 & 100 & 15.49 & 12.60 & 11.41 \\
\hline 0.3 & 100 & 15.49 & 12.60 & 11.47 \\
\hline & & & & \\
\hline 0.005 & 400 & 34.77 & 24.52 & 21.02 \\
\hline 0.03 & 400 & 34.77 & 24.52 & 21.03 \\
\hline 0.3 & 400 & 34.77 & 24.52 & 21.19 \\
\hline & & & & \\
\hline 0.005 & 900 & 60.84 & 38.75 & 31.73 \\
\hline 0.03 & 900 & 60.84 & 38.75 & 31.75 \\
\hline 0.3 & 900 & 60.84 & 38.75 & 32.03 \\
\hline & & & & \\
\hline 0.005 & 2500 & 132.72 & 73.53 & 55.88 \\
\hline 0.03 & 2500 & 132.72 & 73.53 & 55.91 \\
\hline 0.3 & 2500 & 132.72 & 73.53 & 56.46 \\
\hline
\end{tabular}




\section{Set 3: Water Saturation of $\mathbf{0 . 5 5}$}

\begin{tabular}{|r|r|r|r|r|}
\hline \multicolumn{2}{|l|}{ Category 1 } & & \\
\hline \multicolumn{1}{|l|}{ q } & SA & RSP0.1 & RSP1 & RSP10 \\
\hline 0.005 & 100 & 7.68 & 1.87 & 1.20 \\
\hline 0.03 & 100 & 7.68 & 1.87 & 1.22 \\
\hline 0.3 & 100 & 7.68 & 1.87 & 1.32 \\
\hline & & & & \\
\hline 0.005 & 400 & 28.09 & 5.46 & 3.37 \\
\hline 0.03 & 400 & 28.09 & 5.46 & 3.41 \\
\hline 0.3 & 400 & 28.09 & 5.47 & 3.71 \\
\hline & & & & \\
\hline 0.005 & 900 & 61.25 & 10.90 & 6.61 \\
\hline 0.03 & 900 & 61.25 & 10.90 & 6.66 \\
\hline 0.3 & 900 & 61.25 & 10.91 & 7.22 \\
\hline & & & & \\
\hline 0.005 & 2500 & 165.85 & 27.28 & 16.25 \\
\hline 0.03 & 2500 & 165.85 & 27.28 & 16.34 \\
\hline 0.3 & 2500 & 165.85 & 27.30 & 17.48 \\
\hline
\end{tabular}

\begin{tabular}{|r|r|r|r|r|}
\hline \multicolumn{2}{|l|}{ Category 4} & & \\
\hline $\mathrm{q}$ & SA & RSP0.1 & \multicolumn{1}{|l|}{ RSP1 } & RSP10 \\
\hline 0.005 & 100 & 9.84 & 2.14 & 1.45 \\
\hline 0.03 & 100 & 9.84 & 2.14 & 1.47 \\
\hline 0.3 & 100 & 9.84 & 2.15 & 1.58 \\
\hline & & & & \\
\hline 0.005 & 400 & 35.40 & 6.17 & 3.67 \\
\hline 0.03 & 400 & 35.40 & 6.17 & 3.71 \\
\hline 0.3 & 400 & 35.40 & 6.19 & 4.02 \\
\hline & & & & \\
\hline 0.005 & 900 & 76.78 & 12.27 & 6.94 \\
\hline 0.03 & 900 & 76.78 & 12.27 & 7.00 \\
\hline 0.3 & 900 & 76.78 & 12.29 & 7.57 \\
\hline & & & & \\
\hline 0.005 & 2500 & 206.99 & 30.57 & 16.45 \\
\hline 0.03 & 2500 & 206.99 & 30.58 & 16.55 \\
\hline 0.3 & 2500 & 206.99 & 30.62 & 17.71 \\
\hline
\end{tabular}

\begin{tabular}{|r|r|r|r|r|}
\cline { 3 - 5 } \multicolumn{2}{l|}{ Category 2 } & & \\
\hline \multicolumn{1}{|l|}{$\mathrm{q}$} & SA & RSP0.1 & RSP1 & \multicolumn{1}{l|}{ RSP10 } \\
\hline 0.005 & 100 & 2.32 & 2.05 & 1.37 \\
\hline 0.03 & 100 & 2.32 & 2.05 & 1.37 \\
\hline 0.3 & 100 & 2.32 & 2.05 & 1.38 \\
\hline & & & & \\
\hline 0.005 & 400 & 6.98 & 5.53 & 3.70 \\
\hline 0.03 & 400 & 6.98 & 5.53 & 3.70 \\
\hline 0.3 & 400 & 6.98 & 5.53 & 3.73 \\
\hline & & & & \\
\hline 0.005 & 900 & 14.15 & 10.67 & 7.14 \\
\hline 0.03 & 900 & 14.15 & 10.67 & 7.14 \\
\hline 0.3 & 900 & 14.15 & 10.67 & 7.18 \\
\hline & & & & \\
\hline 0.005 & 2500 & 35.94 & 25.80 & 17.27 \\
\hline 0.03 & 2500 & 35.94 & 25.80 & 17.28 \\
\hline 0.3 & 2500 & 35.94 & 25.80 & 17.35 \\
\hline
\end{tabular}

\begin{tabular}{|r|r|r|r|r|}
\cline { 3 - 5 } \multicolumn{2}{|l|}{ Category 5} & & & \\
\hline $\mathrm{q}$ & SA & RSP0.1 & \multicolumn{1}{|l|}{ RSP1 } & RSP10 \\
\hline 0.005 & 100 & 3.54 & 2.50 & 2.22 \\
\hline 0.03 & 100 & 3.54 & 2.50 & 2.22 \\
\hline 0.3 & 100 & 3.54 & 2.50 & 2.25 \\
\hline & & & & \\
\hline 0.005 & 400 & 10.11 & 6.15 & 5.16 \\
\hline 0.03 & 400 & 10.11 & 6.15 & 5.17 \\
\hline 0.3 & 400 & 10.11 & 6.15 & 5.27 \\
\hline & & & & \\
\hline 0.005 & 900 & 20.10 & 11.38 & 9.24 \\
\hline 0.03 & 900 & 20.10 & 11.38 & 9.26 \\
\hline 0.3 & 900 & 20.10 & 11.38 & 9.43 \\
\hline & & & & \\
\hline 0.005 & 2500 & 50.14 & 26.36 & 20.64 \\
\hline 0.03 & 2500 & 50.14 & 26.36 & 20.66 \\
\hline 0.3 & 2500 & 50.14 & 26.36 & 20.98 \\
\hline
\end{tabular}

\begin{tabular}{|r|r|r|r|r|}
\hline \multicolumn{2}{|l|}{ Category 3 } & & & \\
\hline $\mathrm{q}$ & SA & RSP0.1 & RSP1 & RSP10 \\
\hline 0.005 & 100 & 2.19 & 2.35 & 1.78 \\
\hline 0.03 & 100 & 2.19 & 2.35 & 1.78 \\
\hline 0.3 & 100 & 2.19 & 2.35 & 1.78 \\
\hline & & & & \\
\hline 0.005 & 400 & 5.44 & 5.81 & 4.29 \\
\hline 0.03 & 400 & 5.44 & 5.81 & 4.29 \\
\hline 0.3 & 400 & 5.44 & 5.81 & 4.29 \\
\hline & & & & \\
\hline 0.005 & 900 & 10.11 & 10.76 & 7.87 \\
\hline 0.03 & 900 & 10.11 & 10.76 & 7.87 \\
\hline 0.3 & 900 & 10.11 & 10.76 & 7.87 \\
\hline & & & & \\
\hline 0.005 & 2500 & 23.53 & 24.95 & 18.06 \\
\hline 0.03 & 2500 & 23.53 & 24.95 & 18.06 \\
\hline 0.3 & 2500 & 23.53 & 24.95 & 18.06 \\
\hline
\end{tabular}

\begin{tabular}{|r|r|r|r|r|}
\hline \multicolumn{2}{|l|}{ Category 6 } & & \\
\hline \multicolumn{1}{|l|}{$\mathbf{q}$} & SA & RSP0.1 & RSP1 & RSP10 \\
\hline 0.005 & 100 & 3.66 & 3.50 & 3.54 \\
\hline 0.03 & 100 & 3.66 & 3.50 & 3.53 \\
\hline 0.3 & 100 & 3.66 & 3.50 & 3.53 \\
\hline & & & & \\
\hline 0.005 & 400 & 8.13 & 7.56 & 7.27 \\
\hline 0.03 & 400 & 8.13 & 7.56 & 7.27 \\
\hline 0.3 & 400 & 8.13 & 7.56 & 7.27 \\
\hline & & & & \\
\hline 0.005 & 900 & 14.25 & 13.04 & 12.17 \\
\hline 0.03 & 900 & 14.25 & 13.04 & 12.17 \\
\hline 0.3 & 900 & 14.25 & 13.04 & 12.17 \\
\hline & & & & \\
\hline 0.005 & 2500 & 31.01 & 27.79 & 24.95 \\
\hline 0.03 & 2500 & 31.01 & 27.79 & 24.95 \\
\hline 0.3 & 2500 & 31.01 & 27.79 & 24.95 \\
\hline
\end{tabular}


Set 3: Water Saturation of 0.55 (continued)

\begin{tabular}{|r|r|r|r|r|}
\hline \multicolumn{2}{|l|}{ Category 7 } & & & \\
\hline \multicolumn{1}{|l|}{} & SA & RSP0.1 & RSP1 & RSP10 \\
\hline 0.005 & 100 & 7.36 & 2.39 & 1.79 \\
\hline 0.03 & 100 & 7.36 & 2.39 & 1.81 \\
\hline 0.3 & 100 & 7.37 & 2.41 & 1.91 \\
\hline & & & & \\
\hline 0.005 & 400 & 25.31 & 6.52 & 4.37 \\
\hline 0.03 & 400 & 25.31 & 6.52 & 4.41 \\
\hline 0.3 & 400 & 25.31 & 6.58 & 4.71 \\
\hline & & & & \\
\hline 0.005 & 900 & 54.07 & 12.65 & 8.05 \\
\hline 0.03 & 900 & 54.07 & 12.65 & 8.10 \\
\hline 0.3 & 900 & 54.07 & 12.76 & 8.66 \\
\hline & & & & \\
\hline 0.005 & 2500 & 143.92 & 30.81 & 18.56 \\
\hline 0.03 & 2500 & 143.92 & 30.82 & 18.65 \\
\hline 0.3 & 2500 & 143.93 & 31.01 & 19.79 \\
\hline
\end{tabular}

\begin{tabular}{|r|r|r|r|r|}
\hline \multicolumn{2}{|l|}{ Category 8 } & & & \\
\hline $\mathrm{q}$ & SA & RSP0.1 & \multicolumn{1}{|l|}{ RSP1 } & RSP10 \\
\hline 0.005 & 100 & 5.22 & 3.50 & 2.77 \\
\hline 0.03 & 100 & 5.22 & 3.50 & 2.82 \\
\hline 0.3 & 100 & 5.22 & 3.50 & 2.77 \\
\hline & & & & \\
\hline 0.005 & 400 & 14.28 & 7.49 & 5.39 \\
\hline 0.03 & 400 & 14.28 & 7.49 & 5.30 \\
\hline 0.3 & 400 & 14.28 & 7.49 & 5.39 \\
\hline & & & & \\
\hline 0.005 & 900 & 27.89 & 12.81 & 8.47 \\
\hline 0.03 & 900 & 27.89 & 12.81 & 8.46 \\
\hline 0.3 & 900 & 27.89 & 12.81 & 8.47 \\
\hline & & & & \\
\hline 0.005 & 2500 & 68.41 & 27.04 & 15.80 \\
\hline 0.03 & 2500 & 68.41 & 27.04 & 15.80 \\
\hline 0.3 & 2500 & 68.41 & 27.04 & 15.80 \\
\hline
\end{tabular}

\begin{tabular}{|r|r|r|r|r|}
\hline \multicolumn{2}{|l|}{ Category 9 } & & & \\
\hline \multicolumn{1}{|l|}{$\mathbf{q}$} & SA & RSP0.1 & RSP1 & RSP10 \\
\hline 0.005 & 100 & 6.18 & 5.90 & 5.68 \\
\hline 0.03 & 100 & 6.18 & 5.90 & 5.68 \\
\hline 0.3 & 100 & 6.18 & 5.90 & 5.69 \\
\hline & & & & \\
\hline 0.005 & 400 & 12.93 & 11.76 & 11.18 \\
\hline 0.03 & 400 & 12.93 & 11.76 & 11.18 \\
\hline 0.3 & 400 & 12.93 & 11.76 & 11.20 \\
\hline & & & & \\
\hline 0.005 & 900 & 21.88 & 19.24 & 18.14 \\
\hline 0.03 & 900 & 21.88 & 19.24 & 18.14 \\
\hline 0.3 & 900 & 21.88 & 19.24 & 18.17 \\
\hline & & & & \\
\hline 0.005 & 2500 & 45.58 & 38.25 & 35.60 \\
\hline 0.03 & 2500 & 45.58 & 38.25 & 35.60 \\
\hline 0.3 & 2500 & 45.58 & 38.25 & 35.66 \\
\hline
\end{tabular}





\section{Appendix D}

\section{Spreadsheet Tool}

http://www.pnnl.gov/main/publications/external/technical_reports/PNNL-21843_SVEET_1.0.0.xls 



\section{Appendix D}

\section{Spreadsheet Tool: SVEET}

For convenience in application, the calculational procedure described in Appendix $\mathrm{C}$ for estimating the impact of vadose zone contamination on the contaminant concentration in groundwater at a downgradient compliance well has been implemented in a spreadsheet software tool. The Soil Vapor Extraction Endstate Tool (SVEET) allows the user to easily enter data and calculate the estimated groundwater concentration for one or more scenarios conforming to the generalized conceptual model (Section 4.2). This appendix describes the SVEET software, including information on installation, the user interface, and using the software. See Appendix $\mathrm{C}$ for information about the calculations involved in the estimation procedure as well as a walk-through of an example calculation.

\section{D.1 System Requirements}

The following hardware and software are required to use the SVEET software:

- Personal computer based on Intel ${ }^{\circledR}$ IA-32 or Intel ${ }^{\circledR} 64$ processor architectures,

- Microsoft $^{\circledR}$ Windows $^{\circledR}$ XP or Microsoft ${ }^{\circledR}$ Windows $^{\circledR} 7$ operating system,

- Microsoft $^{\circledR}$ Excel $^{\circledR}$ 2003, Excel ${ }^{\circledR}$ 2007, or Excel ${ }^{\circledR} 2010$

\section{D.2 Description of the SVEET Workbook}

The SVEET software Excel workbook has two worksheets available, only one of which will be routinely used. The content of these worksheets are described below.

The "HLC" worksheet (Figure D.1) is a repository for contaminant-specific information, including molecular weight, vapor pressure correlation coefficients, and solubility correlation coefficients. The "HLC" worksheet also has water density information and values for key constants. As an ancillary feature unrelated to the SVEET calculations, users can do a "Quick HLC Calculation" to get a Henry's Law Constant value for a specified contaminant at a designated temperature.

The "SVEET" worksheet (Figure D.2) is where the user will enter data and see calculation results. The "SVEET" worksheet is divided into areas for data input (blue shading), intermediate calculated values (green shading), and the final estimate for groundwater concentration (tan shading). Additional information is presented on the right side of the worksheet, showing the generalized conceptual model figure to clarify the meaning of parameters and a table of the parameter value permissible ranges and key values. By default, the "SVEET" worksheet has space for up to three independent scenarios (columns D, $\mathrm{E}$, and F). 


\begin{tabular}{|c|c|c|c|c|c|c|c|c|c|c|c|c|}
\hline \multirow[b]{2}{*}{$\begin{array}{l}\text { Contaminant } \\
\text { Abbrev. }\end{array}$} & \multirow[b]{2}{*}{ Contaminant } & \multirow{2}{*}{$\begin{array}{c}\text { Molecular } \\
\text { Weight } \\
\text { (g/mol) }\end{array}$} & \multicolumn{3}{|c|}{ Vapor Pressure $(\mathrm{mm} \mathrm{Hg})$} & \multicolumn{7}{|c|}{ Solubility (mass fraction) } \\
\hline & & & A & B & C & $\begin{array}{l}E \\
q \\
n\end{array}$ & A & B & C & D & $\mathbf{E}$ & $\mathbf{F}$ \\
\hline CT & Carbon Tetrachloride & 153.823 & 7.01144 & 1278.54 & 232.888 & 2 & $9.7842 \mathrm{E}-2$ & $-1.4942 \mathrm{E}-3$ & $3.5854 \mathrm{E}-5$ & $2.2775 \mathrm{E}-7$ & 0 & 0 \\
\hline $\mathrm{CF}$ & Chloroform & 119.376 & 7.11148 & 1232.79 & 230.213 & 2 & $9.9500 \mathrm{E}-1$ & $-1.0531 \mathrm{E}-2$ & $7.9819 \mathrm{E}-5$ & $6.6431 \mathrm{E}-7$ & 0 & 0 \\
\hline DCM & Dichloromethane & 84.932 & 7.11464 & 1152.41 & 232.442 & 2 & 1.9610 & $-4.4883 \mathrm{E}-2$ & $8.6617 \mathrm{E}-4$ & $4.9463 \mathrm{E}-6$ & 0 & 0 \\
\hline $\mathrm{CM}$ & Chloromethane & 50.487 & 6.99771 & 870.17 & 235.586 & 3 & 1.4019 & $-6.3562 \mathrm{E}-2$ & $1.7198 \mathrm{E}-3$ & $-2.8262 \mathrm{E}-5$ & $2.5268 \mathrm{E}-7$ & $-9.3470 \mathrm{E}-10$ \\
\hline PCE & Tetrachloroethene & 165.832 & 7.06892 & 1458.45 & 226.986 & 1 & $2.6479 \mathrm{E}-1$ & $-1.5487 \mathrm{E}-3$ & $2.4477 \mathrm{E}-6$ & 0 & 0 & 0 \\
\hline TCE & Trichloroethene & 131.387 & 6.87981 & 1157.83 & 202.58 & 1 & 1.4049 & $-8.2223 \mathrm{E}-3$ & $1.3218 \mathrm{E}-5$ & 0 & 0 & 0 \\
\hline 1,1-DCE & 1,1-Dichloroethene & 96.943 & 7.21678 & 1181.12 & 240.84 & 1 & 6.2741 & $-3.8257 \mathrm{E}-2$ & $6.0461 \mathrm{E}-5$ & 0 & 0 & 0 \\
\hline cDCE & cis-1,2-Dichloroethene & 96.943 & 7.21953 & 1290.28 & 236.887 & 1 & $2.7735 \mathrm{E}+1$ & $-1.7832 \mathrm{E}-1$ & $2.9328 \mathrm{E}-4$ & 0 & 0 & 0 \\
\hline tDCE & trans-1,2-Dichloroethene & 96.943 & 7.21356 & 1244.35 & 239.497 & 1 & 7.8039 & $-4.5457 \mathrm{E}-2$ & $6.9676 \mathrm{E}-4$ & 0 & 0 & 0 \\
\hline VC & Vinyl Chloride & 62.498 & 6.91423 & 911.15 & 239.8 & 4 & $-4.6670 E+2$ & $1.3479 \mathrm{E}+4$ & $1.8523 \mathrm{E}+2$ & $-1.3236 \mathrm{E}-1$ & 0 & 0 \\
\hline $1,1,1,2-\mathrm{TeCA}$ & $1,1,1,2$-Tetrachloroethane & 167.848 & 7.03897 & 1467.16 & 222.34 & 1 & 2.1790 & $-1.3966 \mathrm{E}-3$ & $2.9328 \mathrm{E}-5$ & 0 & 0 & 0 \\
\hline $1,1,2,2-\mathrm{TeCA}$ & $1,1,2,2$-Tetrachloroethane & 167.848 & 6.91043 & 1378.88 & 197.086 & 1 & 4.8798 & $-3.0937 \mathrm{E}-3$ & $5.2051 \mathrm{E}-5$ & 0 & 0 & 0 \\
\hline 1,1,1-TCA & 1,1,1-Trichloroethane & 133.403 & 7.00718 & 1253.2 & 229.624 & 1 & 1.0909 & $-6.5278 \mathrm{E}-3$ & $1.1075 \mathrm{E}-5$ & 0 & 0 & 0 \\
\hline $1,1,2-\mathrm{TCA}$ & 1,1,2-Trichloroethane & 133.403 & 7.14357 & 1457.65 & 228.099 & 1 & 2.8980 & $-1.8585 E-2$ & $3.4896 \mathrm{E}-5$ & 0 & 0 & 0 \\
\hline 1,1-DCA & 1,1-Dichloroethane & 98.959 & 7.18316 & 1269.43 & 237.755 & 1 & 9.4136 & $-5.7249 \mathrm{E}-2$ & $9.1784 \mathrm{E}-5$ & 0 & 0 & 0 \\
\hline $1,2-\mathrm{DCA}$ & 1,2-Dichloroethane & 98.959 & 7.29525 & 1407.85 & 235.48 & 1 & $1.7915 \mathrm{E}+1$ & $-1.1684 \mathrm{E}-1$ & $2.0003 \mathrm{E}-4$ & 0 & 0 & 0 \\
\hline \multirow[t]{2}{*}{ CE } & Chloroethane & 64.514 & 7.13047 & 1097.6 & 246.009 & 2 & $5.8420 \mathrm{E}-1$ & $-1.6863 \mathrm{E}-3$ & $9.3949 \mathrm{E}-5$ & $-2.5316 \mathrm{E}-6$ & 0 & 0 \\
\hline & <dummy row $>$ & & & & & & & & & & & \\
\hline \multirow{2}{*}{\multicolumn{3}{|c|}{$\begin{array}{l}\mathrm{X}=(\mathrm{xp} / 100) \cdot\left(\mathrm{MW}_{\mathrm{w}} / \mathrm{MW}_{\mathrm{i}}\right)=\mathrm{xf} \cdot\left(\mathrm{MW}_{\mathrm{w}} / \mathrm{MW}_{\mathrm{i}}\right) \\
\mathrm{H}=[(\mathrm{P} / 760) / \mathrm{x}] \cdot\left[\mathrm{MW}_{\mathrm{w}} /\left(\rho_{\mathrm{w}} \cdot \mathrm{R}_{\mathrm{gas}} \cdot \mathrm{Tk}\right)\right]\end{array}$}} & \multicolumn{3}{|c|}{$\log (P)=A-B /(T c+C)$} & \multirow{4}{*}{$\begin{array}{l}\text { 1: } \\
\text { 2: } \\
3: \\
4:\end{array}$} & \multirow{4}{*}{\multicolumn{4}{|c|}{$\begin{array}{l}x p=A+B \cdot T k+C \cdot T k^{2} \\
x p=A+B \cdot T C+C \cdot T C^{2}+D \cdot T c^{3} \\
x p=A+B \cdot T c+C \cdot T C^{2}+D \cdot T c^{3}+E \cdot T c^{4}+F \cdot T c^{5} \\
\log (x f)=A+B / T k+C \cdot L o g(T k)+D \cdot T k \\
x p=\text { mass fraction } \times 100 \%\end{array}$}} & \multirow{3}{*}{\multicolumn{2}{|c|}{$\begin{array}{l}\text { Mackay et al., } 2006 \\
\text { Mackay et al., } 2006 \\
\text { Mackay et al., } 2006 \\
\text { Yaws, } 2003\end{array}$}} \\
\hline & & & & \multicolumn{2}{|c|}{ Yaws et al., 2009} & & & & & & & \\
\hline & & $T c=$ Temp & in ${ }^{\circ} \mathrm{C}$ & $\mathrm{np}$. in $\mathrm{K}$ & & & & & & & & \\
\hline & & & & & & & & & & & & \\
\hline
\end{tabular}

Figure D.1. View of the primary data (molecular weights and correlation coefficients) on the "HLC" worksheet of the SVEET workbook (the quick HLC calculation and information for water density and constants are not shown)

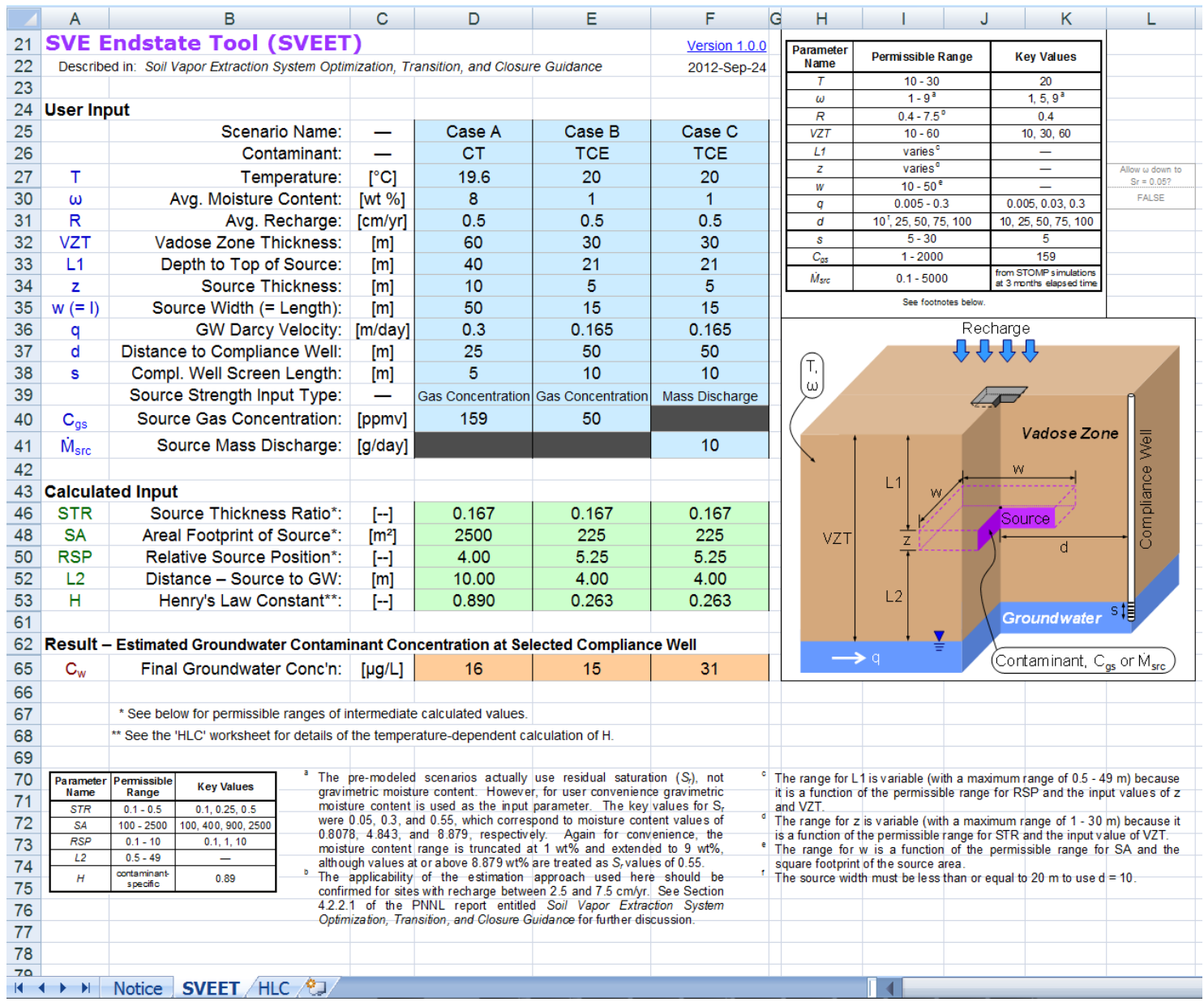

Figure D.2. View of the "SVEET" worksheet showing inputs, intermediate calculations, and results along with reference information. 


\section{D.3 Using the Software}

\section{D.3.1 Enabling Macros}

When creating or re-opening a SVEET workbook, the user may receive a message that the workbook contains macros. The SVEET workbook uses a user-defined function (macro) to perform the interpolations, so macros must be enabled for calculations to work properly. Thus, the user should select the "Enable Macros" option. If not presented with an option to enable macros, the user can try closing and re-opening the file or altering the macro security settings of Excel. Recent versions of Excel have security options found under the name of "Macro Security" or "Trust Center" (depending on the version of Excel) where a macro security option can be selected to prompt/notify the user to confirm, on an individual workbook basis, whether macros should be enabled or not.

\section{D.3.2 Performing Calculations}

Performing calculations with the SVEET software is as simple as entering the required input data (based on the site conceptual model, data collection, and procedures discussed in Sections 2.2 and 4.2 and in Appendix A). On input of valid data, results are available immediately. Data entry for most items consists of entering numbers as the values for parameters in the blue shaded cells for a particular scenario. Three of the inputs (contaminant name, distance to compliance well, and source strength input type) use a selection list to insure valid data are used. The selection list is activated by selecting the input cell on the spreadsheet then clicking on the arrow button that appears. Figure D.3 shows an example of a selection list for the distance to compliance well in the third scenario (column F). The selection of the source strength input type modifies the requested input data to be either source gas concentration or source mass discharge, while graying out the unused parameter.

If invalid input values (or combinations of values) are entered, affected cells are highlighted in a light red shading. Affected cells may be either user inputs or intermediate calculated values. The primary cause for errors is likely to be data values outside the permissible ranges or inconsistent with each other. A table of permissible ranges and a diagram of the generalized conceptual model is included directly on the worksheet to help the user identify issues with improper input data. Figure D.3 shows two examples of invalid input data. In Case A of the figure, the source thickness and L1 value have been specified such that the L2 value is zero and the RSP value cannot be calculated. In Case B of the figure, the groundwater Darcy velocity is specified as $2 \mathrm{~m} /$ day, which is outside the upper allowable value of 0.3 $\mathrm{m} /$ day.

The SVEET workbook includes two features to help maintain the integrity of the calculations. The associated macro code (for doing the interpolations) is locked for viewing or editing. Also, the worksheets are protected and data entry is only allowed in appropriate data input cells. 


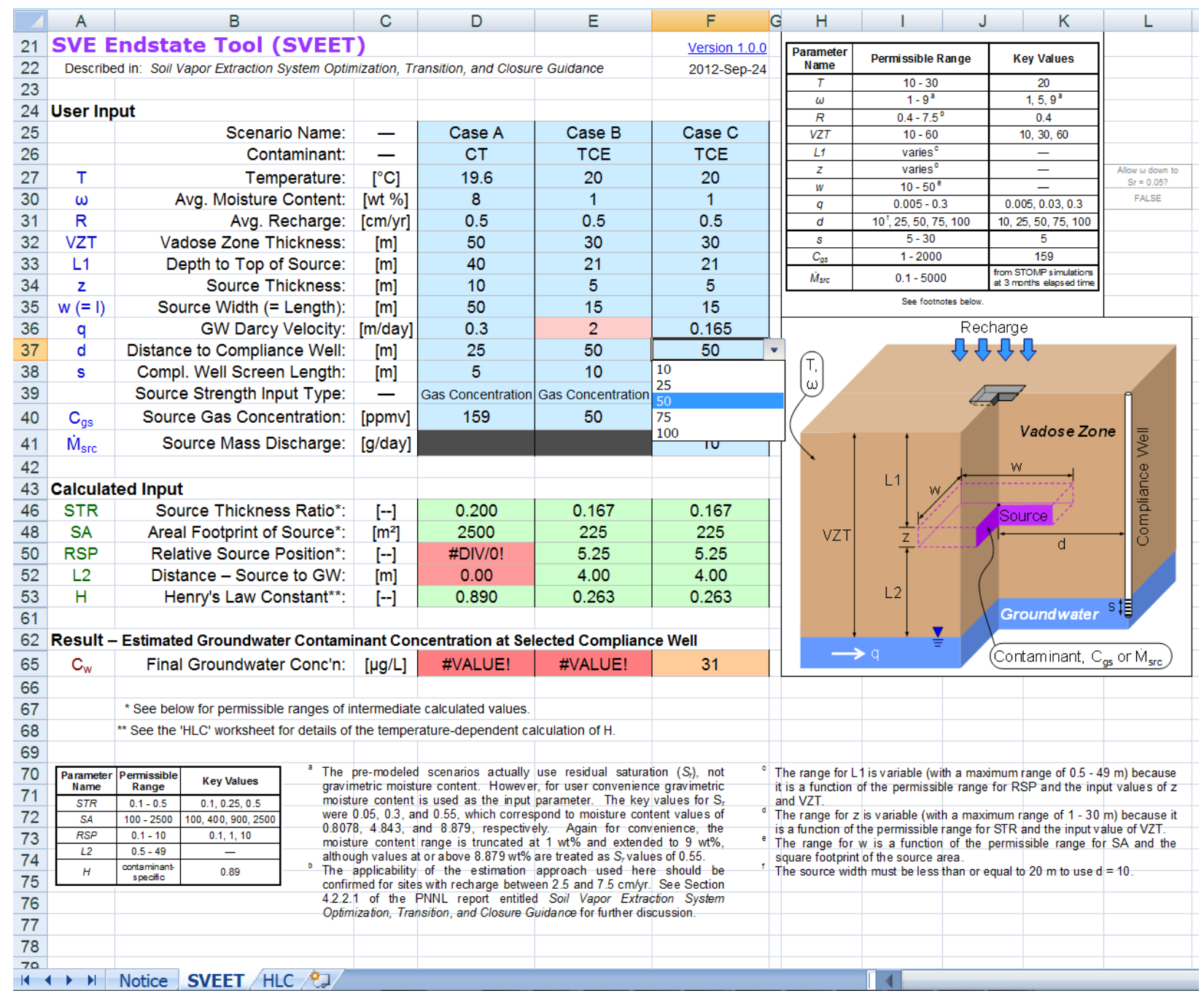

Figure D.3. Example of invalid data (problems highlighted in red shading) on the "SVEET" worksheet (and depiction of the distance to compliance well selection list for Case C) 


\section{Appendix E}

Technical Basis for Estimating Groundwater Contaminant Concentrations as a Function of Vadose Zone Source Characteristics 



\section{Appendix E}

\section{Technical Basis for Estimating Groundwater Contaminant Concentrations as a Function of Vadose Zone Source Characteristics}

A generalized conceptual model approach was developed that can be used to estimate the impact of volatile contaminant sources in the vadose zone on groundwater. The model has the potential to be broadly applicable for sites where vapor-phase transport dominates (e.g., for relatively low recharge sites). The primary target for this conceptual model and related numerical modeling estimate of groundwater impact is for sites where SVE has been applied and removed contaminants from readily accessible portions of the subsurface, but contaminants may persist in localized portions of the vadose zone. This appendix describes the conceptual model, uses numerical simulations to evaluate the parameters controlling impact to groundwater, and presents estimated results for a range of input conditions. Suggestions are provided on how pre-modeled scenarios using this conceptual model may be used to estimate groundwater concentrations for a large range of vadose zone conditions by using linear interpolations. In Appendix C, a framework is presented for calculations of compliance well concentrations, based on the pre-modeled scenarios discussed here.

\section{E.1 Generalized Conceptual Model}

The generalized conceptual model for the analysis in this appendix is shown in Figure E.1. Details of the parameters are described in Section E.2 (and Table C.1 of Appendix C). With this conceptual model and associated parameters, numerical modeling can be used to estimate the groundwater contaminant concentrations at downgradient compliance wells that result from a source in the vadose zone. The generalized conceptual model enables simplification of the modeling domain with inclusion of parameters most important to estimating impact to groundwater. For some sites, notably sites with contaminant sources that are widely dispersed, the basic framework shown in Figure E.1 may not be appropriate and a site-specific approach will be necessary. 


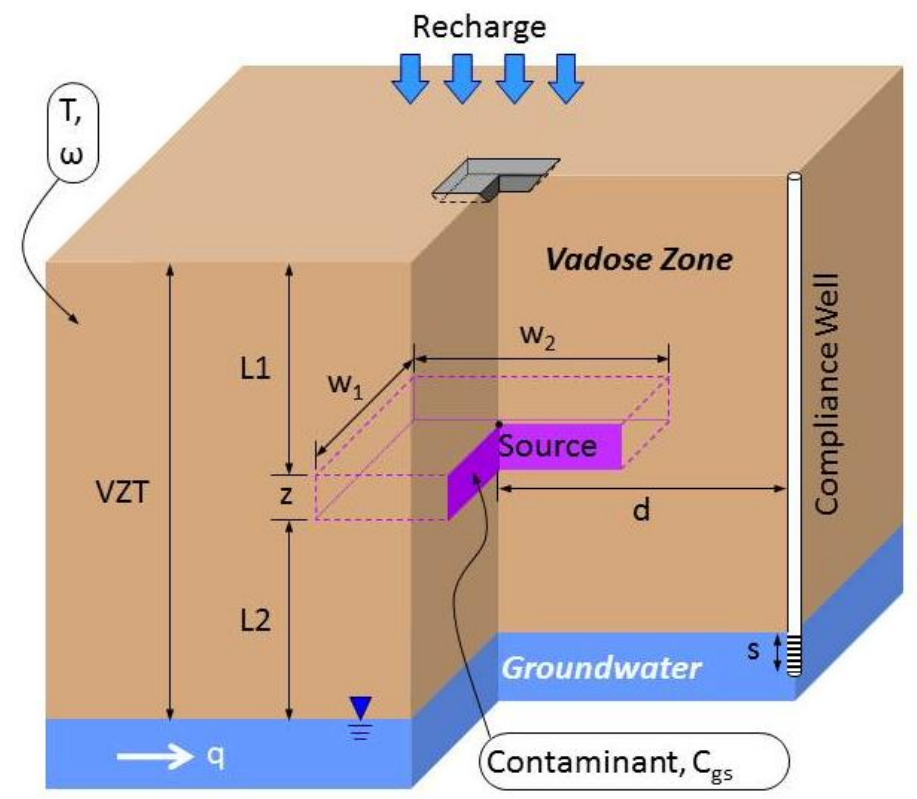

Figure E.1. Generalized conceptual model framework for impact to groundwater. Parameters are described in Table C. 1 in Appendix C (note that, by definition, $w_{1}=w_{2}=w$ ).

The source in the model has a "source strength" as defined by source concentration or contaminant mass discharge from the source. Physically, the source does not have to be homogeneous and may consist of several smaller, disconnected zones. Examples of configurations that may be consolidated into a single source are shown in Figure E.2. In the Figure E.2 scenarios, the contaminant resides within a defined volume and a composite concentration can be assigned for that volume. In the long term, vapor concentrations will equilibrate within the dashed outline on the figure between these distinct sources, resulting in a composite concentration of the overall source zone that effectively drives diffusion towards the surface or the groundwater. In addition, aqueous recharge moving through this zone will become contaminated, but aqueous concentrations will be controlled by equilibrium with vapor concentrations at low-recharge sites. Thus, for sites with relatively low recharge rates, the composite-source vapor concentration will also be a primary factor in the long-term aqueous phase contaminant discharge to the groundwater. Justifications for the single-source approach and the use of a homogeneous vadose zone for vapor transport are provided in the Results and Discussion section based on a numerical analysis.

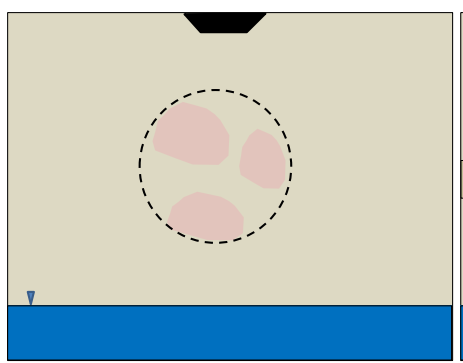

(a)

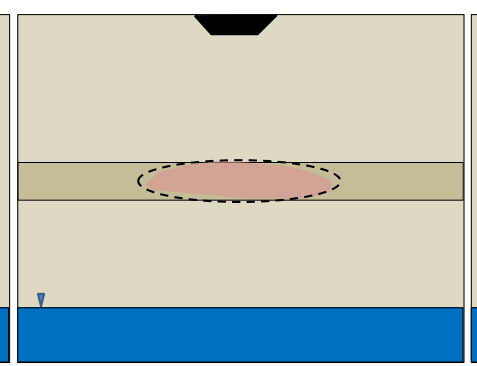

(b)

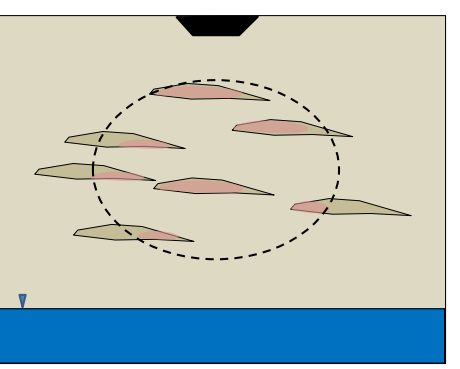

(c)

Figure E.2. Categories of conceptual site models for persistent vadose zone contamination for (a) homogenous subsurface, (b) simple layered subsurface, and (c) multiple layers or lenses in the subsurface. The dashed lines show zones where, over time, vapor concentrations due to diffusion from the source zones will nominally equilibrate as a consolidated vapor contamination source. 
For the conceptual model shown in Figure E.1, it is assumed that the remaining vadose zone contaminant sources are persistent because they reside within lower permeability zones or areas poorly swept by the SVE system (e.g., high moisture zones). For many sites, the remaining vadose zone contaminant sources would be expected to exist within a localized portion of the vadose zone as a remnant of contaminant transport pathways that occurred during the waste disposal period.

At sites with relatively low recharge, vapor-phase transport of volatile contaminants may be most important in terms of long term mass discharge from the vadose zone to the groundwater. Truex et al. (2009) compared the relative vapor phase and recharge-driven contaminant flux to groundwater for a range of recharge and groundwater Darcy flux conditions and found that vapor-phase flux clearly dominates for recharge rates of $5 \mathrm{~cm} / \mathrm{yr}$ and lower, consistent with results of numerical simulations presented by Oostrom et al. (2010). Diffusion is the dominant vapor-phase transport process when contaminant vapor concentrations are less than about $1500 \mathrm{ppmv}$ and density-driven advection is minimal even at vapor concentrations up to 15,000 ppmv (Oostrom et al 2010). Thus, under conditions more likely relevant to evaluating SVE closure, vapor-phase diffusion can be considered to be the most important transport process in the vadose zone. However, for vapor-phase transport conditions, mass transfer of contaminants across the water table is a key process related to the resulting groundwater contamination (Truex et al, 2009; Oostrom et al., 2010). Thus, the generalized conceptual model focuses on diffusive vapor transport and mass transfer at the water table and factors that impact these processes with respect to estimating groundwater contaminant concentrations.

\section{E.2 Methods}

The simulations are conducted for a domain and contaminant distribution consistent with Figure E.2, representing a generalized conceptual model of the subsurface, as described above. The threedimensional (3D) domain considered for the simulations is $2000 \mathrm{~m}$ long $(-1000 \mathrm{~m} \leq x \leq 1000 \mathrm{~m}), 500 \mathrm{~m}$ wide $(-250 \mathrm{~m} \leq \mathrm{y} \leq 250 \mathrm{~m})$, and $80 \mathrm{~m}$ high $(0 \mathrm{~m} \leq z \leq 80 \mathrm{~m})$. The domain represents the conceptual model framework for a vadose zone source configuration as shown in Figure E.1. Recognizing a plane of symmetry at $y=0$, the actual computational domain ranges from $-1000 \mathrm{~m}$ to $1000 \mathrm{~m}$ in the $x$-direction, from 0 to $250 \mathrm{~m}$ in the $y$-direction, and from 0 to $80 \mathrm{~m}$ in the $z$-direction. The Base Case represents a thick arid vadose zone for which this type of approach may be appropriately applied, for instance at the DOE Hanford Site (Carroll et al., 2012; Oostrom et al, 2007; Truex et al., 2012). For the simulations, it is assumed that the remaining persistent source zone, vertically in the middle of the vadose zone, has horizontal dimensions of $(10 \times 10 \mathrm{~m})$. The vertical thickness of the source zone was assumed to be $6 \mathrm{~m}$. The source zone is centered at $x=0 ; y=0$, and $z=50 \mathrm{~m}$.

The water-oil-air operational mode (STOMP-WOA) of the STOMP simulator (White and Oostrom, 2006) was used to simulate multi-fluid flow and transport. The fully implicit, integrated finite difference code has been used to simulate a variety of multi-fluid systems (e.g., White et al., 2004; Oostrom et al., 2005). The applicable governing equations are the component mass-conservation equations for water, organic compounds, and air. The domain was discretized into $152 \times 76 \times 90$ grid blocks, for a total of $1,039,680$ nodes. The discretization was not uniform, with considerable refinement in the source area and near the water table. Several refinement iterations were conducted until no changes were observed in the mass flux emanating from the source area and into the aquifer. Refinement near the water table was needed to optimize transfer from the vapor phase into the saturated zone. For this kind of mass transfer to occur in a discretized model, vapors first have to migrate into the lowest unsaturated grid block. Only 
after partitioning of the vapors into the aqueous phase present in that block, dissolved contaminants may be transported into the highest saturated grid block through diffusion and/or advection. The phase saturations of the lowest unsaturated node have to be at a certain level to optimize transfer due to diffusion. If the water saturation is too low, transfer becomes diffusion limited. However, if the gas saturation is too low, not enough vapors may enter that block to ensure sufficient transfer into the aqueous phase. For our simulations it was determined that a water saturation of 0.8 in the lowest unsaturated node would maximize mass transfer into the saturated zone through diffusion. To obtain this saturation, the associated optimal vertical grid dimensions in just above and below the water table were $0.1 \mathrm{~m}$.

Model parameters values for the Base Case simulation are listed in Table E.1. The dimensional parameters are shown and explained in Figure E.1. The van Genuchten-Mualem (van Genuchten, 1978) relative permeability-saturation-capillary pressure $(k-s-P)$ relations have been used in the simulations. Because the transport was simulated until steady state conditions were obtained, the effects of sorption could be neglected (Carroll et al., 2012). Flow in the saturated zone was from left to right in the $x$ direction. Constant flux boundary conditions with a recharge rate of $0.4 \mathrm{~cm} /$ year were also imposed at the top of the domain. An atmospheric gas pressure of 101,325 $\mathrm{Pa}$ was imposed on the top of the domain and gas was allowed to move freely across the vertical boundaries. Groundwater flow in the saturated zone was imposed with a constant flux boundary condition over the lower $20 \mathrm{~m}$ at the upgradient side of the domain and a specified pressure boundary condition at the downgradient side. To establish an essentially horizontal water table at $20 \mathrm{~m}$ from the model base, the hydraulic conductivity of the saturated zone was assumed to be four orders of magnitude larger than the hydraulic conductivity of the high-permeability sediments in the vadose zone. This assumption allows for a straightforward calculation of mass fluxes into the groundwater and consistent comparisons between the simulations.

The model simulations consisted of two phases. In the first phase, the initial conditions for vapor transport were computed by allowing saturated and unsaturated flow to reach steady-state conditions over a period of 10,000 years. After computing these initial steady-state flow conditions, the second phase of the simulations was conducted by restarting the model with a constant vapor concentration in the source area to simulate transient vapor mass discharge from the source zone and transport in the vadose zone and groundwater. The source vapor concentration was maintained at a constant value throughout the source zone during the simulation through equilibrium interphase partitioning from an immobile organic liquid phase emplaced in the source zone. To ensure that diffusion and tortuosity were not affected by the organic liquid saturation in the source zone, the dependency of these parameters on organic liquid (source material) saturation was ignored. These imposed conditions for vapor transport are consistent with a system where the gas phase contamination has been removed by SVE from the entire vadose zone, except for within the source zone. The transport simulations were conducted for a time period of 150 years, although steady-state conditions were often reached within 10-25 years. The SVE process itself was not simulated. Model outputs included gas and aqueous concentrations, as well as vapor mass discharge from the source zone as a function of time. Groundwater impacts were assessed as the groundwater concentrations mixed over a $5 \mathrm{~m}$ aquifer thickness at the top of the aquifer, representing concentrations averaged over the well-screen interval of a nominal monitoring compliance well. 
Table E.1. Parameter values used in the Base Case simulation. The contaminant is carbon tetrachloride (CT). A conceptual model with pertinent parameters is shown in Figure E.1.

\begin{tabular}{|c|c|c|c|c|}
\hline \multicolumn{2}{|l|}{ Parameter } & Units & Value & Ref. \\
\hline Aqueous recharge rate & $R$ & $\mathrm{~mm} / \mathrm{yr}$ & 4 & $\mathrm{c}$ \\
\hline CT in air diffusion coefficient & $D_{a}$ & $\mathrm{~m}^{2} / \mathrm{d}$ & 0.715 & $\mathrm{e}$ \\
\hline CT in water diffusion coefficient & $D_{w}$ & $\mathrm{~m}^{2} / \mathrm{d}$ & $8.25 \times 10^{-5}$ & $\mathrm{e}$ \\
\hline Henry's Law constant & $\mathrm{H}$ & - & 0.89 & $\mathrm{e}$ \\
\hline Groundwater Darcy velocity & $q$ & $\mathrm{~m} / \mathrm{d}$ & 0.3 & C \\
\hline CT vapor concentration in the source zone & $C_{g s}$ & $\mathrm{mg} / \mathrm{L}$ & $1^{b}$ & C \\
\hline CT solubility in water & sol & $\mathrm{mg} / \mathrm{L}$ & 800 & e \\
\hline Subsurface temperature & $\mathrm{T}$ & ${ }^{\circ} \mathrm{C}$ & 20 & $\mathrm{c}$ \\
\hline Vadose zone thickness & $V Z T$ & $\mathrm{~m}$ & 60 & c \\
\hline Lateral area of source $^{a}$ & $S A$ & $\mathrm{~m}^{2}$ & 100 & c \\
\hline Lateral dimensions of source & $w_{1} \times w_{2}$ & $\mathrm{~m}$ & $10 \times 10$ & c \\
\hline Source thickness & $z$ & $\mathrm{~m}$ & 6 & c \\
\hline Source thickness ratio & $S T R=Z / V Z T$ & - & 0.1 & c \\
\hline Distance from surface to top source & $L_{1}$ & $\mathrm{~m}$ & 27 & c \\
\hline Distance from bottom source to water table & $L_{2}$ & $\mathrm{~m}$ & 27 & c \\
\hline Relative source position & $R S P=L_{1} / L_{2}$ & - & 1 & $\mathrm{c}$ \\
\hline Horiz. distance, source center to compliance wells & $\mathrm{d}$ & $\mathrm{m}$ & $10,25,50,75$, and 100 & $\mathrm{c}$ \\
\hline \multicolumn{5}{|c|}{ Porous medium properties } \\
\hline van Genuchten a parameter & $\alpha$ & $\mathrm{cm}^{-1}$ & 1 & $f$ \\
\hline van Genuchten n parameter & $n$ & - & 2.5 & $f$ \\
\hline Hydraulic conductivity & $\mathrm{K}$ & $\mathrm{cm} / \mathrm{s}$ & $5.73 \times 10^{-3}$ & $d$ \\
\hline Vadose zone average gravimetric moisture content & $\omega$ & wt $\%$ & 1 & c \\
\hline Porosity & $\mathrm{n}$ & - & 0.3 & e \\
\hline
\end{tabular}

a Simulated source area is $50 \mathrm{~m}^{2}$ (half domain)

b A gas concentration of $1 \mathrm{mg} / \mathrm{L}$ equates to a concentration of $159 \mathrm{ppmv}$ for carbon tetrachloride

c Based on selected scenario or calculated from other parameters

d Khaleel et al. (2001)

e Truex et al. (2009)

f Oostrom et al. (2010); Truex et al. (2009)

The appropriateness of the simplified conceptual model domain shown in Figure E.1 and was evaluated by completing a series of simulations examining effects of multiple sources and low permeability layering. The details of these simulations are shown in Table E.2. To evaluate sites where several smaller distinct sources may be considered to be part a composite larger source (e.g., Figure E.2), simulations were conducted with four smaller sources with different dimensions. These smaller sources are all located in the Base Case source zone, maintaining source symmetry in all directions. Each of the four sources represent one quarter of the simulated source zone. To allow for a direct comparison of compliance well concentration resulting from these sources, the vapor pressure of the contaminant was adjusted to provide the same overall source mass discharge from each scenario in Table E.2. Two simulations imposing low permeability layers within the vadose zone were also conducted to investigate their impact on simulated steady state well concentrations. These simulations provide input for justifying the use of the homogeneous vadose zone for the generalized conceptual model presented above. 
Table E.2. Consolidated source and simplified lithology simulations.

\begin{tabular}{|c|c|c|c|c|c|c|c|}
\hline \multicolumn{8}{|c|}{ CONSOLIDATED SOURCE SIMULATIONS } \\
\hline Scenario & $\begin{array}{c}\text { Number of } \\
\text { Sources }\end{array}$ & $\begin{array}{l}\text { Total Source } \\
\text { Volume } \\
\left(\mathrm{m}^{3}\right)\end{array}$ & \multicolumn{2}{|c|}{$\begin{array}{c}\text { Source } \\
\text { Dimensions, } \mathrm{x} \times \mathrm{y} \times \mathbf{z} \\
(\mathrm{m})\end{array}$} & \multicolumn{2}{|c|}{$\begin{array}{c}\text { Percent of Source } \\
\text { Contaminated by } \\
\text { NAPL }\end{array}$} & $\begin{array}{l}\text { Vapor } \\
\text { Pressure } \\
(\mathrm{Pa})\end{array}$ \\
\hline Base Case & 1 & 300 & $10 \times 5 \times 6$ & \multicolumn{3}{|c|}{100} & 15.84 \\
\hline Sim. 2 & 4 & 202.5 & \multicolumn{2}{|l|}{$4.5 \times 4.5 \times 2.5$} & \multicolumn{2}{|l|}{67.5} & 16.15 \\
\hline Sim. 3 & 4 & 128 & $4 \times 4 \times 2$ & \multicolumn{3}{|c|}{42.7} & 17.23 \\
\hline Sim. 4 & 4 & 58 & \multicolumn{2}{|l|}{$3 \times 3 \times 1.5$} & \multicolumn{2}{|l|}{19.3} & 17.91 \\
\hline Sim. 5 & 4 & 16 & \multicolumn{2}{|l|}{$2 \times 2 \times 1$} & \multicolumn{2}{|l|}{5.3} & 18.34 \\
\hline \multicolumn{8}{|c|}{ SIMPLIFIED LITHOLOGY SIMULATIONS } \\
\hline Scenario & $\begin{array}{l}\text { Number of } \\
\text { layers }\end{array}$ & $\begin{array}{l}\text { Thickness } \\
\text { layers } \\
\text { (m) }\end{array}$ & $\begin{array}{c}\text { Vertical Extent } \\
(\mathrm{m})\end{array}$ & & $\begin{array}{l}\text { Hydraulic } \\
\text { nductivity } \\
\text { (cm/s) }\end{array}$ & $\operatorname{van} C$ & $\begin{array}{l}\text { Senuchten } \alpha \\
\left(\mathrm{cm}^{-1}\right)\end{array}$ \\
\hline Sim. 6 & 1 & 6 & $27-33$ & & $1.38 \times 10^{-4}$ & & 0.01 \\
\hline Sim. 7 & 3 & 6 & $\begin{array}{r}7-13 \\
17-23 \\
27-33\end{array}$ & & $1.38 \times 10^{-4}$ & & 0.01 \\
\hline
\end{tabular}

A limited sensitivity analysis was completed for a number of parameters, shown in the conceptual framework in Figure E.1, which may linearly or nonlinearly affect downstream compliance well concentrations. The tested parameters and their ranges are shown in Table E.3. The parameter ranges are discussed in a companion paper by Truex et al. (2012c) for arid vadose zone applications. Each simulation considers one change to the Base Case conditions shown in Table E.1.

Table E.3. Investigated parameters and ranges for estimating contaminant concentration in groundwater at compliance wells located 10, 25, 50, 75, and 100 m horizontally downstream from the source center.

\begin{tabular}{|c|c|c|c|}
\hline Name & Symbol & Units & Simulated Values $^{\mathrm{a}}$ \\
\hline Gravimetric Moisture Content & $\omega$ & wt \% & $1,3,5,7,9$ \\
\hline Vadose Zone Thickness & $V Z T$ & $\mathrm{~m}$ & $10,20,30,45,60$ \\
\hline Source Thickness Ratio & STR & - & $0.1,0.25,0.5^{b}$ \\
\hline Relative Source Position & $R S P$ & - & $0.1,0.5,1,5,10$ \\
\hline Source Area & $S A$ & $\mathrm{~m}^{2}$ & $100,400,900,2500$ \\
\hline Groundwater Darcy Velocity & $q$ & $\mathrm{~m} / \mathrm{d}$ & $0.05,0.0175,0.03,0.165,0.3$ \\
\hline Source Gas Concentration $^{\mathrm{C}}$ & $C_{g s}$ & $\mathrm{mg} / \mathrm{L}$ & $\mathbf{1}, 2,10,20$ \\
\hline Henry's Law Constant & $H$ & - & $0.1,0.5,0.89,1.0$ \\
\hline Compliance Well Screen Length & $s$ & $m$ & $5,10,20$ \\
\hline Recharge Rate & $R$ & $\mathrm{~mm} / \mathrm{yr}$ & $4,8,20,40,75$ \\
\hline
\end{tabular}

a A discussion of value ranges is provided in Truex et al. (2012); base case values are shown in bold

b Given a vadose zone thickness (VZT) of $60 \mathrm{~m}$, the $z$ values corresponding to these STR values are 6,15 , and $30 \mathrm{~m}$

c A gas concentration of $1 \mathrm{mg} / \mathrm{L}$ equates to a concentration of $159 \mathrm{ppmv}$ for carbon tetrachloride 


\section{E.3 Results and Discussion}

\section{E.3.1 Base Case Simulation}

The steady-state vapor concentration plume $y=0$ for the Base Case along the centerline of the domain in the direction of groundwater flow is shown in Figure E.3. The Base Case 5\% vapor concentration contour $(0.05 \mathrm{mg} / \mathrm{L})$ extends upstream and downstream to about 100 and $80 \mathrm{~m}$ from the source center, respectively. The contact length at the water table, within the $0.05 \mathrm{mg} / \mathrm{L}$ concentration profile, is therefore approximately $180 \mathrm{~m}$, which is 18 times larger than the source length of $10 \mathrm{~m}$ in the groundwater flow direction. At $x=0$, the width of the plume (not shown) is about $80 \mathrm{~m}$. The elongated nature of the plume downstream from the source is the result of interactions between the vapor and the moving groundwater. Near the source, vapor partitions into the groundwater. At some distance away downstream from the source, contaminant moves from the aqueous phase back into the vapor phase in the unsaturated zone. In general, contaminant transport mainly occurs through gas-phase diffusion with limited contributions from dissolved transport in the aqueous phase by recharge water.

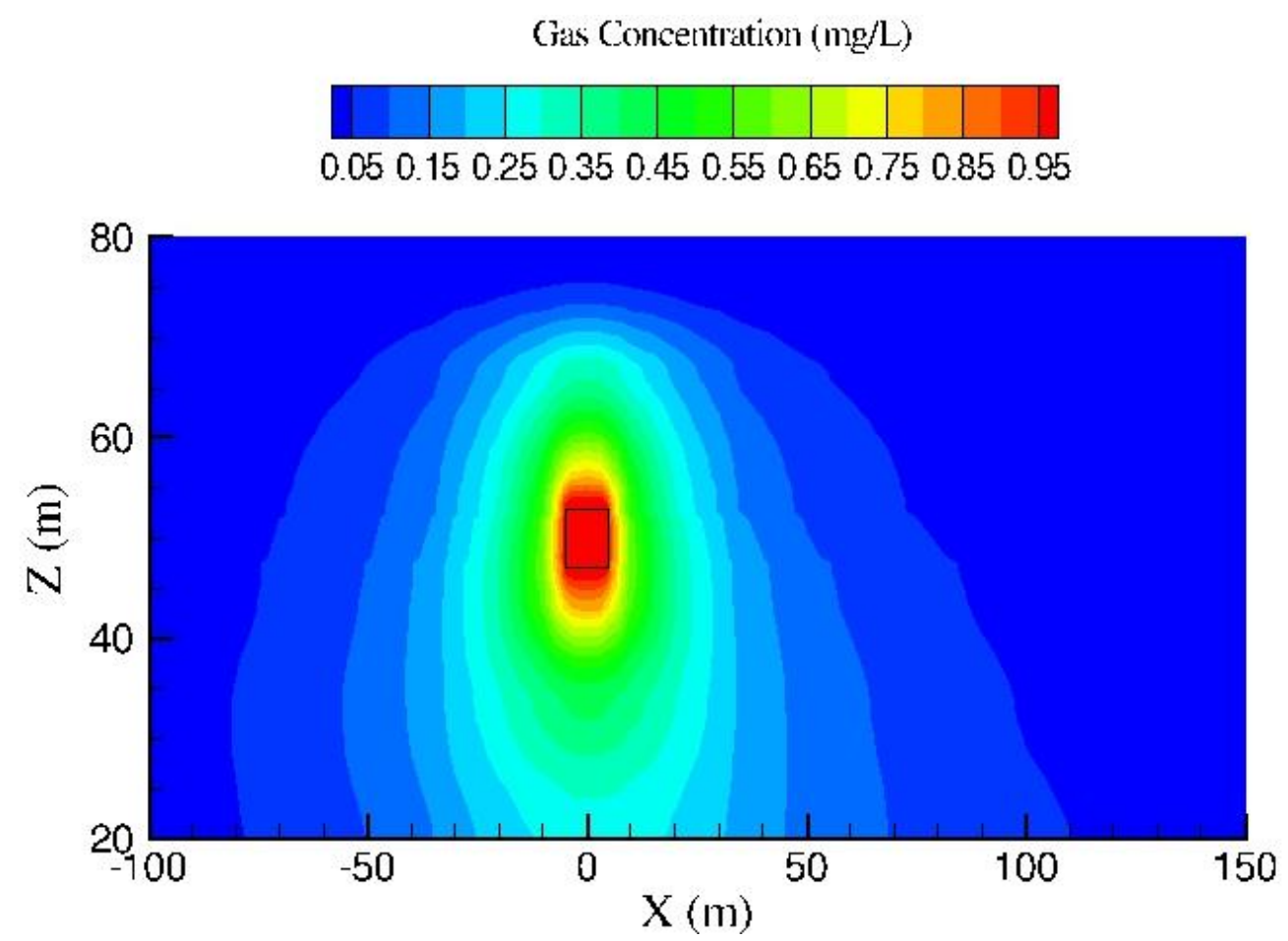

Figure E.3. CT gas concentrations at $y=0$ for the Base Case simulation. The source gas concentration is $1 \mathrm{mg} / \mathrm{L}$.

Well concentrations for the Base Case at the groundwater plume centerline as a function of horizontal distance to the source center are shown as the lowest line in Figure E.4. A maximum concentration of $\sim 10 \mu \mathrm{g} / \mathrm{L}$ is found at $50 \mathrm{~m}$ from the source center. Due to hydrodynamic dispersion and partitioning of the contaminant (CT is used in the based case simulation) back into the vadose zone, the dissolved CT concentrations decrease gradually from $x=50 \mathrm{~m}$ to the downgradient boundary of the computational domain. The vertical extent the groundwater plume is on the order of meters over a distance of $100 \mathrm{~m}$ from the source center. Additional information about volatile organic compound vapors in the vadose zone interacting with groundwater can be found in Carroll et al. (2012) and Oostrom et al. (2010). 


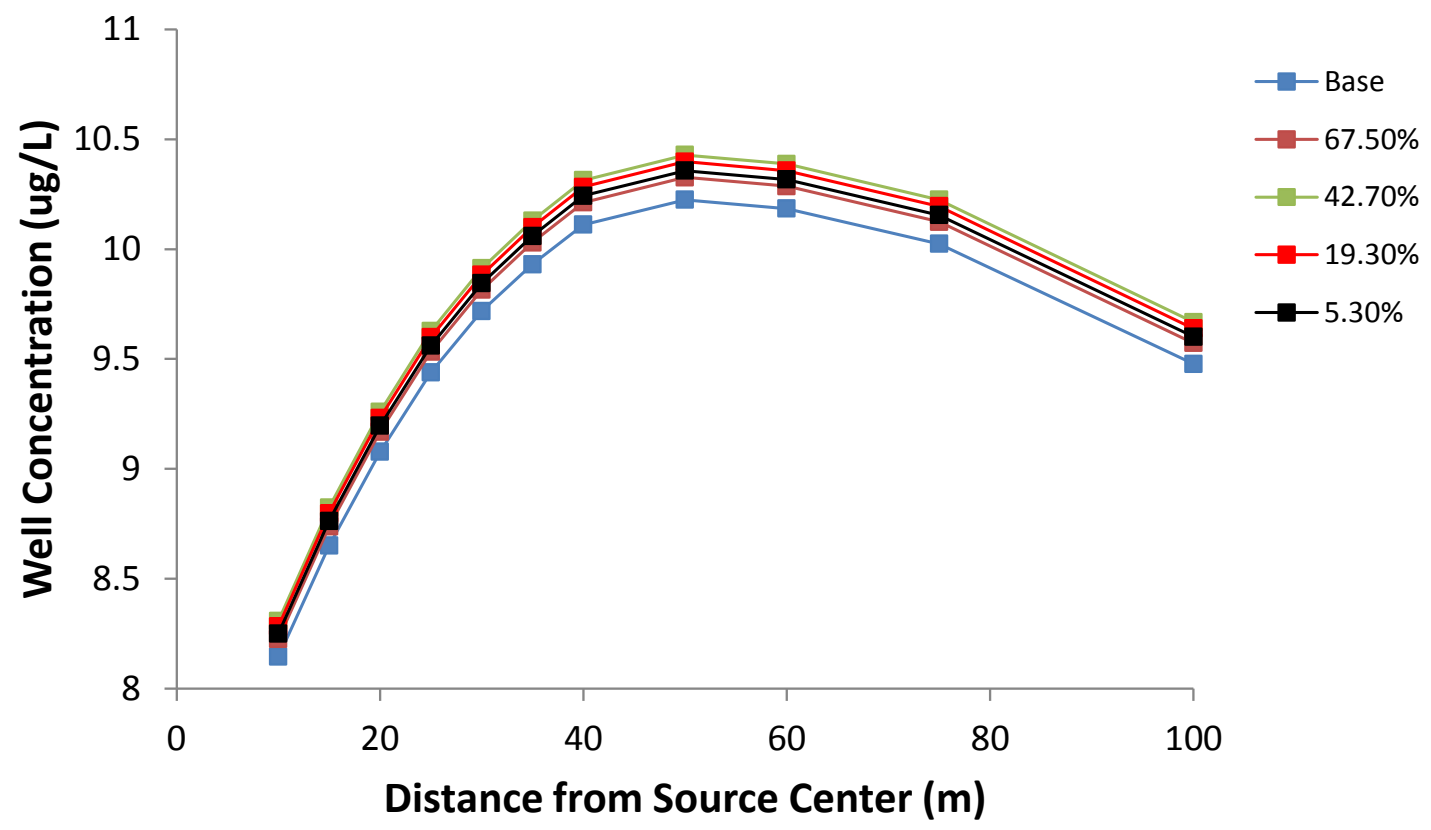

Figure E.4. Well concentration as a function of downgradient horizontal distance from the source center for the base case and source heterogeneity simulations. Simulation details are provided in Table E.2.

\section{E.3.2 Effects of Source Configuration and Low Permeability Layers}

Compliance well concentrations for the simulations investigating effects of source configuration and low permeability layers are shown in Figures 4 and 5 respectively. Figure E. 4 shows that presence of discrete source zones (versus a uniformly distributed source) within the same portion of the vadose zone has only a small effect on simulated groundwater well concentrations, even to an effective source volume of 5.3\% of the Base Case. As long as the overall source mass discharge is minimally affected, similar amounts of water vapor will diffuse downwards to the groundwater, for any of the source configurations. Lower permeability layers also have a small effect on long-term vapor transport. Although the effective diffusion coefficient will decrease with the increasing moisture content in the lower permeability layers, subsurface vapor distribution is only minimally effected by such layers for long term steady state transport. The finding that source configuration and lower permeability layers do not have a large effect on long-term vapor behavior in the vadose zone and on dissolved compliance well concentrations justifies the generalized conceptual model and associated numerical simulation approach with homogeneous equivalent hydraulic properties to evaluate steady state vapor migration in the vadose zone and associated dissolved contaminant transport in resultant groundwater contaminant concentrations. 


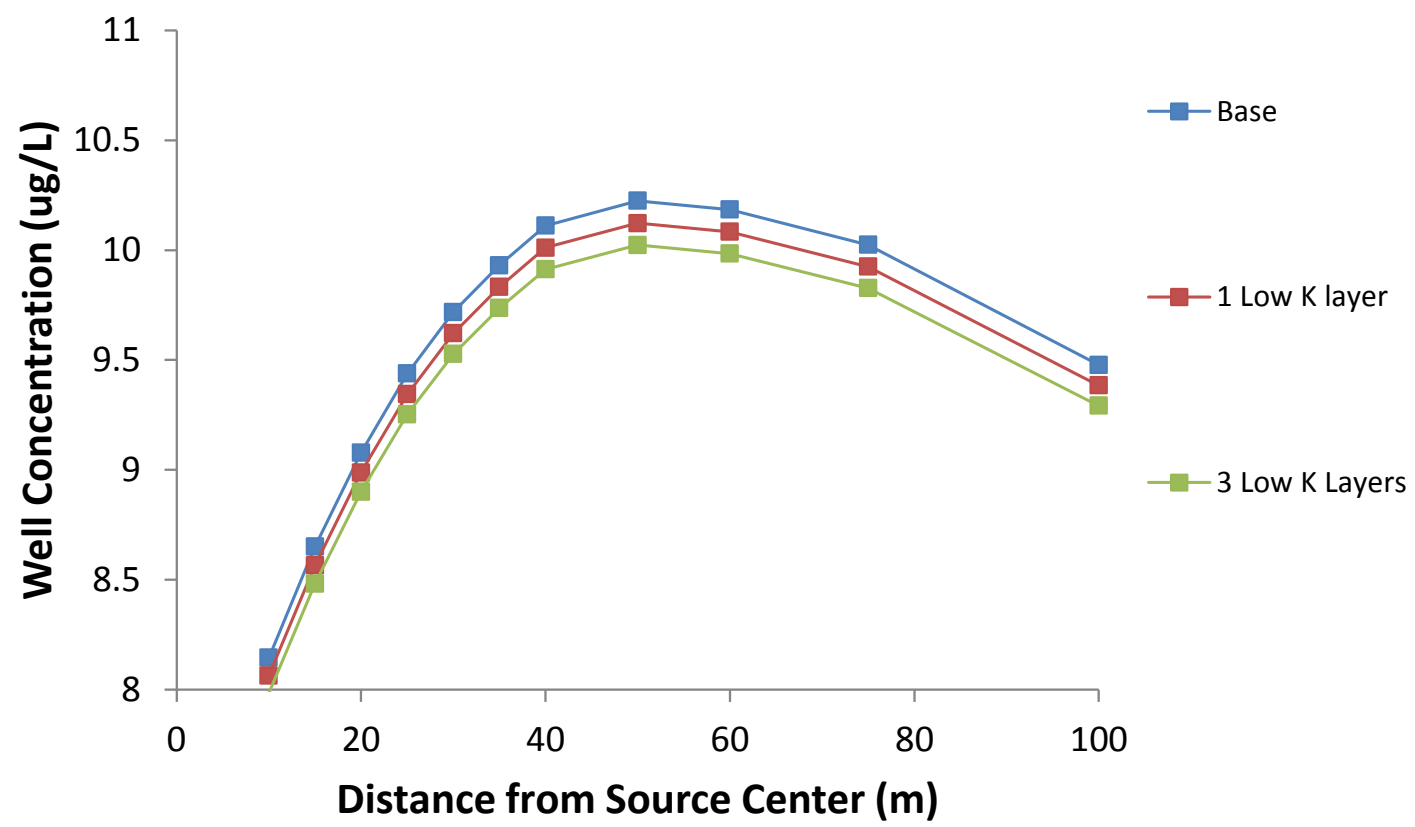

Figure E.5. Well concentration as a function of downgradient horizontal distance from the source center for the base case (homogeneous) and simulations with one and three low permeability (K) layers. Simulation details are provided in Table E.2.

\section{E.3.3 Effects of Linear and Nonlinear Controlling Parameters}

The effects of the controlling parameters listed in Table E.3 are shown in Figures 6 through 13. Each of the figures includes compliance well concentrations and source mass discharge results. In all these figures, except Figures 11 and 12, the well concentrations are shown at two Darcy velocities, 0.03 and 0.3 $\mathrm{m} / \mathrm{d}$ (A and B, respectively). 


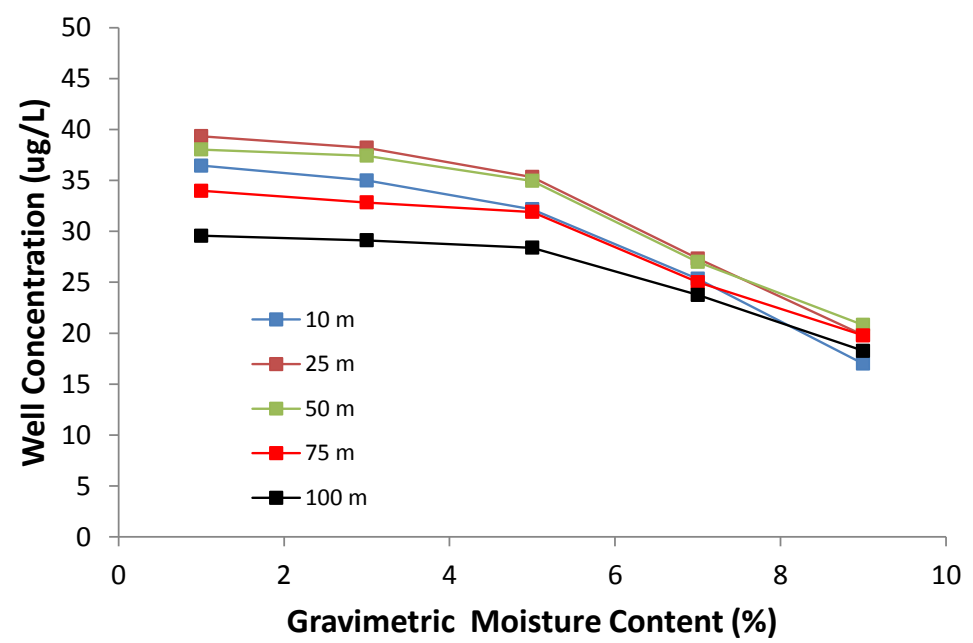

(a)

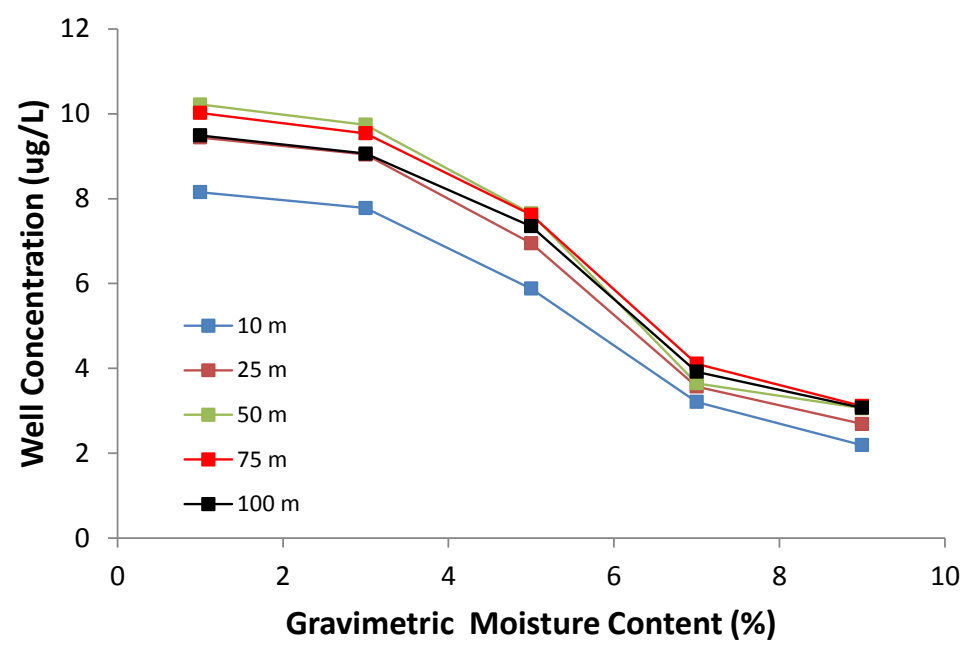

(b)

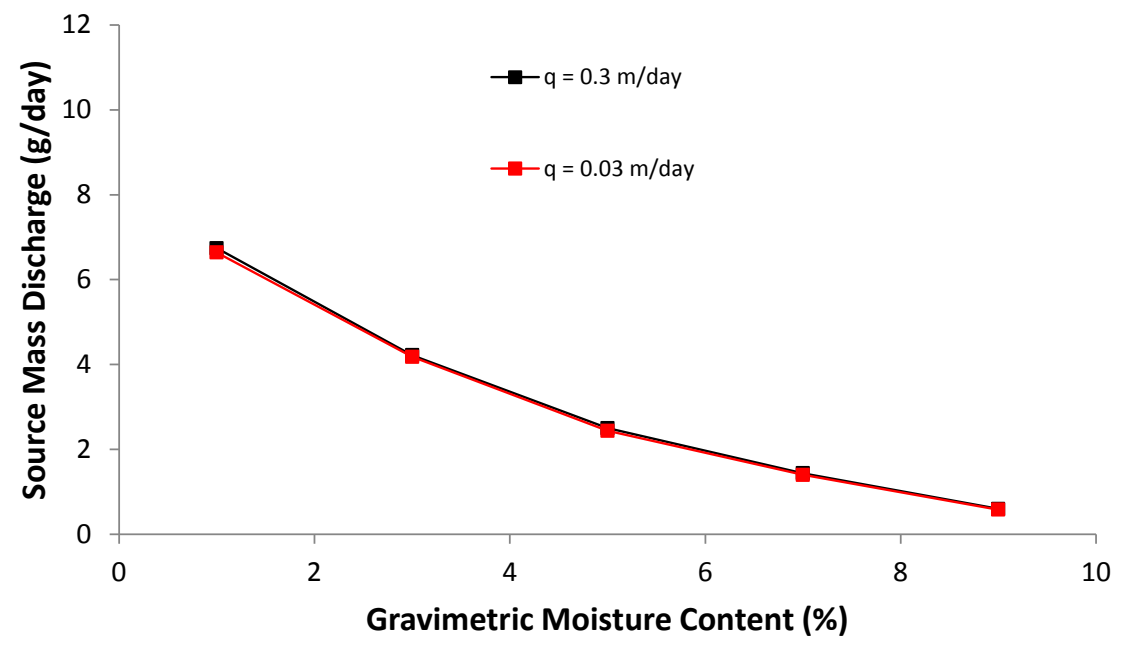

(c)

Figure E.6. Well concentrations at $\mathrm{d}=10,25,50,75$, and $100 \mathrm{~m}$ for (a) $\mathrm{q}=0.03$ and (b) $\mathrm{q}=0.3 \mathrm{~m}$, and (c) source mass discharge as a function of gravimetric moisture content. In this example, $\mathrm{SA}=100 \mathrm{~m}^{2}, \mathrm{VZT}=60 \mathrm{~m}, \mathrm{SRT}=0.1$, and $\mathrm{RSP}=1$. 


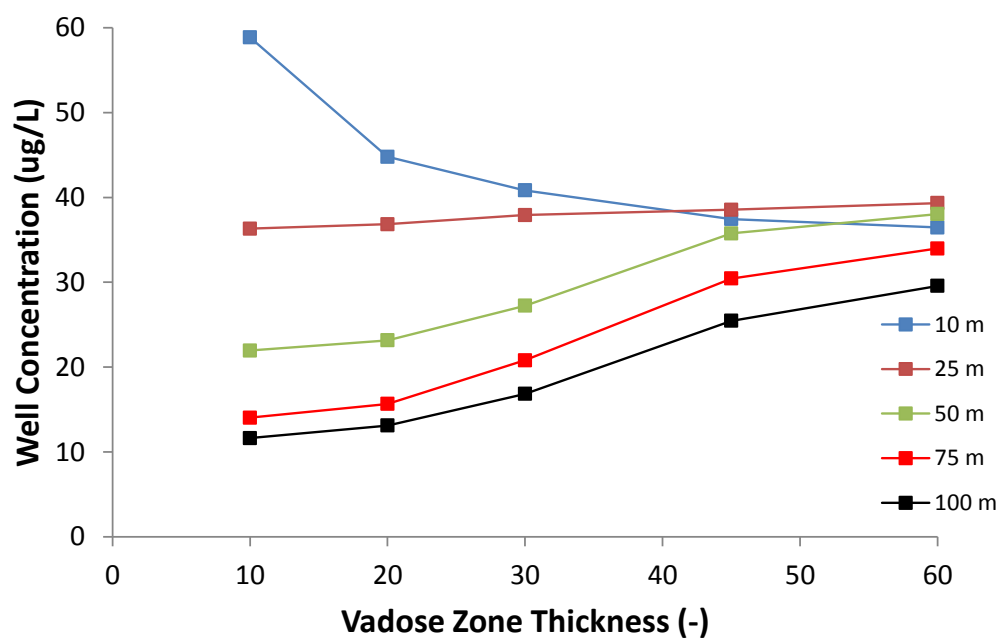

(a)

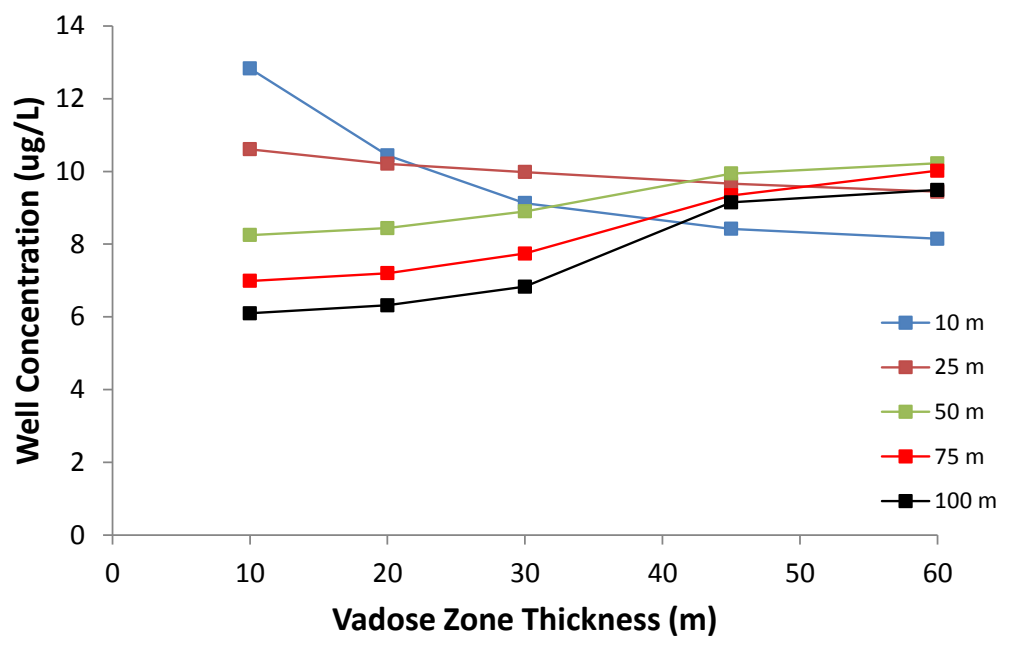

(b)

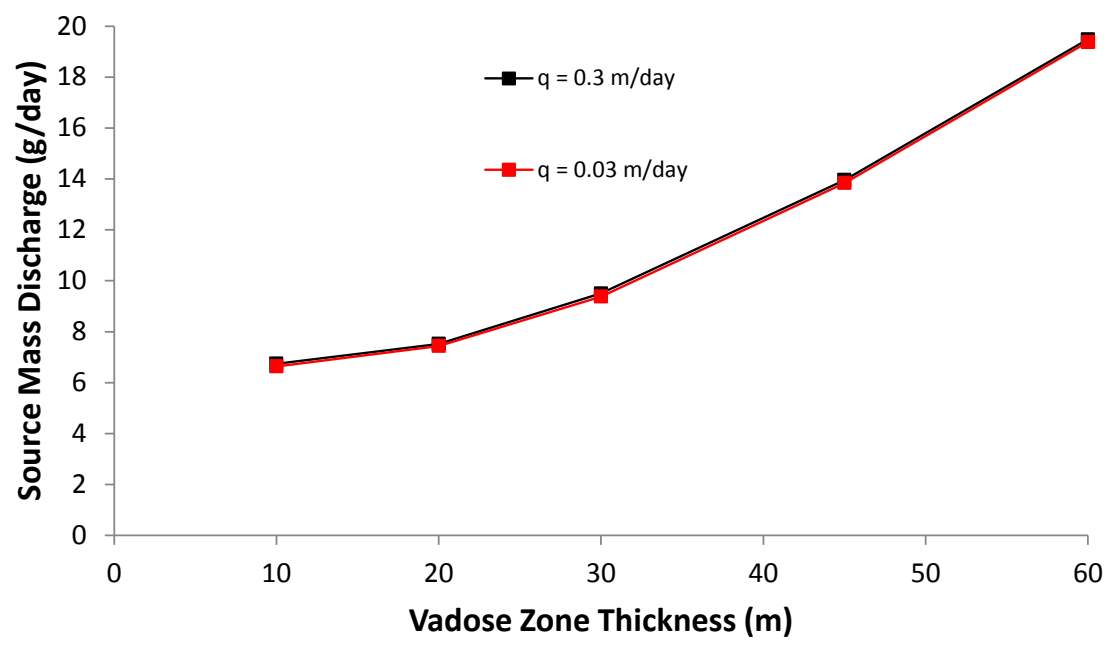

(c)

Figure E.7. Well concentrations at $\mathrm{d}=10,25,50,75$, and $100 \mathrm{~m}$ for (a) $\mathrm{q}=0.03$ and (b) $\mathrm{q}=0.3 \mathrm{~m}$, and (c) source mass discharge as a function of vadose zone thickness (VZT). In this example, $\mathrm{SA}=100 \mathrm{~m}^{2}, \mathrm{RSP}=1$, and $\mathrm{z}=6 \mathrm{~m}$. 


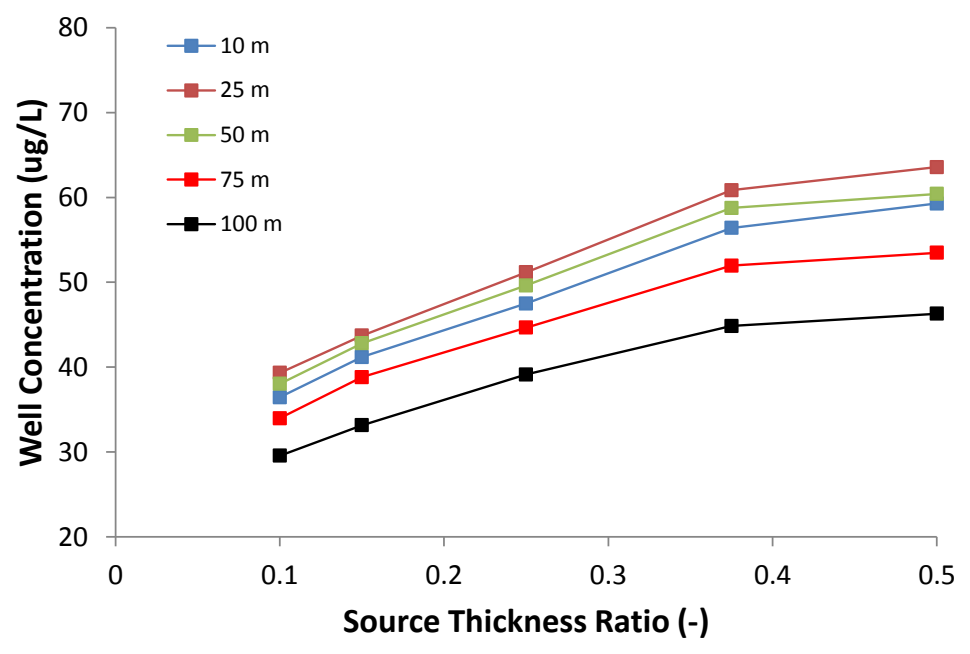

(a)

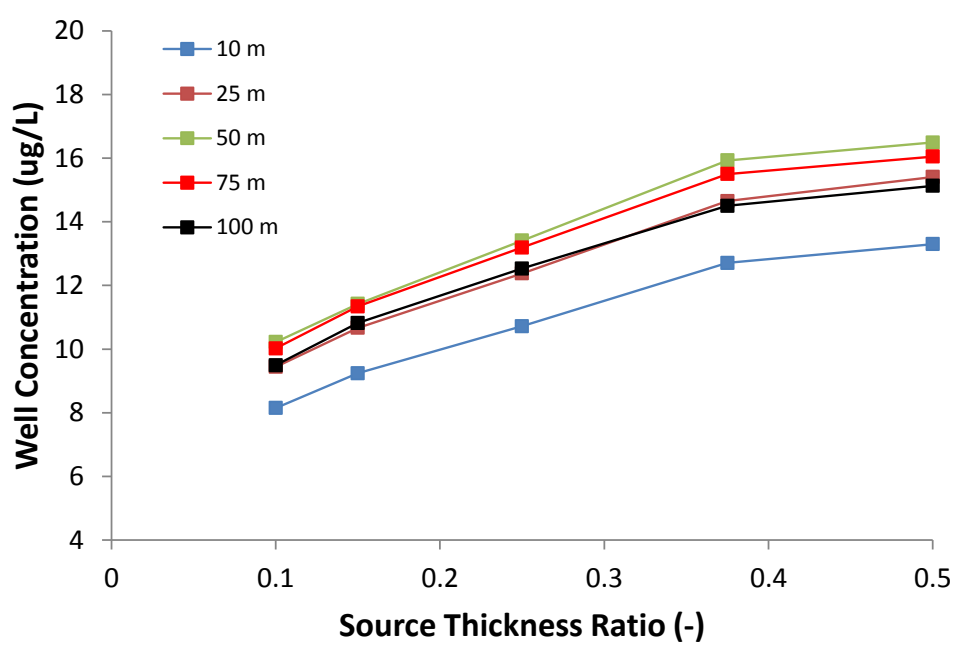

(b)

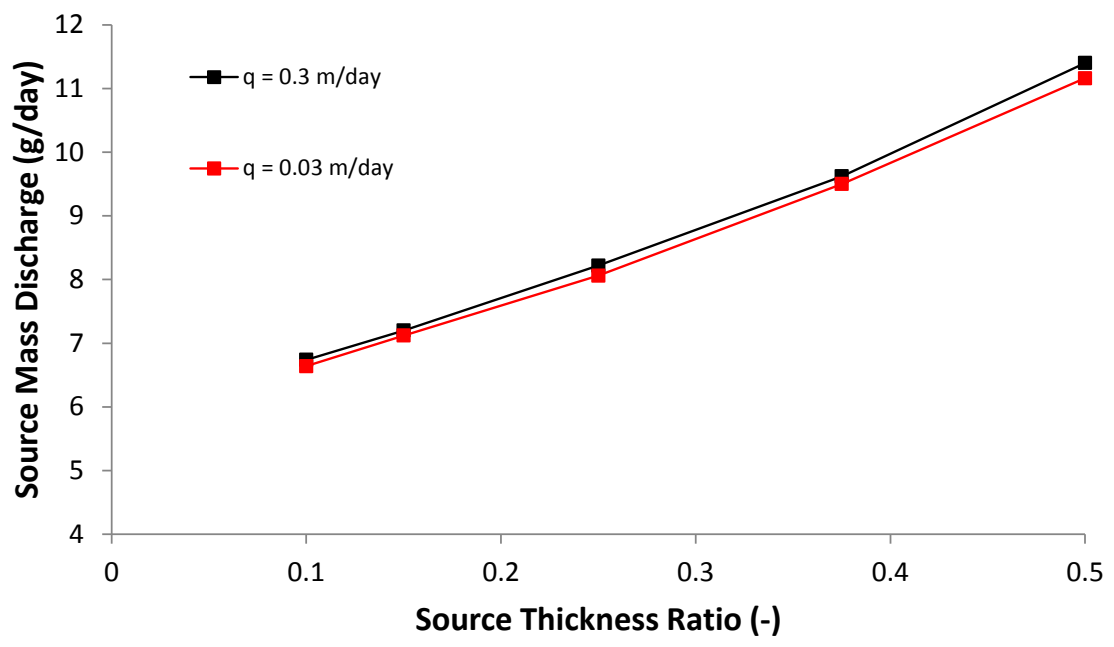

(c)

Figure E.8. Well concentrations at $\mathrm{d}=10,25,50,75$, and $100 \mathrm{~m}$ for (a) $\mathrm{q}=0.03$ and (b) $\mathrm{q}=0.3 \mathrm{~m}$, and (c) source mass discharge as a function of the source thickness ratio (STR). In this example, $\mathrm{SA}=100 \mathrm{~m}^{2}, \mathrm{VZT}=60 \mathrm{~m}$, and $\mathrm{RSP}=1$. 


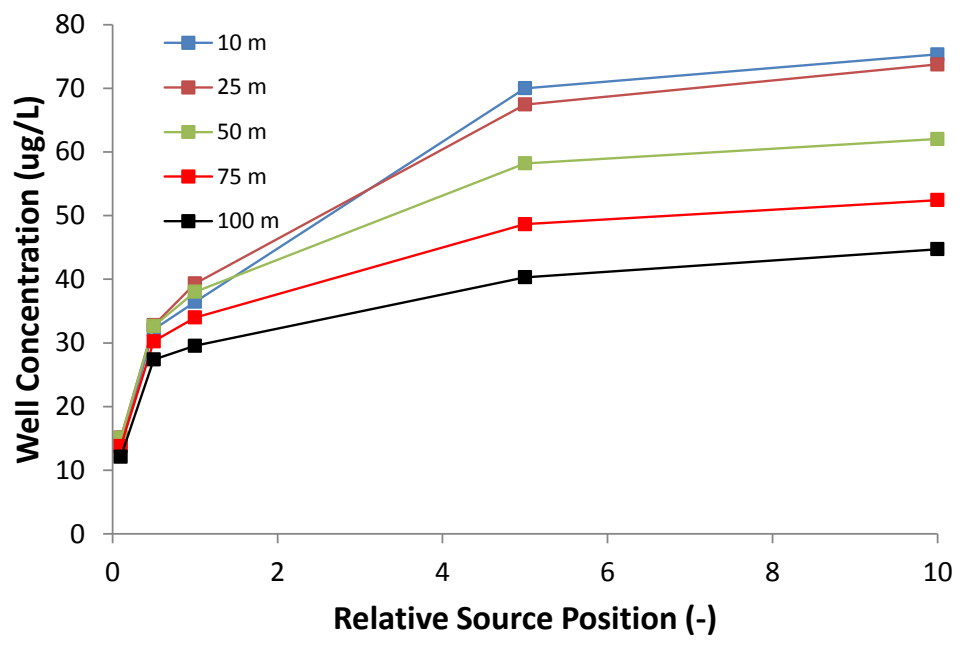

(a)

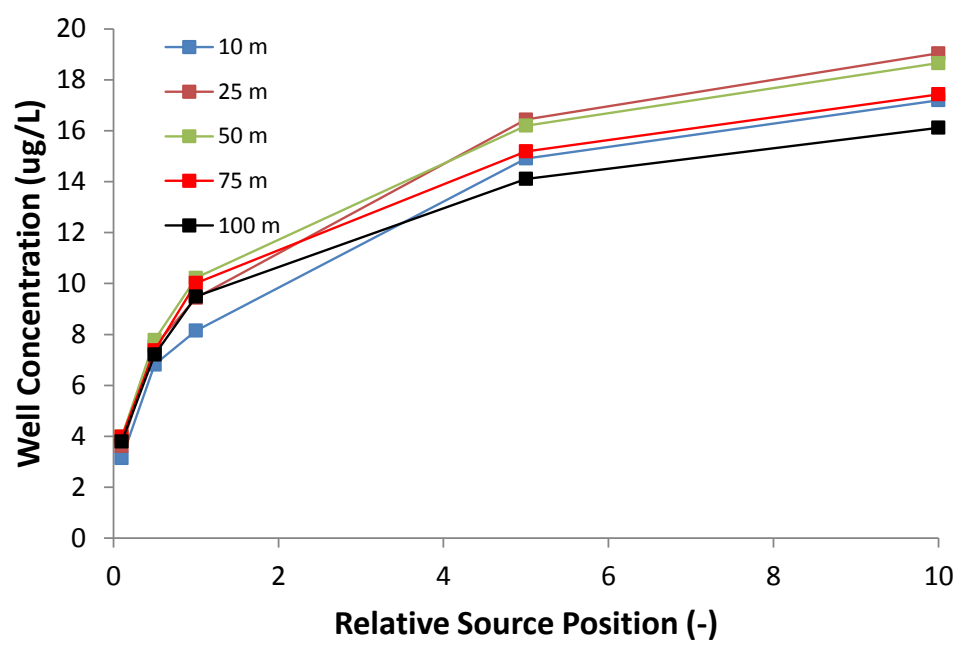

(b)

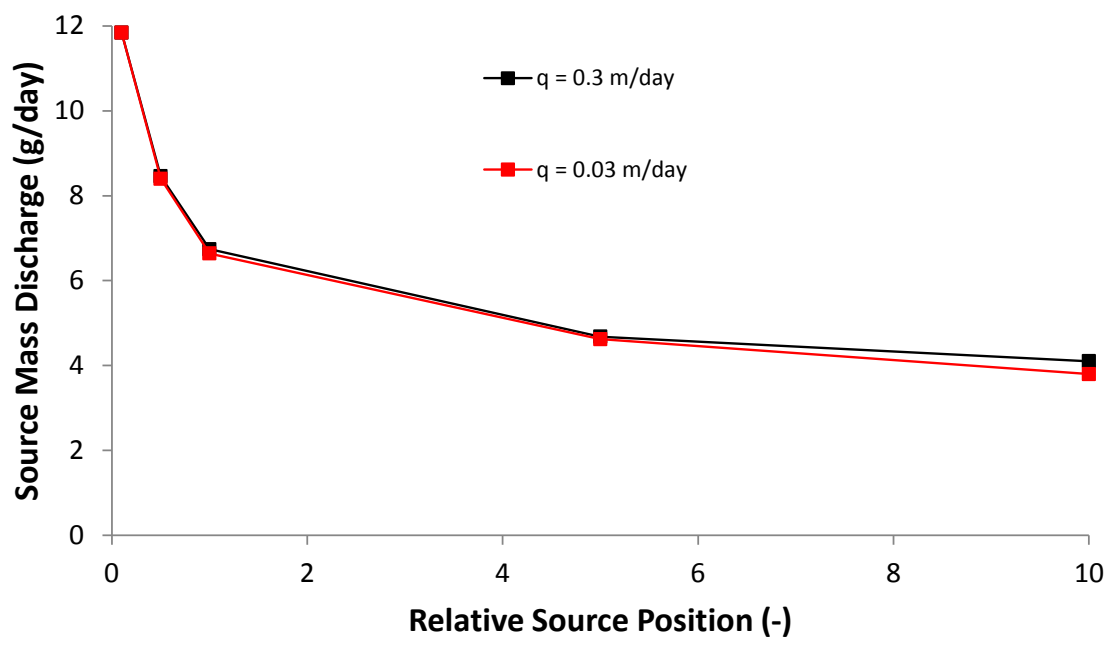

(c)

Figure E.9. Well concentrations at $d=10,25,50,75$, and $100 \mathrm{~m}$ for (a) $\mathrm{q}=0.03$ and (b) $\mathrm{q}=0.3 \mathrm{~m}$, and (c) source mass discharge as a function of relative source position (RSP). In this example, $\mathrm{SA}=100 \mathrm{~m}^{2}, \mathrm{VZT}=60 \mathrm{~m}$, and $\mathrm{STR}=0.1$. 


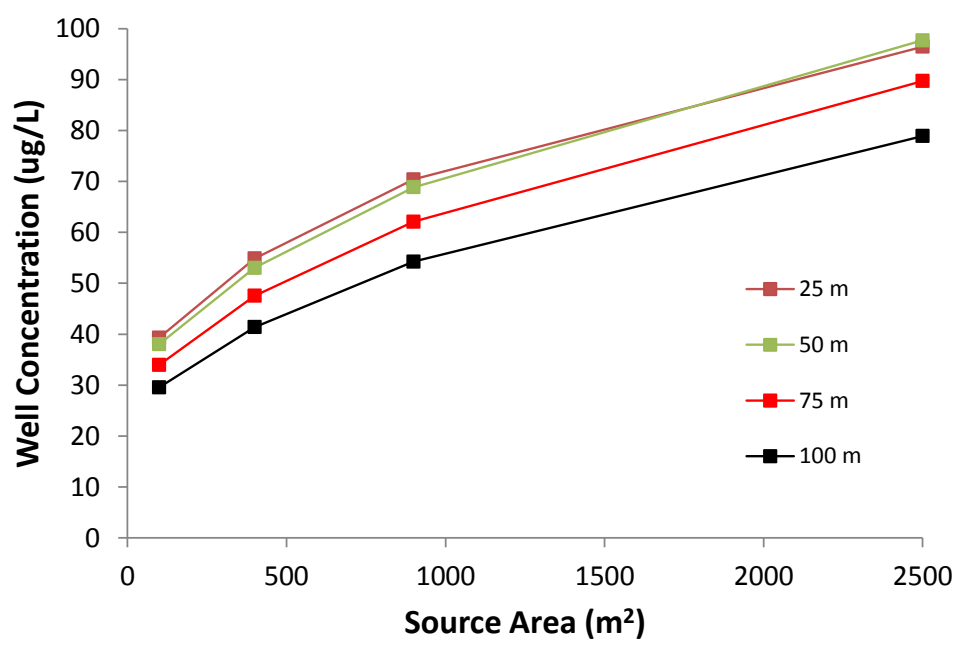

(a)

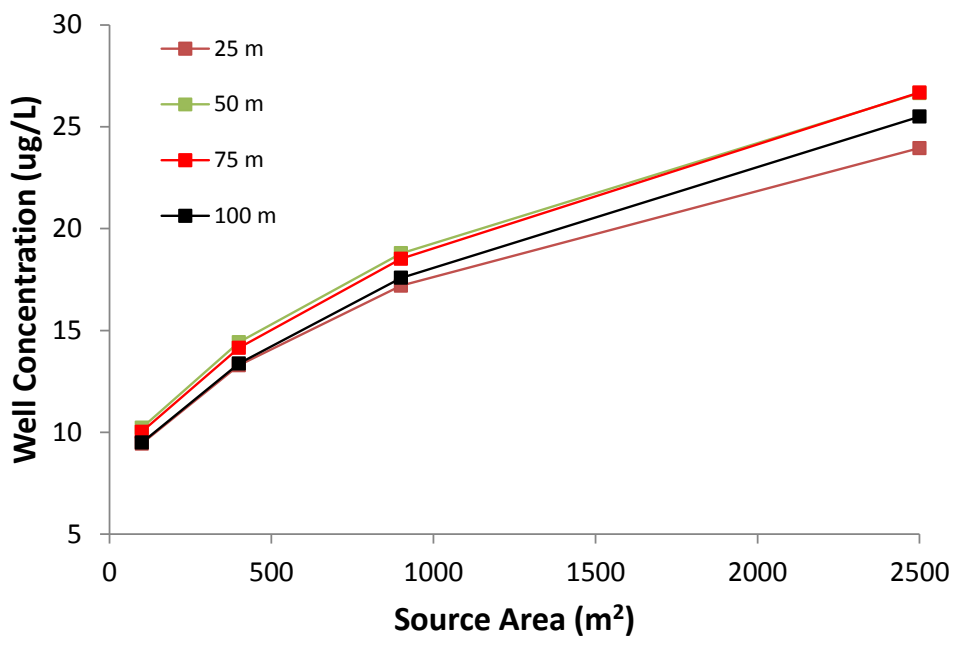

(b)

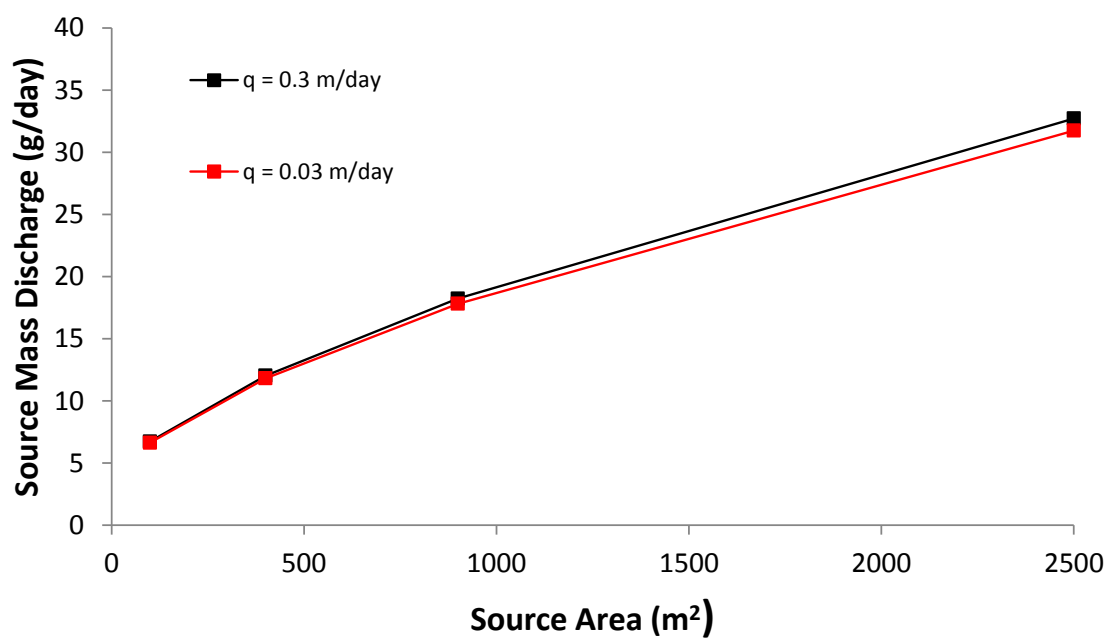

(c)

Figure E.10. Well concentrations at $\mathrm{d}=10,25,50,75$, and $100 \mathrm{~m}$ for (a) $\mathrm{q}=0.03$ and (b) $\mathrm{q}=0.3 \mathrm{~m}$, and (c) source mass discharge as a function of source area (SA). In this example, RSP $=1$, $\mathrm{VZT}=60 \mathrm{~m}$, and STR $=0.1$. 


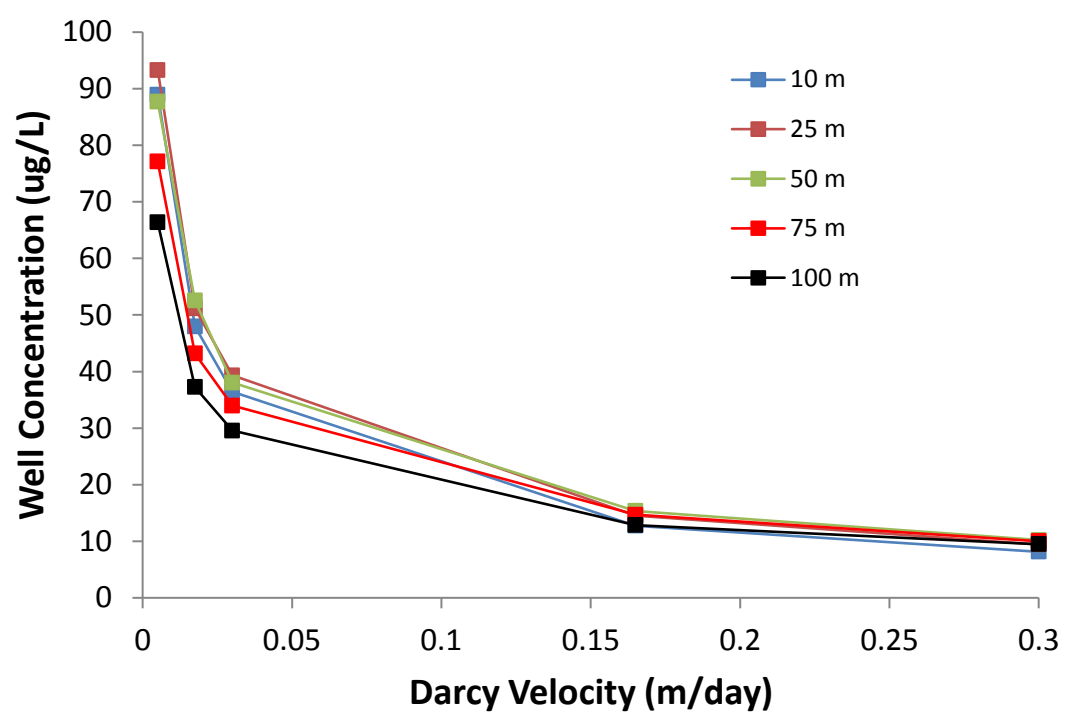

(a)

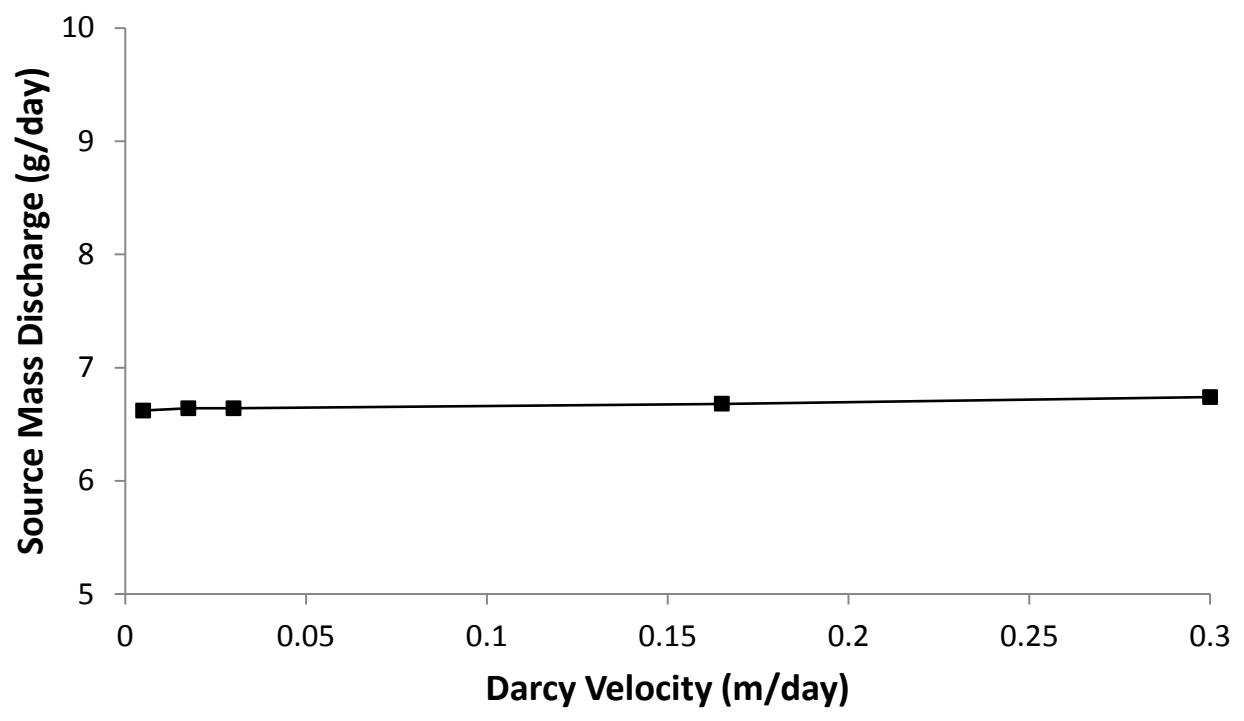

(b)

Figure E.11. Plot of (a) well concentrations at $d=10,25,50,75$, and $100 \mathrm{~m}$, and (b) source mass discharge as a function of Darcy velocity. In this example, RSP $=1, \mathrm{VZT}=60 \mathrm{~m}, \mathrm{STR}=$ 0.1 , and $\mathrm{SA}=100 \mathrm{~m}^{2}$. 


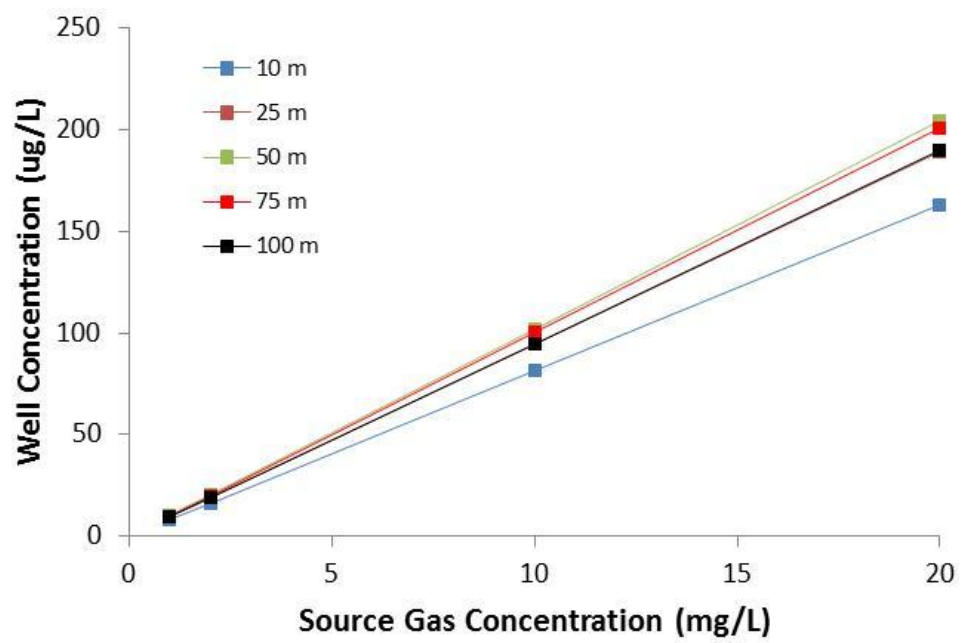

(a)

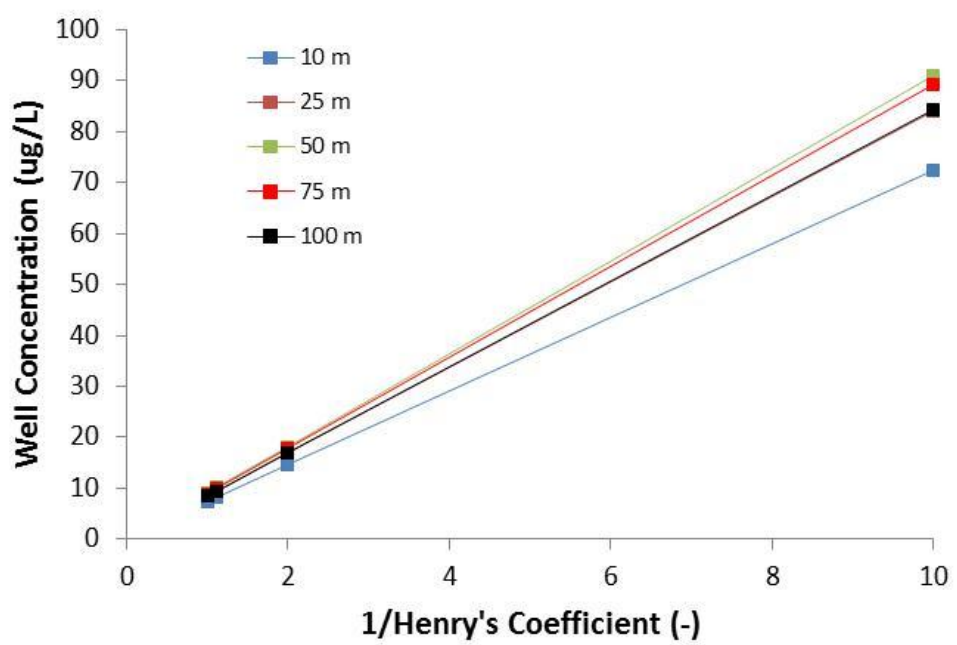

(b)

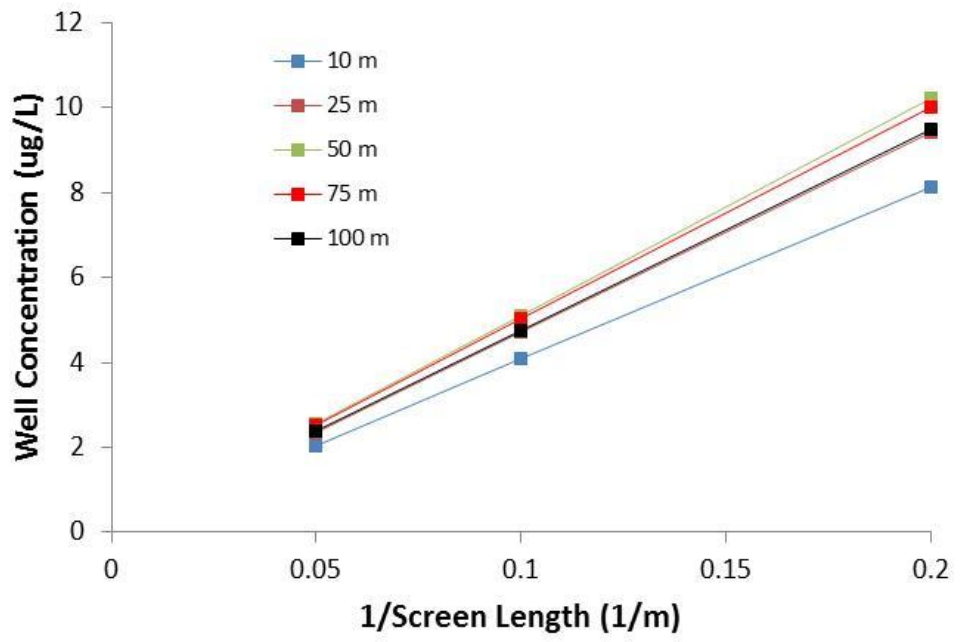

(c)

Figure E.12. Well concentration as a function of (a) source gas concentration, (b) Henry's coefficient, and (c) well screen length. 

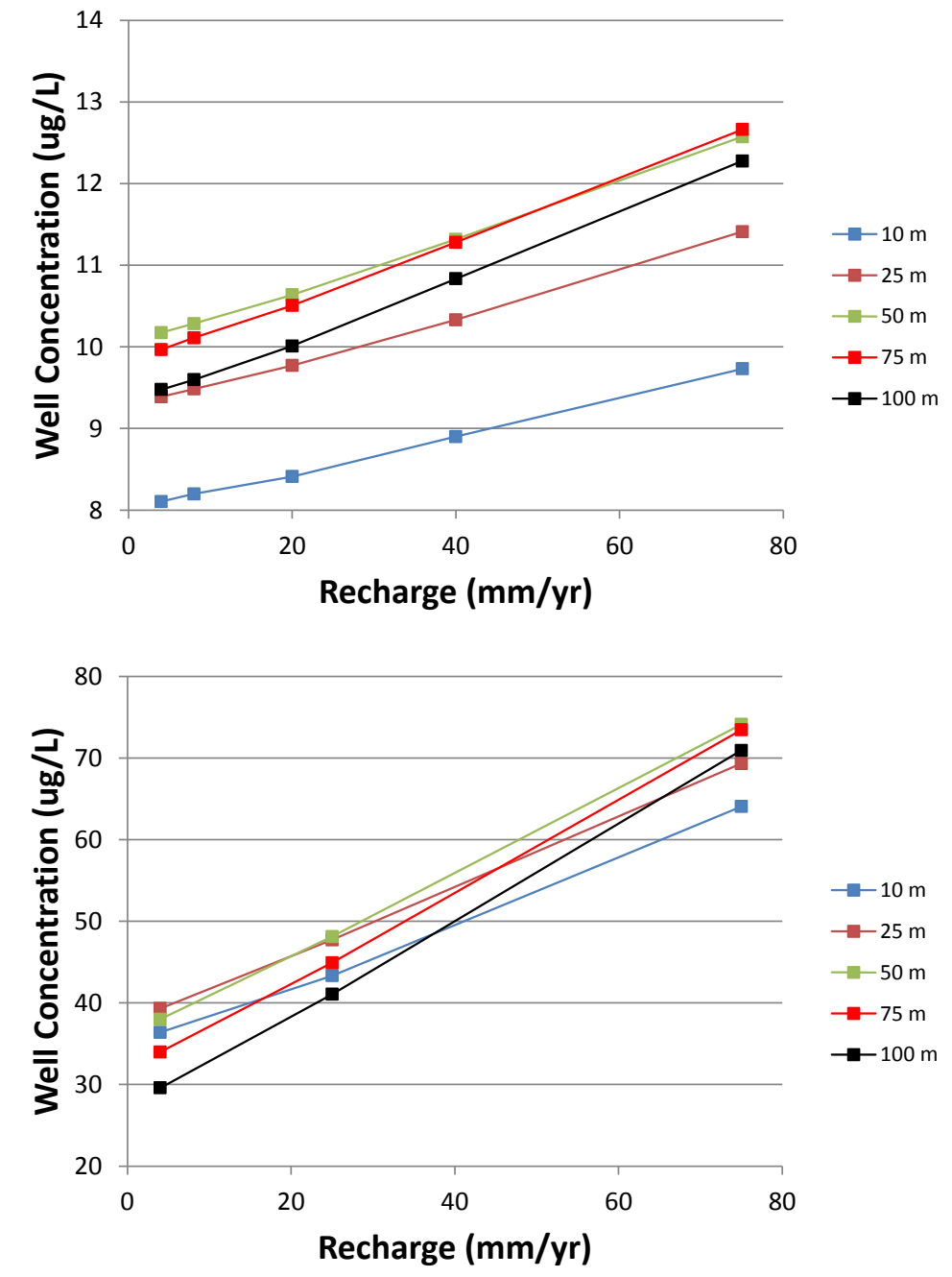

(a)

(b)

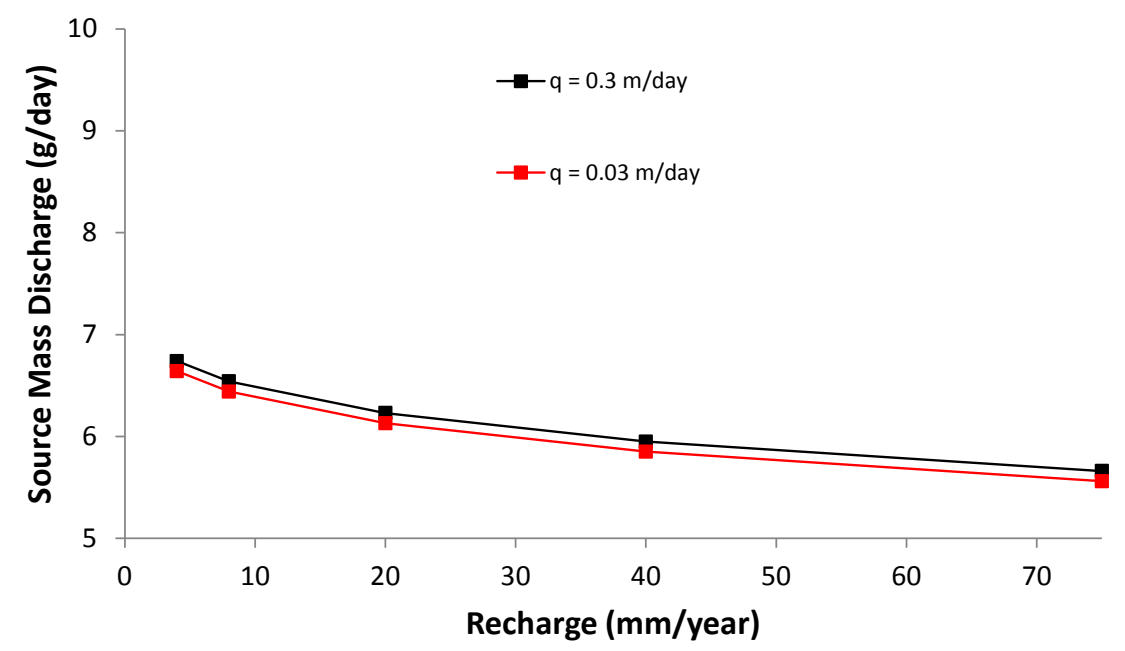

(c)

Figure E.13. Well concentrations at $d=10,25,50,75$, and $100 \mathrm{~m}$ for (a) $\mathrm{q}=0.03$ and (b) $\mathrm{q}=0.3 \mathrm{~m}$, and (c) source mass discharge as a function of recharge. In this example, RSP $=1, \mathrm{VZT}=60$ $\mathrm{m}, \mathrm{SA}=100 \mathrm{~m}^{2}$, and $\mathrm{STR}=0.1$. 
Figure E.6 shows that an increase in gravimetric water content, $\omega$, leads to a decrease in well concentrations and mass discharge. The decrease in well concentrations for both groundwater velocities as a function of $\omega$ is clearly non-linear. For the $0.03 \mathrm{~m} /$ day Darcy velocity simulations, the well concentrations are approximately a factor $4-5$ larger than for the $0.3 \mathrm{~m} / \mathrm{d}$ Darcy velocity simulations. The reason the well concentrations are not inversely proportional to the groundwater velocity is related to the three-dimensional (3D) nature of both the vapor plume in the gas phase and dissolved CT plume in the groundwater.

The partitioning process of vapors into and out of the groundwater is also evident in these figures. At the lower Darcy velocity, the lowest concentrations are at the well at $100 \mathrm{~m}$ from the source center. However, the lowest concentrations for the $q=0.3 \mathrm{~m} / \mathrm{d}$ simulations occurred near the source, indicating an increased dilution due to a higher groundwater velocity near the source. The source mass discharge decreases monotonically with $\omega$, with similar results for both $q$ values. This result indicates that the partitioning into and out of the groundwater has no effect on the source behavior. Similar effects were observed by Truex et al. (2009) and Oostrom et al. (2010), who showed that the vast majority of the vapors emanating from the source are typically transported to the atmosphere. Under most vadose zone scenarios with relatively low recharge, Oostrom et al. (2010) showed that less than 5\% of vapors were transported into the groundwater.

Well concentrations as a function of vadose zone thickness (VZT) show converging nonlinear trends for both groundwater velocities, although the mass discharge increases with an increase in VZT (Figure E.7). For these simulations, having the same source thickness of $6 \mathrm{~m}$, the distances from the source to the ground surface and to the water table determine to a large degree how the vapors behave in the vadose zone and how much partitions in the groundwater. For the largest considered VZT of $60 \mathrm{~m}$, the distance to the water table is far enough to have relatively small differences in well concentrations at different downgradient locations. When the VZT is relatively small, however, the proximity of the water table causes an increase of the mass flux into the groundwater near the source. For those cases, the well concentrations at $10 \mathrm{~m}$ are the largest. The rapid decrease in well concentrations with distance from the source for the shallow vadose zone scenarios is related to the relatively small distance from the water table to the surface. As a result, the diffusive gradient to the ground surface is larger and vapors are more rapidly transported into the atmosphere, leading to large reductions in well concentrations.

An increase in the source thickness ratio $(S T R)$ leads to expected increases in well concentrations for both groundwater velocities (Figure E.8). The responses are near-linear in the range from 0.1 to 0.4 , but level off when the ratio increases beyond 0.4. The source mass discharge increases almost linearly with $S T R$ although a five-time increase in thickness (and therefore source volume) yields to less than a doubling in discharge. This result can be explained by realizing that the vast majority of the source mass discharge comes from its top surface. At that location, the concentration gradient is the largest and most vapor diffuses to the ground surface using this pathway.

The effects of the relative source position $(R S P)$ on both well concentrations and mass discharge are clearly nonlinear (Figure E.9). Interestingly, the well concentrations increase with increasing $R S P$ but the mass discharge shows the opposite response. When the $R S P$ increases, the source is located closer to the water table, which logically results in increased well concentrations. On the other hand, an increasing $R S P$ leads to an increased distance of the source to the surface and therefore a reduced concentration gradient and associated flux to the ground surface. Because mass fluxes to the surface are orders or magnitude larger than the fluxes into the groundwater, the net effect is a decrease in the source mass discharge. 
An increase in source area $(S A)$ leads, as expected, to increases in both well concentrations and source mass discharge, although the increases are far less than proportional (Figure E.10). A $S A$ size increase by up to a factor 25 , only results in well concentration increases by, at the most, a factor 3 . As explained in Carroll et al. (2012), the nonlinear increase with source size is directly related to the 3D nature of the vapor plumes, the vadose zone thickness, and the relative source position. As the source size increases, the ratio of the vapor plume volume and the source volume decreases and will approach a constant value when the source size becomes relatively large. The vapor plume size is, of course, not able to increase linearly with the source size, because it is limited by the vadose zone thickness and the proximity to the surface, where a zero concentration boundary condition is imposed.

Figures 6 through 10 have already shown that for most parameters, an increase in $q$ from 0.03 to 0.3 $\mathrm{m} / \mathrm{d}$ leads to a reduction in compliance well concentrations by a factor of approximately 3-4 over a horizontal distance ranging from 10 to $100 \mathrm{~m}$ from the source center. As can be seen in Figure E.11, a reduction in $q$ to $0.005 \mathrm{~m} / \mathrm{d}$ leads to a least a doubling in the well concentrations. In general, the well concentration $-q$ relation is nonlinear due to the relative magnitudes of diffusive and advective mass transport over the investigated $q$ range. The source mass discharge is independent of $q$, indicating that the vapor partitioning into the groundwater is relatively small for the tested scenarios because most of the emanating vapors are transported to the ground surface.

Parameters that result in proportional or inversely proportional change in well concentrations over the tested ranges are shown in Figure E.12. These parameters are the source gas concentration $\left(C_{g s}\right)$, Henry's Law constant $(H)$, and the screen length $(s)$. These results are consistent with theory and related literature (Yoon et al., 2009). With respect to the linear source concentration behavior, it is known that densitydriven advection might be a factor for relatively high concentrations (Lenhard et al., 1995), but the emphasis in this work is on largely depleted sources that provide persistent low concentration long-term vapors to the vadose zone. Oostrom et al. (2010) demonstrated that density driven advection in the vadose zone is minimal at vapor concentrations up to $15,000 \mathrm{ppmv}$.

Recharge, over the range from 4 to $75 \mathrm{~mm} / \mathrm{yr}$, results in a near-linear response in well concentrations although the responses are not proportional with the increase in recharge (Figure E.13). Although an increase in recharge will result in additional transport across the water table, this advective mass flux is added to the mass flux originating from diffusive gas transport into the capillary fringe, followed by partitioning into the groundwater. The slopes of the $q=0.03 \mathrm{~m} / \mathrm{d}$ simulations are fairly similar at all well locations with an average value of $\sim 0.41 \mu \mathrm{g} / \mathrm{L}-\mathrm{mm}$. For the $q=0.3 \mathrm{~m} / \mathrm{d}$ simulations, the slopes are approximately one order of magnitude smaller with an average value of $\sim 0.042 \mu \mathrm{g} / \mathrm{L}-\mathrm{mm}$. However, in comparing well concentrations at the same locations across different $q$ values, the relationship between recharge and resulting well concentration includes a dependency on the value of $q$ that is not linear (see Appendix C).

\section{E.4 Conclusions and Implications for Waste Site Evaluations}

The analyses above demonstrate that, for sites where vapor-phase transport is a dominant component of the overall contaminant fate and transport from a vadose zone source, (1) the resulting contaminant concentration in groundwater is controlled by a limited set of parameters and (2) a generalized conceptual model for the contaminant and vadose zone configurations can be applied for transport simulations. The functional relationship between dimensional and transport parameters and resulting groundwater concen- 
trations have been defined and provide a basis for establishing a structured approach to evaluating the potential risk to groundwater posed by a vadose zone source.

Over the implied ranges, the compliance well concentrations showed proportionality (or inverse proportionality) with source concentration, Henry's Law constant, and well screen length. An increase in site recharge caused a linear response in well concentration, with slopes dependent on the groundwater velocity. All other tested parameters resulted in nonlinear responses.

This type of evaluation is particularly important to sites where SVE has been applied and reduced contaminant concentrations, but has reached a condition of diminishing returns such that a site must consider whether continuation of SVE, remedy modifications, or remedy closure is warranted. Typically, a key component of this analysis is determination of the projected risk to groundwater if SVE is terminated (USACE 2002; EPA 2001; Truex et al. 2012; Carroll et al. 2012). Evaluation of impacts to groundwater from vadose zone contamination could also contribute to initial site assessment of whether or not remediation is needed or to design of a SVE system by providing information about the vadose zone remediation performance required to meet groundwater contaminant concentration goals.

Additional factors may impact the estimated contaminant groundwater concentrations. One category of such factors is the uncertainty of input parameter values. A sensitivity analysis can be conducted to assess the potential impact of reasonable variation in specific input parameters on the estimated groundwater concentrations. Sites will also need to consider the appropriateness of the simplifying assumptions used in the approach with respect to the site-specific conditions. Other factors are outside the scope of the approach described here, but should be considered for potential impacts. Such factors include the degree of source depletion over time, adsorption, biological transformation, and other physical attenuation mechanisms.

In many cases, it may be appropriate to consider the effect of a diminishing vadose zone source over time. Variants from the base case analysis can be used to evaluate how the resultant groundwater concentration changes as the vadose zone source size and/or concentration is diminished. Sorption can delay the impact to groundwater, but has minimal impact on the overall long-term impact if the source strength remains constant (Carroll et al., 2012). However, at sites where the source is expected to decay, sorption processes may need to be considered as an additional factor attenuating the impact of the vadose zone source on the groundwater. This type of sorption analysis is not included in this approach.

The numerical simulations did not include consideration of several potential natural attenuation processes such as sorption and degradation, which may be active at a specific site in the groundwater. As appropriate, this approach could be augmented with an additional groundwater transport analysis considering the distance and travel time to the compliance well to estimate the amount of attenuation (mass or concentration per time) that would be needed to meet the compliance goal.

\section{E.5 References}

Brusseau ML, VJ Rohay, and MJ Truex. 2010. "Analysis of Soil Vapor Extraction Data to Evaluate Mass-Transfer Constraints and Estimate Source-Zone Mass Flux." Ground Water Monit. Remed., 30(3):57-64. doi: 10.1111/j1745-6592.2010.001286.x 
Carroll KC, M Oostrom, MJ Truex, VJ Rohay, and ML Brusseau. 2012. “Assessing Performance and Closure for Soil Vapor Extraction: Integrating Vapor Discharge and Impact to Groundwater Quality." J. Contam. Hydrol., 128(1-4):71-82. doi: 10.1016/j.jconhyd.2011.10.003.

DiGiulio DC, V Ravi, and ML Brusseau. 1999. "Evaluation of Mass Flux to and from Ground Water Using a Vertical Flux Model (VFLUX): Application to the Soil Vacuum Extraction Closure Problem." Ground Water Monit. Remed., 19(2):96-104.

DiGiulio DC and R Varadhan. 2001. "Analysis of Water Saturation, NAPL Content, Degradation HalfLife, and Lower Boundary Conditions on VOC Transport Modeling: Implications for Closure of Soil Venting Systems." Ground Water Monit. Remed., 21(4):83-95.

EPA. 2001. Development of Recommendations and Methods to Support Assessment of Soil Venting Performance and Closure. EPA/600/R-01/070, U.S. Environmental Protection Agency, Washington, D.C.

Khaleel R, TE Jones, AJ Knepp, FM Mann, DA Myers, PM Rogers, RJ Serne, and MI Wood. 2001. Modeling Data Package for S-SX Field Investigation Report. RPP-8296, Rev. 0, CH2MHill, Hanford Group, Inc., Richland, Washington.

Lenhard RJ, M Oostrom, CS Simmons, and MD White. 1995. "Investigation of Density-Dependent Gas Advection of Trichloroethylene: Experiment and a Model Validation Exercise." J. Contam. Hydrol., 19(1):47-67.

Millington RJ and JP Quirk. 1961. "Permeability of Porous Solids.” Trans. Faraday Soc., 57(7):12001207.

Oostrom M, JH Dane, and TW Wietsma. 2005. "Removal of Carbon Tetrachloride from a Layered Porous Medium by Means of Soil Vapor Extraction Enhanced by Desiccation and Water Table Reduction." Vadose Zone J., 4(4):1170-1182.

Oostrom M, ML Rockhold, PD Thorne, GV Last, and MJ Truex. 2006. Carbon Tetrachloride Flow and Transport in the Subsurface of the 216-Z-9 Trench at the Hanford Site: Heterogeneous Model Development and Soil Vapor Extraction Modeling. PNNL-15914, Pacific Northwest National Laboratory, Richland, Washington.

Oostrom M, ML Rockhold, PD Thorne, GV Last, MJ Truex, and VJ Rohay. 2007. "Carbon Tetrachloride Flow and Transport in the Subsurface of the 216-Z-9 Trench at the Hanford Site." Vadose Zone J., 6(4):971-984.

Oostrom M, MJ Truex, GD Tartakovsky, and TW Wietsma. 2010. "Three-Dimensional Simulation of Volatile Organic Compound Mass Flux from the Vadose Zone to Groundwater." Ground Water Monit. Remed., 30(3):45-56. doi: 10.1111/j1745-6592.2010.001285.x

Rohay VJ. 2007. Performance Evaluation Report for Soil Vapor Extraction Operations at the 200-PW-1 Operable Unit Carbon Tetrachloride Site, Fiscal Year 2006. SGW-33746, Fluor Hanford, Inc., Richland, Washington. 
Truex MJ, M Oostrom, and ML Brusseau. 2009. "Estimating Persistent Mass Flux of Volatile Contaminants from the Vadose Zone to Ground Water." Ground Water Monit. Remed., 29(2):63-72.

Truex MJ, KC Carroll, VJ Rohay, RM Mackley, and KR Parker. 2012. Treatability Test Report: Characterization of Vadose Zone Carbon Tetrachloride Source Strength Using Tomographic Methods at the 216-Z-9 Site. PNNL-21326, Pacific Northwest National Laboratory, Richland, Washington.

USACE. 2002. Engineering and Design: Soil Vapor Extraction and Bioventing. EM 1110-1-4001, U.S. Army Corps of Engineers, Washington, D.C. Last accessed July 17, 2012, at http://publications.usace.army.mil/publications/eng-manuals/EM_1110-1-4001_sec/toc.htm

van Genuchten MTh. 1980. "A Closed Form Equation for Predicting the Hydraulic Conductivity of Unsaturated Soils. Soil Sci. Soc. Am. J., 44(5):892-898.

Varadhan R and JA Johnson. 1997. VLEACH: A One-Dimensional Finite Difference Vadose Zone Leaching Model, Version 2.2. Center for Subsurface Modeling Support, U.S. Environmental Protection Agency, Ada, Oklahoma. Last accessed July 17, 2012, at http://www.epa.gov/ada/csmos/models/vleach.html

White MD, M Oostrom, and RJ Lenhard. 2004. “A Practical Model for Mobile, Residual, and Entrapped NAPL in Water-Wet Porous Media." Groundwater, 42(5):734-746.

White MD and M Oostrom. 2006. STOMP, Subsurface Transport Over Multiple Phases. Version 4.0 User's Guide. PNNL-15782, Pacific Northwest National Laboratory, Richland, Washington.

White MD, M Oostrom, ML Rockhold, and M Rosing. 2008. "Scalable Modeling of Carbon Tetrachloride Migration in the Deep Vadose Zone at the Hanford Site Using the STOMP Simulator." Vadose Zone J., 7(2):654-666.

Yoon H, M Oostrom, TW Wietsma, CJ Werth, and AJ Valocchi. 2009. "Numerical and Experimental Investigation of DNAPL Removal Mechanisms in a Layered Porous Medium by Means of Soil Vapor Extraction." J. Contam. Hydrol., 109(1-4):1-13. 
PNNL-21843

RPT-DVZ-AFRI-006

\section{Distribution}

No. of

Copies

2 Electronic Distribution

U.S. Department of Energy, Office of Environmental Management

Kurt Gerdes

(PDF)

Skip Chamberlain

(PDF)
No. of

Copies

\section{Local Distribution}

U.S. Department of Energy, Richland Operations Office

DOE Public Reading Room H2-53

BL Charboneau

A6-33

JG Morse

A5-11

Pacific Northwest National Laboratory

MJ Truex

K6-96

DM Wellman

K3-62 




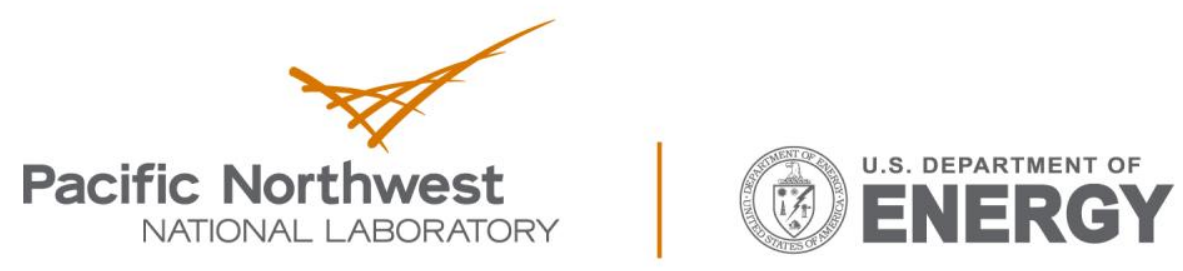

Proudly Operated by Battelle Since 1965

902 Battelle Boulevard

P.O. Box 999

Richland, WA 99352

1-888-375-PNNL (7665)

www.pnnl.gov 